\title{
A GRAVIMETRIC GEOID MODEL FOR ARGENTINA
}

\author{
by \\ CLAUDIA NOEMÍ TOCHO \\ Director: Dr. Michael Sideris \\ Co-Director: Geof. Graciela Font
}

\begin{abstract}
A THESIS
SUBMITTED TO THE

FACULTAD DE CIENCIAS ASTRONÓMICAS Y GEOFÍSICAS

IN PARTIAL FULFILLMENT OF THE REQUIREMENTS FOR THE

DEGREE OF DOCTOR IN GEOPHYSICS
\end{abstract}

LA PLATA

MARCH 27, 2006 


\section{UNIVERSIDAD NACIONAL DE LA PLATA}

\section{FACULTAD DE CIENCIAS ASTRONÓMICAS Y GEOFÍSICAS}

The undersigned certify that they have read and recommend to the Facultad de Ciencias Astronómicas y Geofísicas for acceptance, a thesis entitled "A gravimetric geoid model for Argentina" submitted by Claudia Noemí Tocho in partial fulfillment of the Degree of Doctor in Geophysics.

Supervisor, Dr. M.G. Sideris

Department of Geomatics Engineering, University of Calgary

Co-supervisor, Geof. G. Font

Facultad de Ciencias Astronómicas y Geofísicas, Universidad Nacional de La Plata

Dr.Claudio Brunini

Facultad de Ciencias Astronómicas y Geofísicas, Universidad Nacional de La Plata

Dr. Martha Ghidella

Instituto Antártico Argentino

Dr. Maria Cristina Pacino

Universidad Nacional de Rosario

Date:27 March, 2006 


\begin{abstract}
A new high-accuracy and high-precision gravimetric geoid model (ARG05) for Argentina has been computed. It will be used by the entire scientific community and has been developed using the most current updated databases as well as the most efficient theory and modern methodologies.
\end{abstract}

ARG05 is a purely gravimetric geoid model. The geoid undulations refer to the geocentric ellipsoid GRS80 and they were computed on a $5^{\prime}$ x $5^{\prime}$ grid covering all of Argentina (both land and ocean regions), ranging from $21^{\circ} \mathrm{S}$ to about $55^{\circ} \mathrm{S}$ in latitude and $53^{\circ} \mathrm{W}\left(307 \mathrm{E}^{\circ}\right)$ to about $76^{\circ} \mathrm{W}\left(284 \mathrm{E}^{\circ}\right)$ in longitude.

ARG05 was computed using the classical remove-compute-restore technique. The Fast Fourier Transform technique was employed in the computation of the residual geoid and terrain effects.

Different methods of handling the topography in practical geoid determination have been studied, and both direct and indirect terrain effects had to be taken into account in order to generate a precise gravimetric geoid model for Argentina. The treatment of the topography in ARG05 was based on Helmert's second method of condensation.

ARG05 is developed in four components. The first component is determined from the EGM96 global geopotential model, the second component represents the contribution of the local gravity data reduced by the global field, the third component was determined from the contribution of the terrain corrections to the geoid, and the four component is the primary indirect effect on the geoid.

From comparisons between Global Positioning System (GPS) and Argentinean Height Datum (GPS/levelling-derived) geoid undulations with ARG05, it is estimated that the absolute accuracy of the new geoid, after fit, is around $32 \mathrm{~cm}$ in terms of standard deviation. The relative agreement for the whole Argentina is 1.4 to $0.2 \mathrm{ppm}$ for baselines between $15 \mathrm{~km}$ and $115 \mathrm{~km}$.

Preliminaries studies and results of high-resolution marine geoids solutions by combining satellite altimetry and shipborne data are also presented. 


\section{RESUMEN}

La siguiente tesis presenta un nuevo geoide gravimétrico (ARG05) de alta precisión y alta exactitud para la Republica Argentina. En el mismo se discuten la metodología y los datos utilizados para su cálculo y se plantean los trabajos futuros que se realizarán con el fin de mejorar su precisión y exactitud.

ARG05 es un geoide gravimétrico puro. Las ondulaciones del geoide ARG05 se refieren al elipsoide geocéntrico GRS80 y fueron calculadas en una grilla de $5^{\prime}$ x $5^{\prime}$ cubriendo toda la Argentina (tierra y mar) desde $\operatorname{los} 20^{\circ}$ y $55^{\circ}$ de latitud sur y $53^{\circ}$ a $76^{\circ}$ de longitud oeste.

El cálculo se realizó utilizando la técnica clásica remover-restaurar. La componente del geoide residual así como los efectos de terreno se calcularon utilizando la Transformada rápida de Fourier. Para el tratamiento de la topografía se empleó el segundo método de compensación de Helmert.

ARG05 fue determinado en cuatro componentes. La primera componente fue calculada a partir del modelo de geopotencial EGM96, la segunda componte representa la contribución de los datos de gravedad reducidos por el modelo de geopotencial, la tercera componente fue determinada a partir de las correcciones topográficas en el geoide y la cuarta componente representa el efecto indirecto primario en el geoide.

De comparaciones realizadas entre GPS y nivelación, se estima que la exactitud absoluta del nuevo geoide es de $32 \mathrm{~cm}$ en términos de desviación Standard. La concordancia relativa para toda la Argentina es de 1.4 a 0.2 ppm para líneas bases entre 15 y 115 kilómetros.

También se presentan estudios preliminares y resultados de geoides marinos combinando altimetría satelital y datos de gravedad marinos.

En el siguiente trabajo se enumeran los futuros trabajos a realizar haciendo hincapié en el análisis y evaluación de nuevos modelos de gravedad globales y modelos digitales de terreno y sus implicancias en la determinación práctica de geoides gravimétricos. 


\subsection{Introducción}

El geoide es una superficie equipotencial particular del campo de gravedad terrestre. La idea básica a desarrollar, consiste en determinar el geoide a partir de mediciones de gravedad. Se lo utiliza en varias aplicaciones de Geodesia, Geofísica y Oceanografía.

En Geodesia, el geoide es usado como superficie de referencia para el sistema de alturas ortométricas. Dichas alturas pueden ser calculadas combinando un modelo de geoide gravimétrico con alturas elipsoidales obtenidas a través de Sistemas de Posicionamiento Global (GPS). Esto es una forma económica y sencilla de determinación de alturas ortométricas en áreas montañosas y en áreas sin nivelación convencional.

En Geofísica, el geoide es usado para obtener información acerca de la distribución de masas en el interior de la Tierra; en Oceanografía, para estudiar las variaciones del nivel medio del mar, anomalías en el nivel mar, corrientes y mareas.

Durante los ultimo años se han desarrollado en varias partes del mundo modelos de geoide gravimétricos regionales. Estos desarrollos fueron posibles debido a varios factores. Entre los más importantes podemos enumerar: las mejoras en los desarrollos teóricos y métodos prácticos para determinación del geoide, la disponibilidad de mejores modelos de elevación y modelos de profundidad digital, el cálculo de modelos geopotenciales globales precisos, la posibilidad de controlar el geoide gravimétrico con el geoide obtenido a través de puntos GPS/nivelación y el uso óptimo de datos heterogéneos. Un geoide gravimétrico preciso sobre áreas extensas es posible a través de la combinación de modelos geopotenciales, datos de gravedad y altura.

Las ondulaciones del geoide pueden ser determinadas por medio de la integral de Stokes, por la solución de Molodensky, por un desarrollo en armónicos esféricos o por colocación de mínimos cuadrados. El uso de la integral de Stokes requiere que las masas topográficas exteriores al geoide sean removidas completamente. Por otra parte, las determinaciones de gravedad en superficie deben ser reducidas también a la mencionada superficie de referencia mencionada.

La teoría de Molodensky toma a la superficie de la tierra como condición de borde. Teóricamente, esto evita el problema de desplazamiento de masas y reducciones de 
gravedad. Las ondulaciones del geoide son reemplazadas por anomalías de altura y el geoide es reemplazado por el cuasi geoide.

También, las ondulaciones del geoide pueden ser calculadas mediante un desarrollo de armónicos esféricos a partir de un dado modelo geopotencial. Ellas solo representan la larga longitud de onda del campo de gravedad.

Finalmente, la ventaja de la colocación por mínimos cuadrados reside en que permite utilizar como observaciones, diferentes tipos de datos simultáneamente. Sin embargo, esto puede implicar que se necesite resolver un sistema con un gran número de ecuaciones lineales, lo que en la práctica conduce a que todos los datos no puedan ser utilizados al mismo tiempo dificultando el uso de grandes áreas de integración (Moritz, 1980).

El geoide gravimétrico preciso será determinado empleando la integral de Stokes. Para el cálculo de dicha integral se emplearán las técnicas espectrales basadas en la Transformada Rápida de Fourier (FFT), que son ampliamente usadas en el modelado de geoides continentales, marinos o sobre áreas extensas. (Sideris, 1997).

Se utilizó el software desarrollado en el Departamento de Ingeniería Geomática de la Universidad de Calgary (Li y Sideris, 1993) y el paquete GRAVSOFT (conjunto de rutinas para el modelado del campo de gravedad desarrollado por C. C. Tscherning, perteneciente al Departamento de Geofísica de la Universidad de Copenhague y R. Foresberg y P. Knudsen del KMS). Software adicional fue desarrollado para solucionar problemas específicos, (cálculos de anomalías de gravedad conversión de datos, etc.)

\subsection{Objetivo}

.El objetivo de la tesis doctoral se logró con el cumplimiento de las siguientes tareas

- Recopilar todos los tipos de datos disponibles que serán usados para el cálculo de geoide en Argentina.

- Analizar y revisar estos datos, removiendo valores erróneos y referenciarlos a todos ellos a un datum único. 
- Calcular las anomalías de aire libre incluyendo la corrección atmosférica.

- Aplicar diferentes reducciones topográficas para tener en cuenta las masas topográficas.

- Tomar en cuenta los efectos indirectos de la topografía para cada reducción topográfica utilizada.

- Investigar diferentes métodos de grillado.

- Probar diferentes modelos geopotenciales para seleccionar el que mejor modela la larga longitud de onda de la señal del campo de gravedad en Argentina.

- Investigar los nuevos modelos de gravedad globales a partir de las misiones satelitales dedicadas CHAMP y GRACE.

- Investigar el rol del máximo grado de expansión del modelo geopotencial en relación con las dimensiones del área de integración en la fórmula de Stokes que contiene datos locales de gravedad.

- Calcular el modelo de geoide para toda la Argentina usando la técnica removerrestaurar y obtener su estimación de error. Será calculado usando la técnica de FFT (Schwarz et al. , 1990).

- Comparar los resultados con modelos de geoide obtenidos por soluciones geopotenciales globales y ondulaciones de geoide obtenidas por GPS/nivelación.

- Investigar los procedimientos apropiados para el ajuste de redes de alturas combinando GPS/nivelación/geoide para remover inconsistencias de los datums.

- Llevar a cabo un análisis y modelado de los errores del geoide. La precisión de las ondulaciones del geoide gravimétrico será evaluada mediante la comparación externa con ondulaciones del geoide y puntos de control GPS/nivelación

- Determinar el modelo de geoide marino en la región costera de Argentina. 


\subsection{Metodología}

El área de investigación está situada entre las latitudes $20^{\circ}$ y $55^{\circ}$ Sur y entre las longitudes $50^{\circ}$ y $76^{\circ} \mathrm{W}$. Parte de esta área corresponde al Océano Atlántico.

El geoide marino de alta resolución y alta precisión será computado en el área comprendida entre las latitudes $34^{\circ}$ y $55^{\circ}$ Sur y entre las longitudes $55^{\circ}$ y $70^{\circ} \mathrm{W}$.

Debido a que los valores de gravedad, son provistas por diferentes fuentes se pone especial énfasis en homogeneizarlas al sistema IGSN71.

La Base de Datos proviene de:

- Datos de gravedad del Instituto Geográfico Militar, el Departamento de Gravimetría, y otras Universidades e Instituciones.

- Gravedad marina provista por el Bureau Gravimétrique International (BGI).

- Varios modelos geopotenciales globales y modelos obtenidos a partir de las misiones satelitales CHAMP y GRACE

- Anomalías de gravedad derivadas altimétricamente (KMS01, Sandwell y Smith, GSFC00.1_DG, KMS02)

- Los datos topográficos incluyen los modelos GTOPO30 y GLOBE y las alturas de las estaciones gravimétricas.

- Para aplicaciones marinas, se utilizará el Modelo Digital de Profundidad (DDM) desarrollado por Smith y Sandwell en 1997.

- Datos de puntos GPS/nivelación.

- Datos de altimetría satelital de las misiones GEOSAT, ERS1 y Topex/Poseidón.

Los datos de gravedad del Departamento de Gravimetría fueron reprocesados y almacenados en una base de datos digital.

Todos los datos compilados fueron chequeados para eliminar errores sistemáticos. La existencia de desviaciones y corrimientos de datum en datos de gravedad y alturas 
terrestres puede producir errores importantes y es un punto a ser resuelto antes que el modelo de geoide sea calculado.

Las anomalías de aire libre y Bouguer se calcularon utilizando reducciones Standard y se refirieron al GRS80 (Moritz, 1980). En el cálculo de anomalías de aire libre se tiene en cuenta el término de segundo orden en el gradiente de gravedad normal junto con la corrección atmosférica (Torge, 1989). El geoide gravimétrico se determinó por la técnica remover-restaurar. El efecto de la larga longitud de onda del campo de gravedad obtenido de un modelo geopotencial y los efectos topográficos de corta longitud de onda son removidos de las anomalías de gravedad observada. La integral de Stokes se calcula utilizando FFT para calcular las ondulaciones residuales. Las ondulaciones del geoide final fueron obtenidas restaurando las ondulaciones del geoide del modelo geopotencial y el efecto de la topografía (Schwarz et al. , 1990).

El modelo geopotencial juega un rol importante en este proceso. Los modelos geopotenciales usados y validados son: JGM-3 (Tapley et al., 1996), OSU81 (Rapp, 1981), OSU91A (Rapp et al., 1991), EGM96 (Lemoine et al., 1998) y GPM98a y GPM98b (Wenzel, 1999).Además se trabajó con el modelo combinado EIGEN_CG01C calculado con datos de CHAMP y GRACE.

El método de cálculo del geoide gravimétrico se basó en el uso de la FFT. Las integrales de Stokes y de la corrección topográfica se reformulan como integrales de convolución y se evalúan por FFT.

La FFT requiere que los datos estén grillados. Se evaluaron diferentes métodos de estimación para generar una grilla regular: colocación por cuadrados mínimos, basado en la función de covarianza empírica de los datos de gravedad (krigging ordinario), promedios pesados y el método de curvatura continua en tensión. Las ondulaciones del geoide se calcularon por la formula de Stokes utilizando distintos núcleos, como: núcleo riguroso esférico y el núcleo esférico aproximado (Haagmans, et al., 1992 y Strang van Hees).

El efecto de la topografía es un punto sumamente importante a tener en cuenta, especialmente, en la zona de los Andes. Por ello, diferentes técnicas de reducciones gravimétricas fueron investigadas: el segundo método de condensación de Helmert, el Modelo Residual de Terreno (RTM), el método de inversión de Rudski y las 
reducciones topo-isostáticas. Cada una de ellas dependió del problema del valor de contorno en consideración.

La precisión externa del modelo de geoide gravimétrico se evaluó comparándola con los resultados obtenidos en puntos nivelación/GPS.

Las diferencias sistemáticas entre los datums correspondientes al geoide gravimétrico y el geométrico y los posibles errores de larga longitud de onda del geoide fueron removidos por una transformación de 4 parámetros y un modelo de transformación de 7 parámetros (Kotsakis, 2001).

Se calcularon, las diferencias absolutas y relativas entre los geoides gravimétricos y geométricos.

.La precisión final del geoide gravimétrico residual estimado estuvo sujeta a diferentes errores generados por las diferentes fuentes empleadas en el cálculo (modelos geopotenciales, anomalías de gravedad local y alturas).

Se seleccionaron, dos áreas de prueba para la determinación del geoide gravimétrico las cuales, con posterioridad, fueron extendidas al país completo. La primera incluyó la Provincia de Buenos Aires y parte del Océano Atlántico. Tiene una buena cobertura de datos de gravedad y puntos de control GPS/nivelación. Parte de la misma está en el mar por lo que fue necesario combinar anomalías de gravedad terrestre con anomalías de gravedad derivadas altimétricamente y gravedad marina. Los principales puntos a investigar fueron la combinación de datos heterogéneos y la aplicación de una posible técnica de suavización a lo largo de la costa.

En el área, elegida en segundo término, los Andes, se investigó el efecto directo e indirecto de las masas topográficas.

La determinación de un geoide marino de alta precisión y alta resolución en la región costera de Argentina fue otro de los objetivos a investigar. El mismo se calculó usando altimetría satelital y gravedad marina. Los datos altimétricos de la misión satelital ERS1, junto con gravedad marina y anomalías de gravedad derivadas altimétricamente se usaron para estimar geoides gravimétricos, altimétricos y soluciones combinadas. 
Se tuvo en cuenta el efecto de la topografía casi estacionaria (QSST) para corregir las alturas de la superficie del mar (SSHs) a ondulaciones del geoide. Se puso mucho énfasis en reducir el efecto de la variabilidad de la superficie del mar (SSV mediante la aplicación de filtros pasabajos para reducirlo. Se combinaron, en el dominio espectral los geoides altimétricos y gravimétricos para mejorar la exactitud del geoide gravimétrico puro y las soluciones altimétricas puras en las zonas cercanas a la costa. La exactitud y validación de los modelos finales se realizó comparándolos con alturas del nivel de mar de TOPEX/POSEIDON (T/P) SSHs.

El método utilizado para las soluciones combinadas fue la teoría de los sistemas de entrada-salida (input-output system theory IOST) (Sideris, 1996; Li, 1997, Vergos, 2000). 


\section{ACKNOWLEDGEMENTS}

I wish to express my sincere gratitude to my supervisors, Geof. Graciela Font and Dr. Michael Sideris who put their trust in me. This thesis would not have been possible without them.

I am grateful to Dr. Claudio Brunini, Dr. Marta Ghidella and Dr. Maria Cristina Pacino for their suggestions on my thesis as members of the examination committee.

The financial support for my stays at the University of Calgary has been provided by Dr. M. G. Sideris. These stays gave me not only the opportunity to join and work at the gravity group, but also the chance to meet people from different parts of the world, with different cultures who were very kind to me and helped me a lot. Thanks to George and Rossen for being my friends. I thank Dr. Georgia Fotopoulos for her help and suggestions to my work.

I would like to thank Dr. Denizar Blitzkow, Dr. Maria Cristina Pacino, the Military Geographical Institute, Lic. Raúl Perdomo, Lic. Daniel del Cogliano and all other institutions for providing the gravity and GPS/levelling data.

Special thanks are due to my friends and colleagues at the Facultad de Ciencias Astronómicas y Geofísicas in La Plata.

I would like to thank my friends Cecilia, Claudia, Isabel. Marcela, Marcela, Norma, Margarita; Alejandro, Marcelo, Nora and Luis for their love and friendship.

Finally, thanks go to my family, specially my mother, my aunts and my three boys; Daniel, Agustín and Federico for their understanding, support and patience with me during this research. 


\section{DEDICATION}

To Daniel, Agustín and Federico 
TABLE OF CONTENTS

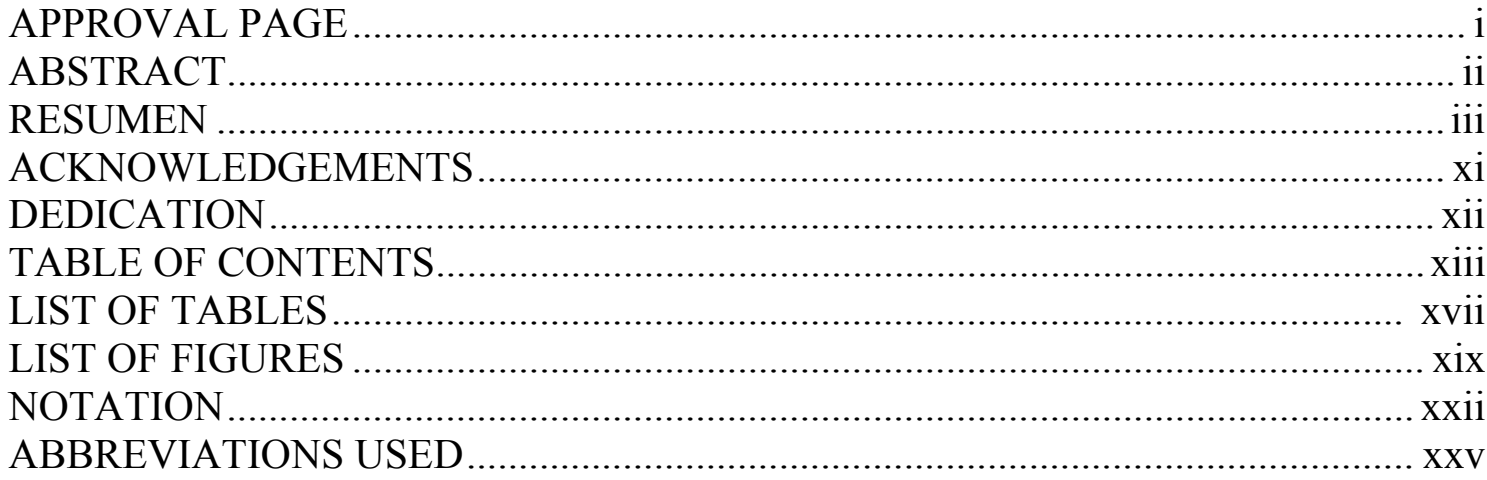

CHAPTER ONE

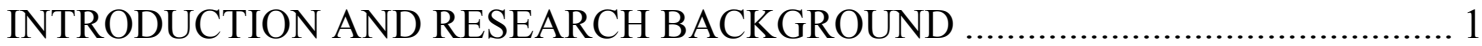

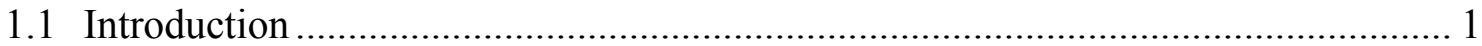

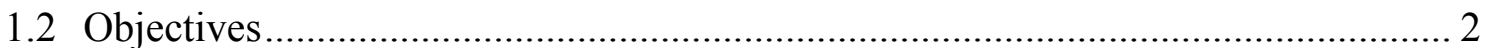

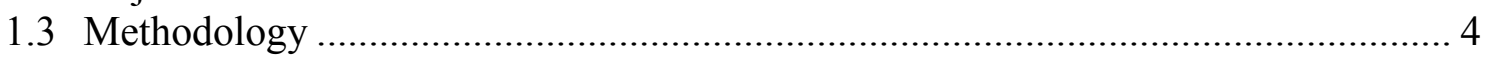

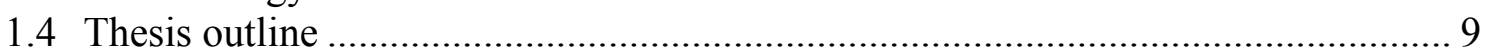

CHAPTER TWO

REGIONAL GRAVIMETRIC GEOID DETERMINATION ..................................... 11

2.1 Formulas for gravimetric geoid computation via the remove-compute-restore

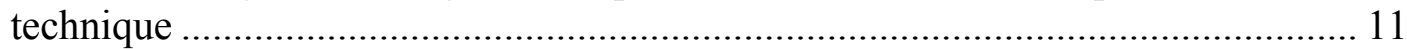

2.2 Fast Fourier Transform formulas for evaluating Stokes's integral ........................ 14

2.2.1 Approximated Spherical Kernel (ASK) ................................................. 16

2.2.2 Rigorous Spherical Kernel (RSK) _.......................................................... 17

2.3 Methods of handling topography in practical geoid determination ....................... 17

2.3.1 Refined Bouguer reduction ................................................................ 19

2.3.1.1 Formulas for terrain corrections.................................................... 21

2.3.1.2 Computation of terrain corrections via 2D FFT ............................ 23

a) Formulas with mass line topographic model ........................ 23

b) Formulas with mass prism topographic model ..................... 23

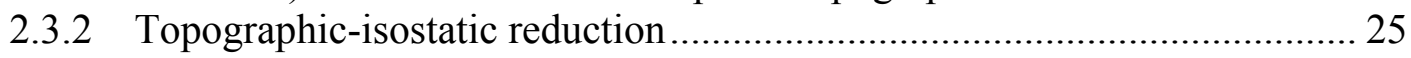

2.3.2.1 Airy-Heiskanen topographic-isostatic reduction ......................... 25

2.3.2.2 Pratt-Hayford topographic-isostatic reduction.............................. 28

2.3.3 Second method of Helmert's condensation................................................ 31

2.3.3.1 FFT formulas for the indirect effect of Helmert's reduction on the

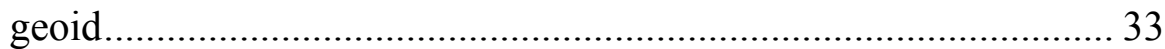

2.3.4 The Rudzki inversion method ................................................................. 33

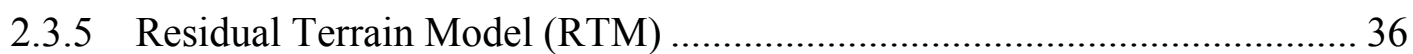

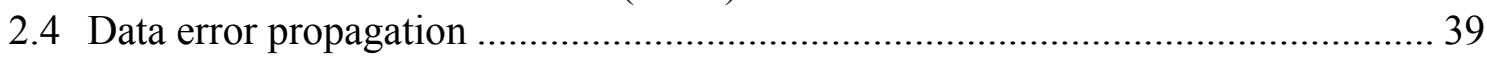

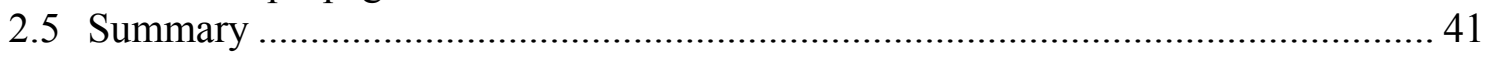

CHAPTER THREE

MARINE GEOID DETERMINATION

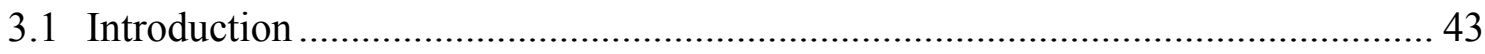

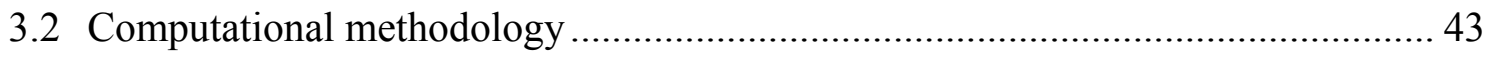




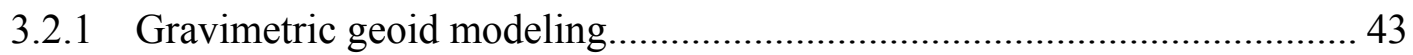

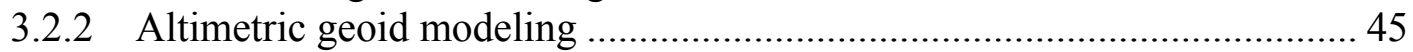

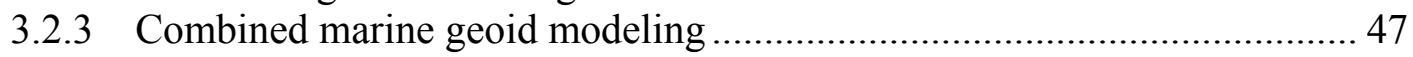

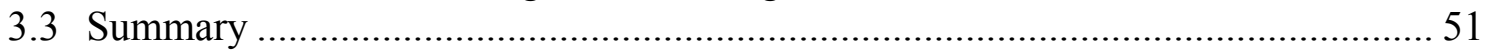

CHAPTER FOUR

GRAVITY, ELEVATION AND BATHYMETRY DATA IN ARGENTINA 53

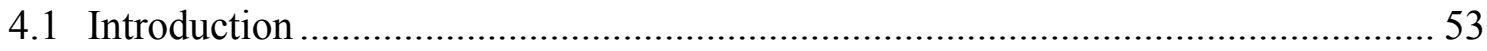

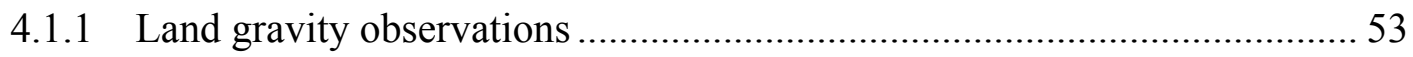

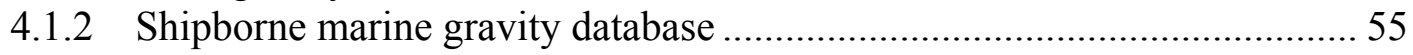

4.1.3 Satellite altimetry derived gravity anomalies.........................................5 56

4.1.3.1 Satellite altimetry gravity anomaly grids ..................................... 56

4.1.4 Digital Elevations Models ........................................................................... 58

4.1.4.1 Evaluation of Digital Elevation Models .......................................... 59

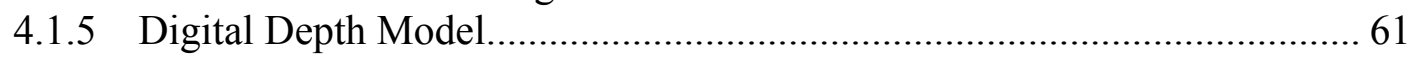

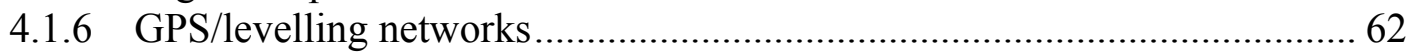

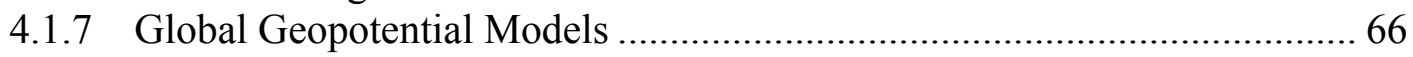

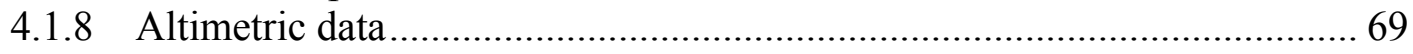

4.1.9 Quasi Stationary Sea Surface Topography (QSST) models....................... 70

4.2 Data pre-processing, evaluation and validation ................................................... 71

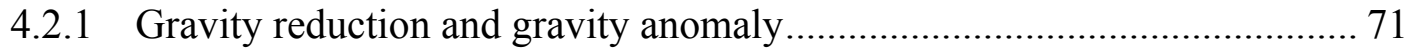

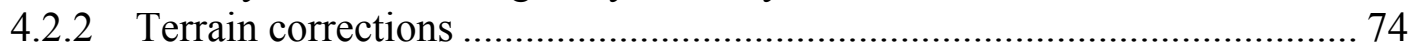

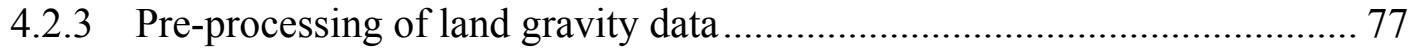

4.2.4 Pre-processing of shipborne data .............................................................. 78

4.2.5 Validation of altimetry-derived free-air gravity anomalies........................ 80

4.3 Determination of the best fitting Global Geopotential Model in Argentina ............ 86

4.3.1 Comparisons between geoid undulations computed from different global geopotential models and geoid undulations derived from GPS/leveling

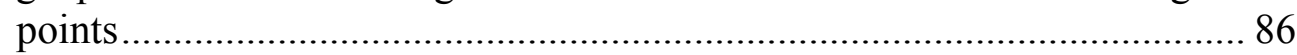

4.3.2 Comparisons between gravity anomalies computed from different global geopotential models and marine, land and free-air gravity anomalies derived

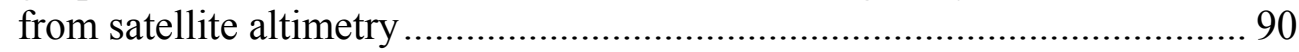

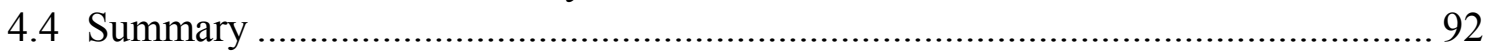

\section{CHAPTER FIVE}

PREDICTION AND STATISTICAL BEHAVIOR OF GRAVITY ANOMALIES ..... 93

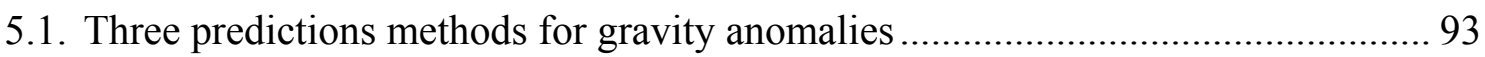

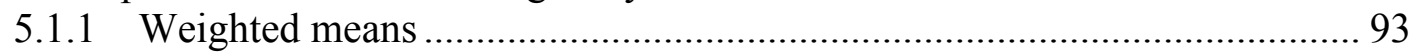

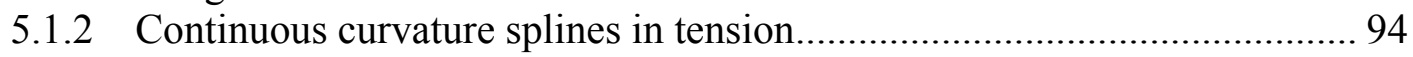

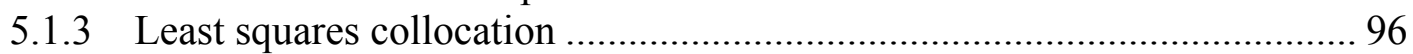

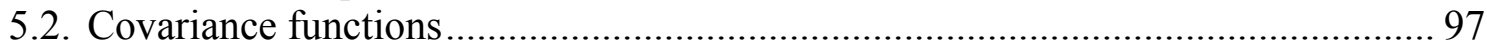

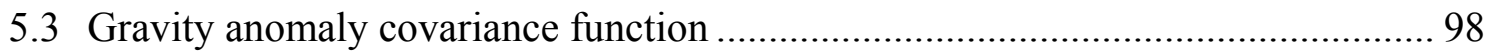

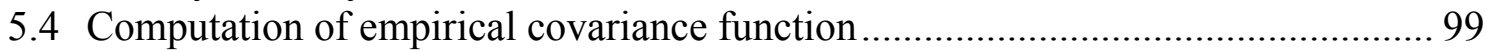

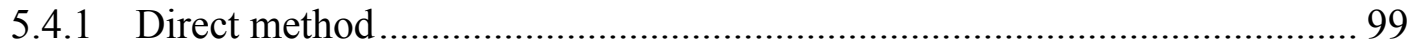

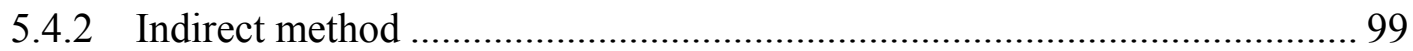

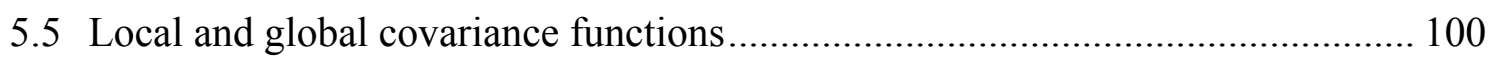

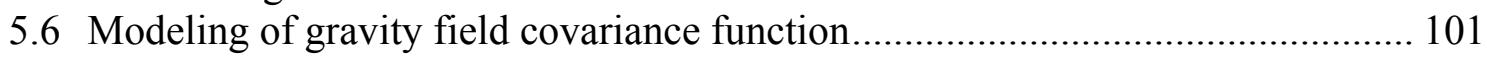

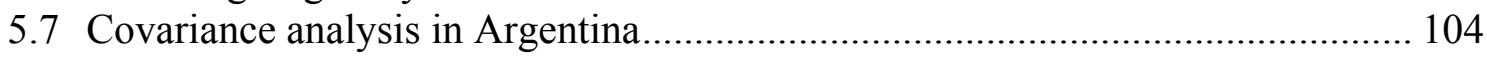

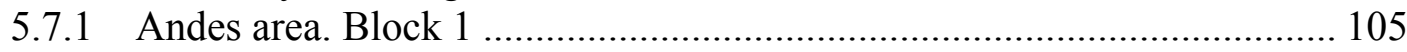

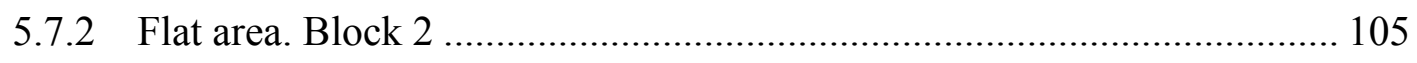


5.7.3 Marine area. Block 3

5.8 Estimation of empirical covariance function and modeling............................... 107

5.9 Geoid spectrum

CHAPTER SIX

DIFFERENT TOPOGRAPHIC REDUCTION METHODS IN PRACTICAL

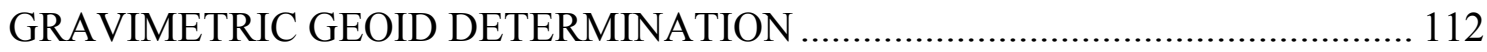

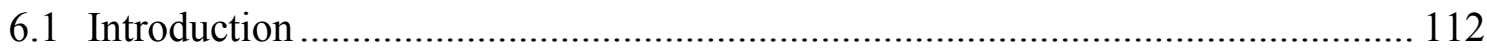

6.2 Gravimetric geoid determination in a flat area................................................ 113

6.3 Gravimetric geoid determination in a rough area.............................................. 122

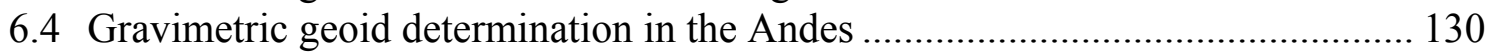

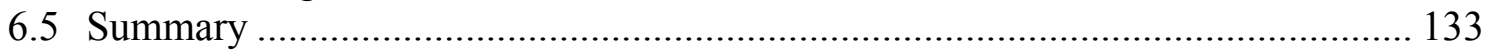

\section{CHAPTER SEVEN}

OPTIMAL MARINE GEOID DETERMINATION IN THE ATLANTIC COASTAL

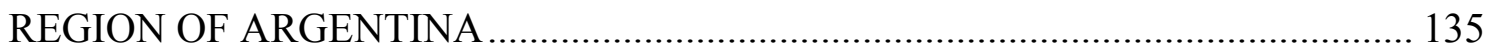

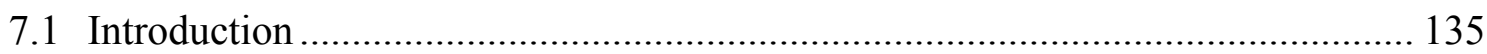

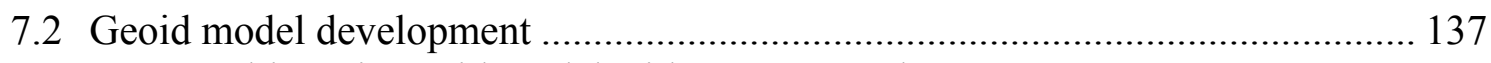

7.2.1 Altimetric geoid model with ERS1-GM data....................................... 137

7.2.2 Gravimetric geoid model................................................................... 140

7.2.2.1 Validation of KMS01 and KMS02 altimetry-derived free-air gravity

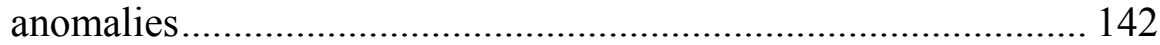

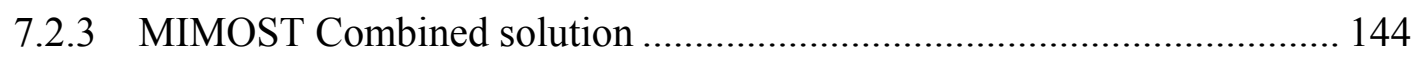

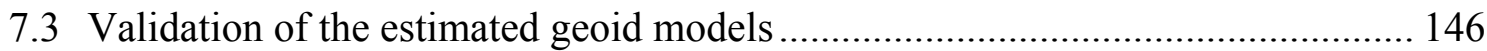

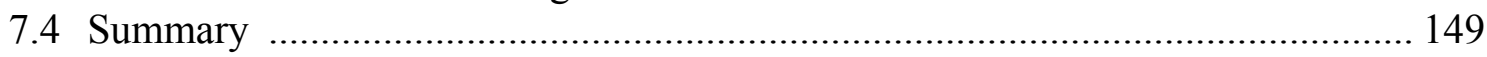

CHAPTER EIGHT …...................................................................................... 151

A HIGH-PRECISION GRAVIMETRIC GEOID MODEL FOR ARGENTINA ........ 151

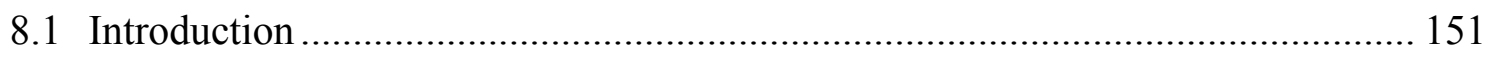

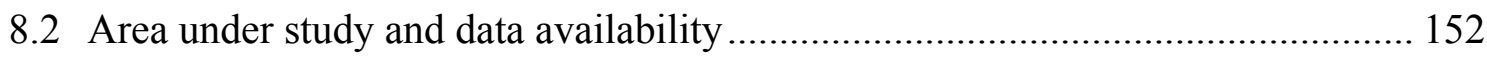

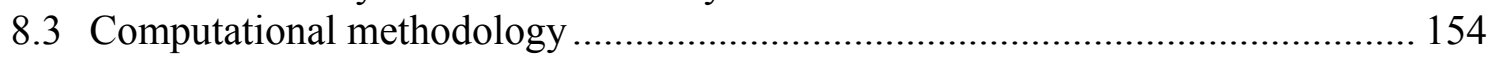

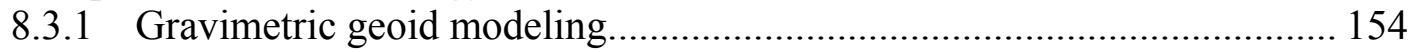

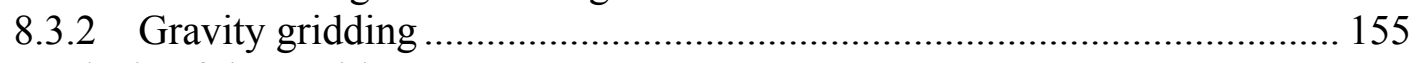

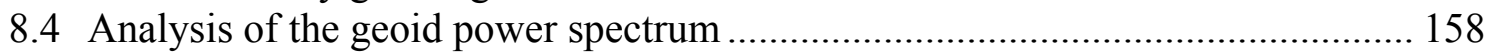

8.5 Gravimetric geoid modeling development .......................................................... 160

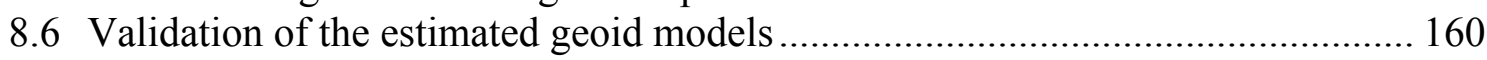

8.6.1 Comparisons at GPS benchmarks ...................................................... 160

8.6.1.1 Absolute differences between gravimetric geoid models and the GPS/levelling geoid .............................................................. 161

8.6.1.2 Relative differences between gravimetric geoid models and the

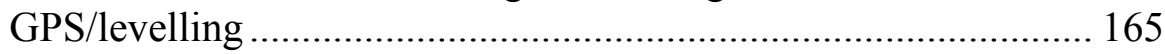

8.6.2 Comparison of geoid height solutions with T/P SSHs ............................ 166

8.6.3 Comparisons between geoid models …................................................... 168

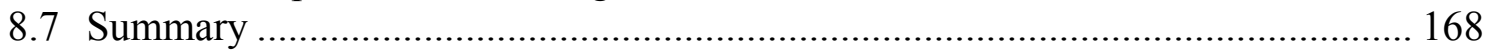

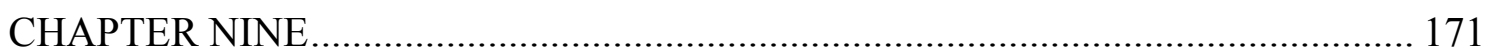

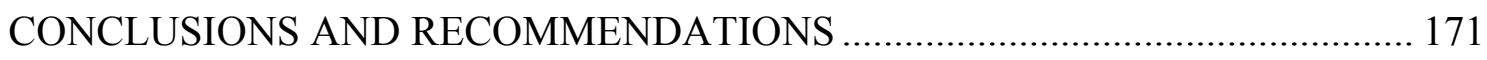

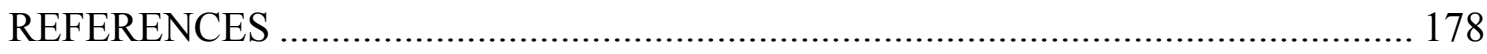


Appendix 1: Statistics of the differences between geoids derived from global geopotential models with GPS/leveling-derived geoid. (All of Argentina). Unit: [m]......

Appendix 2: Statistics of the differences between geoids derived from global geopotential models with GPS/leveling-derived geoid in Buenos Aires province. Unit: $[\mathrm{m}]$

Appendix 3: Statistics of the differences between geoids derived from global geopotential models with GPS/leveling-derived geoid in Chubut. Unit: [m] .... 190

Appendix 4: Statistics of the differences between geoids derived from global geopotential models with GPS/leveling-derived geoid in Mendoza. Unit: [m].

Appendix 5: Statistics of the differences between geoids derived from global geopotential models with GPS/leveling-derived geoid in Neuquén. . Unit: [m]

Appendix 6: Statistics of the differences between geoids derived from global geopotential models with GPS/leveling-derived geoid in Santa Fe. Unit: [m]

Appendix 7: Statistics of the differences between geoids derived from global geopotential models with GPS/leveling-derived geoid in Uruguay. Unit: [m]

Appendix 8: Statistics of the differences between geoids derived from global geopotential models with GPS/leveling-derived geoid in Tierra del Fuego. Unit: [m]

Appendix 9: Statistics of the differences between geoids derived from global geopotential models with GPS/leveling-derived geoid in Points of the POSGAR94 network. Unit: [m]

Appendix 10: Differences between EGM96 and EIGEN_CG01C geoid undulations with GPS/levelling-derived geoid. (after fit) 


\section{LIST OF TABLES}

Table 4.1: $\quad$ Statistics information of the gravity observations.................... 54

Table 4.2: $\quad$ Seafloor topography in the area under study. Unit:[m] ............... 62

Table 4.3: $\quad$ Statistics of ten GPS networks in Argentina........................ 64

Table 4.4: Global Geopotential Models available in this research................. 68

Table 4.5: Terrain corrections in Argentina................................... 75

Table 4.6: Effect of different models and cap size on terrain corrections and geoid.................................................... 76

Table 4.7: Statistics information at the gravity points of the Argentinean database after data removal........................................... 77

Table 4.8: $\quad$ Statistics of shipborne free-air gravity anomalies referred to MSS.

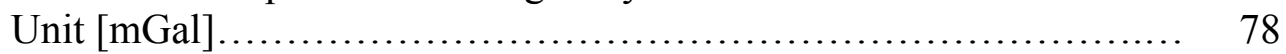

Table 4.9: $\quad$ Statistics of shipborne free-air gravity anomalies referred to MSS. Unit [mGal]

Table 4.10: Statistics of shipborne free-air gravity anomalies referred to the geoid. Unit [mGal].

Table 4.11: Statistics of the gravity anomalies derived from satellite altimetry and EGM96 gravity anomalies.

Table 4.12: Statistics of the differences between different altimetric gravity anomalies grids around Argentina. Unit [mGal].

Table 4.13: Statistics of the differences between different altimetric gravity anomalies grids and marine gravity anomalies grids around Argentina. Unit [mGal]

Table 4.14: Statistical comparisons between gravity anomalies computed from GGMs and marine gravity anomalies. Unit: [mGal].

Table 4.15: Statistical comparisons between gravity anomalies computed from GGMs and KMS02 satellite derived free-air gravity anomalies. Unit: [mGal]....

Table 4.16: Statistical comparisons between gravity anomalies computed from GGMs and land gravity anomalies. Unit:[mGal]............................. 91

Table 5.1: $\quad$ Statistical information for Block 1............................... 105

Table 5.2: $\quad$ Statistics for the gravity anomalies for Block 1. Unit:[mGal]................ 105

Table 5.3: $\quad$ Statistical information for Block 2 ............................. 106

Table 5.4: Statistics for the gravity anomalies for Block 2. Unit:[mGal].............. 106

Table 5.5: $\quad$ Statistics for the gravity anomalies for Block 3. Unit:[mGal]............... 107

Table 5.6: Essential parameters for the GM and RTM-reduced gravity anomaly empirical covariance function....................................... 107

Table 6.1: The statistics of gravity anomalies. Unit: [mGal] ............................... 115

Table 6.2: The statistics of the residual gravity anomalies. Unit: [mGal].............. 119

Table 6.3: Statistics of the differences between gravimetric geoids with GPS/levelling-derived geoid in the flat area. Unit: [m] .............. 121

Table 6.4: The statistics of gravity anomalies. Unit: [mGal] ............................... 123

Table 6.5: The statistics of the residual gravity anomalies. Unit: [mGal].......... 126

Table 6.6: Statistics of indirect effects due to the Helmert's condensation method.........................................................

Table 6.7: Statistics of the differences between gravimetric geoids with 
GPS/levelling-derived geoid in the rough Block 1. Unit: [m]

Table 6.8: Statistics of the GTOPO30. Unit:[m] and $\mathrm{c}_{\mathrm{P}}$. Unit:[mGal]

Table 6.9: Statistics of the gravity anomalies calculated with the four topographic reductions. Unit [mGal]

Table 6.10: Statistics of different gravimetric geoid solutions (Values in the parentheses are after fit) Unit: [m]

Table 7.1: Statistics of the ERS1-GM altimetric geoid models. Unit:

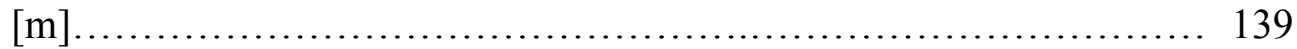

Table 7.2: Statistics of gravimetric geoid models. Unit: $[\mathrm{m}]$..................... 141

Table 7.3: Statistics of KMS01 and KMS02 grids, their differences and shiptracks gravity anomalies offshore Argentina Unit: [mGal].............. 142

Table 7.4: Statistics of the differences between KMS grids and the shipborne marine gravity anomalies. Unit: [mGal].

Table 7.5: Statistics of the geoid models in the smaller area. Unit: [m]

Table 7.6: Statistics of geoid height differences between the estimated models and T/P SSHs in the test area. Unit: [m]. (before and after bias and tilt fit).

Table 8.1: Statistics of the heights and terrain corrections in Argentina.

Table 8.2: Statistics of the Terrain Corrected reconstructed Free-Air gravity anomalies (TCFA) (5' x 5'). Unit:[mGal] ....................... 156

Table 8.3: Statistics of the free-air gravity anomalies (5' x 5'). Unit: [mGal]............. 157

Table 8.4: Statistics of the Terrain Corrected free-air gravity anomalies (5' x 5'). Unit: [mGal].....

Table 8.5: Names of the different geoid solutions presented in this chapter........ 160

Table 8.6: Geoid height difference between various geoid models and GPS/levelling-derived geoid model (All of Argentina). Unit: [m] ...... 162

Table 8.7: Geoid height difference between various geoid models and T/P SSHs. Unit: $[\mathrm{m}]$.

Table 8.8: Statistics for various geoid models and their differences. Unit: [m] ..... 168 


\section{LIST OF FIGURES}

Figure 1.1: Geographical location and topography of Argentina................ 8

Figure 2.1: Geoid, cogeoid and ellipsoid................................... 19

Figure 2.2: Bouguer plate and terrain correction............................. 20

Figure 2.3: Airy-Heiskanen model........................................ 26

Figure 2.4: Pratt-Hayford model................................................ 29

Figure 2.5: Helmert's method of condensation.............................. 32

Figure 2.6: Rudzki inversion method on the sphere......................... 35

Figure 2.7: Rudzki inversion method in planar approximation................. 35

Figure 2.8: $\quad$ RTM reduction.............................................. 37

Figure 2.9: Quasigeoid, changed quasigeoid and ellipsoid.................... 38

Figure 2.10: Flowchart gravimetric geoid modeling ........................... 42

Figure 3.1: Double-input single output system with noise...................... 48

Figure 3.2: Gravimetric geoid modeling................................... 51

Figure 3.3: Altimetric geoid modeling..................................... 52

Figure 4.1: Distribution of land gravity data................................ 55

Figure 4.2: Distribution of shipborne gravity data............................. 55

Figure 4.3: GTOPO30 DEM in Argentina................................... 59

Figure 4.4: GLOBE DEM in Argentina.................................... 59

Figure 4.5: Histogram of the differences between heights at 1452 gravity stations and heights linearly interpolated from GTOPO30................ 60

Figure 4.6: Histogram of the differences between heights at 1452 gravity stations and heights linearly interpolated from GLOBE................... 61

Figure 4.7: Seafloor topography in the area under study (Sandwell and Smith, 1997).......................................................... 62

Figure 4.8: Distribution of GPS/levelling points........................... 62

Figure 4.9: GPS/levelling-derived geoid (before blunders removal)............. 65

Figure 4.10: GPS/levelling-derived geoid (after blunders removal).............. 66

Figure 4.11: Distribution of ERS1-GM SSH.............................. 73

Figure 4.12: TOPEX/POSEIDON tracks.................................... 73

Figure 4.13: Terrain Corrections......................................... 75

Figure 4.14: Differences between KMS02 and KMS01 gravity anomalies......... 82

Figure 4.15: Differences between KMS02 and GSFC gravity anomalies........... 82

Figure 4.16: Differences between KMS02 and Sandwell gravity anomalies........ 82

Figure 4.17: Differences between KMS02 and CLS_SHOM gravity anomalies..... 82

Figure 4.18: Differences between KMS01 and Sandwell gravity anomalies ........ 83

Figure 4.19: Differences between KMS01 and CLS_SHOM gravity anomalies..... 83

Figure 4.20: Differences between KMS01 and GSFC gravity anomalies.............. 83

Figure 4.21: Differences between Sandwell and CLS_SHOM gravity anomalies... 83

Figure 4.22: Differences between Sandwell and GSFC gravity anomalies ......... 84

Figure 4.23: Differences between GSFC and CLS_SHOM gravity anomalies...... 84

Figure 4.24: Differences between CLS and shipborne gravity anomalies......... 84

Figure 4.25: Differences between GSFC and shipborne gravity anomalies......... 84

Figure 4.26: Differences between KMS01 and shipborne gravity data............ 85

Figure 4.27: Differences between Sandwell and shipborne gravity data........... 85

Figure 4.28: Differences between KMS01 and shipborne gravity data............. 85

Figure 4.29: Standard deviation of the absolute differences between the different 
geoid undulations computed from geopotential models with GPS/levelling-derived geoid (before and after fit)................ 89

Figure 5.1: Empirical covariance function and essential parameters............ 101

Figure 5.2: Location of test areas and distribution of gravity data............... 104

Figure 5.3: The empirical and model covariance function for free-air gravity 108

Figure 5.4: The empirical and model covariance function for free-air gravity anomalies reduced from EGM96 and RTM effects (Block 1-rough area) anomalies reduced from EGM96 and RTM effects (Block 2-flat area)

The empirical and model covariance function for free-air gravity anomalies reduced from EGM96 and RTM effects (Block 3-marine area).

Figure 6.1: Distribution of test areas blocks in Argentina.................... 112

Figure 6.2: Distribution of gravity stations on elevation map................. 113

Figure 6.3: Free-air gravity anomalies.................................... 114

Figure 6.4: Refined Bouguer gravity anomalies............................ 115

Figure 6.5: Faye gravity anomalies...................................... 116

Figure 6.6: Airy-Heiskanen gravity anomalies........................... 117

Figure 6.7: RTM gravity anomalies.................................. 117

Figure 6.8: Rudzki gravity anomalies................................... 118

Figure 6.9: $\quad$ EGM96 gravity anomalies.................................. 119

Figure 6.10: Distribution of GPS/levelling benchmarks on elevation map....... 120

Figure 6.11: Distribution of gravity stations on elevation map................. 123

Figure 6.12: Distribution of GPS/levelling on benchmarks on elevation map...... 123

Figure 6.13: Free-air gravity anomalies..................................... 124

Figure 6.14: EGM96 gravity anomalies................................... 124

Figure 6.15: Refined Bouguer gravity anomalies.......................... 125

Figure 6.16: Faye gravity anomalies..................................... 125

Figure 6.17: Airy-Heiskanen gravity anomalies........................... 125

Figure 6.18: RTM gravity anomalies................................... 125

Figure 6.19: Rudzki gravity anomalies................................ 126

Figure 6.20: Indirect effect on the geoid undulation......................... 128

Figure 6.21: Standard deviation of the differences between the geoid undulations from different solutions and the GPS/levelling-derived geoid.(Before fit and after fit with four-parameter transformation model (4P) and with differential similarity transformation model with 7 parameters $(7 \mathrm{P})$

Figure 6.22: Distribution of gravity stations in the area under study............ 131

Figure 6.23: Distribution of GPS/levelling points in the area under study........ 131

Figure 6.24: Gravimetric geoid solution with different gravity reduction mass schemes................................................. 134

Figure 7.1: Shipborne data (red) filled with KMS in gaps (in blue)............ 136

Figure 7.2: The EGM96 QSST in the area under study...................... 136

Figure 7.3: Altimetric geoid with Nres after filtering at $22 \mathrm{~km}$................ 139

Figure 7.4: Altimetric geoid with $\mathrm{N}_{\text {res }}$ without low-pass filtering............... 139

Figure 7.5: Gravimetric geoid in the Atlantic coastal region of Argentina....... 141

Figure 7.6: KMS02-KMS01 in Argentina................................... 143

Figure 7.7: Differences between shipborne data and KMS02................ 143 
Figure 7.8: $\quad$ ERS1-GM altimetric geoid (AG1)............................. 145

Figure 7.9: ERS1-GM altimetric geoid (AG2) ............................ 145

Figure 7.10: Gravimetric geoid) (GG1 .................................. 145

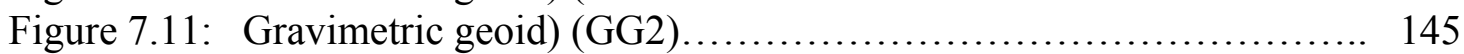

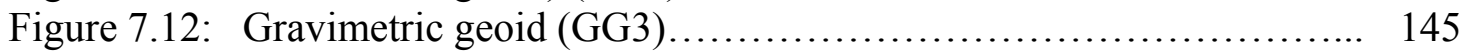

Figure 7.13: MISOT geoid (CG1) .................................... 145

Figure 7.14: MISOT geoid (CG2) ................................... 145

Figure 7.15: MISOT geoid (CG3).................................. 145

Figure 7.16: Geoid height differences between T/P and the ERS1 altimetric geoid (AG2) solution..................................... 148

Figure 7.17: Geoid height differences between T/P and the gravimetric (AG2) (left) and the combined (CG2) solutions (right)................. 148

Figure 8.1: Distribution of gravity data in the area under study............... 153

Figure 8.2: Geoid power spectrum for the different gravity field signals involucrate in the gravimetric geoid determination................. 159

Figure 8.3: Geoid power spectrum from EGM96 and local gravity data......... 159

Figure 8.4: Distribution of GPS/levelling points (land) and T/P SSHs (ocean).................................................... 161

Figure 8.5: Gravimetric geoid. Solution 2.............................. 163

Figure 8.6: Gravimetric geoid. Solution 5............................ 163

Figure 8.7: Standard deviation of the absolute differences (before fit) between the gravimetrically geoids and the GPS/levelling-derived geoid...... 164

Figure 8.8: Standard deviation of the absolute differences (after fit) between the gravimetrically geoids and the GPS/levelling-derived geoid...... 164

Figure 8.9: Relative accuracy between geoid models and GPS/levellingderived geoid across Argentina (before fit)......................... 165

Figure 8.10: Relative accuracy between geoid models and GPS/levellingderived geoid across Argentina (after fit)....................... 166

Figure 8.11: Differences solution 2 and stacked T/P SSHs. Unit: [m] ............ 167

Figure 8.12: Differences solution 5 and stacked T/P SSHs. Unit: [m] ........... 167 
ABBREVIATIONS

\begin{tabular}{|c|c|}
\hline Abbreviation & Description \\
\hline $\mathrm{AH}$ & Airy-Heiskanen \\
\hline AG1 & Altimetric Geoid one (with EGM96) \\
\hline AG2 & Altimetric Geoid two (with "combined EGM") \\
\hline ASK & Approximated Spherical Kernel \\
\hline AVISO & Archiving, Validation and Interpretation of Satellite Oceanographic \\
\hline IADO & Argentinean Institute of Oceanography (IADO) \\
\hline BGI & Bureau Gravimétrique International \\
\hline CAI69 & Campo Inchauspe 69 \\
\hline CSR & Center for Space Research \\
\hline CNES & Centrale Nationale d' Etudes Speciales \\
\hline CHAMP & CHAllenging Minisatellite Payload \\
\hline CLS & Collecte, Localisation, Satellites \\
\hline CG1 & Combined Geoid one with AG1 and GG1 \\
\hline CG3 & Combined Geoid three with AG2 and GG3 \\
\hline CG2 & Combined Geoid two with AG2 and GG2 \\
\hline DLR & Deutsche Forschungsanstalt für Luft und Raumfahrt \\
\hline DDM & Digital Depth Model \\
\hline DEM & Digital Elevation Model \\
\hline DORIS & Doppler Orbitography and Radiolocation Integrated by Satellite \\
\hline DOT & Dynamic Ocean Topography \\
\hline EGM96 & Earth Gravity Model 1996 \\
\hline EROS & Earth Resources Observation Systems \\
\hline ESUSP & Escola Politecnica da Universidade de Sao Paulo \\
\hline ERS1/ERS2 & European Remote-Sensing Satellite $1 / 2$ \\
\hline ESA & European Space Agency \\
\hline ERM & Exact Repeat Mission \\
\hline FFT & Fast Fourier Transform \\
\hline FA & Free-Air anomalies \\
\hline GM & Geodetic Mission \\
\hline GRS67 & Geodetic Reference System 1967 \\
\hline GRS80 & Geodetic Reference System 1980 \\
\hline GEOSAT & GEOdetic SATellite \\
\hline GFZ & GeoForschungsZentrum Potsdam \\
\hline GDRs & Geophysical Data Records \\
\hline GPM2 & Geopotential model GPM2 to degree 200 \\
\hline GPM98CR & Geopotential model GPM98CR to degree 720 \\
\hline GLOBE & Global Land One-Kilometer Base Elevation \\
\hline GPS & Global Positioning System \\
\hline GSFC & Goddard Space Flight Center \\
\hline GG1- & Gravimetric Geoid one (EGM96 and KMS01) \\
\hline GG3 & Gravimetric Geoid three (with the "combined EGM" and KMS02) \\
\hline GG2 & Gravimetric Geoid two (with the "combined EGM" and KMS01) \\
\hline GRACE & Gravity Recover and Climate Experiment \\
\hline GRAVSOFT & GRAVity SOFTware \\
\hline IOST & Input Output System Theory \\
\hline
\end{tabular}




\begin{tabular}{|c|c|}
\hline IFIR & Institute of Physics Rosario \\
\hline IPD & Inter point distance \\
\hline IGSN71 & International Standardisation Net 1971 \\
\hline IUGG & International Union of Geodesy and Geophysics \\
\hline JPL & Jet Propoulsion Laboratory \\
\hline JGM3 & Joint Gravity Model 3 \\
\hline KMS & Kort og Matrikelstyrelsen \\
\hline LSC & Least Square Collocation \\
\hline ML & Mass line \\
\hline MP & Mass prism \\
\hline MSL & Mean Sea Level \\
\hline MSS & Mean Sea Surface \\
\hline MIMOST & Multiple Input Multiple Output System Theory \\
\hline NASA & National Aeronautics and Space Administration \\
\hline NGDC & National Geophysical Data Center \\
\hline NIMA & National Imagery and Mapping Agency \\
\hline NOAA & National Oceanic and Atmospheric Administration \\
\hline UNLP & National University of La Plata \\
\hline UNT & National University of Tucuman \\
\hline OSU & Ohio State University \\
\hline OSU81 & Ohio State University Global Geopotential Model $1981^{\mathrm{a}}$ \\
\hline OSU86 & Ohio State University Global Geopotential Model 1986 \\
\hline OSU89 & Ohio State University Global Geopotential Model $1989^{a}$ \\
\hline OSU91A & Ohio State University Global Geopotential Model $1991^{\mathrm{a}}$ \\
\hline ppm & Part per million \\
\hline POSGAR & POSiciones Geodesicas Argentinas \\
\hline PSD & Power Spectral Density \\
\hline PH & Pratt-Hayford \\
\hline QSST & Quasi Stationary Sea Surface Topography \\
\hline RTM & Residual Terrain Model \\
\hline RSK & Rigorous Spherical Kernel \\
\hline rms & root mean square (error) \\
\hline SLR & Satellite Laser Ranging \\
\hline SST & Sea Surface Topography \\
\hline SSV & Sea Surface Variability \\
\hline SHOM & Service Hydrographique et Océanographique de la Marine \\
\hline $\mathrm{TC}$ & Terrain correction \\
\hline $\mathrm{T} / \mathrm{P}$ & TOPEX/POSEIDON \\
\hline TDRSS & Tracking and Data Relay Satellite System \\
\hline TRANET & Tracking System \\
\hline GPM98A & Ultra high degree geopotential model GPM98A to degree 1800 \\
\hline GPM98B & Ultra high degree geopotential model GPM98B to degree 1800 \\
\hline US & United States \\
\hline UBA & University of Buenos Aires \\
\hline WGS & World Geodetic System \\
\hline
\end{tabular}




\section{NOTATION}

\begin{tabular}{|c|c|}
\hline Symbol & Description \\
\hline $\mathrm{a}$ & Altimetric geoid observations \\
\hline$\sigma_{\mathrm{n}}(\mathrm{T}, \mathrm{T})$ & Anomalous potential degree variances \\
\hline $\mathrm{c}_{\mathrm{n}}(\Delta \mathrm{g}, \Delta \mathrm{g})$ & Anomaly degree variances \\
\hline $\mathrm{t}^{\prime}$ & Anti- root depth \\
\hline$\delta g_{a t m}$ & Atmospheric gravity correction \\
\hline$\delta \mathrm{A}$ & Attraction change \\
\hline M & Averaging operator \\
\hline$h_{b}$ & Bathymetric depth \\
\hline$\Delta \mathrm{g}_{\mathrm{B}}$ & Bouguer anomaly \\
\hline$\Delta \mathrm{V}$ & Change of the gravitational potential at the geoid \\
\hline$\omega$ & Circular frequency \\
\hline$\sigma_{N}^{2}$ GRAV & Combined gravimetric geoid \\
\hline $\mathrm{D}$ & Compensation depth/Constant flexural rigidity \\
\hline$*$ & Complex conjugate \\
\hline $\mathrm{T}_{\mathrm{xx}}, \mathrm{T}_{\mathrm{xy}}$ and $\mathrm{T}_{\mathrm{yy}}$ & Constant horizontal forces per unit length \\
\hline$\delta \mathrm{N}$ & $\begin{array}{l}\text { Contribution to the geoid undulation of the gravity anomaly at the } \\
\text { computation point }\end{array}$ \\
\hline$*$ & Convolution operator \\
\hline$. \mathrm{x}, . \mathrm{y}, . \mathrm{z}$ & Coordinates in $\mathrm{x}, \mathrm{y}$, and $\mathrm{z}$ directions \\
\hline$\left(\varphi_{\mathrm{P}}, \lambda_{\mathrm{P}}\right)$ & Coordinates of the computation point \\
\hline$\left(\varphi_{\mathrm{Q}}, \lambda_{\mathrm{Q}}\right)$ & Coordinates of the data point \\
\hline $\mathrm{R}$ & Correlation function \\
\hline$\xi$ & Correlation length \\
\hline $\mathrm{C}$ & Covariance/total squared curvature \\
\hline$\kappa$ & Curvature \\
\hline$\chi$ & Curvature parameter \\
\hline$\omega_{\mathrm{c}}$ & Cut-off frequency \\
\hline$\Delta \rho$ & Density contrast \\
\hline$\rho^{\prime}$ & Density of the inverted topography \\
\hline$\rho$ & Density of the topographical masses \\
\hline$\rho_{\mathrm{m}}$ & Density of the upper mantle \\
\hline$\rho_{\mathrm{w}}$ & Density of water \\
\hline$h^{\prime}$ & Depth of the ocean \\
\hline$h_{\text {bref }}$ & Depth reference surface \\
\hline$\Delta \mathrm{g}_{\mathrm{T}}$ & Direct terrain effect or direct topographical effect on gravity \\
\hline $\mathrm{s}$ & Distance kernel \\
\hline f & Ellipsoidal flattening \\
\hline $\mathrm{h}_{\mathrm{e}}$ & Ellipsoidal height \\
\hline$\varepsilon_{\mathrm{n}}(\Delta \mathrm{g}, \Delta \mathrm{g})$ & $\begin{array}{l}\text { Error anomaly degree variances associated with the coefficients of the } \\
\text { geopotential model }\end{array}$ \\
\hline$\sigma_{\mathrm{h}}$ & Error of the heights \\
\hline $\mathrm{E}[]$ & Expectation operator \\
\hline
\end{tabular}




\begin{tabular}{|c|c|}
\hline $\mathrm{F}$ & Fourier transform/ Free-air reduction \\
\hline$\Delta \mathrm{g}_{\mathrm{FA}}$ & Free-air gravity anomaly \\
\hline$\overline{\mathrm{P}_{\mathrm{n}, \mathrm{m}}}$ & Fully normalized associated Legendre functions \\
\hline$\overline{\mathrm{C}_{\mathrm{nm}}}, \mathrm{S}_{\mathrm{nm}}^{\mathrm{SST}}$ & Fully normalized DOT spherical harmonic coefficients \\
\hline$\overline{\mathrm{C}_{\mathrm{n}, \mathrm{m}}}, \overline{\mathrm{S}_{\mathrm{n}, \mathrm{m}}}$ & $\begin{array}{l}\text { Fully normalized spherical harmonic coefficients of the disturbing } \\
\text { potential }\end{array}$ \\
\hline $\mathrm{r}$ and $\mathrm{r}^{\prime}$ & Geocentric radial distances of points $\mathrm{P}$ and $\mathrm{Q}$ \\
\hline$\varphi, \lambda$ & Geodetic latitude and longitude \\
\hline$\sigma_{N_{\Delta g}}^{2}$ & Geoid error variance due to the error of the gravity anomalies \\
\hline$\sigma_{\mathrm{N}_{\mathrm{GM}}}^{2}$ & Geoid error variance due to the error of the gravity anomalies \\
\hline$\sigma_{\mathrm{N}_{\mathrm{T}}}^{2}$ & Geoid error variance due to the errors of the height data. \\
\hline $\mathrm{N}_{\mathrm{GM}}$ & Geoid height from geopotential model \\
\hline $\mathrm{N}(\omega)$ & Geoid spectrum \\
\hline $\mathrm{N}$ & Geoid undulation (geoid height) \\
\hline Go & Gradient variance \\
\hline g & Gravimetric geoid observations \\
\hline $\mathrm{A}_{\text {comp }}$ & Gravitational attraction due to compensated masses \\
\hline $\mathrm{A}_{\text {cond }}$ & Gravitational attraction due to condensed masses \\
\hline$A_{\text {inv }}$ & Gravitational attraction due to inverted masses \\
\hline $\mathrm{A}_{\mathrm{T}}$ & Gravitational attraction due to topography \\
\hline $\mathrm{V}_{\mathrm{T}}$ & Gravitational potential due the actual topographical masses \\
\hline $\mathrm{V}_{\text {comp }}$ & Gravitational potential of compensated masses \\
\hline $\mathrm{V}_{\text {cond }}$ & Gravitational potential of condensed topography \\
\hline $\mathrm{V}_{\text {inv }}$ & Gravitational potential of inverted topography \\
\hline $\mathrm{V}_{\mathrm{RTM}}$ & Gravitational potential of the reference masses due a RTM reduction \\
\hline$\Delta \mathrm{g}$ & Gravity anomaly \\
\hline$\Delta_{\mathrm{GM}}$ & Gravity anomaly from geopotential model \\
\hline $\mathrm{W}$ & Gravity potential \\
\hline$\Delta \varphi, \Delta \lambda$ & Grid spacing in latitude and longitude, respectively \\
\hline$\zeta$ & Height anomaly \\
\hline $\mathrm{h}_{\text {ref }}$ & Height of the smooth reference surface \\
\hline $\mathrm{h}_{1}$ and $\mathrm{h}_{2}$ & Impulse responses \\
\hline$\delta \Delta \mathrm{g}$ & Indirect effect on gravity \\
\hline $\mathrm{N}_{\text {ind }}$ & Indirect effect on the geoid \\
\hline $\mathrm{m}^{\text {grav }}$ and $\mathrm{m}^{\text {alt }}$ & Input noises \\
\hline $\mathrm{E}$ & Integration area \\
\hline $\mathrm{F}^{-1}$ & Inverse Fourier transform \\
\hline$\nabla^{2}$ & Laplacian operator \\
\hline $\mathrm{dm}$ and $\mathrm{dm}$ & Mass elements \\
\hline $\mathrm{n}_{\max }$ & Maximum degree and order of expansion of the geopotential solution \\
\hline G & Mean gravity of the Earth/gravitational constant \\
\hline$\varphi_{\mathrm{m}}$ & Mean latitude \\
\hline $\bar{\gamma}$ & Mean normal gravity \\
\hline $\mathrm{R}$ & Mean radius of the Earth/radius of the sphere considered by Rudzki \\
\hline $\mathrm{g}$ & Measured gravity value \\
\hline$\gamma$ & Normal gravity \\
\hline
\end{tabular}




\begin{tabular}{|c|c|}
\hline$\gamma_{\mathrm{a}}$ & Normal gravity at equator \\
\hline$\gamma_{\mathrm{b}}$ & Normal gravity at poles \\
\hline $\mathrm{k}$ & Normal gravity constant \\
\hline $\mathrm{H}^{*}$ & Normal height \\
\hline q & Normal vertical stress \\
\hline $\mathrm{N}$ and $\mathrm{M}$ & Number of parallels and meridians in the grid \\
\hline$\alpha$ & Optimal parameter \\
\hline $\mathrm{H}$ & Orthometric height \\
\hline e & Output system noise/Eccentricity \\
\hline $\mathrm{S}$ & Planar distance \\
\hline $\mathrm{p}$ & Power of the prediction \\
\hline $\mathrm{n}^{\text {alt }}$ & Pure altimetric input signals \\
\hline$n^{\text {grav }}$ & Pure gravimetric input signals \\
\hline$\zeta$ & Quasigeoid \\
\hline$\varsigma_{c}(\varphi, \lambda)$ & Quasi-stationary component of the SST \\
\hline$\omega$ & Radial frequency \\
\hline $\mathrm{R}_{\mathrm{B}}$ & Radius of the Bjerhammar sphere \\
\hline$\Delta \mathrm{g}_{\mathrm{rB}}$ & Refined Bouguer anomaly \\
\hline $\mathrm{N}_{\Delta \mathrm{g}}$ & Residual geoid \\
\hline$\zeta_{\Delta \mathrm{g}_{\mathrm{RTM}}}$ & Residual height anomalies \\
\hline t & Root depth \\
\hline$\zeta_{\text {ind }}$ & RTM indirect quasigeoid effect \\
\hline $\mathrm{a}$ & Scale factor \\
\hline $\mathrm{a}$ & Semimajor axis of the reference ellipsoid \\
\hline $\mathrm{b}$ & Semiminor of the reference ellipsoid \\
\hline$\sigma_{\mathrm{n}}(\Delta \mathrm{g}, \Delta \mathrm{g})$ & $\begin{array}{l}\text { Signal gravity anomalies degree variances estimated using the } \\
\text { Tscherning/Rapp model. }\end{array}$ \\
\hline$\sigma$ & Sphere of integration \\
\hline$\psi$ & Spherical distance \\
\hline$\sigma$ & Standard deviation \\
\hline $\mathrm{e}_{\mathrm{Cnm}}^{2}$ and $\mathrm{e}_{\mathrm{Snm}}^{2}$ & Standard deviation of the fully normalized geopotential coefficients. \\
\hline $\mathrm{S}$ & Stokes's kernel \\
\hline$\overline{\mathrm{S}}(\psi)$ & Summation of the Stokes spherical kernel \\
\hline$\kappa$ & Surface density of condensation layer \\
\hline $\mathrm{T}$ & Tension parameter \\
\hline$c_{p}$ & Terrain correction \\
\hline $\mathrm{h}$ & Topographical height \\
\hline Co & Variance \\
\hline$\sigma_{\overline{\mathrm{C}}_{\mathrm{nm}}}^{2} \sigma_{\overline{\mathrm{S}}_{\mathrm{nm}}}^{2}$ & Variance of the fully normalized geopotential coefficients \\
\hline$\sigma_{\Delta \mathrm{g}_{\mathrm{GM}}}^{2}$ & Variances of the gravity anomalies from the geopotential model \\
\hline$\sigma_{\Delta \mathrm{g}}^{2}$ & Variances of the residual gravity anomalies \\
\hline $\mathrm{W}$ & Weighting function \\
\hline
\end{tabular}




\section{CHAPTER ONE}

\section{INTRODUCTION AND RESEARCH BACKGROUND}

\subsection{Introduction}

The main objective of this thesis is the determination of a precise gravimetric geoid for Argentina. Its importance lies on the fact that it will be the official gravimetric geoid for the country, thus it will be used by the entire scientific community.

The shape of the Earth is often described by the geoid. The geoid is that equipotential surface of the Earth's gravity field that most closely approximates the mean sea surface. At every point, the local plumb line is perpendicular to the geoid surface. It is, therefore, a natural reference surface for orthometric heights measured along the plumb line.

The geoid is used in geodetic, geophysical and oceanographic applications. In geodesy, the geoid is used as the reference surface for the orthometric height system. Orthometric heights can be determined without levelling by combining a gravimetric geoid model and ellipsoidal heights derived from the Global Positioning System (GPS). This is a cost effective way for orthometric height determination in mountainous areas and in areas without conventional levelling. In geophysics, the geoid is used to obtain knowledge about the distribution of the masses in the interior of the Earth. In oceanography, the geoid is used to study mean sea level variations, sea level anomalies, tides and currents.

During the last years, the development of regional gravimetric geoids has increased. Improvements in the theory and practical methods of geoid determination, the availability of better digital elevation models and digital depth models, the computation of accurate global geopotential models, the possibility to control the gravimetric geoid with the GPS/levelling derived geoid and the optimal use of heterogeneous data are the main factors that made the developments possible. A precise gravimetric geoid over large areas is possible with a combination of geopotential models, gravity data and heights.

Geoid undulations can be determined by Stokes's integration, Molodensky's solution, or least squares collocation. The use of Stokes's integral requires that the topographical 
masses outside the geoid be removed completely and thus a gravity reduction is necessary in order to reduce the measurements from the Earth's surface to the geoid.

Molodensky's theory takes the Earth's surface as the boundary surface. Theoretically, it avoids the problem of mass shifting and gravity reduction. Geoid undulations are replaced by height anomalies and the geoid is replaced by the quasigeoid.

The use of spectral techniques, based on the Fast Fourier Transform (FFT), is widely used for the computation of large regional and continental geoids (Sideris, 1997).

We will use the software developed in the Department of Geomatics Engineering, University of Calgary (Li and Sideris, 1993) and GRAVSOFT - a set of routines for gravity field modeling developed by C.C. Tscherning of the Geophysical Department of the University of Copenhagen and R. Forsberg and P. Knudsen from Kort og Matrikelstyrelsen (KMS), Denmark (Tscherning et al., 1992). Some modifications, especially in the TC program written by Forsberg (1984) were made at the Department of Geomatics Engineering, University of Calgary, in order to compute different gravity reductions (Bajrachaya et al., 2002).

The GRAVSOFT package contains a complete suite of programs for geoid modeling, conversion of satellite altimetry data to gravity, prediction of deflections of the vertical, etc., by a host of methods, such as, least-squares collocation, planar or spherical FFT, and Stokes's integration, and implements software for covariance function fit and approximation, computation of terrain effects, handling and manipulation of data sets and grids, etc.

Additional software will be developed in order to solve specific problems (gravity anomalies calculation, convert all data to the same format, etc).

\subsection{Objectives}

The main objectives of this research are the determination of a precise land gravimetric geoid model for Argentina and the determination of a precise marine geoid for the Atlantic coastal region of Argentina. They will be achieved through the following tasks: 
- Collect all the available data types that will be used for the computation of the geoids models in Argentina.

- Remove data blunders and reference all data to a unified datum.

- Apply reductions to the measured gravity points. The atmospheric and free air corrections should be applied to the data to obtain point free-air gravity anomalies.

- Apply different topographic reductions to take into account the attraction of the topographic masses.

- Take into account the topographic indirect effect for each topographic reduction used.

- Investigate different gridding procedures. Collocation (krigging), continuous curvature splines in tension (Smith and Wessel, 1990) and weighted means will be used in the gridding procedure.

- Test different geopotential models in order to select the one that best models the long wavelength of the gravity field signal in Argentina.

- Compute the geoid model for the entire Argentina using the remove-restore technique and derive its error estimates. The gravimetric geoid model will be computed using the efficient Fast Fourier Transform (FFT) technique (Schwarz et al., 1990).

- Make comparisons with geoid models derived from global geopotential solutions, and GPS/levelling derived geoid undulations.

- Investigate proper procedures for the adjustment of combined GPS/levelling/geoid height networks to remove datum inconsistencies.

- Carry out an analysis and modeling of the geoid errors. The accuracy of the gravimetric geoid undulations will be evaluated using an external comparison with geoid undulations derived from GPS/levelling on benchmarks.

- Determine the marine geoid model in the coastal region of Argentina. 


\subsection{Methodology}

A gravimetric geoid model will be computed for Argentina. The area under investigation is situated between latitudes $21^{\circ} \mathrm{S}$ to $55^{\circ} \mathrm{S}$ and between longitudes $53^{\circ} \mathrm{W}$ to $76^{\circ} \mathrm{W}$. Part of this area is in the Atlantic Ocean.

Since the point gravity measurements were provided by different sources, they first have to be homogenised. They are provided in different systems so they have to be unified to the International Gravity Standardisation Net 1971 (IGSN71).

The gravimetric data to be used in the geoid computation will include:

- Point surface gravity. Sources of these data will be the Military Geographic Institute, other Universities and the Gravity Department of the University of La Plata.

- Marine gravity provided by the Bureau Gravimétrique International (BGI).

- Global geopotential models.

- Satellite altimetry derived gravity anomalies. We will use the following global models:

KMS01 and KMS02 global marine free-air gravity field models computed from ERS1 plus GEOSAT satellite altimetry by Per Knudsen and Ole Andersen at the Geodetic Division of Kort og Matrikelstyrelsen (KMS), the National Survey and Cadastre of Denmark.

Global marine gravity field models by processing satellite altimetry data computed by D. Sandwell and W Smith (Smith and Sandwell, 1997).

GSFC00.1_DG computed from a Mean Sea Surface model in 2'x2' grid size between latitude $\pm 80^{\circ}$ (GSFC00.1_MSS). The data were downloaded from the Geodynamics, Geophysics, and Space Geodesy Group at Raytheon ITSS.

Free-air gravity anomalies provided by CLS/Space Oceanographic Group

- The topographic data on land include GTOPO30 and GLOBE Elevation Models (DEMs) and point gravity station heights. 
GTOPO30 is a global Digital Elevation Model (DEM) with a horizontal grid spacing of 30 arc second (approximately 1 kilometre). GTOPO30, completed in late 1996, was developed in the US Geological Survey's Earth Resources Observation Systems (EROS) Data Center (EDC).

GLOBE (Global Land One-kilometre Base Elevation) is a global Digital Elevation Model (DEM) developed by NOAA National Data Center, NGDC.

- The bathymetric data for marine application will come from the 2' Digital Depth Model (DDM) developed by Smith and Sandwell in 1997.

- GPS/levelling data.

- Satellite altimetry data from the European Earth Remote-Sensing Satellite 1 (ERS1) and three year stacked TOPEX/POSEIDON (T/P) Sea Surface Heights (SSHs).

The gravity data belonging to the Gravity Department of the University of La Plata will be reprocessed and saved in a digital database. All data that have been collected need to be checked for systematic errors. The existence of biases and datum shifts in terrestrial gravity and heights is a very important point and must be resolved before a geoid model is calculated. Standard reductions must be applied to derive free-air gravity and refined Bouguer anomalies. The GRS80 normal gravity field will be used (Moritz, 1980). The second order term in the normal vertical gradient together with the atmospheric correction (Torge, 1989) will be taken into account in the free-air reduction.

The high precision gravimetric geoid will be determined by the well-known removecompute-restore technique. The long wavelength gravity field spectrum derived from a geopotential model and the short wavelength topographic effects will be removed from the observed gravity anomalies. A Fourier representation of Stokes's integral formula will be used to compute residual undulations. The final geoid undulations will be obtained by restoring the geoid undulation of the geopotential model and of the effect of the topography (Schwarz et al., 1990).

The geopotential model plays an important role in this procedure. The following global geopotential models will be used and validated: JGM-3 (Tapley et al., 1996), OSU81 (Rapp, 1981), OSU91A (Rapp et al., 1991), EGM96 (Lemoine et al., 1998), GPM98a 
and GPM98b (Wenzel, 1999) and the new high-resolution global gravity field model EIGEN-CG01C derived from combining CHAMP and GRACE satellite missions and surface gravity data (Reigber et al., 2004). Comparisons between the long wavelength contributions to the geoid computed by these geopotential models will be made. Comparisons with the geoid undulations obtained from GPS on benchmarks will allow us to choose the best geopotential model that will be used as reference field in Argentina.

The method to compute the gravimetric geoid is based on the use of the Fast Fourier Transform technique (FFT). Stokes's and terrain correction integrals will be reformulated as convolution integrals and evaluated efficiently by Fast Fourier Transform if the data are given on regular grids.

Geoid undulations will be computed via Stokes's formula with the rigorous spherical kernel by the one-dimensional Fast Fourier Transform algorithm (Haagmans et al. 1993).

FFT needs gridded data. Different methods of prediction will be evaluated to produce a regular grid: least-squares collocation, which is based on the empirical covariance function of the gravity anomalies, ordinary Krigging, weighted means and continuous curvature splines in tension (Smith and Wessel, 1990). In the interpolation procedure, we need to smooth the data to obtain the most reliable result possible.

Different methods of handling topography will be investigated and they will depend on boundary value problem under consideration (Bajracharya et al., 2002):

- The Helmert condensation method.

- Residual Terrain Model (RTM).

- Rudzki inversion method.

- Topographic -isostatic reductions.

The external accuracy of the gravimetric geoid model will be evaluated by comparing it with results derived from GPS/levelling data. Geometrical geoid undulation can be determined by combining the ellipsoidal height $h_{e}$ with the orthometric height $H$ on 
levelled benchmarks occupied by GPS receivers. The systematic datum differences between the gravimetric geoid and the GPS/levelling data, and the possible long wavelength errors of the geoid, will be removed by a four-parameter transformation and a seven-parameter transformation model (Kotsakis, 2001). The absolute differences between the gravimetric and the GPS/levelling geoid will be calculated.

The final accuracy of the predicted gravimetric geoid is subject to different errors coming from the different sources used in the computation (geopotential model, local gravity anomalies and heights). These errors will be propagated into the geoid results. Covariance functions, for different gravity surveys, and areas with different topographies will be analysed.

Argentina is located in Southern South America; with a total area of 2,766,890 $\mathrm{km}^{2}$ is the second-largest country in South America (after Brazil). Argentina is a very huge country ranging from $20^{\circ} \mathrm{S}$ to about $55^{\circ} \mathrm{S}$ in latitude and $53^{\circ} \mathrm{W}\left(307 \mathrm{E}^{\circ}\right)$ to about $76^{\circ} \mathrm{W}\left(284 \mathrm{E}^{\circ}\right)$ in longitude. Figure 1.1 illustrates the geographical location and topography of Argentina. Argentina is bounded to the west with the highest mountain range in America, the Andes, so different topographic reduction methods in practical gravimetric geoid determination are crucial for taking care of this problem. To the east, Argentina borders on the Atlantic Ocean so the combination with shipborne gravity data and satellite altimetry derived free air gravity anomalies constitute other of the problems that were also taken into account.

Preliminary analysis will be carried out in different test areas for land and for sea. Then it will be extended to the entire country. The first area will be a flat area in Buenos Aires province. This area has a good coverage of gravity data and GPS on benchmarks

The second area will be a rough one near the Andes, in order to investigate the direct effect of the topographic masses and the indirect effect to improve the short wavelength information of the geoid. Rigorous formulas for the terrain correction have been proposed ( $\mathrm{Li}$ and Sideris, 1993). The effect of using mass prism and line prism topographic models will be investigated. We will use a constant density value through the entire investigation. 


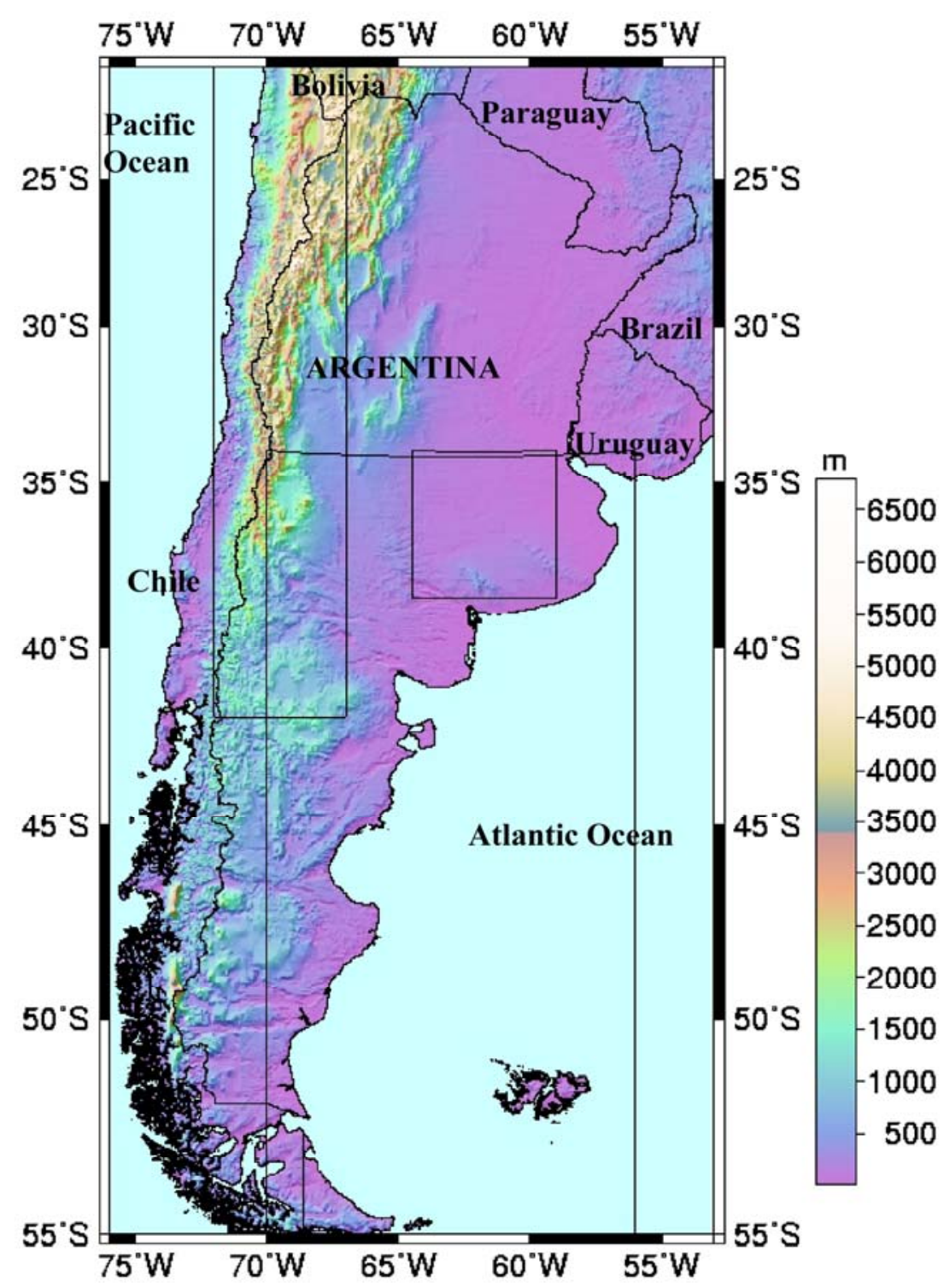

Figure 1.1: Geographical location and topography of Argentina

The third area is a marine area, where a marine gravimetric geoid for the Atlantic coastal region of Argentina will be investigated using shipborne gravity data and altimetric data. The remove-restore technique will be applied again. An appropriate gravity reduction will be used to remove the high frequency of the bathymetry in the remove step and the long wavelength contribution of the gravity field will be removed from a geopotential model. These two contributions will be restored just after applying Stokes's integral. The altimetric geoid model will be computed using altimetric data from the ERS1 satellite mission and the marine gravimetric geoid will be computed using marine gravity provided by the International Gravimetric Bureau (BGI). Both the 
gravimetric and the altimetric geoid will be combined to obtain the final marine solution, using Input Output System Theory (IOST) in order to improve the accuracy of the marine gravimetric geoid and the altimetric geoid close to the coastlines (Sideris, 1996; Vergos, 2002).

The final gravimetric geoid for Argentina will be computed combining land data, shipborne data and altimetry data.

\subsection{Thesis outline}

The thesis consists of nine chapters. The content of the next eight chapters are summarize as follows:

Chapter 2 describes the theoretical background and the methodology applied for the determination of the regional gravimetric geoid. Special emphasis will be put on the terrain effects for the different gravity reductions methods to handle the topography of western Argentina, which is one of the roughest areas in the world.

Chapter 3 presents the theoretical background for the determination of the marine geoid. This includes the remove-compute-restore technique for the altimetric and gravimetric geoid modeling and an introduction to the Multiple Input System Theory employed in this investigation.

Chapter 4 describes all the different types of data involved in the gravimetric geoid determination. It also includes the data preparation validation and evaluation procedures; these steps are crucial because the quality and the availability of the data will directly affect the quality of the later geoid determination in terms of accuracy.

Chapter 5 describes some basic concepts of covariance, correlation and power spectral density functions. The statistical behavior of gravity anomalies will be investigated in different areas with different topographies in Argentina.

Chapter 6 presents some numerical investigations carried out in different land areas with very different types of topography in order to investigate the best method of handling 
topography in practical geoid determination for the subsequent geoid computation for the whole Argentina.

In chapter 7, numerical results of altimetric, gravimetric and combined geoid solution for the Atlantic coastal region of Argentina are presented. The validation of the new models is carried out through comparisons with T/P Sea Surface Heights, which were used as control due to their very high accuracy.

Chapter 8 presents the results of the new high precision, high-accuracy and highresolution gravimetric geoid for Argentina computed with the most updated database available for the country together with the most efficient computational methodology.

And finally, chapter 9 outlines the main conclusions and recommendations for future work. 


\section{CHAPTER TWO}

\section{REGIONAL GRAVIMETRIC GEOID DETERMINATION}

The gravimetric geoid undulations in Argentina are calculated using the removecompute-restore technique. This technique combines a global geopotential model (GM), local gravity anomalies $\Delta \mathrm{g}$, and the topography/bathymetry, represented by a Digital Elevation Model (DEM) and a Digital Depth Model (DDM), respectively.

The global geopotential model, local gravity anomalies and digital terrain/bathymetry model represent the low, medium and high frequencies of the gravity signal, respectively.

\subsection{Formulas for gravimetric geoid computation via the remove-compute-restore technique}

The long wavelength reference field of a geopotential model and the short wavelength topographic effects are removed mathematically from the observed gravity anomalies. Stokes's integration is then used to convert the reduced, or residual, gravity anomalies to geoid undulations. The final geoid undulation is obtained by restoring the geoid effects of the geopotential model reference field and of the topography represented by a Digital Elevation Model.

The residual geoid undulations are estimated using the Stokes formula with gravity anomalies as input. Before applying Stokes's formula, the gravity anomalies must be reduced in the remove step of the remove-restore technique:

$\Delta \mathrm{g}=\Delta \mathrm{g}_{\mathrm{FA}}-\Delta \mathrm{g}_{\mathrm{T}}-\Delta \mathrm{g}_{\mathrm{GM}}$

where $\Delta \mathrm{g}_{\mathrm{FA}}$ is the free-air gravity anomaly, $\Delta_{\mathrm{GM}}$ is the reference gravity anomaly computed from a geopotential model, and $\Delta \mathrm{g}_{\mathrm{T}}$ is the direct terrain effect, also called direct topographical effect on gravity, which depends on the reduction method used.

The gravimetric geoid is obtained, in the restore step by

$\mathrm{N}=\mathrm{N}_{\Delta \mathrm{g}}+\mathrm{N}_{\text {ind }}+\mathrm{N}_{\mathrm{GM}}$ 
where $\mathrm{N}_{\mathrm{GM}}$ is the reference geoidal undulation implied by the geopotential model, $\mathrm{N}_{\mathrm{ind}}$ is the indirect effect on the geoid and depends on the reduction method used, and $\mathrm{N}_{\Delta \mathrm{g}}$ represents residual geoid computed with residual gravity anomalies given in equation (2.1).

The advantage of the terrain remove-restore scheme is that the reduced gravity anomalies are smaller, have lower variability, are easy to grid, and the geoid errors due to terrain effects are minimised (Forsberg, 1997).

In the classical solution, the geoidal undulation can be computed, in spherical approximation, using Stokes's integral, which is the solution of the third boundary value problem (Heiskanen and Moritz, 1967)

$$
\mathrm{N}=\frac{\mathrm{R}}{4 \pi \gamma} \iint_{\sigma} \Delta \mathrm{gS}(\psi) \mathrm{d} \sigma
$$

where $\sigma$ denotes the sphere of integration, $R$ is the mean radius of the Earth, $\gamma$ is the normal gravity, $\mathrm{S}(\psi)$ is the Stokes kernel function defined in equation (2.5), $\psi$ is the spherical distance between the data point and the computation point, and $\Delta \mathrm{g}$ is the residual gravity anomaly on the geoidal surface given by equation (2.1).

Stokes formula can be written in explicit form as:

$$
\mathrm{N}\left(\varphi_{\mathrm{P}}, \lambda_{\mathrm{P}}\right)=\frac{\mathrm{R}}{4 \pi \gamma} \int_{\lambda} \int_{\varphi} \Delta \mathrm{g}\left(\varphi_{\mathrm{Q}}, \lambda_{\mathrm{Q}}\right) \mathrm{S}\left(\varphi_{\mathrm{P}}, \lambda_{\mathrm{P}}, \varphi_{\mathrm{Q}}, \lambda_{\mathrm{Q}}\right) \cos \varphi_{\mathrm{Q}} \mathrm{d} \varphi \mathrm{d} \lambda
$$

where $S\left(\varphi_{P}, \lambda_{P}, \varphi_{Q}, \lambda_{Q}\right)$ is the spherical Stokes kernel function defined by:

$$
\begin{aligned}
\mathrm{S}\left(\varphi_{\mathrm{P}}, \lambda_{\mathrm{P}}, \varphi_{\mathrm{Q}}, \lambda_{\mathrm{Q}}\right)= & \frac{1}{\sin \frac{\psi}{2}}-4-6 \sin \frac{\Psi}{2}+10 \sin ^{2}\left(\frac{\psi}{2}\right)-\left[3-6 \sin ^{2}\left(\frac{\psi}{2}\right)\right] \\
& \ln \left[\sin \frac{\psi}{2}+\sin ^{2}\left(\frac{\Psi}{2}\right)\right]
\end{aligned}
$$

where

$$
\sin ^{2} \frac{\psi}{2}=\sin ^{2} \frac{\varphi_{\mathrm{P}}-\varphi_{\mathrm{Q}}}{2}+\sin ^{2} \frac{\lambda_{\mathrm{P}}-\lambda_{\mathrm{Q}}}{2} \cos \varphi_{\mathrm{P}} \cos \varphi_{\mathrm{Q}}
$$

With gridded gravity anomalies, the discrete Stokes integral can be written as 
$\mathrm{N}\left(\varphi_{\mathrm{P}}, \lambda_{\mathrm{P}}\right)=\frac{\mathrm{R} \Delta \varphi \Delta \lambda}{4 \pi \gamma} \sum_{\varphi_{\mathrm{Q}}=\varphi_{1}}^{\varphi_{\mathrm{M}}} \sum_{\lambda_{\mathrm{Q}}=\lambda_{1}}^{\lambda_{\mathrm{N}}} \mathrm{S}\left(\psi_{\mathrm{PQ}}\right) \Delta \mathrm{g}\left(\varphi_{\mathrm{Q}}, \lambda_{\mathrm{Q}}\right) \cos \varphi_{\mathrm{Q}}$

where $\varphi_{\mathrm{P}}$ and $\lambda_{\mathrm{P}}$ are the coordinates of the computation point; $\varphi_{\mathrm{Q}}$ and $\lambda_{\mathrm{Q}}$ are the coordinates of the data point; $\Delta \varphi$ and $\Delta \lambda$ are the grid spacing in latitude and longitude; $\mathrm{N}$ and $\mathrm{M}$ are the number of parallels and meridians in the grid; and $\Delta \mathrm{g}$ is the reduced gravity anomaly given by equation (2.1)

To account for the singularity of the kernel function $\left(\psi=0\right.$ when $\varphi=\varphi_{P}$ and $\left.\lambda=\lambda_{P}\right)$, the contribution to the geoid undulation of the gravity anomaly at the computation point can be evaluated separately as (Schwarz et al., 1990).

$$
\delta \mathrm{N}=\frac{\sqrt{\Delta \mathrm{x} \Delta \mathrm{y}}}{\gamma \sqrt{\pi}} \Delta \mathrm{g}
$$

The shifting of the topographical masses changes the gravitational field of the Earth, including the potential of the geoid, so the surface computed by the Stokes formula, after the displacement of the masses and without considering the indirect effect on the geoid, is the cogeoid.

The indirect effect on the geoid in equation (2.2) is

$$
\mathrm{N}_{\text {ind }}=\frac{\Delta \mathrm{V}}{\gamma}
$$

where $\Delta \mathrm{V}$ is the change of the gravitational potential at the geoid due to the terrain reduction applied and $\gamma$ is the normal gravity.

$$
\begin{aligned}
& \Delta \mathrm{V}=\mathrm{V}_{\mathrm{T}}-\mathrm{V}_{\text {comp }} \\
& \Delta \mathrm{V}=\mathrm{V}_{\mathrm{T}}-\mathrm{V}_{\text {cond }} \\
& \Delta \mathrm{V}=\mathrm{V}_{\mathrm{T}}-\mathrm{V}_{\mathrm{inv}} \\
& \Delta \mathrm{V}=\mathrm{V}_{\mathrm{T}}-\mathrm{V}_{\mathrm{RTM}}
\end{aligned}
$$

where $\mathrm{V}_{\mathrm{T}}$ is the gravitational potential due the actual topographical masses; $\mathrm{V}_{\text {comp }}$ is the gravitational potential of the compensates masses for a topographic-isostatic reduction using an Airy-Heiskanen or Pratt-Hayford model; $\mathrm{V}_{\text {cond }}$ is the gravitational potential of the condensed masses using a Helmert reduction; $V_{\text {inv }}$ is the gravitational potential of 
the inverted masses due a Rudzki inversion method and $\mathrm{V}_{\mathrm{RTM}}$ represents the gravitational potential of the reference masses due a RTM reduction.

The indirect effect on gravity, which reduces gravity anomalies from the geoid to the cogeoid, is expressed by

$\delta \Delta \mathrm{g}=0.3086 \mathrm{~N}_{\text {ind }}[\mathrm{mGal}]$

This effect should be added to equation (2.1) if, for example, the Helmert second's method of condensation is applied.

From the contribution of the geopotential model, a reference gravity anomaly $\left(\Delta \mathrm{g}_{\mathrm{GM}}\right)$ and a reference geoidal undulation $\left(\mathrm{N}_{\mathrm{GM}}\right)$ can be calculated. The gravity anomaly estimated at a position $\left(\phi_{\mathrm{P}}, \lambda_{\mathrm{P}}\right)$ is expressed in spherical approximation as:

$\Delta \mathrm{g}_{\mathrm{GM}}=\mathrm{G} \sum_{\mathrm{n}=2}^{\mathrm{n}=\mathrm{n}_{\max }}(\mathrm{n}-1) \sum_{\mathrm{m}=0}^{\mathrm{n}}\left(\overline{\mathrm{C}_{\mathrm{n}, \mathrm{m}}} \cos \mathrm{m} \lambda_{\mathrm{P}}+\overline{\mathrm{S}_{\mathrm{n}, \mathrm{m}}} \sin \mathrm{m} \lambda_{\mathrm{P}}\right) \overline{\mathrm{P}_{\mathrm{n}, \mathrm{m}}}\left(\operatorname{sen} \phi_{\mathrm{P}}\right)$

and the reference geoidal undulation as:

$\mathrm{N}_{\mathrm{GM}}=\mathrm{R} \sum_{\mathrm{n}=2}^{\mathrm{n}=\mathrm{n}_{\max }} \sum_{\mathrm{m}=0}^{\mathrm{n}}\left(\overline{\mathrm{C}_{\mathrm{n}, \mathrm{m}}} \cos \mathrm{m} \lambda_{\mathrm{P}}+\overline{\mathrm{S}_{\mathrm{n}, \mathrm{m}}} \sin \mathrm{m} \lambda_{\mathrm{P}}\right) \overline{\mathrm{P}_{\mathrm{n}, \mathrm{m}}}\left(\operatorname{sen} \phi_{\mathrm{P}}\right)$

where $G$ is the mean gravity of the Earth, $R$ is the mean radius of the Earth, $\overline{C_{n, m}}$ and $\overline{\mathrm{S}_{\mathrm{n}, \mathrm{m}}}$ are the fully normalized spherical harmonic coefficients of the disturbing potential, $\overline{\mathrm{P}_{\mathrm{n}, \mathrm{m}}}$ are the fully normalized associated Legendre functions (Heiskanen and Moritz, 1967), and $\mathrm{n}_{\max }$ denotes the maximum degree and order of expansion of the geopotential solution.

\subsection{Fast Fourier Transform formulas for evaluating Stokes's integral}

The Fast Fourier Transform (FFT) method will be used to evaluate the discrete Stokes formula. This technique allows for the evaluation of the discrete Stokes integral for all the points on a regular grid simultaneously. That is why, together with the fast computation time, it is one of the best approaches for the determination of large-scale regional geoids, like the Argentinean geoid. 
The FFT is a powerful tool for the spectral evaluation of the Stokes integral in the frequency domain (Schwartz et al., 1990).

The first time that the discrete Stokes integral was evaluated with the FFT method, the 2D planar FFT, was used (Schwarz and Sideris, 1985; Schwarz et al., 1990). In planar approximation, the Stokes kernel function in equation (2.5) can be approximated for small distance $\psi$ by:

$$
\mathrm{S}\left(\varphi_{\mathrm{P}}, \lambda_{\mathrm{P}}, \varphi_{\mathrm{Q}}, \lambda_{\mathrm{Q}}\right) \approx \frac{1}{\sin \frac{\psi_{\mathrm{PQ}}}{2}} \approx \frac{2}{\psi_{\mathrm{PQ}}} \approx \frac{2 \mathrm{R}}{\mathrm{s}_{\mathrm{PQ}}}
$$

where $\mathrm{s}_{\mathrm{PQ}}$ is the planar distance between the points $\mathrm{P}$ and $\mathrm{Q}$, and in rectangular coordinates is:

$$
\mathrm{s}_{\mathrm{PQ}}=\sqrt{\left(\mathrm{x}_{\mathrm{P}}-\mathrm{x}_{\mathrm{Q}}\right)^{2}+\left(\mathrm{y}_{\mathrm{P}}-\mathrm{y}_{\mathrm{Q}}\right)^{2}}
$$

The discrete Stokes formula (2.7) can be expressed in planar approximation as:

$$
\mathrm{N}\left(\mathrm{x}_{\mathrm{P}}, \mathrm{y}_{\mathrm{P}}\right)=\frac{\Delta \mathrm{x} \Delta \mathrm{y}}{2 \pi \gamma} \sum_{\mathrm{x}_{\mathrm{Q}}=\mathrm{x}_{1}}^{\mathrm{X}_{\mathrm{M}}} \sum_{\mathrm{y}_{\mathrm{Q}}=\mathrm{y}_{1}}^{\mathrm{y}_{\mathrm{N}}} \frac{1}{\mathrm{~s}_{\mathrm{PQ}}} \Delta \mathrm{g}\left(\mathrm{x}_{\mathrm{Q}}, \mathrm{y}_{\mathrm{Q}}\right)
$$

This equation is a 2D discrete convolution and $\mathrm{N}$ can be evaluated at all gridded points simultaneously by the 2D FFT (Schwartz et al., 1990)

$$
\mathrm{N}\left(\mathrm{x}_{\mathrm{P}}, \mathrm{y}_{\mathrm{P}}\right)=\frac{\Delta \mathrm{x} \Delta \mathrm{y}}{2 \pi \gamma} \mathrm{F}^{-1}\left\{\mathrm{~F}\left\{\frac{1}{\mathrm{~s}_{\mathrm{P}}}\right\} \mathrm{F}\left\{\Delta \mathrm{g}\left(\mathrm{x}_{\mathrm{P}}, \mathrm{y}_{\mathrm{P}}\right\}\right\}\right.
$$

where $\mathrm{F}$ and $\mathrm{F}^{-1}$ are the two-dimensional Fourier transforms operator and its inverse It can also be evaluated by the $1 \mathrm{D}$ FFT

$$
\begin{aligned}
& \mathrm{N}\left(\mathrm{x}_{\mathrm{P}}, \mathrm{y}_{\mathrm{P}}\right)=\frac{\Delta \mathrm{x} \Delta \mathrm{y}}{2 \pi \gamma} \mathrm{F}^{-1}\left\{\sum_{\mathrm{x}_{\mathrm{P}}=\mathrm{x}_{1}}^{\mathrm{X}_{\mathrm{M}}} \mathrm{F}\left\{\frac{1}{\mathrm{~s}_{\mathrm{P}}}\right\} \mathrm{F}\left\{\Delta \mathrm{g}\left(\mathrm{x}_{\mathrm{P}}, \mathrm{y}_{\mathrm{P}}\right\}\right\}\right. \\
& \mathrm{N}\left(\mathrm{x}_{\mathrm{P}}, \mathrm{y}_{\mathrm{P}}\right)=\frac{\Delta \mathrm{x} \Delta \mathrm{y}}{2 \pi \gamma} \mathrm{F}^{-1}\left\{\sum_{\mathrm{y}_{\mathrm{P}}=\mathrm{y}_{1}}^{\mathrm{y}_{\mathrm{M}}} \mathrm{F}\left\{\frac{1}{\mathrm{~s}_{\mathrm{P}}}\right\} \mathrm{F}\left\{\Delta \mathrm{g}\left(\mathrm{x}_{\mathrm{P}}, \mathrm{y}_{\mathrm{P}}\right\}\right\}\right.
\end{aligned}
$$

Equations (2.18) and (2.19) are used when the grid size is too large to be handled by the capacity of the available computer memory. 
Throughout this thesis, two methods will be used for the evaluation of the discrete Stokes integral: the 2D spherical FFT (Strang Van Hess, 1990) and the 1D spherical FFT (Haagmans et al., 1993).

The Stokes formulas evaluated with FFT are linear convolutions but most of the fast Fourier algorithms are intended for the computation of circular convolutions. Edge effects are produced by the circular convolution; the required zero-padding methods to reduce these effects are described by $\mathrm{Li}$ (1993).

\subsubsection{Approximated spherical Kernel (ASK)}

Equations (2.5) and (2.6) show that the Stokes function is not only a function of latitude and longitude differences but also it is a function of the latitudes of the computation point and the data point. The discrete Stokes integral expressed in equation (2.7) is not a $2 \mathrm{D}$ discrete convolution so it cannot be evaluated by 2D FFT.

In 1990, Strang van Hess suggested to use $\cos ^{2} \varphi_{m}$ instead of $\cos \varphi_{P} \cos \varphi_{Q}$ in equation (2.6), where $\varphi_{\mathrm{m}}$ is the mean latitude of the whole computation area and Forsberg and Sideris (1993) gave a more accurate approximation given by:

$$
\cos \varphi_{\mathrm{P}} \cos \varphi_{\mathrm{Q}} \approx \cos ^{2} \varphi_{\mathrm{m}}-\sin ^{2} \frac{\left(\varphi_{\mathrm{P}}-\varphi_{\mathrm{Q}}\right)}{2}
$$

Inserting this in equation (2.6), we obtain:

$$
\sin ^{2}\left(\frac{\psi}{2}\right)=\sin ^{2} \frac{\varphi_{\mathrm{p}}-\varphi_{\mathrm{Q}}}{2}+\sin ^{2} \frac{\lambda_{\mathrm{p}}-\lambda_{\mathrm{Q}}}{2} \cos \varphi_{\mathrm{p}} \sin \varphi_{\mathrm{Q}}=\sin ^{2} \frac{\varphi_{\mathrm{p}}-\varphi_{\mathrm{Q}}}{2}+\sin ^{2} \frac{\lambda_{\mathrm{p}}-\lambda_{\mathrm{Q}}}{2} \cos \varphi_{\mathrm{m}}^{2}
$$

$$
\sin ^{2}\left(\frac{\psi}{2}\right) \approx \sin ^{2} \frac{\varphi_{\mathrm{p}}-\varphi_{\mathrm{Q}}}{2}+\sin ^{2} \frac{\lambda_{\mathrm{p}}-\lambda \mathrm{Q}}{2}\left(\cos ^{2} \varphi_{\mathrm{m}}-\sin ^{2} \frac{\left(\varphi_{\mathrm{p}}-\varphi_{\mathrm{Q}}\right)}{2}\right)
$$

where $\varphi_{\mathrm{m}}$ is a constant for all the area and the approximated Stokes function is only dependent on the latitude and longitude difference. With one of these approximations, equation (2.7) can be written as a two-dimensional convolution. The geoid undulations on all gridded points can be computed simultaneously by means of the two-dimensional Fast Fourier Transform as: 
$\mathrm{N}\left(\varphi_{\mathrm{P}}, \lambda_{\mathrm{P}}\right)=\frac{\mathrm{R} \Delta \varphi \Delta \lambda}{4 \pi \gamma} \mathrm{F}^{-1}\left\{\mathrm{~F}\left\{\Delta \mathrm{g}\left(\varphi_{\mathrm{P}}, \lambda_{\mathrm{P}}\right) \cos \varphi_{\mathrm{P}}\right\} \mathrm{F}\left\{\mathrm{S}\left(\psi_{\mathrm{P}}\right)\right\}\right.$

\subsubsection{Rigorous Spherical Kernel (RSK)}

Due to approximations of the kernel function, non-exact results can be achieved by the spherical 2D FFT method. Another approach to evaluate the convolution integrals on the sphere was presented by Haagmans et al. (1993) where the 1D FFT techniques is used instead of the traditional 2D FFT technique. Considering the fact that Stokes's kernel is constant for all computation points on one parallel, but different for computation points with different latitudes, only an east-west convolution is carried out by the 1D FFT while the north-south integration can be performed by pointwise integration. The results are the same as those from the pointwise integration on the sphere. Stokes's integral on the sphere using 1D FFT can be expressed as a convolution in the East-West direction as:

$$
\mathrm{N}\left(\varphi_{\mathrm{P}}, \lambda_{\mathrm{P}}\right)=\frac{\mathrm{R} \Delta \varphi \Delta \lambda}{4 \pi \gamma} \mathrm{F}_{1}^{-1}\left\{\sum _ { \varphi = \varphi _ { 1 } } ^ { \varphi _ { \mathrm { M } } } \left\{\mathrm{~F}_{1}\left\{\Delta \mathrm{g}\left(\varphi_{\mathrm{P}}\right) \cos \varphi_{\mathrm{P}}\right\} \mathrm{F}_{1}\left\{\mathrm{~S}\left(\psi_{\mathrm{P}}\right\}\right\}\right.\right.
$$

where $F_{1}$ and $F_{1}^{-1}$ represent the one-dimensional Fourier transform operator and its inverse, which are performed in the longitudinal direction, and $\Delta \varphi$ and $\Delta \lambda$ are the grid spacings in latitude and longitude.

\subsection{Methods of handling the topography in practical geoid determination}

The effect of the topography is one of the most important aspects in the determination of precise geoid undulations or height anomalies, especially for mountainous regions such as Argentina.

The use of Stokes's formula in gravimetric geoid determination requires that the gravity anomalies represent boundary values on the geoid; this means that the measured gravity (usually taken on the surface of the Earth) must be reduced to the geoid and there must be no masses outside the geoid (Heiskanen and Moritz, 1967). The process of shifting or removing the masses outside the geoid is called gravity reduction. There are several gravity reductions used in physical geodesy and the most common methods are: the 
refined Bouguer reduction, topographic-isostatic reductions, the Rudzki inversion method and the second method of Helmet's condensation. The Residual Terrain Model (RTM) reduction (Forsberg, 1984) is another type of reduction, which takes into account the high frequencies of the topography and yields the quasigeoid.

Theoretically, all reduction methods should lead us to the same geoid, if the gravity reductions were rigorously applied (Heiskanen and Moritz, 1967) even though each reduction treats the topography in a different way (Omang and Forsberg, 2000; Bajaracharja, 2003; Bajaracharja and Sideris, 2004; Bajaracharja and Sideris, 2005).

As we have mentioned before, the original potential of the Earth is changed due the removal or shifting the masses outside the geoid in the gravity reduction process. The geoid is defined as the equipotential surface with potential $\mathrm{W}_{\mathrm{o}}$. For a point originally on the geoid, after applying a gravity reduction, the potential changes by an amount $\delta \mathrm{W}$ Thus, after the gravity reduction process, the point originally on the geoid has a potential $\mathrm{W}_{\mathrm{o}}-\delta \mathrm{W}$ (by convention) and, by the definition of geoid, it is not on the geoid anymore. It is on the cogeoid. That is why Stokes's formula using equation (2.1) yields the cogeoid. The real geoid and the cogeoid are separated by a distance $\left(\mathrm{N}_{\text {ind }}\right)$, which is called the indirect effect of the gravity reduction on geoid undulation, and is given by:

$$
\mathrm{N}_{\text {ind }}=\frac{\delta \mathrm{W}}{\gamma}
$$

Comparing this formula with equation (2.8), we can see that $\delta \mathrm{W}$ is the same as the change of the gravitational potential $\mathrm{dV}$ since the centrifugal potential before and after the gravity reduction is the same. A positive sign of $\mathrm{N}_{\text {ind }}$ means that the geoid is above the cogeoid. See Figure (2.1).

Since the Stokes procedure with terrain-reduced $\Delta \mathrm{g}$ yields the cogeoid rather than the geoid, the gravity anomalies used must be boundary values at the surface of the cogeoid, so gravity anomalies must be moved from the geoid (point $\mathrm{P}_{0}$ ) to the cogeoid (point $\mathrm{P}_{\mathrm{c}}$ ) by applying a simple free-air reduction expressed in equation (2.11). The change of $\Delta \mathrm{g}$ is $\delta \Delta \mathrm{g}$, the secondary indirect effect on gravity due to the gravity reduction. Considering this indirect effect, equation (2.3) can be rewritten as:

$$
\mathrm{N}=\frac{\mathrm{R}}{4 \pi \gamma} \underset{\sigma}{\int}(\Delta \mathrm{g}+\delta \Delta \mathrm{g}) \mathrm{S}(\psi) \mathrm{d} \sigma
$$




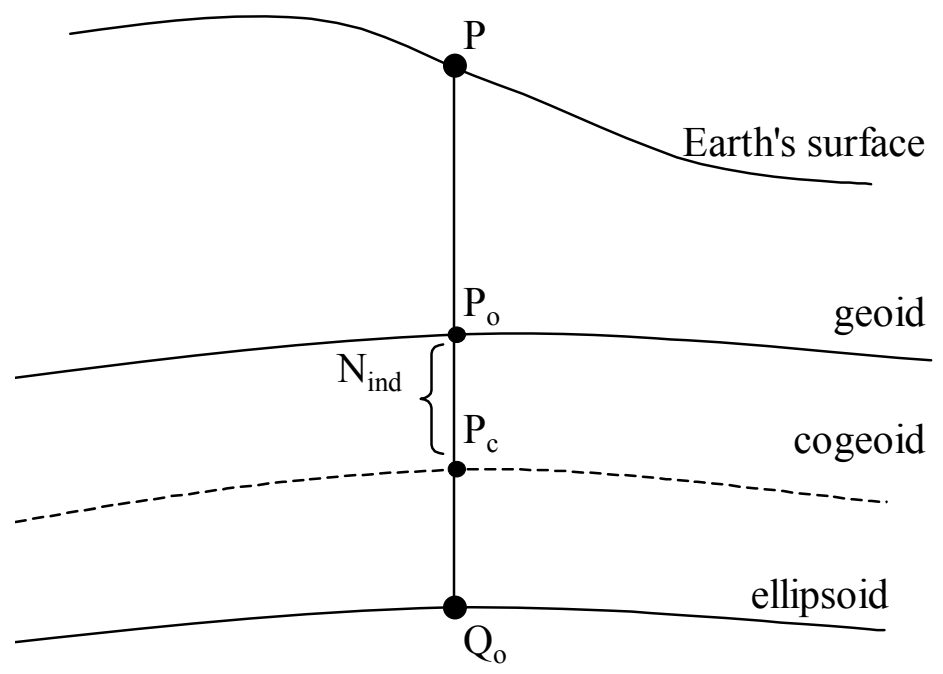

Figure 2.1: Geoid, cogeoid and ellipsoid

The following gravimetric reduction techniques will be investigated in this thesis.

- Refined Bouguer reduction

- Topographic-isostatic reduction

- Helmert's second condensation method

- Rudzki inversion method

- Residual Terrain Model

In principle, every gravity reduction that gives boundary values at the geoid is equally suitable for geoid determination if the indirect effect is properly taken into account. In all the reduction methods it is necessary to know the density of the masses between the geoid and the surface of the topography. During this study, a constant density $\rho=2.67 \mathrm{~g} / \mathrm{cm}^{3}$ is assumed. A second assumption is also made, i.e., the actual free-air gravity gradient is assumed to be equal to the normal free-air gravity gradient.

\subsubsection{Refined Bouguer reduction}

The objective of the refined Bouguer reduction is to remove all the topographic masses outside the geoid but, because the indirect effect is very large in this case, refined Bouguer anomalies are not used for geoid determination. The complete Bouguer reduction is used in this thesis to remove the gravimetric effect of the terrain prior the 
interpolation and gridding in order to avoid aliasing of the short wavelength gravity features. Complete Bouguer anomalies have very good interpolatory properties (Heiskanen and Moritz, 1967).

The refined Bouguer reduction takes into account not only the Bouguer plate, which considers that the area around the gravity station $\mathrm{P}$ is flat and the masses between the geoid and the earth's surface have constant density $\rho$, but also the deviations of the actual topography from the Bouguer plate at $\mathrm{P}_{0}$ This is the terrain correction effect, which is usually one order of magnitude smaller than the simple Bouguer term.

The procedure to compute refined Bouguer anomalies is:

- measure gravity $\left(g_{P}\right)$ at a point $\mathrm{P}$ of the Earth's surface;

- remove all the masses outside the geoid using the Bouguer plate and terrain correction. This is computed by subtracting the attraction of an infinite Bouguer plate from the observed gravity and adding the terrain correction;

- lower the gravity station from $\mathrm{P}$ to $\mathrm{P}_{\mathrm{o}}$ on the geoid using the free-air reduction $\mathrm{F}$;

- $\quad$ subtract normal gravity $\gamma$ at corresponding point $Q_{o}$ on the reference ellipsoid.

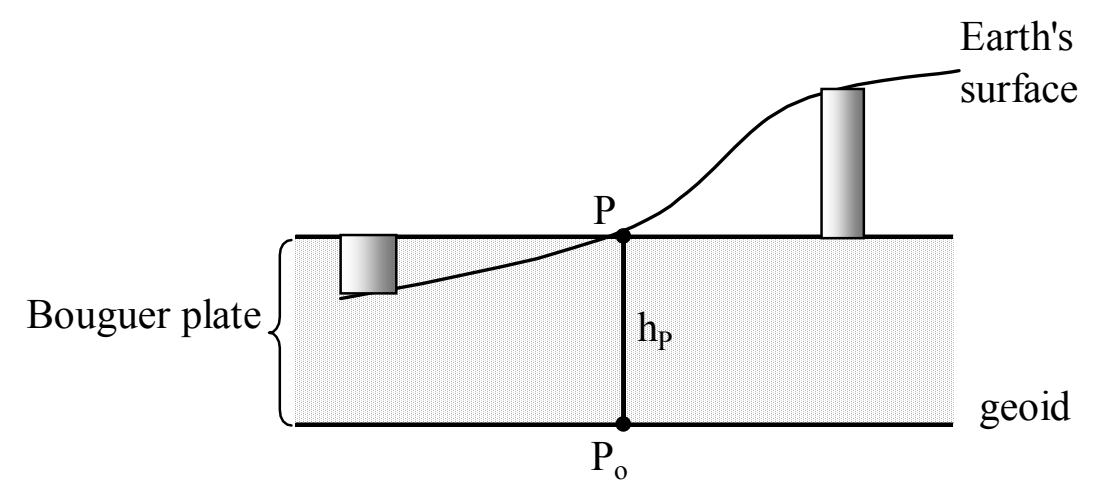

Figure 2.2: Bouguer plate and terrain correction

Refined Bouguer anomalies $\left(\Delta \mathrm{g}_{\mathrm{rB}}\right)$ are computed by:

$\Delta \mathrm{g}_{\mathrm{rB}}=\mathrm{g}_{\mathrm{P}}-\Delta \mathrm{g}_{\mathrm{T}}+\mathrm{F}-\gamma_{\mathrm{Q}_{\mathrm{o}}}$

The direct topographic effect on gravity due to the refined Bouguer reduction $\mathrm{Ar}_{\mathrm{B}}$ can be expressed as: 
$\Delta \mathrm{g}_{\mathrm{T}}=\mathrm{Ar}_{\mathrm{B}}=2 \pi \mathrm{G} \rho \mathrm{h}_{\mathrm{P}}-\mathrm{c}_{\mathrm{P}}$

where $c_{P}$ is the terrain correction, $G$ is the gravitational constant and $\rho$ is the density of the topographic masses. If the terrain correction is not considered, complete Bouguer anomalies are obtained.

The free-air reduction (F) lowers the gravity station from the Earth's surface point $\mathrm{P}$ to the corresponding point $\mathrm{P}_{\mathrm{o}}$ on the geoid by use of the free-air gradient:

$\mathrm{F}=-\frac{\partial \mathrm{g}}{\partial \mathrm{H}} \mathrm{H}$

where $\frac{\partial g}{\partial \mathrm{H}}$ is the actual vertical component of the gravity gradient, the minus sign indicates that gravity decreases with increasing elevation, and $\mathrm{H}$ is the orthometric height.

For many practical purposes, it is sufficient to use the normal gradient of gravity,

$\mathrm{F} \approx-\frac{\partial \gamma}{\partial \mathrm{h}} \mathrm{h}$

In the classical geoid determination using Stokes's solution, the free-air gravity anomalies are referred to the geoid surface and they can be expressed as:

$\Delta \mathrm{g}_{\mathrm{FA}}=\mathrm{g}_{\mathrm{P}}+\mathrm{F}-\gamma_{\mathrm{Q}_{\mathrm{o}}}$

Normal gravity on the reference ellipsoid will be computed using Somigliana's closed formula

$\gamma=\frac{a \gamma_{a} \cos ^{2} \varphi+b \gamma_{b} \sin ^{2} \varphi}{\sqrt{a^{2} \cos ^{2} \varphi+b^{2} \sin ^{2} \varphi}}$

where $\gamma_{\mathrm{a}}$ and $\gamma_{\mathrm{b}}$ represent the normal gravity at equator and the pole, a is the semimajor axis and $b$ is the semiminor axis of the reference ellipsoid, and $\varphi$ is the geodetic latitude. In this thesis, all the geometrical parameters of the reference ellipsoid will be those for the Geodetic Reference System 1980 (GRS80); see Moritz (2000).

\subsubsection{Formulas for terrain corrections}

Terrain corrections (TC) are very important quantities in gravity reductions not only for geodetic purposes but for geophysical applications, as well. In geodesy, terrain 
corrections are used not only for the computation of gravimetric geoid undulations but also for interpolation and extrapolation of data.

The terrain correction accounts for the deviations between the Bouguer plate and the topography. Terrain corrections will be computed in this thesis using the program TC2DFTPL, developed by Yecai Li at the University of Calgary (Li and Sideris, 1993). TC2DFTPL computes the topographic gravimetric correction by means of the 2D Fast Fourier Transform so gridded data are used as input data. It uses different topographic models, like a mass prism (MP) model or mass line (ML) model. The formulas are expressed by $2 \mathrm{D}$ convolutions and the computations can be done up third order terms. In order to speed up the convergence of the series, optimizations can be made ( $\mathrm{Li}$ and Sideris, 1993).

The terrain correction at a point $\mathrm{P}$ is

$c_{P}=G \iint_{E}^{h} \int_{h}^{h_{p}} \frac{\rho(x, y, z)\left(h_{P}-z\right)}{s^{3}\left(x_{P}-x, y_{P}-y, h_{P}-z\right)} d x d y d z$

where the distance kernel is defined as: $\mathrm{s}=\left(\left(\mathrm{x}_{\mathrm{P}}-\mathrm{x}\right)^{2}+\left(\mathrm{y}_{\mathrm{P}}-\mathrm{y}\right)^{2}+\left(\mathrm{h}_{\mathrm{P}}-\mathrm{h}\right)^{2}\right)^{1 / 2}, \mathrm{G}$ is Newton's gravitational constant, $\rho(\mathrm{x}, \mathrm{y}, \mathrm{z})$ is the topographic density at the running point, $\mathrm{h}_{\mathrm{P}}$ is the topographic height at point $\mathrm{P}$ and $\mathrm{E}$ denotes the integration area.

Using a gridded digital topographic model and taking the density as constant, we obtain

$c_{p}=-G \rho \sum_{n=0}^{N-1} \sum_{m=0}^{M-1} \int_{x_{n}-\Delta x / 2}^{x_{n}+\Delta x / 2} \int_{y_{m}-\Delta y / 2}^{y_{m}+\Delta y / 2} \int_{h_{p}}^{h_{n m}} \frac{\left(h_{p}-z\right)}{s^{3}\left(x_{i}-x, y_{j}-y, h_{p}-z\right)} d x d y d z$

Performing the integral respect $\mathrm{z}$, we get

$\mathrm{c}_{\mathrm{P}}=\mathrm{G} \rho \sum_{\mathrm{n}=0 \mathrm{~m}=0}^{\mathrm{N}-1 \mathrm{M}-1} \sum_{\mathrm{x}_{\mathrm{n}}-\Delta \mathrm{x} / 2}^{\mathrm{x}_{\mathrm{n}}+\Delta \mathrm{x} / 2} \int_{\mathrm{y}_{\mathrm{m}}-\Delta \mathrm{y} / 2}^{\mathrm{y}_{\mathrm{m}}+\Delta \mathrm{y} / 2}\left(\frac{1}{\mathrm{~s}\left(\mathrm{x}_{\mathrm{P}}-\mathrm{x}, \mathrm{y}_{\mathrm{P}}-\mathrm{y}, 0\right)}-\frac{1}{\mathrm{~s}\left(\mathrm{x}_{\mathrm{P}}-\mathrm{x}, \mathrm{y}_{\mathrm{P}}-\mathrm{y}_{\mathrm{H}} \mathrm{h}_{\mathrm{P}}-\mathrm{h}_{\mathrm{nm}}\right)}\right) \mathrm{dxdydz}$

$\mathrm{c}_{\mathrm{P}}$ can then be computed using a mass prism topographic model or a mass line topographic model. The topographic height is given on a regular grid. The height within each cell is represented by a prism with the mean height and mean density of the 
topography, which is called a mass prism topographic model (MP). When the mass of the prism is mathematically concentrated along its vertical symmetry axis, the topography within the prism is represented by a line, giving a mass line topographic model (ML).

\subsubsection{Computation of terrain corrections via 2D FFT}

\section{a) Formulas with mass line topographic model}

The terrain correction $\mathrm{c}_{\mathrm{P}}$ is:

$\mathrm{c}_{\mathrm{P}}=\mathrm{c}_{1}+\mathrm{c}_{2}+\mathrm{c}_{3}$

where

$$
\begin{aligned}
& \mathrm{c}_{1}=\frac{\mathrm{G} \rho}{2}\left[\mathrm{~h}_{\mathrm{P}}^{2} \mathrm{~F}^{1}\left\{\mathrm{H}_{0} \mathrm{R}_{1}\right\}-2 \mathrm{~h}_{\mathrm{P}}^{2} \mathrm{~F}^{1}\left\{\mathrm{H}_{1} \mathrm{R}_{1}\right\}+\mathrm{F}^{1}\left\{\mathrm{H}_{2} \mathrm{R}_{1}\right\}\right] \\
& \mathrm{c}_{2}(\mathrm{i}, \mathrm{j})=-\frac{3 \mathrm{G} \rho}{8}\left[\left(\left(\mathrm{~h}_{\mathrm{ij}}^{2}-\alpha^{2}\right)^{2}-\alpha^{4}\right) \mathrm{F}^{-1}\left\{\mathrm{H}_{0} \mathrm{R}_{2}\right\}-4 \mathrm{~h}_{\mathrm{ij}}\left(\mathrm{h}_{\mathrm{ij}}^{2}-\alpha^{2}\right) \mathrm{F}^{-1}\left\{\mathrm{H}_{1} \mathrm{R}_{2}\right\}\right. \\
& \mathrm{c}_{3}(\mathrm{i}, \mathrm{j})=\frac{15 \mathrm{G} \rho}{48}\left[\left(\left(\mathrm{~h}_{\mathrm{ij}}^{2}-\alpha^{2}\right)^{3}-\alpha^{6}\right) \mathrm{F}^{-1}\left\{\mathrm{H}_{0} \mathrm{R}_{3}\right\}-6 \mathrm{~h}_{\mathrm{ij}}\left(\mathrm{h}_{\mathrm{ij}}^{2}-\alpha^{2}\right)^{2} \mathrm{~F}^{-1}\left\{\mathrm{H}_{1} \mathrm{R}_{3}\right\}\right.
\end{aligned}
$$

where $\mathrm{H}_{\mathrm{k}}$ and $\mathrm{R}_{\mathrm{k}}$

$$
\begin{aligned}
& \mathrm{H}_{\mathrm{k}}=\mathrm{F}\left\{\mathrm{h}^{\mathrm{k}}\right\}, \mathrm{k}=0,1,2,3,4,5,6 \\
& \mathrm{R}_{0}=\mathrm{F}\left\{\frac{\Delta \mathrm{x} \Delta \mathrm{y}}{\left(\mathrm{x}^{2}+\mathrm{y}^{2}\right)^{1 / 2}} \frac{\Delta \mathrm{x} \Delta \mathrm{y}}{\left(\mathrm{x}^{2}+\mathrm{y}^{2}+\mathrm{\alpha}^{2}\right)^{1 / 2}}\right\} \text { and } \mathrm{R}_{\mathrm{k}}=\mathrm{F}\left\{\frac{\Delta \mathrm{x} \Delta \mathrm{y}}{\left(\mathrm{x}^{2}+\mathrm{y}^{2}+\alpha^{2}\right)^{2 \mathrm{k}+1}}\right\} \mathrm{k}=1,2,3
\end{aligned}
$$

The optimal value for $\alpha^{2}$ is one-half of the variance of the heights; $\alpha$ is an optimal parameter to improve the convergence of the series (Li, 1993).

$$
\alpha^{2}=\frac{\sigma_{\mathrm{h}}^{2}}{2}
$$

\section{b) Formulas with a mass prism topographic model}

$$
\mathrm{c}_{\mathrm{P}}=\mathrm{c}_{1}+\mathrm{c}_{2}+\mathrm{c}_{3}
$$




$$
\begin{aligned}
& \mathrm{c}_{1}=\frac{\mathrm{G} \rho}{2}\left[\mathrm{~h}_{\mathrm{P}}^{2} \mathrm{~F}^{-1}\left\{\mathrm{H}_{0} \mathrm{~F}_{1}\right\}-2 \mathrm{~h}_{\mathrm{P}} \mathrm{F}^{-1}\left\{\mathrm{H}_{1} \mathrm{~F}_{1}\right\}+\mathrm{F}^{-1}\left\{\mathrm{H}_{2} \mathrm{~F}_{1}\right\}\right] \\
& \mathrm{c}_{2}(\mathrm{i}, \mathrm{j})=-\frac{\mathrm{G} \rho}{8}\left[\left(\left(\mathrm{~h}_{\mathrm{ij}}^{2}-\alpha^{2}\right)^{2}-\alpha^{4}\right) \mathbf{F}^{-1}\left\{\mathrm{H}_{0} \mathrm{~F}_{2}\right\}-4 \mathrm{~h}_{\mathrm{ij}}\left(\mathrm{h}_{\mathrm{ij}}^{2}-\alpha^{2}\right) \mathrm{F}^{-1}\left\{\mathrm{H}_{1} \mathrm{~F}_{2}\right\}\right. \\
& \mathrm{c}_{3}(\mathrm{i}, \mathrm{j})=\frac{\mathrm{G} \rho}{48}\left[\left(\left(\mathrm{~h}_{\mathrm{ij}}^{2}-\alpha^{2}\right)^{3}-\alpha^{6}\right) \mathbf{F}^{-1}\left\{\mathrm{H}_{0} \mathrm{~F}_{3}\right\}-6 \mathrm{~h}_{\mathrm{ij}}\left(\mathrm{h}_{\mathrm{ij}}^{2}-\alpha^{2}\right)^{2} \mathbf{F}^{-1}\left\{\mathrm{H}_{1} \mathrm{~F}_{3}\right\}\right.
\end{aligned}
$$

where $H_{k}$ is the same given in (2.30) and

$$
\begin{aligned}
& F_{1}=F\left(f_{11}(x, y, \alpha)+f_{11}(y, x, \alpha)+f_{12}(x, y, \alpha)\right. \\
& F_{2}=F\left(f_{21}(x, y, \alpha)+f_{21}(y, x, \alpha)+f_{22}(x, y, \alpha)\right. \\
& F_{3}=F\left(f_{31}(x, y, \alpha)+f_{31}(y, x, \alpha)+f_{32}(x, y, \alpha)\right. \\
& \alpha^{2}=\sigma_{h}^{2}
\end{aligned}
$$$$
f_{11}(x, y, \alpha)=\frac{-x}{(y+r(x, y, \alpha) r(x, y, \alpha)} \mid \begin{aligned}
& x_{n}+\frac{\Delta x}{2} \mid y_{m}+\frac{\Delta y}{2} \\
& x_{n}-\frac{\Delta x}{2} \mid y_{m}-\frac{\Delta y}{2}
\end{aligned}
$$$$
f_{12}(x, y, \alpha)=\frac{x y\left(r^{2}+\alpha^{2}\right)}{\left(x^{2} y^{2}+\alpha^{2} r^{2}\right) r}-\frac{1}{\alpha} \arctan \frac{x y}{\alpha r}\left|\begin{array}{l}
x_{n}+\frac{\Delta x}{2} \mid y_{m}+\frac{\Delta y}{2} \\
x_{n}-\frac{\Delta x}{2}
\end{array}\right| y_{m}-\frac{\Delta y}{2}
$$$$
f_{21}(x, y, \alpha)=-\frac{x(y+2 r)}{3(y+r)^{2} r^{3}} \mid \begin{aligned}
& x_{n}+\frac{\Delta x}{2} \mid y_{m}+\frac{\Delta y}{2} \\
& x_{n}-\frac{\Delta x}{2} \mid y_{m}-\frac{\Delta y}{2}
\end{aligned}
$$$$
f_{22}(x, y, \alpha)=\frac{x y}{3\left(x^{2} y^{2}+\alpha^{2} r^{2}\right) r}\left[\frac{2\left(r^{2}+\alpha^{2}\right)^{2}}{x^{2} y^{2}+\alpha^{2} r^{2}}-\frac{r^{2}}{\alpha^{2}}+\frac{\alpha^{2}}{r^{2}}-4\right]-
$$$$
-\frac{1}{3 \alpha^{3}} \arctan \frac{\mathrm{xy}}{\alpha \mathrm{r}} \mid \begin{aligned}
& \mathrm{x}_{\mathrm{n}}+\frac{\Delta \mathrm{x}}{2} \mid \mathrm{y}_{\mathrm{m}}+\frac{\Delta \mathrm{y}}{2} \\
& \mathrm{x}_{\mathrm{n}}-\frac{\Delta \mathrm{x}}{2}
\end{aligned} \mathrm{y}_{\mathrm{m}}-\frac{\Delta \mathrm{y}}{2}
$$ 


$$
\begin{aligned}
f_{31}(x, y, \alpha)= & -\left.\frac{x}{15(y+r) r^{3}}\left[\frac{1}{y+r}\left(\frac{y}{r^{2}}+\frac{4}{r}+\frac{2}{y+r}\right)+\frac{y}{r^{2}}\right]\right|_{n}-\frac{\Delta x}{2} \mid y_{m}-\frac{\Delta y}{2} \\
f_{32}(x, y, \alpha)= & \frac{x y}{15\left(x^{2} y^{2}+\alpha^{2} r^{2}\right) r}\left[\frac{3 r^{2}}{\alpha^{4}}+\frac{6}{r^{2}}-\frac{3 \alpha^{2}}{r^{4}}+\frac{2\left(r^{2}+\alpha^{2}\right)}{x^{2} y^{2}+\alpha^{2} r^{2}}+\right. \\
& \frac{2\left(r^{2}+\alpha^{2}\right)}{x^{2} y^{2}+\alpha^{2} r^{2}}\left(11-\frac{2 \alpha^{2}}{r^{2}}+\frac{r^{2}}{\alpha^{2}}-\frac{4\left(r^{2}+\alpha^{2}\right)^{2}}{x^{2} y^{2}+\alpha^{2} r^{2}}-\right. \\
& -\frac{1}{5 \alpha^{3}} \arctan \frac{x y}{\alpha r}\left|x_{n}+\frac{\Delta x}{2}\right|_{y_{m}}+\frac{\Delta y}{2}-\left.\frac{\Delta x}{2}\right|_{y_{m}}-\frac{\Delta y}{2}
\end{aligned}
$$

\subsubsection{Topographic-isostatic reduction}

The objective of an isostatic reduction of gravity is the regularization of the Earth's crust, according to some model of isostasy (Heiskanen and Moritz, 1967). Isostatic anomalies are computed by not only removing the topographical masses but also restoring the effect of the compensation masses below the geoid.

There are two classical isostatic models, the Airy-Heiskanen model and the PrattHayford model.

\subsubsection{Airy-Heiskanen topographic-isostatic reduction}

The Airy-Heiskanen (AH) model was developed by G.B. Airy in 1855 . Heiskanen gave a precise formulation for geodetic problems. It is based on the assumption of a constant crust density and a non constant level of compensation, where the normal column of height $(h=0)$ has a thickness $D$. The mountains $(h>0)$ form roots of depth $t$, and the higher the mountains are, the deeper the roots are. Below ocean $\left(h^{\prime}<0\right)$ anti-roots with a thickness $t^{\prime}$ are found.

According to the Airy model, all crust blocks have the same density but different thickness, with higher top surfaces (mountains) having deeper roots. The root thickness below mountains is derived by 


$$
\mathrm{h} \rho=\mathrm{t} \Delta \rho \Rightarrow \mathrm{t}=\frac{\rho \mathrm{h}}{\Delta \rho}
$$

and the anti-root for ocean areas is derived by:

$$
\mathrm{h}^{\prime}\left(\rho_{\mathrm{w}}-\rho\right)=\mathrm{t}^{\prime} \Delta \rho \Rightarrow \mathrm{t}^{\prime}=\frac{\mathrm{h}^{\prime}\left(\rho_{\mathrm{w}}-\rho\right)}{\Delta \rho}
$$

If a crust with constant density $\rho$ equal to $2.67 \mathrm{~g} / \mathrm{cm}^{3}$ floating on a denser mantle with constant density equal to $3.27 \mathrm{~g} / \mathrm{cm}^{3}$ is assumed, the density contrast $\Delta \rho=\rho_{\mathrm{m}}-\rho$ is equal to $0.6 \mathrm{~g} / \mathrm{cm}^{3}$, and considering a density of $1.030 \mathrm{~g} / \mathrm{cm}^{3}$ for the salt water, the thickness for the root and the anti-root are $t=4.45 \mathrm{~h}$ and $\mathrm{t}^{\prime}=2.73 \mathrm{~h}^{\prime}$. The thickness D of the normal crust varies between 30 to $40 \mathrm{~km}$.

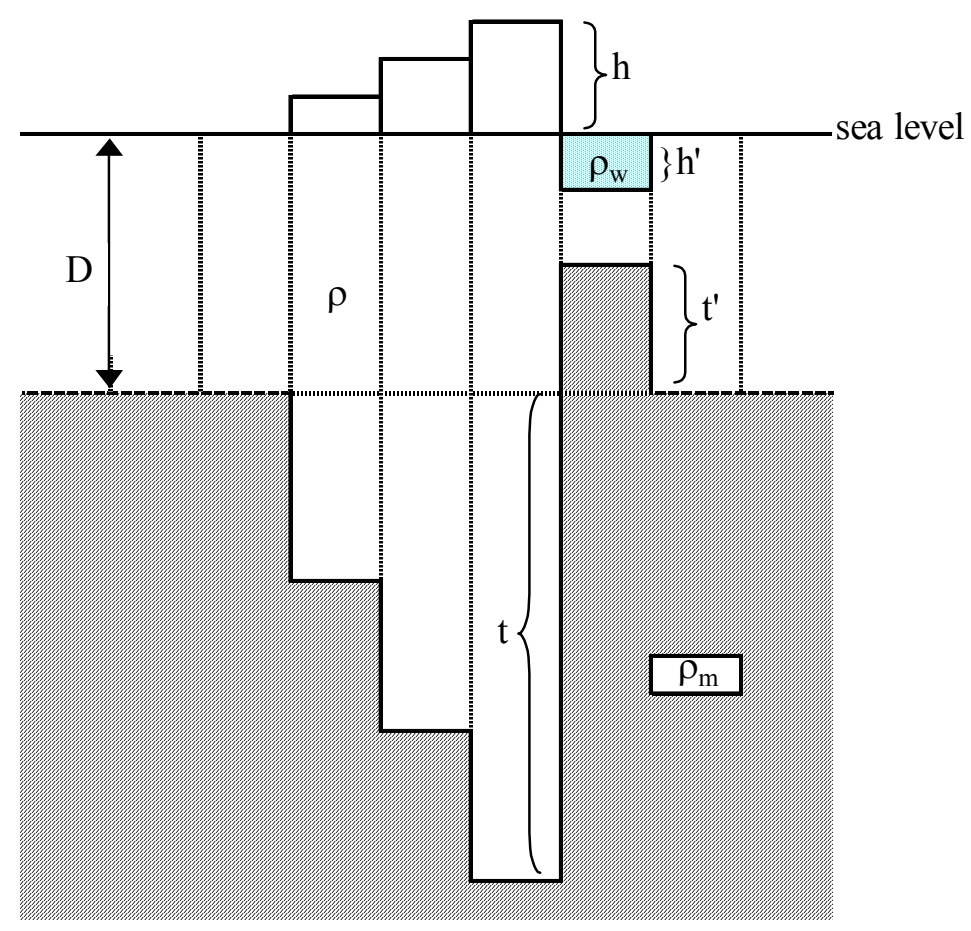

Figure 2.3: Airy-Heiskanen model

The procedure to compute the Airy-Heiskanen topographic-isostatic anomalies is:

- measure gravity $\left(g_{\mathrm{P}}\right)$ at a point $\mathrm{P}$ of the Earth's surface;

- remove all the masses above the geoid;

- restore compensated masses according to $\mathrm{AH}$ reduction; 
- lower the gravity station from $\mathrm{P}$ to $\mathrm{P}_{\mathrm{o}}$ on the geoid using the free-air reduction;

- $\quad$ subtract normal gravity $\gamma$ at corresponding point $Q_{o}$ on the reference ellipsoid.

Airy-Heiskanen topographic-isostatic anomalies are computed by:

$$
\Delta \mathrm{g}_{\mathrm{AH}}=\mathrm{g}_{\mathrm{P}}-\mathrm{A}_{\mathrm{T}}+\mathrm{A}_{\operatorname{comp}(\mathrm{AH})}+\mathrm{F}-\gamma_{\mathrm{Q}_{0}}=\mathrm{g}_{\mathrm{P}}+\mathrm{F}-\gamma_{\mathrm{Q}_{0}}-\delta \mathrm{A}_{\mathrm{AH}}=\Delta \mathrm{g}_{\mathrm{FA}}-\delta \mathrm{A}_{\mathrm{AH}}
$$

where $\mathrm{A}_{\text {comp }(\mathrm{AH})}$ is the attraction of the compensated masses within the depth of the root.

The direct topographical effect on gravity due the AH reduction scheme is equal to the gravity attraction change $\delta \mathrm{A}_{\mathrm{AH}}$ and it is evaluated at the point $\mathrm{P}$ on the Earth's surface.

$$
\Delta \mathrm{g}_{\mathrm{T}}=\delta \mathrm{A}_{\mathrm{AH}}=\mathrm{A}_{\mathrm{T}}-\mathrm{A}_{\operatorname{comp}(\mathrm{AH})}
$$

These terms can be expressed (for a point $\mathrm{P}$ at the origin of the coordinate system) as:

$$
\begin{aligned}
& A_{T}=G \iiint_{E}^{h} \frac{\rho(x, y, z)\left(h_{P}-z\right)}{s^{3}\left(x_{P}-x, y_{P}-y, h_{P}-z\right)} d x d y d z \\
& A_{\text {comp(AH) }}=G \iint_{E} \int_{-D-t}^{-D} \frac{\Delta \rho(x, y, z)\left(h_{P}-z\right)}{s^{3}\left(x_{P}-x, y_{P}-y, h_{P}-z\right)} d x d y d z
\end{aligned}
$$

Equations (2.61) and (2.62) can be numerically integrated using rectangular prisms with the computation point coinciding with the origin of the coordinate system as (Nagy, 1966):

$$
\begin{aligned}
& \mathrm{A}_{\mathrm{T}}=-\mathrm{G} \rho \iiint \mathrm{x} \ln (\mathrm{y}+\mathrm{r})+\mathrm{y} \ln (\mathrm{x}+\mathrm{r})-\left.\left.\left.\mathrm{z} \arctan \frac{\mathrm{xy}}{\mathrm{zr}}\right|_{\mathrm{x}_{1}} ^{\mathrm{x}_{2}}\right|_{\mathrm{y}_{1}} ^{\mathrm{y}_{2}}\right|_{0} ^{\mathrm{h}} \\
& \mathrm{A}_{\mathrm{comp}(\mathrm{AH})}=-\mathrm{G} \Delta \rho \iiint \mathrm{x} \ln (\mathrm{y}+\mathrm{r})+\mathrm{y} \ln (\mathrm{x}+\mathrm{r})-\left.\left.\left.\mathrm{z} \arctan \frac{\mathrm{xy}}{\mathrm{zx}}\right|_{\mathrm{x}_{1}} ^{\mathrm{x}_{2}}\right|_{\mathrm{y}_{1}} ^{\mathrm{y}_{2}}\right|_{-\mathrm{D}-\mathrm{t}} ^{-\mathrm{D}}
\end{aligned}
$$

where the coordinates $\mathrm{x}_{1}, \mathrm{x}_{2}, \mathrm{y}_{1}, \mathrm{y}_{2}, \mathrm{z}_{1}$ and $\mathrm{z}_{2}$ represent the corner of a prism

The change of potential $\Delta \mathrm{V}$ in equation (2.9) is for the $\mathrm{AH}$ topo-isostatic reduction scheme expressed by

$$
\Delta \mathrm{V}=\mathrm{V}_{\mathrm{T}}-\mathrm{V}_{\operatorname{comp}(\mathrm{AH})}
$$


where $\mathrm{V}_{\mathrm{T}}$ represents the gravitational potential of the actual topography and $\mathrm{V}_{\mathrm{comp}(\mathrm{AH})}$ is the gravitational potential of the compensated masses due the $\mathrm{AH}$ reduction scheme. They can be given as:

$$
\begin{aligned}
& \mathrm{V}_{\mathrm{T}}=\mathrm{G} \rho \iint_{\mathrm{E}}^{\mathrm{h}} \int_{0}^{\mathrm{s}} \frac{1}{\mathrm{~s}\left(\mathrm{x}_{\mathrm{P}}-\mathrm{x}, \mathrm{y}_{\mathrm{P}}-\mathrm{y}, \mathrm{h}_{\mathrm{P}}-\mathrm{z}\right)} \mathrm{dxdydz} \\
& \mathrm{V}_{\mathrm{comp}(\mathrm{AH})}=\mathrm{G} \Delta \rho \iint_{\mathrm{E}} \int_{-\mathrm{D}-\mathrm{t}}^{-\mathrm{D}} \frac{1}{\mathrm{~s}\left(\mathrm{x}_{\mathrm{P}}-\mathrm{x}, \mathrm{y}_{\mathrm{P}}-\mathrm{y}, \mathrm{h}_{\mathrm{P}}-\mathrm{z}\right)} \mathrm{dxdydz}
\end{aligned}
$$

The potential change has to be evaluated at point $\mathrm{P}_{\mathrm{o}}$ on the geoid.

The secondary indirect effect on gravity due to the AH reduction scheme has to be taken into account.

Equations (2.66) and ((2.67) can also be numerically integrated using rectangular prisms with the computation point coinciding with the origin of the coordinate system (Nagy, 1966):

$$
\begin{aligned}
& \mathrm{V}_{\mathrm{T}}=-\mathrm{G} \rho \iiint \mathrm{xy} \ln (\mathrm{z}+\mathrm{r})+\mathrm{xz} \ln (\mathrm{y}+\mathrm{z})+\mathrm{yz} \ln (\mathrm{x}+\mathrm{r})- \\
& -\frac{\mathrm{x}^{2}}{2} \tan ^{-1}\left(\frac{\mathrm{yz}}{\mathrm{xr}}\right)-\frac{\mathrm{y}^{2}}{2} \tan ^{-1}\left(\frac{\mathrm{xz}}{\mathrm{yr}}\right)-\left.\left.\left.\frac{\mathrm{z}^{2}}{2} \tan ^{-1}\left(\frac{\mathrm{xy}}{\mathrm{zr}}\right)\right|_{\mathrm{x}_{1}} ^{\mathrm{x}_{2}}\right|_{\mathrm{y}_{1}} ^{\mathrm{y}_{2}}\right|_{0} ^{\mathrm{h}_{(\mathrm{x}, \mathrm{y}}} \\
& \mathrm{V}_{\mathrm{comp}(\mathrm{AH})}=-\mathrm{G} \Delta \rho \iiint \mathrm{xy} \ln (\mathrm{z}+\mathrm{r})+\mathrm{xz} \ln (\mathrm{y}+\mathrm{z})+\mathrm{yz} \ln (\mathrm{x}+\mathrm{r})- \\
& -\frac{\mathrm{x}^{2}}{2} \tan ^{-1}\left(\frac{\mathrm{yz}}{\mathrm{xr}}\right)-\frac{\mathrm{y}^{2}}{2} \tan ^{-1}\left(\frac{\mathrm{xz}}{\mathrm{yr}}\right)-\left.\left.\left.\frac{\mathrm{z}^{2}}{2} \tan ^{-1}\left(\frac{\mathrm{xy}}{\mathrm{zr}}\right)\right|_{\mathrm{x}_{1}} ^{\mathrm{x}_{2}}\right|_{\mathrm{y}_{1}} ^{\mathrm{y}_{2}}\right|_{-\mathrm{D}-\mathrm{t}} ^{-\mathrm{D}}
\end{aligned}
$$

\subsubsection{Pratt-Hayford topographic-isostatic reduction}

The Pratt-Hayford model assumes a crustal layer of constant thickness D and lateral variations in density in order to obtain isostatic equilibrium in the level of compensation, generally assumed as $100 \mathrm{~km}$ (Heiskanen and Moritz, 1967). If $\rho$ is the density of the normal crust for the normal column of height $(\mathrm{h}=0)$, continental columns $(\mathrm{h}>0)$ generate densities lower than $\rho$, while the densities below oceanic columns $\left(\mathrm{h}^{\prime}<0\right)$ are higher than $\rho$.

The equilibrium condition for the continents is

$$
\mathrm{D} \rho=(\mathrm{D}+\mathrm{h}) \rho_{1}
$$


so below mountains there is a mass deficiency given by:

$$
\Delta \rho=\rho-\rho_{1}=\frac{h}{D+h} \rho
$$

For the oceans, the condition of equal weight is expressed as

$$
\mathrm{D} \rho=\mathrm{h}^{\prime} \rho_{\mathrm{w}}+\left(\mathrm{d}-\mathrm{h}^{\prime}\right) \rho^{\prime}
$$

thus below the oceans there is a mass surplus given by

$$
\Delta \rho^{\prime}=\rho^{\prime}-\rho=\frac{\mathrm{h}^{\prime}}{\mathrm{D}-\mathrm{h}^{\prime}}\left(\rho-\rho_{\mathrm{w}}\right)
$$

$\rho=2.67 \mathrm{gr} / \mathrm{cm}^{3}$ and $\rho_{\mathrm{w}}=1.030 \mathrm{gr} / \mathrm{cm}^{3}$ are usually taken to the normal crust density and the density for the oceanic crust.

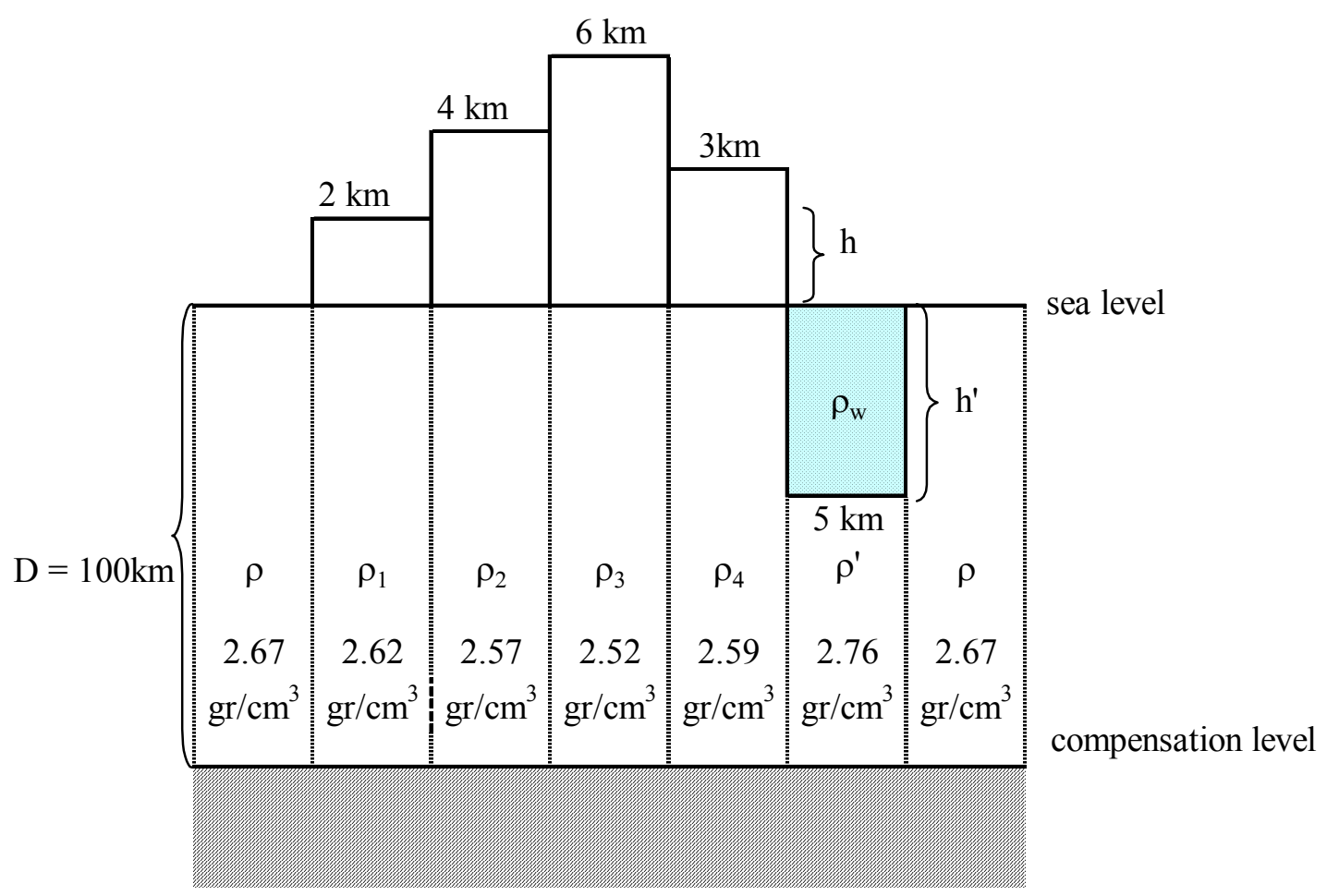

Figure 2.4: Pratt-Hayford model

The procedure to compute Pratt-Hayford topographic-isostatic anomalies is:

- measure gravity $\left(\mathrm{g}_{\mathrm{P}}\right)$ at a point $\mathrm{P}$ of the Earth's surface;

- remove all the masses above the geoid; 
- restore compensated masses according to $\mathrm{PH}$ reduction;

- lower the gravity station from $\mathrm{P}$ to $\mathrm{P}_{\mathrm{o}}$ on the geoid using the free-air reduction;

- $\quad$ subtract normal gravity $\gamma$ at corresponding point $Q_{o}$ on the reference ellipsoid.

Pratt-Hayford topographic-isostatic anomalies are computed by:

$\Delta \mathrm{g}_{\mathrm{AH}}=\mathrm{g}_{\mathrm{P}}-\mathrm{A}_{\mathrm{T}}+\mathrm{A}_{\text {comp }}+\mathrm{F}-\gamma_{\mathrm{Q}_{0}}=\mathrm{g}_{\mathrm{P}}-\delta \mathrm{A}_{\mathrm{PH}}+\mathrm{F}-\gamma_{\mathrm{Q}_{0}}=\Delta \mathrm{g}_{\mathrm{FA}}-\delta \mathrm{A}_{\mathrm{PH}}$

where $\mathrm{A}_{\text {comp }(\mathrm{PH})}$ is the attraction of the compensated masses.

The direct topographical effect on gravity due the $\mathrm{PH}$ reduction scheme is equal to the attraction change $\delta \mathrm{A}_{\mathrm{PH}}$,

$$
\Delta \mathrm{g}_{\mathrm{T}}=\delta \mathrm{A}_{\mathrm{AH}}=\mathrm{A}_{\mathrm{T}}-\mathrm{A}_{\operatorname{comp}(\mathrm{PH})}
$$

The term $\mathrm{A}_{\mathrm{T}}$ is represented by equation (2.52) and

$$
A_{\operatorname{comp}(P H)}=G \iiint_{E} \int_{-D}^{0} \frac{\Delta \rho(x, y, z)\left(h_{P}-z\right)}{s^{3}\left(x_{P}-x, y_{P}-y, h_{P}-z\right)} d x d y d z
$$

Usually the refined Bouguer reduction is done using a constant density $\rho$ so to restore equality of masses the attraction of the compensated masses according to the $\mathrm{PH}$ model is computed with a density contrast given by:

$$
\Delta \rho=\frac{h}{D} \rho
$$

The change of potential $\Delta \mathrm{V}$ in equation (2.8) for the $\mathrm{PH}$ topo-isostatic reduction scheme is expressed by

$$
\Delta \mathrm{V}=\mathrm{V}_{\mathrm{T}}-\mathrm{V}_{\mathrm{comp}(\mathrm{PH})}
$$

where $\mathrm{V}_{\mathrm{T}}$ represents the gravitational potential of the actual topography and it is the same as equation (2.54) and $\mathrm{V}_{\text {comp(PH) }}$ is the gravitational potential of the compensated masses due $\mathrm{AH}$ reduction scheme and it can be given as:

$$
\mathrm{V}_{\mathrm{comp}(\mathrm{PH})}=\mathrm{G} \Delta \rho \iint_{\mathrm{E}} \int_{-\mathrm{D}}^{0} \frac{1}{\mathrm{~s}\left(\mathrm{x}_{\mathrm{P}}-\mathrm{x}, \mathrm{y}_{\mathrm{P}}-\mathrm{y}, \mathrm{h}_{\mathrm{P}}-\mathrm{z}\right)} \mathrm{dxdydz}
$$

The computation point of the potential change is at point $\mathrm{P}_{\mathrm{o}}$ on the geoid. 
The attraction $\mathrm{A}_{\text {comp }(\mathrm{PH})}$ and the potential of the compensating masses $\mathrm{V}_{\text {comp }(\mathrm{PH})}$ can be evaluated in the same way as in equations (2.64) and (2.69):

$$
\begin{aligned}
& \mathrm{A}_{\operatorname{comp}(\mathrm{PH})}=-\mathrm{G} \Delta \rho \iiint \mathrm{x} \ln (\mathrm{y}+\mathrm{r})+\mathrm{y} \ln (\mathrm{x}+\mathrm{r})-\left.\left.\left.\mathrm{z} \arctan \frac{\mathrm{xy}}{\mathrm{zx}}\right|_{\mathrm{x}_{1}} ^{\mathrm{x}_{2}}\right|_{\mathrm{y}_{1}} ^{\mathrm{y}_{2}}\right|_{-\mathrm{D}} ^{0} \\
& \mathrm{~V}_{\mathrm{comp}(\mathrm{PH})}=-\mathrm{G} \Delta \rho \iiint \mathrm{xy} \ln (\mathrm{z}+\mathrm{r})+\mathrm{xz} \ln (\mathrm{y}+\mathrm{z})+\mathrm{yz} \ln (\mathrm{x}+\mathrm{r})- \\
& -\frac{\mathrm{x}^{2}}{2} \tan ^{-1}\left(\frac{\mathrm{yz}}{\mathrm{xr}}\right)-\frac{\mathrm{y}^{2}}{2} \tan ^{-1}\left(\frac{\mathrm{xz}}{\mathrm{yr}}\right)-\left.\left.\left.\frac{\mathrm{z}^{2}}{2} \tan ^{-1}\left(\frac{\mathrm{xy}}{\mathrm{zr}}\right)\right|_{\mathrm{x}_{1}} ^{\mathrm{x}_{2}}\right|_{\mathrm{y}_{1}} ^{\mathrm{y}_{2}}\right|_{-\mathrm{D}} ^{0}
\end{aligned}
$$

The secondary indirect effect on gravity due to the $\mathrm{PH}$ gravity reduction must be taken into account.

\subsubsection{Second method of Helmert's condensation}

The second method of Helmert's condensation considers that the topographical masses between the geoid and the surface of the topography are condensed in a surface layer on the geoid with surface density $\kappa=\rho \mathrm{h}$, where $\mathrm{h}$ is the height of the topography. The condensation implies corrections to the gravity anomaly and the introduction of indirect effect due to the change of potential caused by the condensation.

This method is one of the most common methods used in the classical solution of geodetic boundary value problems (Sideris and She, 1995; Omang and Forsberg, 2000; Li, 1993; Bajaracharja, 2003; Bajaracharja and Sideris, 2005).

This reduction can be viewed as a limit case of the Pratt-Hayford isostatic reduction with depth of condensation zero.

The procedure to compute Helmert anomalies is:

- measure gravity $\left(\mathrm{g}_{\mathrm{P}}\right)$ at a point $\mathrm{P}$ of the Earth's surface;

- remove all the masses above the geoid. The attraction of the topographic masses above the geoid is computed at the point $\mathrm{P}$ and it is subtracted from the observed value $\left(\mathrm{g}_{\mathrm{P}}\right)$;

- lower the gravity station from $\mathrm{P}$ to $\mathrm{P}_{\mathrm{o}}$ on the geoid using the free-air reduction;

- condense all the masses on a layer on the geoid with density $\kappa=\rho$. The attraction of the condensed masses is computed at the point $\mathrm{P}_{\mathrm{o}}$ and added to the result computed in the preceding step; 
- subtract normal gravity $\gamma$ at corresponding point $Q_{0}$ on the reference ellipsoid:

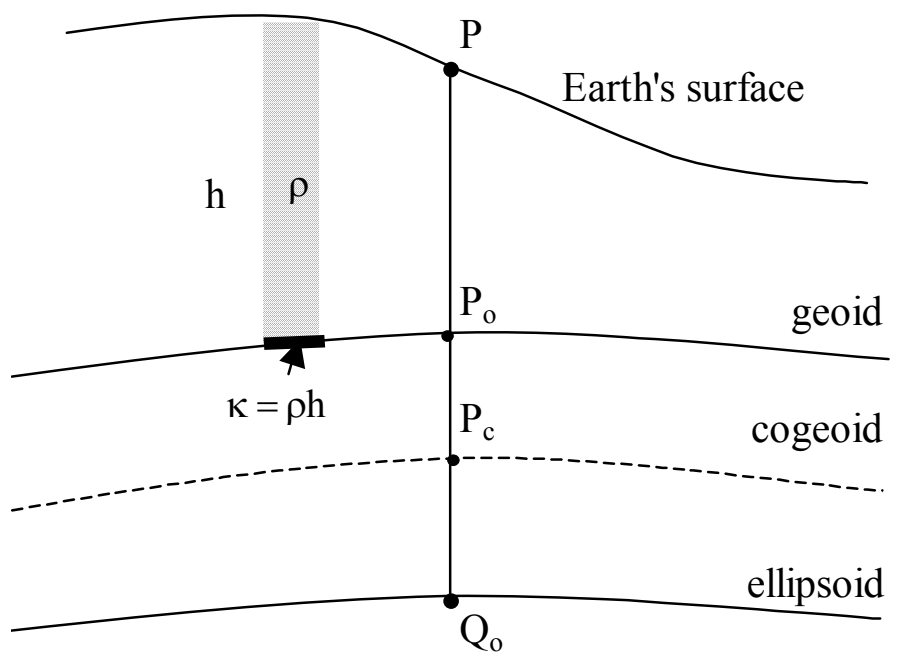

Figure 2.5: Helmert's method of condensation

This procedure gives Helmert anomalies on the geoid computed from the expression

$\Delta \mathrm{g}_{\text {Helmert }}=\mathrm{g}_{\mathrm{P}}-\mathrm{A}_{\mathrm{T}}+\mathrm{A}_{\text {cond }}+\mathrm{F}-\gamma_{\mathrm{Q}_{0}}=\mathrm{g}_{\mathrm{P}}-\delta \mathrm{A}_{\text {Helmert }}+\mathrm{F}-\gamma_{\mathrm{Q}_{0}}=\Delta \mathrm{g}_{\mathrm{FA}}-\delta \mathrm{A}_{\text {Helmert }}$

where $\mathrm{A}_{\text {cond }}$ is the attraction of the condensed masses at $\mathrm{P}_{0}$.

The direct topographical effect on gravity $\Delta \mathrm{g}_{\mathrm{T}}$, given in equation (2.1), due this reduction scheme is the attraction change $\delta \mathrm{A}$, which is equal to the classical terrain correction $\mathrm{c}_{\mathrm{P}}$

$\Delta \mathrm{g}_{\mathrm{T}}=\delta \mathrm{A}_{\text {Helmert }}=\mathrm{A}_{\mathrm{T}}-\mathrm{A}_{\text {cond }}=-\mathrm{c}_{\mathrm{P}}$

Faye anomaly or Helmert's gravity anomaly differs from the free-air gravity anomalies at the same point by the terrain correction. They represent boundary values in the Helmert/Stokes approach.

$\Delta \mathrm{g}_{\text {Helmert }}=\Delta \mathrm{g}_{\text {Faye }}=\mathrm{g}_{\mathrm{P}}+\mathrm{F}-\gamma_{\mathrm{Q}_{0}}+\mathrm{c}_{\mathrm{P}}=\Delta \mathrm{g}_{\mathrm{FA}}+\mathrm{c}_{\mathrm{P}}$

A small correction $\delta \Delta \mathrm{g}$, called the indirect effect on gravity, has to be considered before applying Stokes 's formula to transform gravity anomalies from geoid to cogeoid $\delta \Delta \mathrm{g}$ is, according to Sideris and She (1995), expressed as: 
$\delta \Delta \mathrm{g} \approx \frac{2 \pi{\mathrm{G} \rho \mathrm{h}_{\mathrm{P}}^{2}}_{\mathrm{R}}}{\mathrm{R}}$

The indirect effect of Helmert's reduction on the geoid, considering the first two terms is given, in planar approximation, following (Wichiencharoen, 1982) as:

$\mathrm{N}_{\text {ind }}=-\frac{\pi \mathrm{G} \rho}{\gamma} \mathrm{h}_{\mathrm{P}}^{2}-\frac{\mathrm{G} \rho}{6 \gamma} \iint_{\mathrm{E}} \frac{\mathrm{h}^{3}-\mathrm{h}_{\mathrm{P}}^{3}}{\mathrm{~s}^{3}} \mathrm{dxdy}+\ldots$

where $\gamma$ is the normal gravity and $\mathrm{s}$ is the planar distance between computation and running point.

\subsubsection{FFT formulas for the indirect effect of Helmert's reduction on the geoid}

The indirect effect due the Helmert's second condensation method can be computed up to the second term and in planar approximation with a grid of digital elevation heights by the following discrete formula:

$$
\mathrm{N}_{\text {ind }}=-\frac{\pi \mathrm{G} \rho}{\gamma} \mathrm{h}_{\mathrm{P}}^{2}+\frac{\mathrm{G} \rho \Delta \mathrm{x} \Delta \mathrm{y}}{6 \gamma} \mathrm{h}_{\mathrm{p}}^{3} \sum_{\mathrm{x}_{\mathrm{Q}}=\mathrm{x}_{1}}^{\mathrm{x}_{\mathrm{M}}} \sum_{\mathrm{y}_{\mathrm{Q}}=\mathrm{y}_{1}}^{\mathrm{y}_{\mathrm{N}}} \frac{1}{\mathrm{~s}^{3}}-\frac{\mathrm{G} \rho \Delta \mathrm{x} \Delta \mathrm{y}}{6 \gamma} \sum_{\mathrm{x}_{\mathrm{Q}}=\mathrm{x}_{1} \mathrm{y}_{\mathrm{Q}}=\mathrm{y}_{1}}^{\mathrm{x}_{\mathrm{M}}} \sum_{\mathrm{s}}^{\mathrm{y}_{\mathrm{N}}} \frac{1}{\mathrm{~h}^{3}}
$$

where the second and third terms are 2D discrete convolutions and they can be evaluated by the 2D FFT given the indirect effect for all grid points simultaneously.

The 2D FFT for evaluating equation (2.87) is:

$$
\mathrm{N}_{\text {ind }}=-\frac{\pi \mathrm{G} \rho}{\gamma} \mathrm{h}_{\mathrm{P}}^{2}+\frac{\mathrm{G} \rho \Delta \mathrm{x} \Delta \mathrm{y}}{6 \gamma} \mathrm{h}_{\mathrm{p}}^{3} \mathrm{~F}^{-1}\left\{\mathrm{~F}\left\{\frac{1}{\mathrm{~s}^{3}}\right\} \mathrm{F}\{1\}-\frac{\mathrm{G} \rho \Delta \mathrm{x} \Delta \mathrm{y}}{6 \gamma} \mathrm{F}^{-1}\left\{\mathrm{~F}\left\{\frac{1}{\mathrm{~s}^{3}}\right\} \mathrm{F}\left\{\mathrm{h}^{3}\right\}\right.\right.
$$

\subsubsection{The Rudzki inversion method}

The Rudzki inversion method was not a common gravimetric reduction for geoid determination, but during the last years studies carried out in the Canadian Rocky Mountains show that the Rudzki geoid solution performs as well as the Helmert and RTM geoids solutions in terms of the standard deviations and maximum and minimum range compared to GPS/levelling derived geoid heights (Bajracharya, 2003; Bajracharya and Sideris, 2004; Bajracharya and Sideris, 2005). The Rudzki inversion method is a gravity reduction that shifts all the topographic masses inside the geoid in such a way that the indirect effect on the geoid is zero. For this gravity reduction, equation (2.9) is: 
$\Delta \mathrm{V}=\mathrm{V}_{\mathrm{T}}-\mathrm{V}_{\mathrm{inv}}=0$

so $\mathrm{V}_{\mathrm{T}}=\mathrm{V}_{\text {inv }}$

M. P. Rudzki presented the inversion method in 1911 (Rudzki, 1911). He considered the geoid as a sphere of radius $\mathrm{R}$ as it is shown in Figure (2.6). He also let a mass element $\mathrm{dm}$ at a point $\mathrm{Q}$ be replaced by a mass element $\mathrm{dm}$ ' at a certain point $\mathrm{Q}^{\prime}$ inside the geoid and on the same ray from the center of the sphere. The gravitational potential at a point $\mathrm{P}_{\mathrm{o}}$ on the geoid due to the mass elements $\mathrm{dm}$ and $\mathrm{dm}$ ' is:

$\mathrm{dV}_{\mathrm{T}}=\mathrm{G} \frac{\mathrm{dm}}{\mathrm{l}}=\frac{\mathrm{Gdm}}{\sqrt{\mathrm{r}^{2}+\mathrm{R}^{2}-2 \mathrm{rR \operatorname {cos } \theta}}}$
$\mathrm{dV}_{\text {inv }}=\mathrm{G} \frac{\mathrm{dm}}{\mathrm{l}^{\prime}}=\frac{G d m^{\prime}}{\sqrt{\mathrm{r}^{\prime 2}+\mathrm{R}^{2}-2 \mathrm{r}^{\prime} \mathrm{R} \cos \theta}}$

$d V_{T}$ is equal to $d V_{\text {inv }}$ if

$\mathrm{dm}^{\prime}=\frac{\mathrm{R}}{\mathrm{r}} \mathrm{dm}$

and $r^{\prime}=\frac{R^{2}}{r}$

This last condition indicates that the point $\mathrm{Q}$ and $\mathrm{Q}^{\prime}$ are related by inversion in the sphere.

If $\mathrm{Q}(\mathrm{x}, \mathrm{y}, \mathrm{z})$ and $\mathrm{Q}^{\prime}\left(\mathrm{x}^{\prime}, \mathrm{y}^{\prime}, \mathrm{z}^{\prime}\right)$ are any two points which are inverse in the sphere, at distances $r$ and $r$ ' respectively from the origin, the equations for the transformations of coordinates are according to Kellogg (1929).

$\mathrm{x}=\frac{\mathrm{R}^{2}}{\mathrm{r}^{\prime 2}} \mathrm{x}^{\prime} \quad \mathrm{y}=\frac{\mathrm{R}^{2}}{\mathrm{r}^{\prime 2}} \mathrm{y}^{\prime} \quad \mathrm{z}=\frac{\mathrm{R}^{2}}{\mathrm{r}^{\prime 2}} \mathrm{z}^{\prime} \quad \mathrm{r} \mathrm{r}^{\prime}=\mathrm{R}^{2}$

The last equation is the same as the condition (2.94).

Even though the condition (2.95) expresses that the inverted masses $\mathrm{dm}$ ' are smaller than the topographic masses $\mathrm{dm}$, they can be consider equal because the change is of the order of $10^{-8}$.

$\mathrm{dm}^{\prime}=\mathrm{dm}$ 


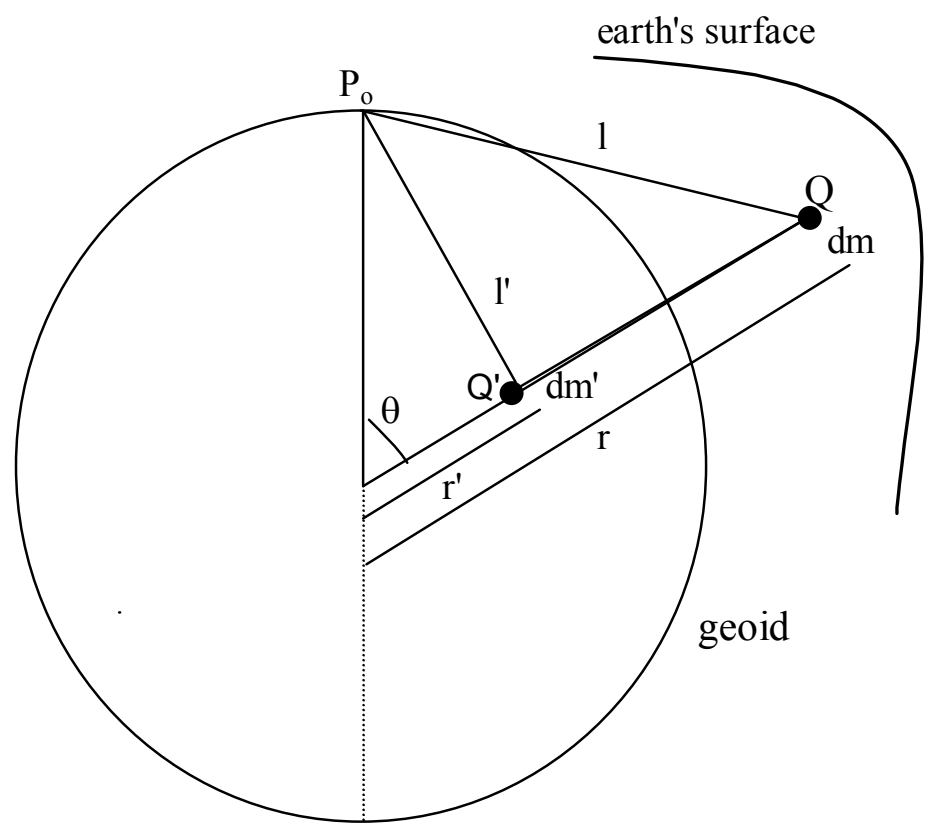

Figure 2.6: Rudzki inversion method on the sphere

It is usual to apply the Rudzki inversion reduction in planar approximation; the sphere is replaced by a plane and the point Q' is the ordinary mirror image of Q. The Rudzki reduction in planar approximation can be seen in Figure (2.7).

earth's surface

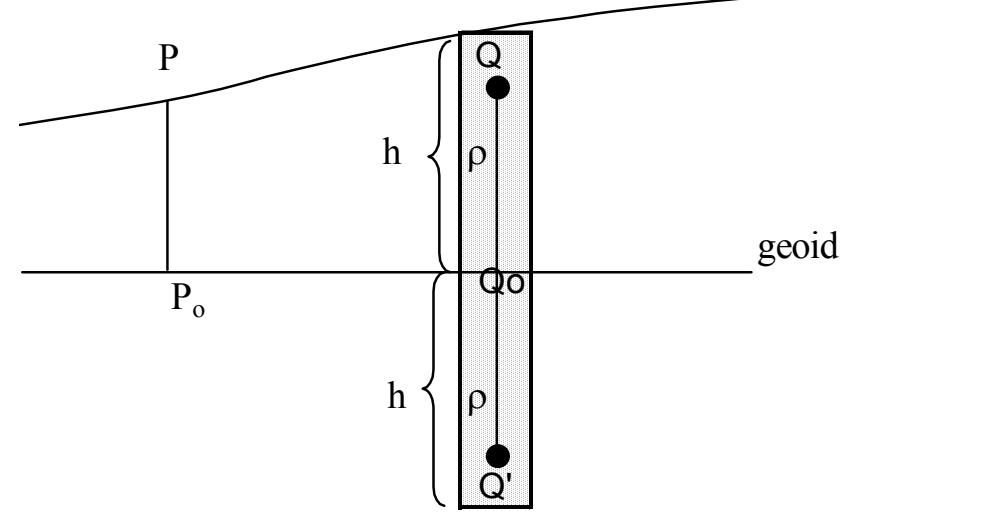

Figure 2.7: Rudzki inversion method in planar approximation

The procedure to compute Rudzki anomalies is:

- measure gravity $\left(\mathrm{g}_{\mathrm{P}}\right)$ at a point $\mathrm{P}$ of the Earth's surface; 
- remove all the masses above the geoid;

- lower the gravity station from $\mathrm{P}$ to $\mathrm{P}_{\mathrm{o}}$ on the geoid using the free-air reduction;

- $\quad$ restore the inverted masses;

- $\quad$ subtract normal gravity $\gamma$ at corresponding point $\mathrm{Q}_{0}$ on the reference ellipsoid;

- This procedure gives Rudzki anomalies on the geoid computed from the expression

$$
\Delta \mathrm{g}_{\text {Rudzki }}=\mathrm{g}_{\mathrm{P}}-\mathrm{A}_{\mathrm{T}}+\mathrm{A}^{\mathrm{inv}}+\mathrm{F}-\gamma_{\mathrm{Q}_{0}}=\mathrm{g}_{\mathrm{P}}+\mathrm{F}-\gamma_{\mathrm{Q}_{0}}-\delta \mathrm{A}_{\mathrm{inv}}=\Delta \mathrm{g}_{\mathrm{FA}}-\delta \mathrm{A}_{\mathrm{inv}}
$$

The direct topographical effect on gravity $\Delta \mathrm{g}_{\mathrm{T}}$, given in equation (2.1), due this reduction scheme is the attraction change $\delta \mathrm{A}_{\text {inv }}$

$$
\Lambda \mathrm{g}_{\mathrm{T}}=\mathrm{A}_{\mathrm{T}}-\mathrm{A}_{\mathrm{inv}}=\delta \mathrm{A}_{\mathrm{inv}}
$$

where $A_{T}$ is the attraction of the topographic masses above the geoid and $A_{\text {inv }}$ is the attraction of the inverted topographical masses, with the density of the topographic masses being equal to the density of the inverted masses and the thickness of the inverted masses equal to the height of the topography.

$$
A_{\text {inv }}=G \iint_{E} \int_{-h}^{0} \frac{\rho(x, y, z)\left(h_{P}-z\right)}{s^{3}\left(x_{P}-x, y_{P}-y, h_{P}-z\right)} d x d y d z
$$

Equations (2.99) can also be numerically integrated using rectangular prisms with the computation point coinciding with the origin of the coordinate system (Nagy, 1966):

$$
A_{\text {inv }}=-G \rho \iiint \mathrm{x} \ln (\mathrm{y}+\mathrm{r})+\mathrm{y} \ln (\mathrm{x}+\mathrm{r})-\left.\left.\left.\mathrm{z} \arctan \frac{\mathrm{xy}}{\mathrm{zx}}\right|_{\mathrm{x}_{1}} ^{\mathrm{x}_{2}}\right|_{\mathrm{y}_{1}} ^{\mathrm{y}_{2}}\right|_{-h} ^{0}
$$

The indirect effect due to the Rudzki inversion method on the geoid is zero.

\subsubsection{Residual Terrain Model (RTM)}

The RTM reduction method takes into account the high frequencies of the topography, so a mean elevation surface is chosen and the effect of the topography above this long wavelength topographic surface is first removed and later restored.

The direct topographical effect on gravity $\Delta \mathrm{g}_{\mathrm{T}}$, given in equation (2.1), due to this reduction scheme is the attraction change $\delta \mathrm{A}_{\mathrm{RTM}}$ 
$\Lambda \mathrm{g}_{\mathrm{T}}=\mathrm{A}_{\mathrm{T}}-\mathrm{A}_{\mathrm{RTM}}=\delta \mathrm{A}_{\mathrm{RTM}}$

$A_{\text {RTM }}=G \iint_{E} \int_{0}^{h r e f} \frac{\rho(x, y, z)\left(h_{P}-z\right)}{s^{3}\left(x_{P}-x, y_{P}-y, h_{P}-z\right)} d x d y d z$

where $\mathrm{h}$ is the topographical height, given by a digital elevation model and $\mathrm{h}_{\mathrm{ref}}$ is the height of the smooth reference surface.

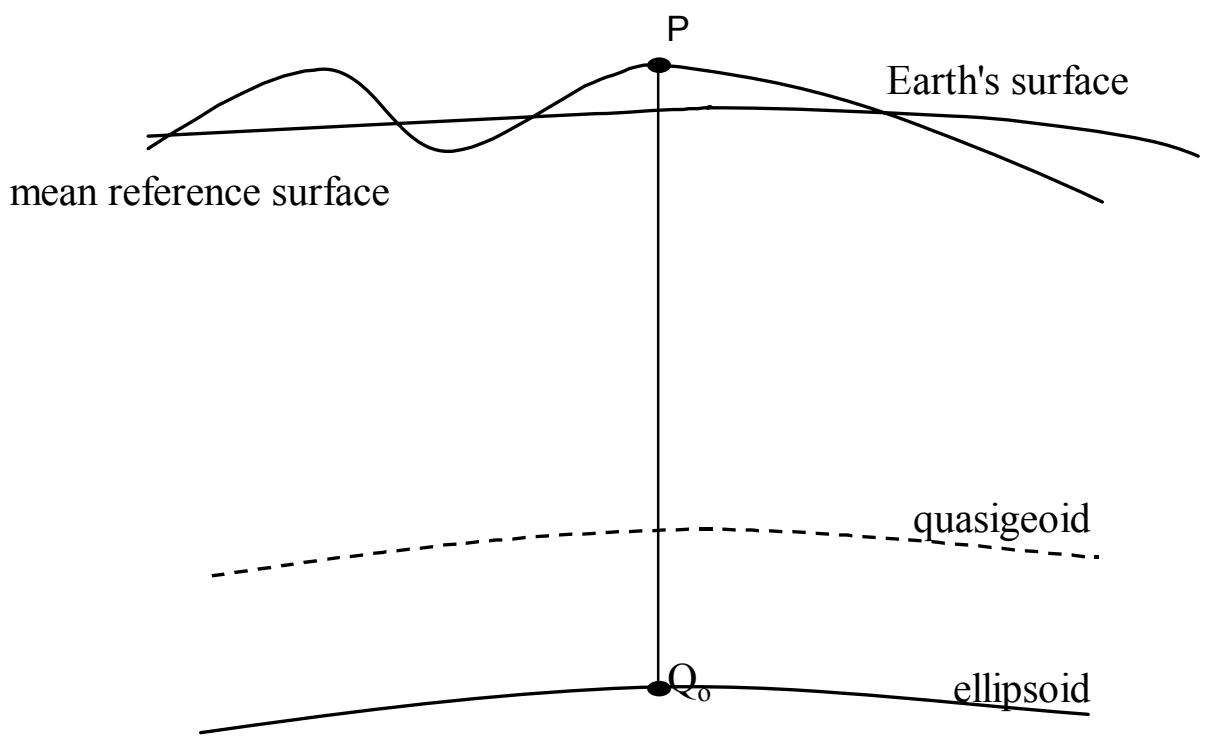

Figure 2.8: RTM reduction

When the mean elevation surface is a sufficiently long-wavelength surface, the RTM gravity terrain effect is given by the approximate expression (Forsberg, 1984)

$$
\delta \mathrm{A}_{\mathrm{RTM}} \approx 2 \pi \mathrm{G} \rho\left(\mathrm{h}-\mathrm{h}_{\mathrm{ref}}\right)-\mathrm{c}_{\mathrm{P}}
$$

which is a Bouguer reduction to the reference surface and $c_{P}$ is the classical terrain correction.

The RTM gravity anomalies are expressed as:

$$
\begin{aligned}
& \Delta \mathrm{g}_{\mathrm{RTM}}=\mathrm{g}_{\mathrm{P}}-\gamma_{\mathrm{Q}}-\delta \mathrm{A}_{\mathrm{RTM}} \\
& \Delta \mathrm{g}_{\mathrm{RTM}}=\Delta \mathrm{g}_{\mathrm{FA}}-2 \pi \mathrm{G} \rho\left(\mathrm{h}-\mathrm{h}_{\text {ref }}\right)+\mathrm{c}_{\mathrm{P}}
\end{aligned}
$$


where $\Delta \mathrm{g}_{\mathrm{FA}}$ is the surface free-air anomaly; it refers to the surface of the topography and it is obtained by subtracting from the surface gravity the normal gravity calculated with the following equation:

$\gamma_{\mathrm{Q}}=\gamma_{\mathrm{Q}_{\mathrm{o}}}+\frac{\partial \gamma}{\partial \mathrm{h}_{\mathrm{e}}} \mathrm{H}^{*}+\frac{1}{2} \frac{\partial^{2}}{\partial \mathrm{h}^{2}} \mathrm{H}^{* 2}+\ldots$

where $\gamma_{\mathrm{Q}}$ is the normal gravity at the telluroid point $\mathrm{Q}$ and $\mathrm{H}^{*}$ is the normal height (see Figure 2.9).

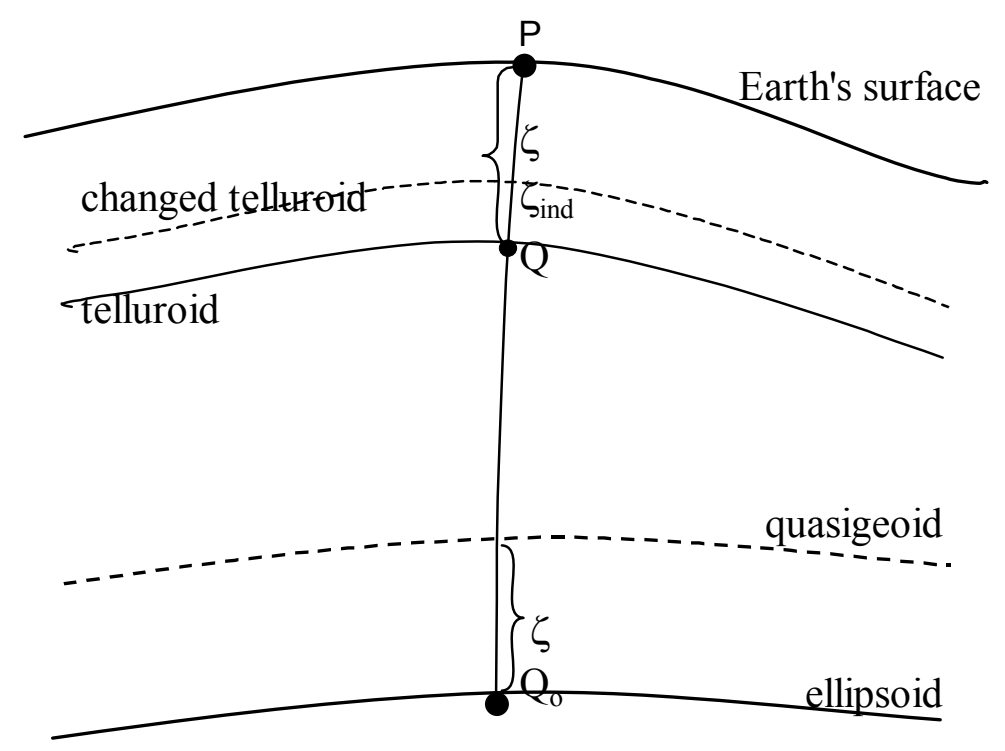

Figure 2.9: Quasigeoid, changed quasigeoid and ellipsoid

$\Delta \mathrm{g}_{\mathrm{FA}}=\mathrm{g}_{\mathrm{P}}-\gamma_{\mathrm{Q}}$

The RTM reduction method yields the quasigeoid. Equation (2.2) is replaced by the following equation

$\zeta=\zeta_{\Delta \mathrm{g}_{\mathrm{RTM}}}+\zeta_{\mathrm{GM}}+\zeta_{\mathrm{ind}}$

where $\zeta$ is the height anomaly, the residual height anomalies $\zeta_{\Delta \mathrm{g}_{\mathrm{RTM}}}$ are computed using Stokes 's formula with the RTM gravity anomalies as input. 
$\zeta_{\text {ind }}$ is the RTM indirect quasigeoid effect. It is the distance between the original telluroid and the changed telluroid after the RTM reduction was performed. It is shown in Figure 2. 9 and it is expressed in linear approximation as:

$$
\zeta_{\text {ind }}=\zeta_{\mathrm{RTM}}=\frac{\mathrm{G} \rho}{\gamma} \iint_{\mathrm{E}} \int_{\mathrm{h}_{\mathrm{ref}}}^{\mathrm{h}} \frac{1}{\mathrm{~s}\left(\mathrm{x}_{\mathrm{P}}-\mathrm{x}, \mathrm{y}_{\mathrm{P}}-\mathrm{y}, \mathrm{h}_{\mathrm{p}}-\mathrm{z}\right)} \mathrm{dxdydz}=\frac{\mathrm{G} \rho\left(\mathrm{h}-\mathrm{h}_{\mathrm{ref}}\right)}{\gamma} \int_{-\infty}^{\infty} \int_{-\infty}^{\infty} \frac{1}{\mathrm{~s}} \mathrm{dxdy}(
$$

where $\mathrm{s}$ is the planar distance.

The quasigeoid is converted to geoid using the quasigeoid-geoid separation given in Heiskanen and Moritz (1967) as

$$
\mathrm{N} \approx \zeta+\frac{\Delta \mathrm{g}_{\mathrm{B}}}{\bar{\gamma}} \mathrm{H}
$$

where $\bar{\gamma}$ represents the mean normal gravity; $\mathrm{H}$ is the orthometric height and $\Delta \mathrm{g}_{\mathrm{B}}$ the Bouguer anomaly.

\subsection{Data error propagation}

For regional geoid determination, the accuracy of the gravimetric geoid computed with the remove-restore technique will depend on the density, accuracy and coverage of the local gravity anomalies, the height data and the errors of the geopotential model.

Applying the theory of error propagation to the geoid determination, the error variance of the gravimetric geoid undulations can be expressed by:

$$
\sigma_{\mathrm{N}_{\mathrm{GRAV}}}^{2}=\sigma_{\mathrm{N}_{\Delta \mathrm{g}}}^{2}+\sigma_{\mathrm{N}_{\mathrm{GM}}}^{2}+\sigma_{\mathrm{N}_{\mathrm{T}}}^{2}
$$

where $\sigma_{N}^{2}{ }_{N}$ GRAV is the combined gravimetric geoid error variance, $\sigma_{N_{\Delta g}}^{2}$ is the geoid error variance due to the error of the gravity anomalies, $\sigma_{\mathrm{N}_{\mathrm{GM}}}^{2}$ is the geoid error variance due to the errors of the geopotential model and $\sigma_{\mathrm{N}_{\mathrm{T}}}^{2}$ is the geoid error variance due to the errors of the height data. Equation (2.101) assumes that the data errors are uncorrelated.

Each of the expressions in equation (2.101) can be given according to Li (1994) as: 
$\sigma_{\mathrm{N}_{\Delta \mathrm{g}}}^{2}=\left(\frac{\mathrm{R} \Delta \varphi \Delta \lambda}{4 \pi \gamma}\right)^{2}\left(\sigma_{\Delta \mathrm{g}}^{2} \cos ^{2} \varphi+\sigma_{\Delta \mathrm{g}_{\mathrm{GM}}}^{2} \cos ^{2} \varphi\right) *(\mathrm{~S}(\psi)-\overline{\mathrm{S}}(\psi))^{2}$

With gridded gravity anomalies, this equation can be evaluated by the $2 \mathrm{D}$ Fourier transform as:

$$
\sigma_{\mathrm{N}_{\Delta \mathrm{g}}}^{2}=\left(\frac{\mathrm{R} \Delta \varphi \Delta \lambda}{4 \pi \gamma}\right)^{2} \mathrm{~F}^{-1}\left\{\mathrm{~F}\left\{\sigma_{\Delta \mathrm{g}}^{2} \cos ^{2} \varphi+\sigma_{\Delta \mathrm{g}_{\mathrm{GM}}}^{2} \cos ^{2} \varphi\right\} \mathrm{F}\left\{(\mathrm{S}(\psi)-\overline{\mathrm{S}}(\psi))^{2}\right\}\right\}
$$

where $\sigma_{\Delta \mathrm{g}}^{2}$ are the variances of the residual gravity anomalies, $\sigma_{\Delta \mathrm{g}_{\mathrm{GM}}}^{2}$ are the variances of the gravity anomalies from the geopotential model and are computed from the variances of the geopotential model, $\mathrm{S}(\psi)$ is the spherical Stokes kernel and $\overline{\mathrm{S}}(\psi)$ is the summation of the Stokes spherical kernel up to degree $n_{\max }$

$\overline{\mathrm{S}}(\psi)=\sum_{\mathrm{n}=2}^{\mathrm{n}_{\max }} \frac{2 \mathrm{n}+1}{\mathrm{n}-1} \mathrm{P}_{\mathrm{n}}(\cos (\psi))$

The contribution of the random noise of the geopotential model coefficients to the combined gravimetric geoid undulation error variance can be computed by:

$$
\sigma_{\mathrm{N}_{\mathrm{GM}}}^{2}=\mathrm{R}^{2} \sum_{\mathrm{n}=2}^{\mathrm{n}_{\max }} \sum_{\mathrm{m}=\mathrm{o}}^{\mathrm{n}}\left(\sigma_{\overline{\mathrm{C}}_{\mathrm{nm}}}^{2}+\sigma_{\overline{\mathrm{S}}_{\mathrm{nm}}}^{2}\right)
$$

and

$$
\sigma_{\Delta \mathrm{g}_{\mathrm{GM}}}^{2}=\mathrm{G}^{2} \sum_{\mathrm{n}=2}^{\mathrm{n}_{\mathrm{max}}}(\mathrm{n}-1)^{2} \sum_{\mathrm{m}=\mathrm{o}}^{\mathrm{n}}\left(\sigma_{\overline{\mathrm{C}}_{\mathrm{nm}}}^{2}+\sigma_{\overline{\mathrm{S}}_{\mathrm{nm}}}^{2}\right)
$$

where $\sigma_{\overline{\mathrm{C}}_{\mathrm{nm}}}^{2}$ and $\sigma_{\mathrm{S}_{\mathrm{nm}}}^{2}$ are the variance of the fully normalized geopotential coefficients The errors of gravity field parameters computed from a geopotential model like $\Delta \mathrm{g}_{\mathrm{GM}}$ or $\mathrm{N}_{\mathrm{GM}}$ used in the remove-restore procedure suffer from two effects.

- The commission error produced by the statistical errors of the coefficients themselves. An approximate method to estimate the commission errors uses the error degree variances of the geopotential model (Sideris and She, 1995).

- The omission error produced by neglecting of the coefficients above $\mathrm{n}_{\max }$. The estimation of the omission errors or truncation errors requires the knowledge of the signal degree variances above the maximum degree to which the geopotential 
model are used $\left(n_{\max }\right)$ from a signal gravity anomaly degree variance model (e.g., the Tscherning and Rapp model (Tscherning and Rapp, 1974).

Signal gravity anomaly degree variance are related to the coefficients of the geopotential model by:

$$
\sigma_{\mathrm{nn}}^{2}(\Delta \mathrm{g}, \Delta \mathrm{g})=(\mathrm{n}-1)^{2} \gamma^{2} \sum_{\mathrm{m}=\mathrm{o}}^{\mathrm{n}}\left(\overline{\mathrm{C}}_{\mathrm{nm}}^{2}+\overline{\mathrm{S}}_{\mathrm{nm}}^{2}\right)
$$

The expression for $\sigma_{\mathrm{N}_{\mathrm{T}}}^{2}$ is:

$\sigma_{\mathrm{N}_{\mathrm{T}}}^{2}=\left(\frac{\mathrm{G} \rho \pi}{\gamma}\right)^{2} \sigma_{\mathrm{h}}^{2}$

where $\sigma_{h}$ is the error of the heights

\subsection{Summary}

The flowchart depicted in Figure 2.10 summarizes the principal steps of the removecompute-restore technique applied in this research to compute the combined geoid solution for Argentina. 


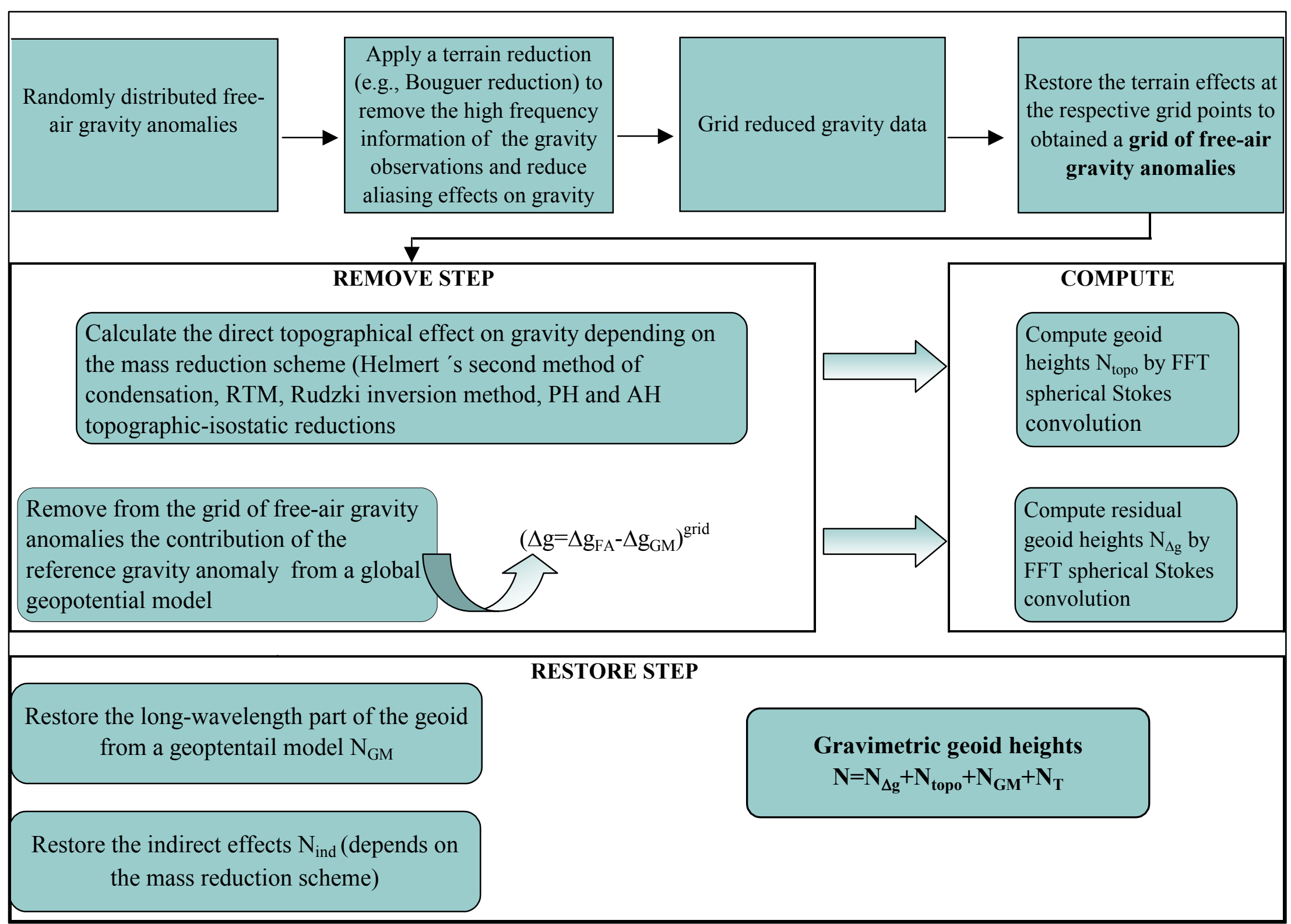

Figure 2.10: Flowchart gravimetric geoid modeling 


\section{CHAPTER THREE}

\section{MARINE GEOID DETERMINATION}

\subsection{Introduction}

As we have seen in Figure 1.1, Argentina is limited with the Atlantic Ocean to the East so it is also necessary to study the marine gravity field due to its applications in marine geodesy, geophysics and oceanography. The main objective of this chapter is to present the theoretical background related to determination of a high-accuracy and highresolution marine geoid model by combining satellite altimetry and sea gravimetry. The theoretical foundations related to the estimation of the gravimetric and altimetric geoid models (Li and Sideris, 1997; Vergos, 2002) and the combined geoid solution using the Multiple Input Multiple Output System Theory (MIMOST) (Sideris, 1996; Li, 1996; Andritsanos et al., 2000; and Andritsanos and Tziavos, 2002) will be outlined. Satellite altimetry gives observations of sea surface heights that are approximately equal to geoid heights; they are very useful in mapping the ocean geoid and in studying the marine gravity field (Li, 1996). Shipborne data will be used to compute the marine gravimetric geoid.

\subsection{Computational methodology}

\subsubsection{Gravimetric geoid modeling}

Marine gravimetric geoid determination is based on shipborne and satellite altimetryderived gravity anomalies. The latter are used to augment the ship data and fill in gaps. It is often that the ship gravity anomalies refer to the sea surface and not the geoid itself, thus their use will lead to the determination of a mean sea surface and not a geoid model. These gravity anomalies have to be free-air reduced so as to produce gravity anomalies on the surface of the geoid. The free-air gravity anomalies are computed using the well-known reduction formula

$$
\Delta \mathrm{g}_{\mathrm{FA}}=\Delta \mathrm{g}+\mathrm{F}
$$


where $\mathrm{F}$ is the free-air reduction. In marine regions the height needed for the reduction is that of the Quasi-stationary Sea Surface Topography (QSST), which varies between 0.2 and $-0.7 \mathrm{~m}$ for the EGM96.QSST (Lemoine et al., 1998) in the study area.

Thus, for practical purposes it is sufficient to use the normal gradient of gravity to compute the free-air reduction as

$$
\mathrm{F} \approx-\frac{\delta \gamma}{\delta \mathrm{h}} \mathrm{h} \approx-0.3086 \mathrm{~h}
$$

where $\mathrm{h}$ is the QSST in meters, derived from a global model.

Even though, this effect of about a tenth of a miligal and it can be considered negligible, it is applied in order not to introduce an additional error.

This pre-processing step is necessary for the data homogenization so that they can be used for the determination of the gravimetric geoid. The marine gravimetric geoid will be computed using the remove-compute-restore technique employing Stokes's formula for the prediction of residual geoid heights. Before the prediction of the geoid the gravity anomalies have to be reduced to a geopotential model during the remove step. Furthermore the effect of the topography, actually that of the bathymetry in marine areas, has to be taken into account through a topographic reduction. In this study, a residual terrain model (RTM) reduction was used to account for the bathymetry. The RTM effect on gravity is given by the approximate expression (Forsberg, 1984)

$$
\delta \mathrm{A}_{\mathrm{RTM}} \approx 2 \pi \mathrm{G} \Delta \rho\left(\mathrm{h}_{\mathrm{b}}-\mathrm{h}_{\mathrm{b}_{\mathrm{ref}}}\right)-\mathrm{c}
$$

where $h_{b}$ is the bathymetric depth given by a global bathymetry model, $h_{\text {bref }}$ is the depth of a smooth mean reference surface and $\Delta \rho$ is the density contrast between Earth's crust and seawater. The reference bathymetric surface is obtained by simple averaging the fine bathymetry grid and then low-pass filtering it using a moving-average window, with a resolution around $100 \mathrm{~km}$. tc and tcgrid programs from the GRAVSOFT software (Tscherning et al., 1992) are used for the RTM reduction and to filter height data for RTM height reference surfaces.

The residual gravity anomalies $\left(\Delta \mathrm{g}_{\mathrm{res}}=\Delta \mathrm{g}_{\mathrm{FA}}-2 \pi \mathrm{G} \rho\left(\mathrm{h}-\mathrm{h}_{\mathrm{ref}}\right)+\mathrm{c}-\Delta \mathrm{g}_{\mathrm{GM}}\right)$ are then gridded $\left(\Delta \mathrm{g}_{\mathrm{res}}\right)^{\text {grid }}$ and the contribution of the bathymetry is restored prior to the 
calculation of the geoid height (indirect use of the terrain reduction) $\left(\Delta \mathrm{g}_{\mathrm{res}}\right)^{\text {grid }}+2 \pi \mathrm{G} \rho\left(\mathrm{h}-\mathrm{h}_{\mathrm{ref}}\right)^{\text {grid }}$, yielding a grid of Faye gravity anomalies relative to the geopotential model. The bathymetry refers to masses below the geoid so its effect has to be restored before the use Stokes formula for the estimation of geoid heights (Dahl and Forsberg, 1998). The gridding is performed using program geogrid using weighted means from the same GRAVSOFT package.

Different approximations to Stokes's kernel function are investigated to compute residual geoid undulations, all in the spectral domain, e.g., the 2D-FFT spherical Stokes convolution to evaluate the kernel function (Strang Van Hess, 1990) and the 1D-FFT rigorous spherical Stokes convolution (Haagmans et al., 1993).

The final gravimetric geoid is obtained by restoring the contribution of the reference model.

\subsubsection{Altimetric geoid modeling}

An altimetric satellite measures the time taken by a radar pulse to travel from the satellite to the sea surface and then back to the satellite receiver. Combined with precise satellite location data, altimetry measurements yield Sea Surface Heights (SSHs). The derived SSHs have to be corrected for several geophysical effects (tides, tidal loading, ionosphere, wet and dry troposphere, inverse barometer and electromagnetic bias) and instrumental errors (ultra-stable oscillator, centre of gravity, corrections for instrument and algorithm effects that can not be modeled and waveforms). After applying the above corrections, Corrected Sea Surface Heights (CorSSHs) are available for one or more satellites (e.g., GEOSAT, ERS1).

Sea Surface Heights contain information about both the geoid and the sea surface topography (SST); the latter consists of a time-dependent and a nearly time-independent component (quasi-stationary part). Stacking the repeat tracks can eliminate the effect of the time-dependent component and part of the sea surface variability effects that influence the data. 
These altimetric measurements refer to the sea surface so they have to be reduced to the geoid. This is performed by estimating the QSST at each sub-satellite point and removing the contribution of the QSST from the CorSSH value. The quasi-stationary component of the SST is modeled by a spherical harmonic series of the Dynamic Ocean Topography (DOT) as follows:

$\varsigma_{c}(\varphi, \lambda)=R \sum_{n=1}^{n_{\max }} \sum_{m=0}^{n}\left(\bar{C}_{n m}^{S S T} \operatorname{cosm} \lambda+\bar{S}_{n m}^{S S T} \operatorname{sinm} \lambda\right) \bar{P}_{n m}(\sin \varphi)$

where $\varsigma_{c}(\varphi, \lambda)$ is the contribution of the model coefficients, $n_{\max }$ denotes the maximum degree and order of expansion of the DOT model, $\overline{\mathrm{P}}_{\mathrm{nm}}(\sin \phi)$ are the fully normalized associated Legendre functions, and $\overline{\mathrm{C}}_{\mathrm{nm}}^{\mathrm{SST}}, \overline{\mathrm{S}}_{\mathrm{nm}}^{\mathrm{SST}}$ are the fully normalized DOT spherical harmonic coefficients.

After the removal of the effect of the QSST the CorSSHs refer to the geoid and can be used to derive an altimetric geoid model. As in the gravimetric geoid computation, the contribution of a geopotential model was removed to derive reduced SSHs (SSHsred). The so-reduced SSHs (SSHsred) may still contain some blunders, so a 3 rms test is used to identify and remove gross-errors. If the mean value of the reduced SSHs is small enough (e.g., bellow $10 \mathrm{~cm}$ ), then the $3 \mathrm{rms}$ test can be applied. That is so because by using a $3 \mathrm{rms}$ test we assume that all systematic errors have been removed from the data and only random errors remain. If the mean value of the SSHred is larger, an RTM reduction is applied first to obtain smoother residual SSHs. The computation of the RTM effects on residual geoid heights has been based on the same concept as in the gravimetric geoid. In both cases, the GRAVSOFT software (Tscherning et al., 1992) has been used to create the reference bathymetric grid and estimate the RTM reduction on geoid heights.

The residual Sea Surface Heights represent the medium wavelengths of the geoid heights and can be considered as residual geoid heights (Nres). After all these processing steps the Nres are ready to be gridded. The gridding of the randomly distributed data is based on a weighted means method using the inverse of the square of the distance as the weight for each irregular observation. It was done using the program geogrid from the GRAVSOFT software (Tscherning et al., 1992). 
If the area under study is located in a closed sea, then the derived Nres constitute the final estimated residual altimetric geoid height. But, if the area investigated is in an open ocean area, then the effects of temporal oceanic phenomena like the Sea Surface Variability (SSV) influence the data and appear as noise in the Nres. Such effects need to be removed or at least reduced so as to derive reliable predictions. Since the effect of the SSV appears as high-frequency noise in the altimetric data, it can be reduced by low-pass filtering the Nres grid. This was performed using Wiener filtering, which is equivalent to least squares collocation in the frequency domain. Assuming Kaula's rule for the geoid kernel spectrum $F(\omega)$, we have

$$
F(\omega)=\frac{\omega_{\mathcal{c}}^{4}}{\omega^{4}+\omega_{\mathrm{c}}^{4}}
$$

where $\omega$ is the radial frequency and the cut-off frequency $\omega_{c}$ is determined empirically based on a criterion of maximum noise reduction with minimum signal loss. Program geofour from the GRAVSOFT software (Tscherning et al., 1992) is used for applying this type of filter.

Then, the final step to compute the altimetric geoid (Nalt) is to restore the contribution of the geopotential model and the contribution of the bathymetry.

\subsubsection{Combined marine geoid modeling}

A combined geoid solution can be determined using Least Square Collocation (LSC) or the Multiple Input Multiple Output System Theory (MIMOST) (Sideris, 1996; Wu, 1996; Li, 1996; Li, 1996). In this research, the combined geoid will be estimated using MIMOST for the optimal combination of heterogeneous noisy data in order to investigate whether the combined use of shipborne gravity and satellite altimetry data improves the geoid compared to the purely gravimetric case and if the shipborne information can improve the low accuracy of the altimetric geoid determination in coastal regions.

The system used in this research corresponds to a double-input single-output system with noise. The system can be seen in Figure 3.1. 
Mathematically, the system can be expressed by:

$\mathrm{n}=\left(\mathrm{n}^{\text {grav }}+\mathrm{m}^{\text {grav }}\right) * \mathrm{~h}_{1}+\left(\mathrm{n}^{\text {alt }}+\mathrm{m}^{\text {alt }}\right) * \mathrm{~h}_{2}+\mathrm{e}$

where $\mathrm{n}$ is the combined geoid output (system output), $\mathrm{n}^{\text {grav }}$ and $\mathrm{n}^{\text {alt }}$ are the pure gravimetric and the pure altimetric input signals, $\mathrm{m}^{\text {grav }}$ and $\mathrm{m}^{\text {alt }}$ are the input noises, $\mathrm{g}=\mathrm{n}^{\text {grav }}+\mathrm{m}^{\text {grav }}$ and $\mathrm{a}=\mathrm{n}^{\text {alt }}+\mathrm{m}^{\text {alt }}$ are the gravimetric and altimetric geoid observations considered as noise-contaminated input signals, $h_{1}$ and $h_{2}$ are impulse responses, e is the output system noise and * is the convolution operator.

Equation (3.6) can be written in the frequency domain as:

$$
\begin{aligned}
& \mathrm{N}(\omega)=\left(\mathrm{N}^{\text {grav }}(\omega)+\mathrm{M}^{\text {grav }}(\omega)\right) \mathrm{H}_{1}(\omega)+\left(\mathrm{N}^{\text {alt }}(\omega)+\mathrm{M}^{\text {alt }}(\omega)\right) \mathrm{H}_{2}(\omega)+\mathrm{E}(\omega) \\
& \mathrm{N}(\omega)=\mathrm{G}(\omega) \mathrm{H}_{1}(\omega)+\mathrm{A}(\omega) \mathrm{H}_{2}(\omega)+\mathrm{E}(\omega)=\hat{N}(\omega)+\mathrm{E}(\omega)
\end{aligned}
$$

where $\omega$ is the circular frequency, $\mathrm{N}(\omega)$ is the spectrum of the output combined geoid, $\mathrm{N}^{\text {grav }}(\omega)$ and $\mathrm{N}^{\text {alt }}(\omega)$ are the spectrum of the input altimetric and gravimetric signals, $\mathrm{M}^{\text {grav }}(\omega)$ and $\mathrm{M}^{\mathrm{alt}}(\omega)$ are the spectra of the gravimetric and altimetric noises, $\mathrm{G}(\omega)$ and $A(\omega)$ are the spectrum of the input gravimetric and altimetric observations, $H_{1}(\omega)$ and $H_{2}(\omega)$ are the corresponding frequency responses of $h_{1}$ and $h_{2}$, which are the theoretical operators connecting the input and output signals, and $\mathrm{E}(\omega)$ is the system noise expressed in the frequency domain.

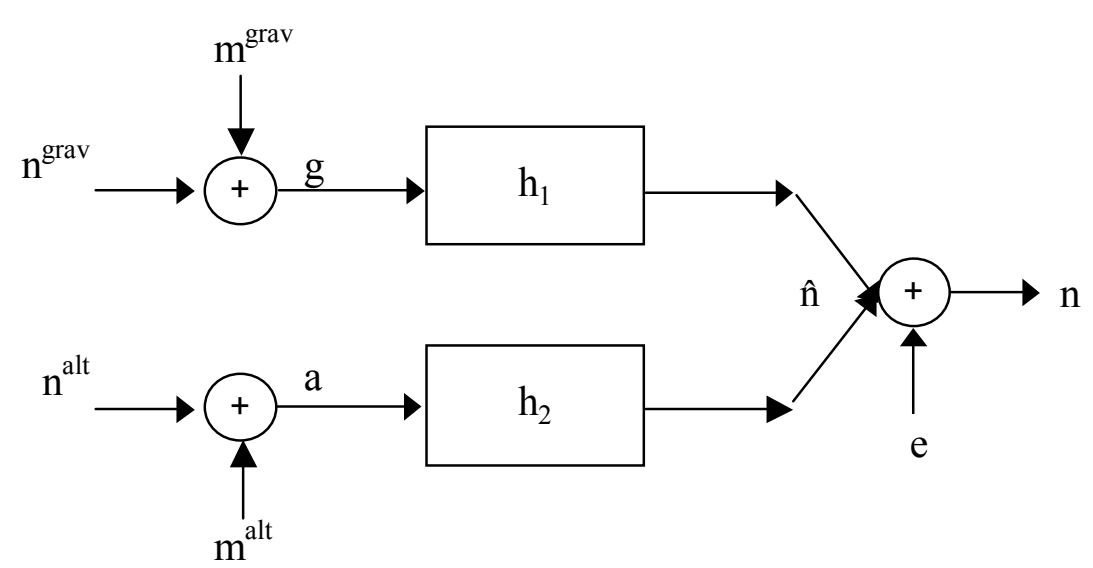

Figure 3.1: Double-input single output system with noise 
Equations (3.7) and (3.8) can be rewritten as:

$$
\begin{aligned}
\mathrm{E}(\omega) & =\mathrm{N}(\omega)-\hat{\mathrm{N}}(\omega)= \\
& \left.=\mathrm{N}(\omega)-\left[\left(\mathrm{N}^{\text {grav }}(\omega)+\mathrm{M}^{\text {grav }}(\omega)\right) \mathrm{H}_{1}(\omega)+\mathrm{N}^{\text {alt }}(\omega)+\mathrm{M}^{\text {alt }}(\omega)\right) \mathrm{H}_{2}(\omega)\right] \\
\mathrm{E}(\omega) & \left.\left.=\mathrm{N}(\omega)-[\mathrm{G}(\omega)) \mathrm{H}_{1}(\omega)+\mathrm{A}(\omega)\right) \mathrm{H}_{2}(\omega)\right]
\end{aligned}
$$

Multiplying $\mathrm{E}(\omega)$ by $\mathrm{E}^{*}(\omega)$ (super script * denotes the complex conjugate) and taking the mathematical expectation E, the system output noise power spectral density (PSD) is:

$$
\begin{aligned}
& \mathrm{P}_{\mathrm{ee}}=\mathrm{E}\left[\mathrm{E}(\omega) \mathrm{E}^{*}(\omega)\right]=\mathrm{P}_{\mathrm{nn}}-\mathrm{H}_{1} \mathrm{P}_{\mathrm{gn}}-\mathrm{H}_{2} \mathrm{P}_{\mathrm{an}}-\mathrm{H}_{1}^{*} \mathrm{P}_{\mathrm{ng}}+\mathrm{H}_{1}^{*} \mathrm{H}_{1} \mathrm{P}_{\mathrm{gg}}+ \\
& +\mathrm{H}_{1}^{*} \mathrm{H}_{2} \mathrm{P}_{\mathrm{ag}}-\mathrm{H}_{2}^{*} \mathrm{P}_{\mathrm{na}}+\mathrm{H}_{1} \mathrm{H}_{2}^{*} \mathrm{P}_{\mathrm{ga}}+\mathrm{H}_{2}^{*} \mathrm{H}_{2} \mathrm{P}_{\mathrm{aa}}=\mathrm{P}_{\mathrm{nn}}-\mathrm{P}_{\mathrm{nnn}}
\end{aligned}
$$

The optimal transfer functions $\hat{\mathrm{H}}_{1}(\omega)$ and $\hat{\mathrm{H}}_{2}(\omega)$ are the particular $\mathrm{H}_{1}$ and $\mathrm{H}_{2}$ that are minimizing the power spectral density of the output noise $\left(\mathrm{P}_{\mathrm{ee}}(\omega)\right)$ at any frequency over all possible choices of $\mathrm{H}_{1}(\omega)$ and $\mathrm{H}_{2}(\omega)$ using the next criterion.

$$
\begin{aligned}
& P_{\text {ee }}(\omega)=\left[\mathrm{N}(\omega)-\left[\left(\mathrm{N}^{\text {grav }}(\omega)+\mathrm{M}^{\text {grav }}(\omega)\right) \mathrm{H}_{1}(\omega)+\left(\mathrm{N}^{\text {alt }}(\omega)+\mathrm{M}^{\text {alt }}(\omega)\right) \mathrm{H}_{2}(\omega)\right]\right]^{2} \\
& =\text { minimum }
\end{aligned}
$$

The optimal frequency response functions $\hat{H}_{1}(\omega)$ and $\hat{H}_{2}(\omega)$ are obtained by setting the following partial derivates equal to zero

$$
\frac{\partial \mathrm{P}_{\mathrm{ee}}(\mathrm{N})}{\partial \mathrm{H}_{1}^{*}}=0 \text { and } \frac{\partial \mathrm{P}_{\mathrm{ee}}(\mathrm{N})}{\partial \mathrm{H}_{2}^{*}}=0
$$

Assuming that the input noises $\left(\mathrm{m}^{\text {grav }}\right.$ and $\mathrm{m}^{\text {alt }}$ ) are uncorrelated with known PSDs and the signals and noises are also uncorrelated, the optimal transfer functions $\hat{H}_{1}(\omega)$ and $\hat{\mathrm{H}}_{2}(\omega)$ are:

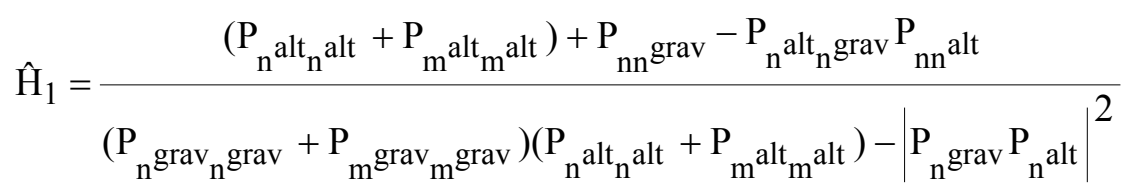




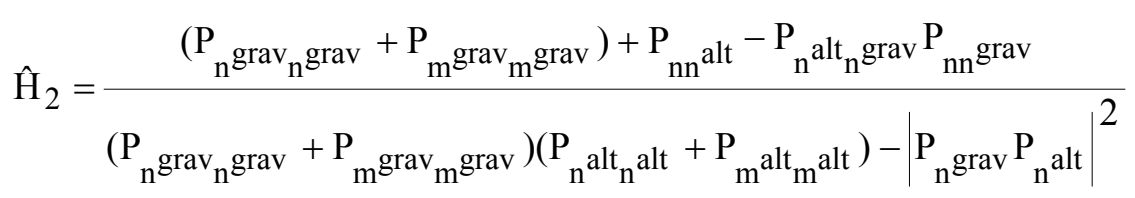

We can expressed, the estimated output signal, in the frequency domain as:

$$
\hat{\mathrm{N}}(\omega)=\left[\left(\mathrm{N}^{\text {grav }}(\omega)+\mathrm{M}^{\text {grav }}(\omega)\right) \hat{\mathrm{H}}_{1}(\omega)+\left(\mathrm{N}^{\text {alt }}(\omega)+\mathrm{M}^{\text {alt }}(\omega)\right) \hat{H}_{2}(\omega)\right]
$$

and the minimum power spectral density of the system output noise by the following equation:

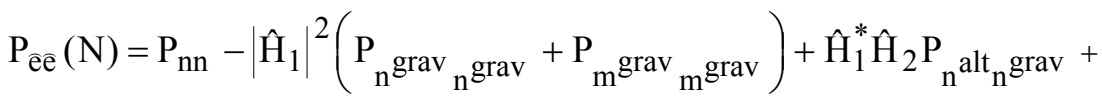

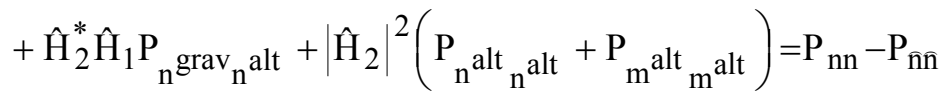

where $\mathrm{P}_{\mathrm{n}}$ grav ${ }_{\mathrm{n}}$ grav and $\mathrm{P}_{\mathrm{n}}$ alt $_{\mathrm{n}}$ alt are the auto-power spectral densities of $\mathrm{n}^{\text {grav }}$ and $\mathrm{n}^{\text {alt }}$; $\mathrm{P}_{\mathrm{m}}{ }^{\text {grav }} \mathrm{m}^{\text {grav }}$ and $\mathrm{P}_{\mathrm{m}}{ }^{\text {alt }} \mathrm{m}^{\text {alt }}$ are the noise power spectral densities of $\mathrm{n}^{\text {grav }}$ and $\mathrm{n}^{\text {alt }}$; $\mathrm{P}_{n}{ }_{\text {grav }}{ }_{n}{ }^{\text {alt }}=P_{n}^{*} n^{\text {alt }} n^{\text {grav }}$ are the cross-power spectral densities between $n^{\text {grav }}$ and $n^{\text {alt }}$; $\mathrm{P}_{n n}$ grav and $\mathrm{P}_{\mathrm{nn}}$ alt are the cross-power spectral densities between the output $\mathrm{n}$ and $\mathrm{n}^{\text {grav }}$ and $\mathrm{n}^{\text {alt }}$ and $\mathrm{P}_{\overline{\mathrm{ee}}}(\mathrm{N})$ is the power spectral density of the prediction error.

The input signals in the combined solution are the residual gravimetric and altimetric geoid heights before restoring the contribution of the geopotential model. That is done to avoid introducing long-wavelength errors. The two inputs of the system are contaminated by uncorrelated noise $\mathrm{m}^{\text {alt }}$ and $\mathrm{m}^{\text {grav }}$ with known Power Spectral Density (PSDs).

The MIMOST solution can be estimated only if the noise PSD $\left(\mathrm{P}_{\mathrm{mm}}\right)$ is known. When no information is available about the errors of the input data, simulated noise using a random number generator can be used as input errors in the prediction and the input error power spectrum can be computed (Andritsanos and Tziavos, 2002). The variances used in the generation of the noise fields will be defined from the comparisons of our geoid models with the T/P SSHs, which will be used as control points.

The algorithm and the related formulae are given in Sideris (1996) and Andritsanos and Tziavos, (2002). More details of the input-output system theory (IOST) can be found in 
(Bendat and Piersol, 1986; Li and Sideris, 1997; Andritsanos and Tziavos, 2002 and Vergos, 2002).

\subsection{Summary}

The following flowcharts summarize the computational methodologies described in this chapter for the gravimetric and altimetric geoid developments (Figures 3.3 and 3.4) respectively.

Data:

shipborne gravity anomalies satellite altimetry-derived gravity anomalies
Shipborne free-air gravity anomalies refer to sea level $\Rightarrow$ reduce to the geoid with a freeair reduction $-0.3086 \mathrm{z}_{\mathrm{QSST}}$

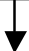

Remove the contribution of a GM

Remove the contribution of the bathymetry (e.g., by RTM reduction)

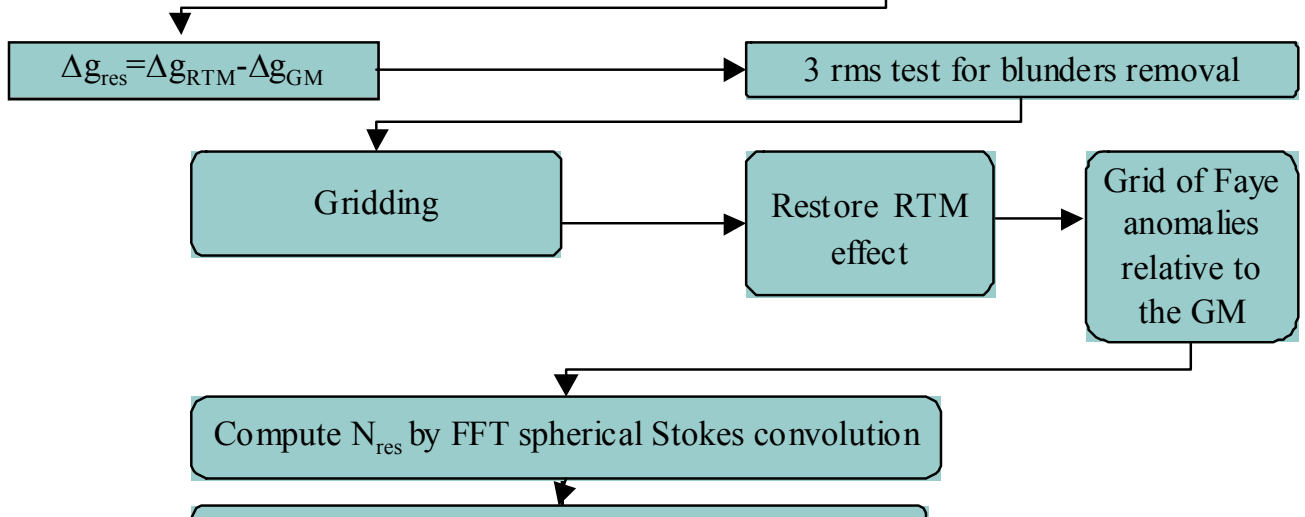

Restore the contribution of $\mathrm{N}_{\mathrm{GM}}$

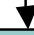

Gravimetric Geoid Heights

Figure 3.2: Gravimetric geoid modeling 


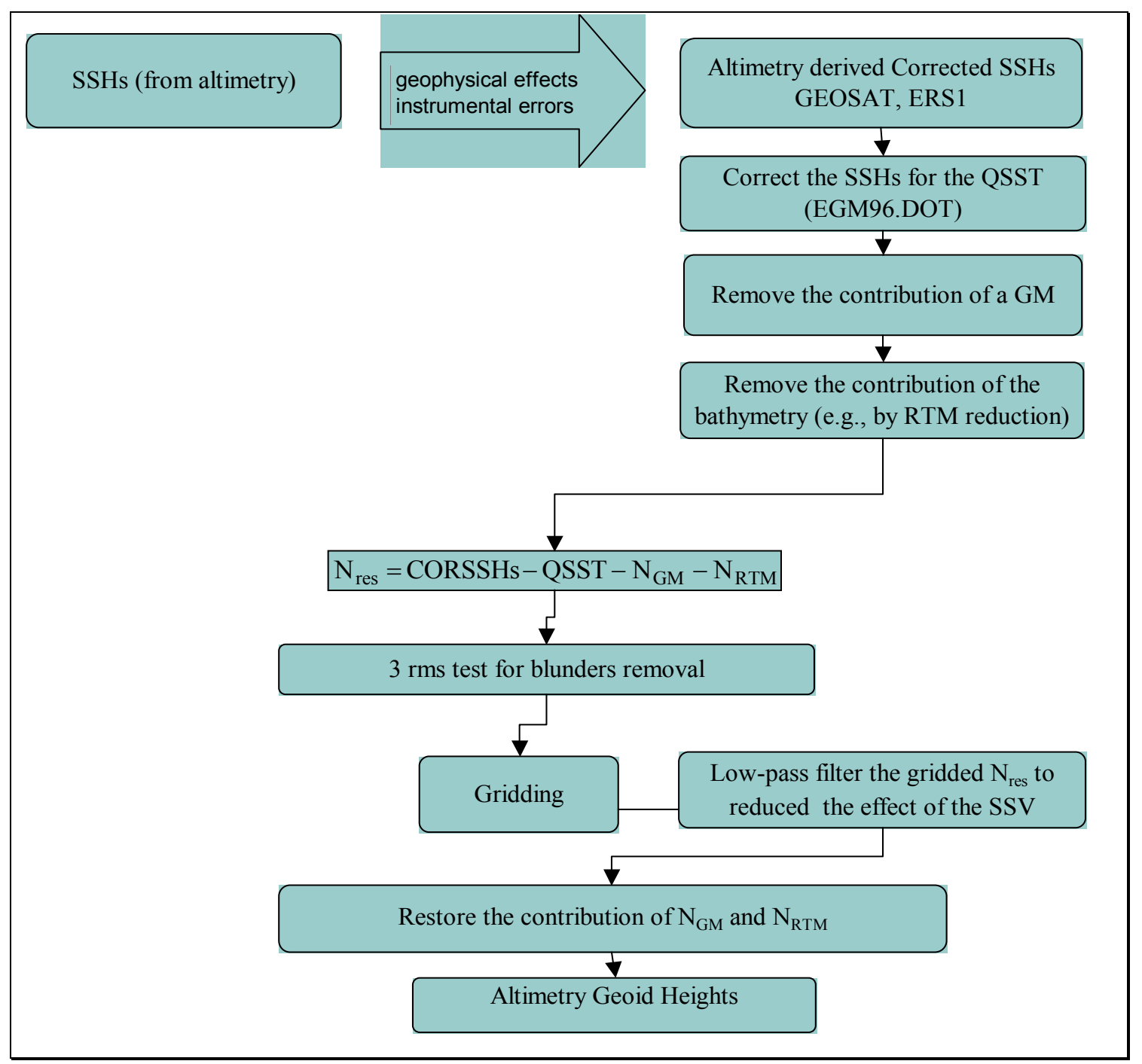

Figure 3.3: Altimetric geoid modeling 


\section{CHAPTER FOUR}

\section{GRAVITY, ELEVATION AND BATHYMETRY DATA IN ARGENTINA}

\subsection{Introduction}

This chapter presents all the data available for this research and describes the data preparation, pre-processing and evaluation for the determination of the gravimetric geoid model in Argentina and the optimal marine geoid determination in the Atlantic coastal region of Argentina.

The original database includes:

- Land gravity observations

- Shipborne marine gravity observations

- Free-air gravity anomalies derived from satellite altimetry

- Spot Heights, Digital Elevation Models (DEM) and Digital Depth Models (DDM)

- GPS/levelling observations

- Global Geopotential Models

- Gravity models from CHAMP and GRACE gravity missions

- Corrected Sea Surface Heights from the ERS1 Geodetic Mission

- Topex/Poseidon altimetry data

- Quasi Stationary Sea Surface Topography (QSST) models

\subsubsection{Land gravity observations}

During the past five years many efforts were carried out in order to collect as many gravity data as possible in order to generate the most homogenized gravity database in Argentina. A total number of 73373 were collected from different sources. The 
distribution of the land gravity observations can be seen in Figure 4.1 and Table 4.1 shows statistical information about the gravity observations.

Table 4.1: Statistics of the gravity observations.

\begin{tabular}{|c|c|c|c|c|c|c|c|}
\hline Source & $\begin{array}{l}N^{\circ} \text { of } \\
\text { points }\end{array}$ & & Unit & $\min$ & $\max$ & mean & $\sigma$ \\
\hline $\begin{array}{l}\text { Freie Universitaet } \\
\text { Berlin, Germany }\end{array}$ & $5648 \mathrm{pts}$ & $\begin{array}{l}\text { latitude } \\
\text { longitude } \\
\text { g IGSN71 } \\
\text { height }\end{array}$ & $\begin{array}{l}\text { [degree] } \\
{[\mathrm{mGal}]} \\
{[\mathrm{m}]}\end{array}$ & $\begin{array}{l}-29.45 \\
-71.41 \\
977310.00 \\
0.10\end{array}$ & $\begin{array}{l}-20.06 \\
-63.86 \\
979294.92 \\
6204.00\end{array}$ & $\begin{array}{l}-24.95 \\
-67.93 \\
978304.65 \\
2223.33\end{array}$ & $\begin{array}{l}2.30 \\
1.82 \\
456.74 \\
1383.15\end{array}$ \\
\hline $\begin{array}{l}\text { Freie Universitaet } \\
\text { Berlin, Germany }\end{array}$ & $3041 \mathrm{pts}$ & $\begin{array}{l}\text { latitude } \\
\text { longitude } \\
\text { g IGSN71 } \\
\text { height }\end{array}$ & $\begin{array}{l}\text { [degree] } \\
{[\mathrm{mGal}]} \\
{[\mathrm{m}]}\end{array}$ & $\begin{array}{l}-42.21 \\
-71.93 \\
979252.70 \\
1.00\end{array}$ & $\begin{array}{l}-35.47 \\
-62.27 \\
980303.15 \\
2281.40 \\
\end{array}$ & $\begin{array}{l}-39.38 \\
-68.31 \\
979917.46 \\
682.02 \\
\end{array}$ & $\begin{array}{l}1.60 \\
2.51 \\
200.96 \\
436.73 \\
\end{array}$ \\
\hline $\begin{array}{l}\text { National University of } \\
\text { Tucuman } \\
\text { (UNT) }\end{array}$ & 348 pts & $\begin{array}{l}\text { latitude } \\
\text { longitude } \\
\text { g IGSN71 } \\
\text { height } \\
\end{array}$ & $\begin{array}{l}\text { [degree] } \\
{[\mathrm{mGal}]} \\
{[\mathrm{m}]}\end{array}$ & $\begin{array}{l}-28.93 \\
-66.53 \\
978271.04 \\
137.00 \\
\end{array}$ & $\begin{array}{l}-26.80 \\
-64.16 \\
979172.10 \\
3290.00 \\
\end{array}$ & $\begin{array}{l}-27.89 \\
-65.33 \\
978990.13 \\
503.34 \\
\end{array}$ & $\begin{array}{l}0.50 \\
0.46 \\
121.18 \\
388.38 \\
\end{array}$ \\
\hline $\begin{array}{l}\text { Argentinean Institute of } \\
\text { Oceanography (IADO) }\end{array}$ & $2757 \mathrm{pts}$ & $\begin{array}{l}\text { latitude } \\
\text { longitude } \\
\text { g IGSN71 } \\
\text { height }\end{array}$ & $\begin{array}{l}\text { [degree] } \\
{[\mathrm{mGal}]} \\
{[\mathrm{m}]}\end{array}$ & $\begin{array}{l}-40.64 \\
-64.00 \\
979690.58 \\
-42.30 \\
\end{array}$ & $\begin{array}{l}-35.00 \\
-56.84 \\
980225.85 \\
516.22 \\
\end{array}$ & $\begin{array}{l}-37.92 \\
-61.25 \\
979955.52 \\
130.31 \\
\end{array}$ & $\begin{array}{l}1.09 \\
1.82 \\
101.54 \\
87.71 \\
\end{array}$ \\
\hline $\begin{array}{l}\text { Gravity Department, } \\
\text { University of } \\
\text { La Plata (UNLP) }\end{array}$ & $2466 \mathrm{pts}$ & $\begin{array}{l}\text { latitude } \\
\text { longitude } \\
\text { g IGSN71 } \\
\text { height } \\
\end{array}$ & $\begin{array}{l}\text { [degree }] \\
{[\mathrm{mGal}]} \\
{[\mathrm{m}]}\end{array}$ & $\begin{array}{l}-54.81 \\
-71.47 \\
977645.33 \\
-38.33 \\
\end{array}$ & $\begin{array}{l}-22.24 \\
-56.68 \\
981469.07 \\
4220.29 \\
\end{array}$ & $\begin{array}{l}-36.63 \\
-61.32 \\
979823.51 \\
211.53 \\
\end{array}$ & $\begin{array}{l}3.45 \\
2.88 \\
430.17 \\
660.16 \\
\end{array}$ \\
\hline $\begin{array}{l}\text { Gravity Department, } \\
\text { University of } \\
\text { La Plata (UNLP } \\
\& \text { (IADO) }\end{array}$ & 937 pts & $\begin{array}{l}\text { latitude } \\
\text { longitude } \\
\text { g IGSN71 } \\
\text { height } \\
\end{array}$ & $\begin{array}{l}\text { [degree }] \\
{[\mathrm{mGal}]} \\
{[\mathrm{m}]}\end{array}$ & $\begin{array}{l}-40.85 \\
-66.15 \\
-79845.46 \\
-68.10 \\
\end{array}$ & $\begin{array}{l}-37.10 \\
-58.77 \\
980238.66 \\
516.22 \\
\end{array}$ & $\begin{array}{l}-39.10 \\
-61.68 \\
980070.33 \\
47.98 \\
\end{array}$ & $\begin{array}{l}0.80 \\
1.60 \\
80.84 \\
68.59 \\
\end{array}$ \\
\hline $\begin{array}{l}\text { Institute of Physics } \\
\text { Rosario (IFIR) }\end{array}$ & $1234 \mathrm{pts}$ & $\begin{array}{l}\text { latitude } \\
\text { longitude } \\
\text { g IGSN71 } \\
\text { height } \\
\end{array}$ & $\begin{array}{l}\text { [degree] } \\
{[\mathrm{mGal}]} \\
{[\mathrm{m}]}\end{array}$ & $\begin{array}{l}-51.65 \\
-73.30 \\
977645.33 \\
4.60 \\
\end{array}$ & $\begin{array}{l}-24.12 \\
-61.76 \\
981192.97 \\
4220.29 \\
\end{array}$ & $\begin{array}{l}-35.91 \\
-67.87 \\
979543.54 \\
963.43 \\
\end{array}$ & $\begin{array}{l}8.25 \\
2.81 \\
900.82 \\
977.54 \\
\end{array}$ \\
\hline Antarctic Institute & 207 pts & $\begin{array}{l}\text { latitude } \\
\text { longitude } \\
\text { g IGSN71 } \\
\text { height }\end{array}$ & $\begin{array}{l}\text { [degree] } \\
{[\mathrm{mGal}]} \\
{[\mathrm{m}]}\end{array}$ & $\begin{array}{l}-52.12 \\
-70.75 \\
981122.64 \\
13.72 \\
\end{array}$ & $\begin{array}{l}-51.48 \\
-69.07 \\
981212.73 \\
204.20 \\
\end{array}$ & $\begin{array}{l}-51.86 \\
-69.88 \\
981174.88 \\
116.29 \\
\end{array}$ & $\begin{array}{l}0.17 \\
0.48 \\
21.27 \\
45.01 \\
\end{array}$ \\
\hline Chile & 2011 pts & $\begin{array}{l}\text { latitude } \\
\text { longitude } \\
\text { g IGSN71 } \\
\text { height }\end{array}$ & $\begin{array}{l}\text { [degree }] \\
{[\mathrm{mGal}]} \\
{[\mathrm{m}]}\end{array}$ & $\begin{array}{l}-47.61 \\
-73.84 \\
977236.91 \\
1.00\end{array}$ & $\begin{array}{l}-18.01 \\
-68.00 \\
980743.29 \\
4696.00\end{array}$ & $\begin{array}{l}-29.45 \\
-70.48 \\
978876.68 \\
1543.17\end{array}$ & $\begin{array}{l}7.51 \\
1.60 \\
924.79 \\
1401.27\end{array}$ \\
\hline $\begin{array}{l}\text { University of Buenos } \\
\text { Aires (UBA) }\end{array}$ & $474 \mathrm{pts}$ & $\begin{array}{l}\text { latitude } \\
\text { longitude } \\
\text { g IGSN71 } \\
\text { height } \\
\end{array}$ & $\begin{array}{l}\text { [degree }] \\
{[\mathrm{mGal}]} \\
{[\mathrm{m}]}\end{array}$ & $\begin{array}{l}-54.82 \\
-71.70 \\
978483.97 \\
0.00 \\
\end{array}$ & $\begin{array}{l}-22.17 \\
-57.65 \\
981464.04 \\
3193.53 \\
\end{array}$ & $\begin{array}{l}-35.65 \\
-65.73 \\
979640.79 \\
567.08 \\
\end{array}$ & $\begin{array}{l}8.65 \\
3.23 \\
821.05 \\
717.31 \\
\end{array}$ \\
\hline $\begin{array}{l}\text { Military Geographic } \\
\text { Institute (IGM) }\end{array}$ & $13442 \mathrm{pts}$ & $\begin{array}{l}\text { latitude } \\
\text { longitude } \\
\text { g IGSN71 } \\
\text { height } \\
\end{array}$ & $\begin{array}{l}\text { [degree] } \\
{[\mathrm{mGal}]} \\
{[\mathrm{m}]}\end{array}$ & $\begin{array}{l}-54.79 \\
-72.86 \\
978099.94 \\
1.80 \\
\end{array}$ & $\begin{array}{l}-22.10 \\
-53.65 \\
981467.92 \\
3849.73 \\
\end{array}$ & $\begin{array}{l}-34.66 \\
-63.77 \\
979625.32 \\
335.60 \\
\end{array}$ & $\begin{array}{l}6.21 \\
3.93 \\
539.37 \\
428.38 \\
\end{array}$ \\
\hline $\begin{array}{l}\text { Escola Politecnica da } \\
\text { Universidade de Sao } \\
\text { Paulo (ESUSP) }\end{array}$ & 50527 pts & $\begin{array}{l}\text { latitude } \\
\text { longitude } \\
\text { g IGSN71 } \\
\text { height } \\
\end{array}$ & $\begin{array}{l}\text { [degree }] \\
{[\mathrm{mGal}]} \\
{[\mathrm{m}]}\end{array}$ & $\begin{array}{l}-53.36 \\
-74.97 \\
977310.00 \\
0.00 \\
\end{array}$ & $\begin{array}{l}-21.00 \\
-53.00 \\
981337.79 \\
6204.00 \\
\end{array}$ & $\begin{array}{l}-27.85 \\
-62.70 \\
978910.97 \\
939.35 \\
\end{array}$ & $\begin{array}{l}6.53 \\
5.81 \\
733.53 \\
1269.18 \\
\end{array}$ \\
\hline $\begin{array}{l}\text { Argentinean Institute of } \\
\text { Oceanography (IADO) }\end{array}$ & $1617 \mathrm{pts}$ & $\begin{array}{l}\text { latitude } \\
\text { longitude } \\
\text { g IGSN71 } \\
\text { height }\end{array}$ & $\begin{array}{l}\text { [degree }] \\
{[\mathrm{mGal}]} \\
{[\mathrm{m}]}\end{array}$ & $\begin{array}{l}-39.00 \\
-68.41 \\
979518.87 \\
-20.90\end{array}$ & $\begin{array}{l}-35.01 \\
-63.37 \\
980050.37 \\
1099.00 \\
\end{array}$ & $\begin{array}{l}-37.31 \\
-65.22 \\
979855.90 \\
245.09\end{array}$ & $\begin{array}{l}1.05 \\
1.31 \\
109.38 \\
147.51\end{array}$ \\
\hline
\end{tabular}




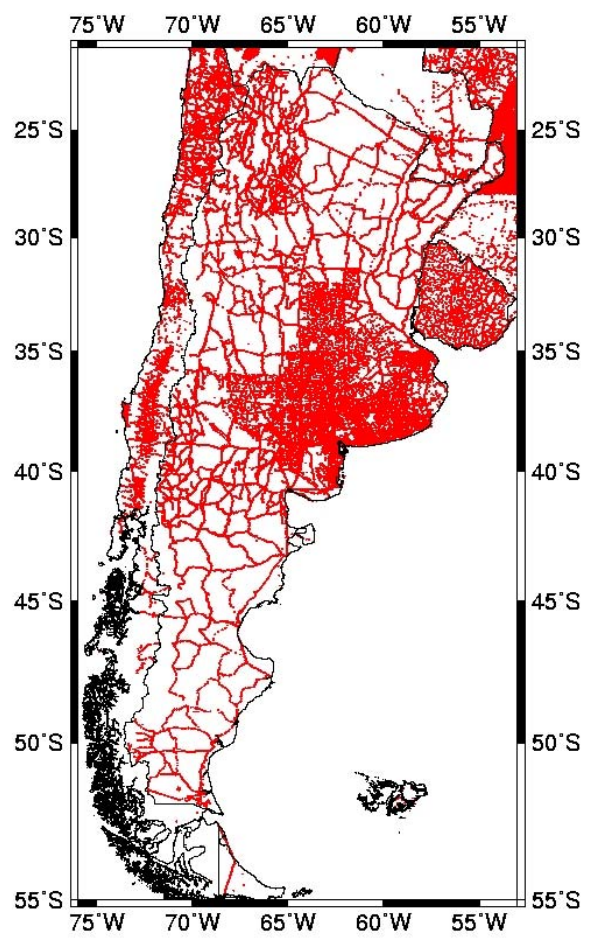

Figure 4.1: Distribution of land gravity data

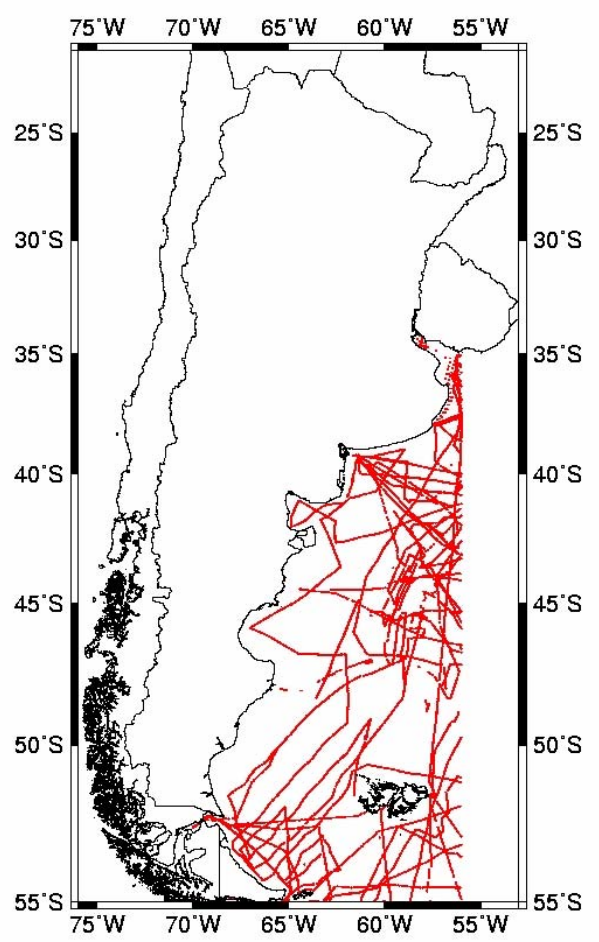

Figure 4.2: Distribution of shipborne gravity data

\subsubsection{Shipborne marine gravity database}

The shipborne data around Argentina was provided by the International Gravimetric Bureau (personal communication). The sea data records include: source number, coordinates (latitude and longitude), accuracy of position, system position, type of observation, elevation of the station, elevation type, accuracy of elevation, determination of the elevation, supplemental elevation, observed gravity in microgal, free-air gravity anomalies, Bouguer gravity anomalies, estimate of the standard deviation of the free-air gravity anomalies and Bouguer gravity anomalies, terrain corrections, information about terrain corrections, density used for terrain corrections, accuracy of gravity, correction of observed gravity, date of the observation, velocity of the ship, Eötvos correction, country code, confidentiality, validity, original number of the station, sequence number, leg number, reference station and a number. For more 
details in the sea data format record description, BGI (International Gravimetric Bureau) should be contacted.

The marine gravity database contains a total of 17352 shipborne gravity observations in an area limited between latitudes $21^{\circ} \mathrm{S}$ to $55^{\circ} \mathrm{S}$ and between longitudes $55^{\circ} \mathrm{W}\left(304^{\circ} \mathrm{E}\right)$ to $70^{\circ} \mathrm{W}\left(290^{\circ} \mathrm{E}\right)$. The distribution of the shipborne gravity observation can be seen in Figure 4.2.

\subsubsection{Satellite altimetry derived gravity anomalies}

The sparse shipborne gravity distribution around Argentina can deteriorate the geoid accuracy near the coast. Therefore, gravity anomalies derived from altimetry can be very useful to improve the poorer marine gravity coverage and thus improve the quality and accuracy of the geoid.

Different altimetry-derived global gravity anomaly datasets are tested to fill in the sparse coverage of shipborne gravity measurements offshore Argentina. The evaluation of these global models in the area under study will be presented in the next section.

During the past twenty years all marine areas have been covered. There are several techniques to compute gravity anomalies from satellite altimetry

\subsubsection{Satellite altimetry gravity anomaly grids}

The satellite altimetry gravity grids available in the area under study are:

\section{- CLS_SHOM v.99 Free-air gravity anomaly field}

Free-Air Gravity anomaly field CLS SHOM99 has been developed by CLS (Collecte, Localization, Satellites) under a contract from SHOM (Service Hydrographique et Océanographique de la Marine). The free-air gravity anomalies have been estimated using a 3-year TOPEX/POSEIDON, a 2-year ERS1, a 2-year GEOSAT and the 2 168day non repeat cycle data sets of the ERS1 geodetic phase. All these data sets have been preprocessed in order to be more homogeneous and referenced to the 3-year T/P and also to be less contaminated by the ocean topography variable signal. A mean dynamic topography model has also been subtracted from the altimetric heights. This model is 
based on the Levitus climatology (Levitus, 1994). The free-air gravity surface has been estimated on a grid of 2-minute by 2-minute resolution using a local inverse method, which also provides an estimation error field. This global model is computed between 0.0 and 360 degrees in longitude and between 82 and -82 degrees in latitude. The freeair gravity anomaly is referenced to the TOPEX/POSEIDON Earth ellipsoid on the TOPEX/POSEIDON frame $(\mathrm{a}=6378136.3 \mathrm{~m} ; 1 / \mathrm{f}=298.257$ and $\mathrm{GM}=398600.4415$ $\mathrm{km}^{3} / \mathrm{s}^{2}$ ). For more information, please see Hernandez and Schaeffer (2000).

\section{- KMS01 and KMS02}

KMS01 and KMS02 are the newest release of the KMS Global marine free air gravity field, computed from ERS1 and GEOSAT satellite altimetry. Data from the geodetic missions of ERS and GEOSAT have been used, as well as from the Exact Repeat Mission (ERM) ERM60-63 of ERS2. The ERS ERM data (repeat 1-85) from the NASA Pathfinder project have also been used to ensure complete coverage in arctic and antarctic regions (Andersen et al., 1998; Andersen et al., 2005). KMS grids are 2 arcminute by 2-arc minute gravity grids and they have been computed via conversion of marine geoid heights using the inverse Stokes formula.

\section{- $\quad$ Sandwell v9.2}

It is a grid of gravity anomalies converted from GEOSAT and ERS1 satellite altimetry. Gravity anomalies are constructed from grids of east and north deflections of the vertical using Fourier analysis. Gravity anomalies are computed after a grid of east and north vertical deflections were built from satellite profiles of geoid heights by the integration of Lap lace's equation using FFT. The version 9.2 is available on 1 or 2 arcminute grids; we used the 2 arc-minute by 2 arc-minute grid to have the same grid spacing of the other available grids. More information can be found in the web page, http://topex.ucsd.edu/marine_grav/mar_grav.html.

\section{- GSFC00.1 Marine Gravity Anomaly}

The altimetric gravity anomaly GSFC00.1_DG produced by the Goddard Space Flight Center was computed from GSFC00.1_MSS in 2 arc-minute by 2 arc-minute grid by numerical evaluation of the inverse Stokes integral. GSFC00.1_MSS is a mean sea surface model in 2 arc-minute by 2 arc-minute grid size between latitude $80^{\circ} \mathrm{S}$ to $80^{\circ} \mathrm{N}$. 
It was computed by combining satellite altimeter data from many missions. The data used are: 6-years of T/P data (Cycles 11 to 232), multi-years of ERS1/2 35-day repeat cycle (ERS1 Phase C: Cycles 1 to 18; Phase G: Cycle 1 to 13; ERS2: Cycle 1 to 29); GEOSAT ERM (exact repeat mission, Cycle 1 to 41); GEOSAT GM and ERS1 168day data. The reference frame is: $\mathrm{a}=6378136.3 \mathrm{~m} ; \mathrm{f}=1 / 298.257$; Potential $=62636858.702 \mathrm{~m}^{2} / \mathrm{s}^{2}$ and $\mathrm{GM}=398600.4415 \mathrm{~km}^{3} / \mathrm{s}^{2}$. For more details on the data used and the methodology of mean sea surface computation, see Wang (2001).

\subsubsection{Digital Elevations Models}

Digital elevation models (DEMs) are an important source of data for the gravimetric geoid computation. Two DEMs are available for this research: GTOPO30 and GLOBE.

\section{- GTOPO30}

GTOPO30 is a global digital elevation model (DEM). It was developed by the US. Geological Survey's Earth Resources Observation Systems (EROS) Data Center (EDC) and it was completed in 1996. Elevations in GTOPO30 are regularly spaced at 30-arc seconds (approximately 1 kilometer). GTOPO30 is a global data set covering the full extent of latitude from 90 degrees South to 90 degrees North, and the full extent of longitude from 180 degrees West to 180 degrees East. The horizontal coordinate system is decimal degrees of latitude and longitude referenced to the World Geodetic System 84 (WGS84). The vertical units represent elevation in meters above mean sea level.

A rectangular subgrid was extracted over the study area where the elevation values range from 1 to 6,725 meters with a mean value of 701 meters and a standard deviation of 1056.2 meters. There is no data over ocean areas. The GTOPO30 DEM for Argentina can be seen in Figure 4.3.

\section{- Global Land One-Kilometer Base Elevation (GLOBE)}

The Global Land One-Kilometer Base Elevation (GLOBE) digital elevation model (DEM) was released by the National Oceanic and Atmospheric Administration, NOAA's National Geophysical Data Center (NGDC). GLOBE is a global data set covering 180 degrees West to 180 degrees East longitude and 90 degrees North to 90 
degrees South latitude. The horizontal grid spacing is 30 arc-seconds (about $1 \mathrm{~km}$ ) in latitude and longitude. The horizontal coordinate system is seconds of latitude and longitude is referenced to the World Geodetic System 84 (WGS84). The vertical units represent elevation in meters above Mean Sea Level (MSL). More information can be found in the following web page: http:/www.ngdc.noaaa.gov/mgg/topo/globe.html.

A rectangular subgrid was extracted over the study area where the elevation values range from -127 to 6798 meters, with a mean value of 701 meters and a standard deviation of 1055.79 meters. There is no data over ocean areas. The GLOBE DEM is illustrated in Figure 4.4.

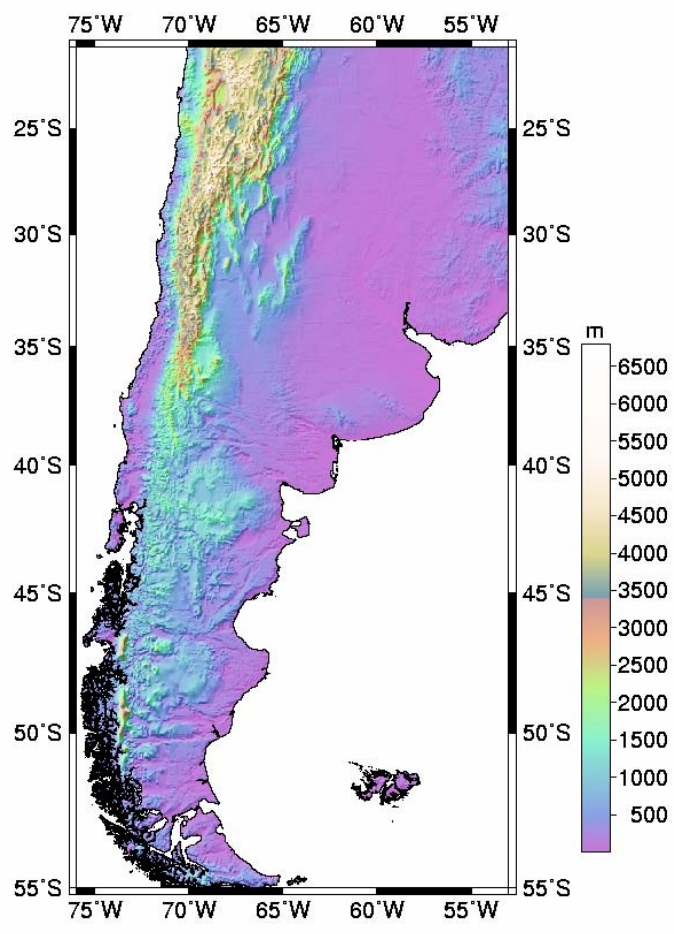

Figure 4.3: GTOPO30 DEM in Argentina

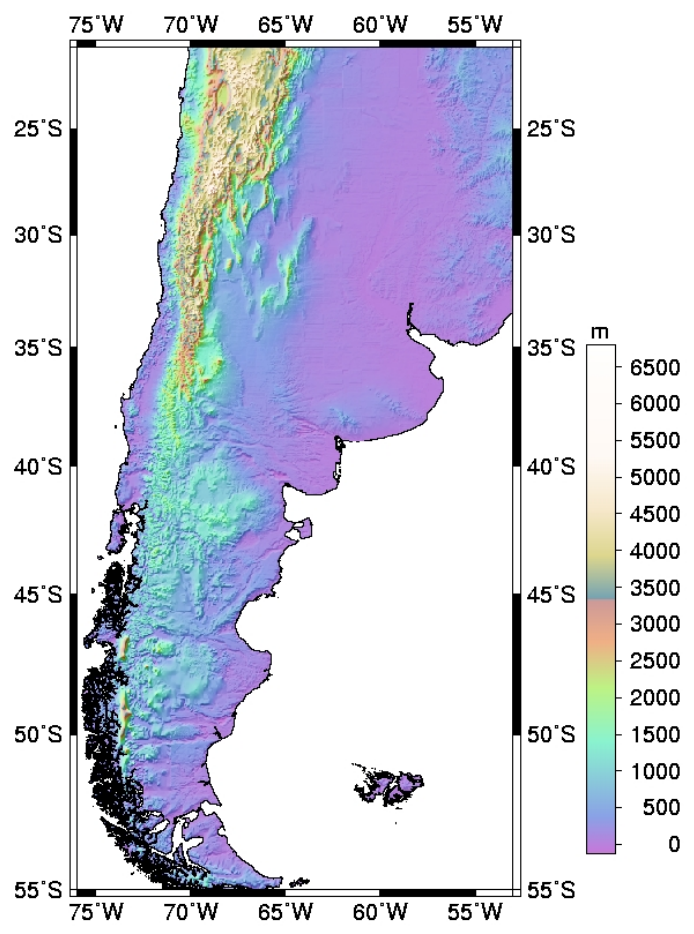

Figure 4.4: GLOBE DEM in Argentina

\subsubsection{Evaluation of Digital Elevation Models}

Comparisons between the gridded height data from both DEMs and point height of the gravity stations have been made. Both types of heights are used in the geoid computation. DEM data are used, for example, for the computation of terrain correction or indirect effects and the height of the gravity station is used to compute point gravity 
anomalies. One of the roughest areas in Argentina, limited by latitudes $32^{\circ} \mathrm{S}$ to $42^{\circ} \mathrm{S}$ and longitudes $72^{\circ} \mathrm{W}$ to $68^{\circ} \mathrm{W}$, was selected to perform these comparisons. From GTOPO30 and GLOBE DEMs, heights at 1452 gravity stations were interpolated using bilinear interpolation and the differences of both types of heights as well of the histograms of these differences were made.

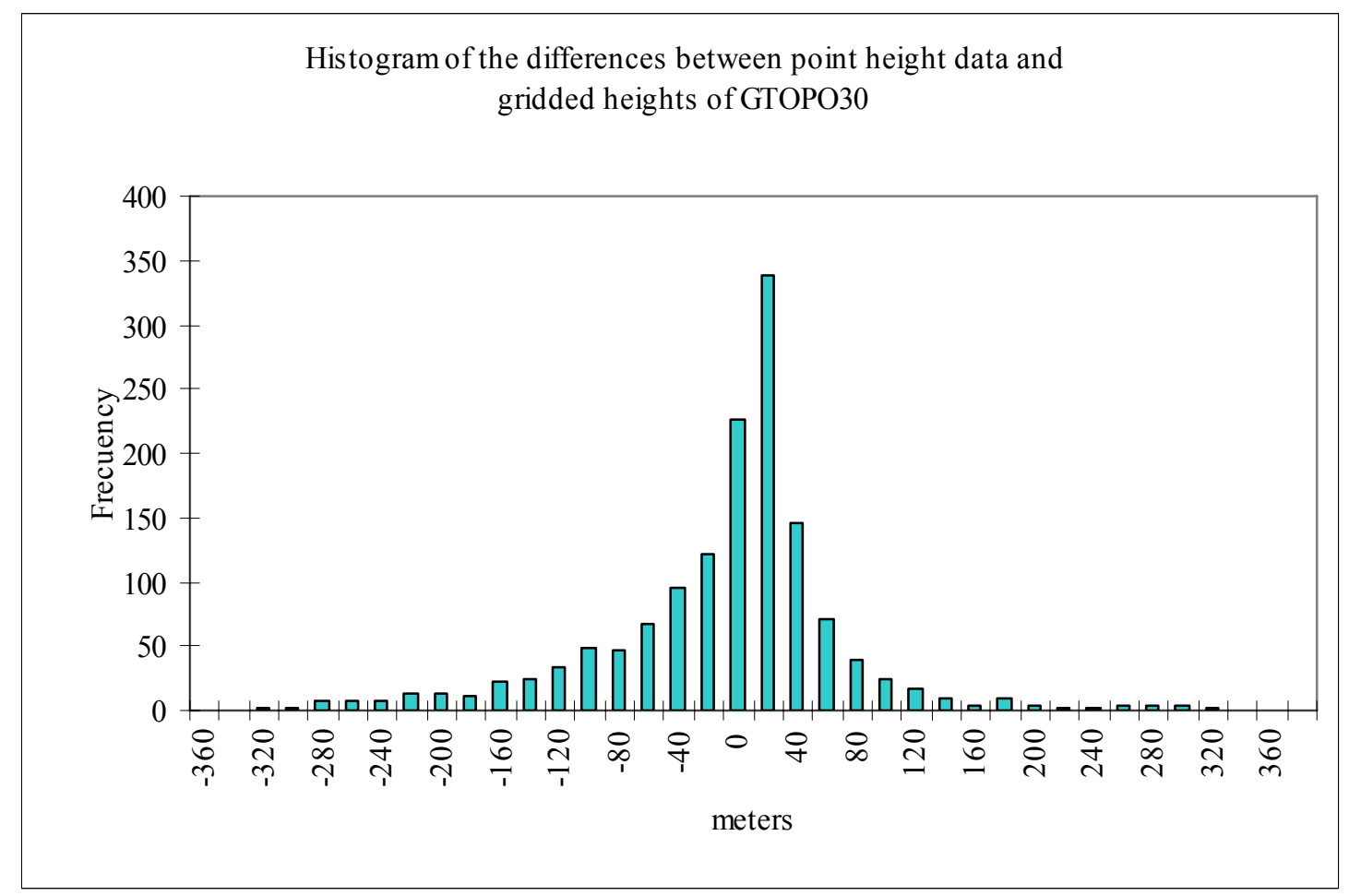

Figure 4.5: Histogram of the differences between heights at 1452 gravity stations and heights linearly interpolated from GTOPO30

The histogram shown in Figure 4.5 presents the maximum towards positive values; an asymmetric distribution; and a large number of negative differences, which can be reflected, in a negative median (-2.409 meters).

The histogram shown in Figure 4.6 presents, like the GTOPO30 DEM, the maximum towards positive values; an asymmetric distribution; and a large number of negative differences, which can be reflected, in a negative median (-4.746 meters).

We can conclude that, in this test, there are no significant differences between the two DEMs. GTOPO30 has a standard deviation $79.723 \mathrm{~m}$; a mean value of $-18.299 \mathrm{~m}$; and a median of $-2.409 \mathrm{~m}$. GLOBE has a standard deviation $79.835 \mathrm{~m}$; a mean value of $20.241 \mathrm{~m}$; and a median of $-4.746 \mathrm{~m}$. From these results, GTOPO30 DEM seem to have 
a slightly better agreement with existing point heights, therefore it will be used throughout this research.

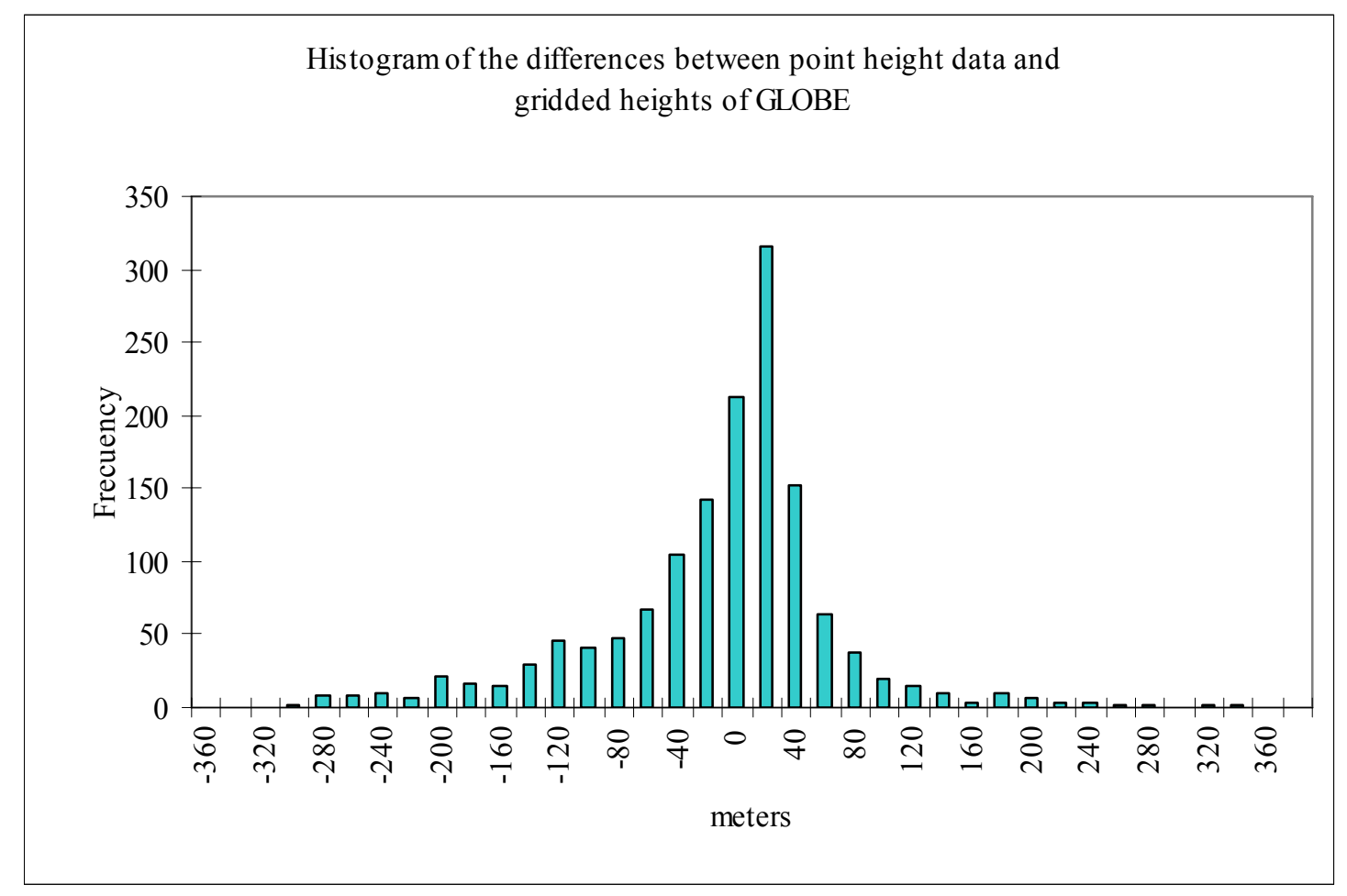

Figure 4.6: Histogram of the differences between heights at 1452 gravity stations and heights linearly interpolated from GLOBE

Digital elevation models are very important in geoid determination but they area one of the most significant limitations of the geoid accuracy due to poor data quality and computational approximations (Smith and Roman, 2000). Most of the gravity stations used in this research have been measured on the high precision levelling network. In rough areas, the influence of the topographic masses near the gravity stations is very important and a more detailed grid of elevations will be necessary for further investigations.

\subsubsection{Digital Depth Model}

The topographic/bathymetric data used, for example, for the RTM reduction in the marine geoid determination were those of the Smith and Sandwell model (Smith and Sandwell, 1997), which were derived from altimetry. Sandwell and Smith have 
computed a global marine gravity field by processing satellite altimetry data, and the topography (bathymetry) of the seafloor has been predicted from the gravity data. The statistics of the sea floor topography can be seen in Table 4.2 and the map of the bathymetry in the area under study is depicted in Figure 4.7.

Table 4.2: Seafloor topography in the area under study. Unit: [m].

\begin{tabular}{l|cccc}
\hline & $\min$ & $\max$ & $\operatorname{mean}$ & $\sigma$ \\
\hline DDM (Sandwell and Smith, 1997) & -8057 & 588 & -1850.99 & 2025.68 \\
\hline
\end{tabular}

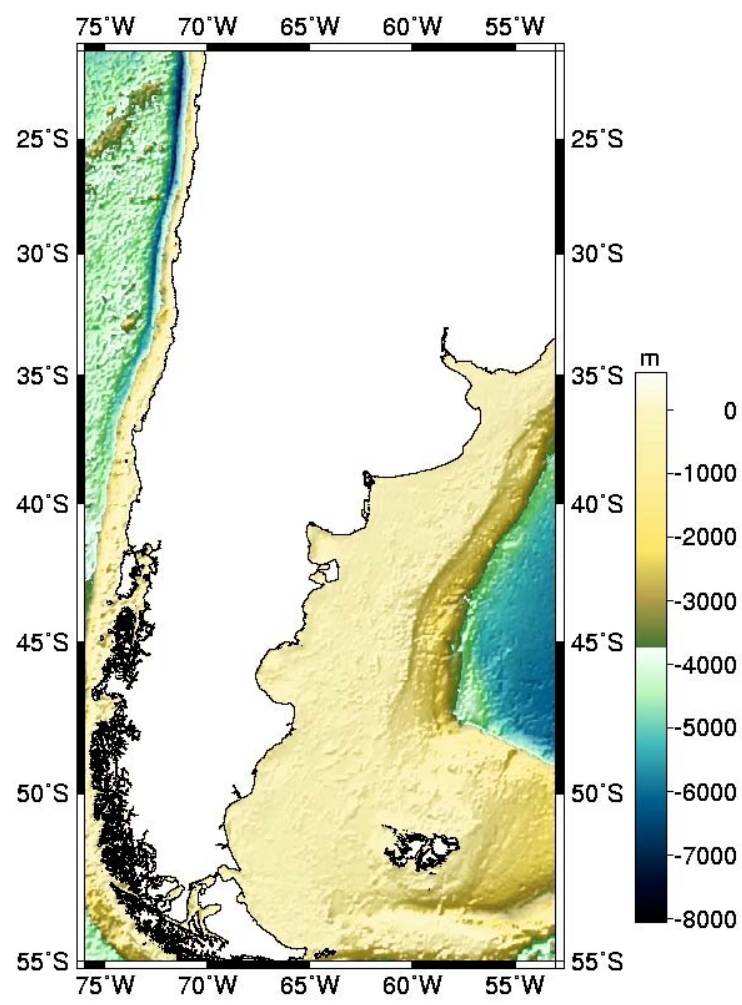

Figure 4.7: Seafloor topography in the area under study (Sandwell and Smith, 1997)

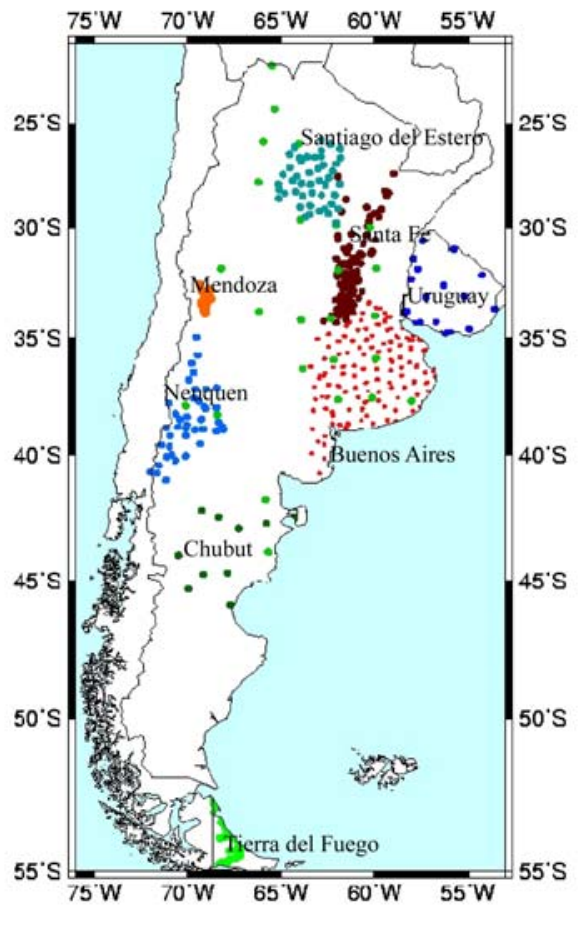

Figure 4.8: Distribution of GPS/levelling points

\subsubsection{GPS/levelling networks}

The accuracy of the gravimetric geoid undulations can be evaluated by two methods: one is the external comparison with geometrical geoid undulations from GPS and spirit levelling and the other is the internal propagation of data errors. For the first method, points with GPS-derived ellipsoidal heights and orthometric heights with respect to a 
local datum constitute an important type of data to be incorporated in the database in order to determine discrete precise geoid undulations by the geometrical approach.

Geometrical geoid undulation on land can be determined, for the absolute and relative cases (height differences between two points $\mathrm{i}$ and $\mathrm{j}$ ), by:

$$
\begin{aligned}
& \mathrm{N}^{\mathrm{GPS}}=\mathrm{h}_{\mathrm{e}}-\mathrm{H} \\
& \mathrm{N}_{\mathrm{j}}{ }^{\mathrm{GPS}}-\mathrm{N}_{\mathrm{i}}{ }^{\mathrm{GPS}}=\left(\mathrm{h}_{\mathrm{ej}}-\mathrm{h}_{\mathrm{ei}}\right)-\left(\mathrm{H}_{\mathrm{j}}-\mathrm{H}_{\mathrm{i}}\right) \Rightarrow \Delta \mathrm{N}^{\mathrm{GPS}}=\Delta \mathrm{h}_{\mathrm{e}}-\Delta \mathrm{H}
\end{aligned}
$$

where $h_{e}$ is the ellipsoidal height from GPS and H is the orthometric height. However, the use of the relationship (4.1) has some limitations due to systematic and random errors in the derived heights $h_{e}$ and $H$. There are systematic and gross errors in levelling, especially at higher altitudes. Levelling points are often difficult to access and they are sometimes covered by vegetation or destroyed. Other limitations are: datum inconsistencies ( $h_{e}$ and $H$ refer to different reference surfaces); assumptions and theoretical approximations made in the normal/orthometric correction; the effect of not taking into account the differences between the ellipsoidal normal and the plumb line (deflection of the vertical) which can cause an error in the geometric geoid determination (Zhang, 1997). Geometrical geoid cannot be derived at sea, so interpolation is difficult near the coast. The geometrical geoid can be derived with a very high relative and absolute accuracy but one of the main disadvantages is its poor resolution.

The errors that affect the accuracy of the ellipsoidal heights are originated from three sources: satellite or orbit errors, signal propagation and receiver errors (Fotopoulos, 2003). Some of these errors are: atmospheric effects produced by the ionosphere and troposphere, the Earth body tides, the ocean tides, the atmospheric loading, orbital errors of the GPS satellites, the antenna phase centre, set-up effects of the antenna, and multipath effects.

GPS/benchmark height information on 744 points across Argentina has been collected from different institutions since 1999. This data includes latitude and longitude, ellipsoidal heights and levelling heights. The ellipsoidal heights are referred to the POSGAR 1994 (POSiciones Geodesicas ARgentinas) datum, except for the Chubut network, and the levelling data correspond to the existing high precision levelling of 
Argentina. POSGAR 94 is Argentina's official geodetic system and it was established through GPS measurements to realize the WGS84 reference system in the country.

Nine GPS/levelling networks will be used for the external evaluation of the gravimetric geoid accuracy. The nine networks are located in the provinces of Mendoza (Lenzano, 2001), Santa Fe (Rodriguez et al., 1999), Neuquén (Querejeta, 2001), Buenos Aires (Perdomo and Del Cogliano, 1999), Santiago del Estero (Goldar, 2001), Tierra del Fuego (Perdomo and Hormaechea, 1999) and Chubut (Orellano, 2002), one is in Uruguay (Subiza, 1999) and another one is the PosgAR network. These GPS networks are located in different topographies. The distribution of GPS/levelling points in Argentina is shown in Figure 4.8. Information about the GPS networks is summarized in Table 4.3.

Table 4.3: Statistics of the ten GPS networks in Argentina.

\begin{tabular}{|c|c|c|c|c|c|c|}
\hline Area & $\begin{array}{l}N^{\circ} \text { of } \\
\text { points }\end{array}$ & \multicolumn{2}{|c|}{$\begin{array}{c}\text { Latitude } \\
\text { range }\end{array}$} & \multicolumn{2}{|c|}{$\begin{array}{c}\text { Longitude } \\
\text { range }\end{array}$} & Reference \\
\hline PosgAR94 & 27 & $22.1538 \mathrm{~S}^{\circ}$ & $43.9094 \mathrm{~S}^{\circ}$ & $58.0092^{\circ} \mathrm{W}$ & $70.0816^{\circ} \mathrm{W}$ & IGM \\
\hline Buenos Aires & 180 & $33.4196 \mathrm{~S}^{\circ}$ & $40.7799 \mathrm{~S}^{\circ}$ & $56.6775^{\circ} \mathrm{W}$ & $63.4417^{\circ} \mathrm{W}$ & $\begin{array}{l}\text { (Perdomo et } \\
\text { al., 1999) }\end{array}$ \\
\hline Mendoza & 116 & $32.5888 \mathrm{~S}^{\circ}$ & $33.9481 \mathrm{~S}^{\circ}$ & $68.6833^{\circ} \mathrm{W}$ & $69.3586^{\circ} \mathrm{W}$ & $\begin{array}{l}\text { (Lenzano et } \\
\text { al., } \\
2001)\end{array}$ \\
\hline & 139 & $32.5906 \mathrm{~S}^{\circ}$ & $35.4794 \mathrm{~S}^{\circ}$ & $67.5097^{\circ} \mathrm{W}$ & $69.5891^{\circ} \mathrm{W}$ & \\
\hline Neuquén & 48 & $34.9635 \mathrm{~S}^{\circ}$ & $41.0514 \mathrm{~S}^{\circ}$ & $68.0541^{\circ} \mathrm{W}$ & $71.9435^{\circ} \mathrm{W}$ & $\begin{array}{l}\text { (Querejeta, } \\
\text { 2001) }\end{array}$ \\
\hline Santa Fe & 93 & $27.450 \mathrm{~S}^{\circ}$ & $34.319 \mathrm{~S}^{\circ}$ & $58.987^{\circ} \mathrm{W}$ & $62.731^{\circ} \mathrm{W}$ & $\begin{array}{l}\text { (Rodríguez et } \\
\text { al., 1999) }\end{array}$ \\
\hline Santiago del Estero & 47 & $25.8041 \mathrm{~S}^{\circ}$ & $29.7635 \mathrm{~S}^{\circ}$ & $61.8179^{\circ} \mathrm{W}$ & $65.1606^{\circ} \mathrm{W}$ & (Goldar, 2001) \\
\hline Tierra del Fuego & 56 & $52.6591 \mathrm{~S}^{\circ}$ & $54.8076 \mathrm{~S}^{\circ}$ & $67.1903^{\circ} \mathrm{W}$ & $68.6064^{\circ} \mathrm{W}$ & $\begin{array}{l}\text { (Perdomo et } \\
\text { al., 1999) }\end{array}$ \\
\hline Chubut & 10 & $42.2745 \mathrm{~S}^{\circ}$ & $45.8938 \mathrm{~S}^{\circ}$ & $64.2636^{\circ} \mathrm{W}$ & $70.4439^{\circ} \mathrm{W}$ & $\begin{array}{l}\text { (Orellano, } \\
2002)\end{array}$ \\
\hline Uruguay & 28 & $30.5982 \mathrm{~S}^{\circ}$ & $34.8883 \mathrm{~S}^{\circ}$ & $53.5808^{\circ} \mathrm{W}$ & $58.5140^{\circ} \mathrm{W}$ & Subiza 1999 \\
\hline All of Argentina & 744 & $22.1538 \mathrm{~S}^{\circ}$ & $54.8076 \mathrm{~S}^{\circ}$ & $53.5808^{\circ} \mathrm{W}$ & $71.9435^{\circ} \mathrm{W}$ & \\
\hline
\end{tabular}

Before all these GPS/levelling points are used for comparisons, it was necessary to clean the data (identify outliers and blunders). A 2D contour map of the geometric geoid was plotted and after a visual inspection test, a total of 192 points were identified as blunders and were eliminated from the original database. The 2D contour maps, before 
and after blunders removal, can be seen in Figures 4.9 and 4.10, respectively. The biggest discrepancy was found at a point of the PosgAR network where the difference between the GPS/leveling derived geoid and the geoid computed from EGM96 was $77.74 \mathrm{~m}$; two points were eliminated from the Neuquén network where the differences were of the order of 23 and 26 meters; in Santa Fe, only one point with 16 meters difference was eliminated; the complete set of points of Mendoza and the complete Santiago del Estero network where the differences were very doubtful were eliminated. The final GPS/levelling data in Argentina after the suspicious observations were removed consist of 552 GPS/levelling points.

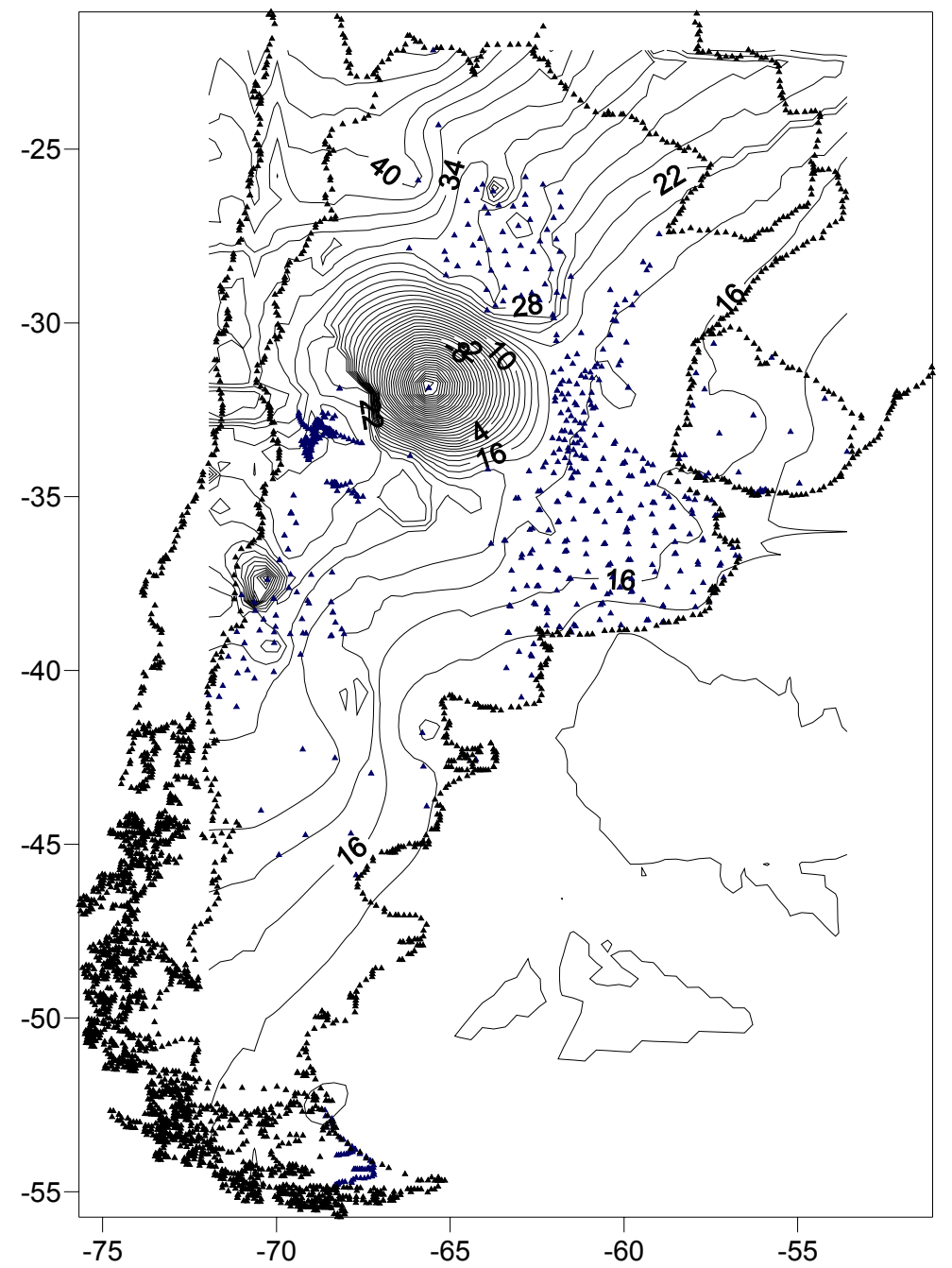

Figure 4.9: GPS/levelling-derived geoid (before blunders removal) 


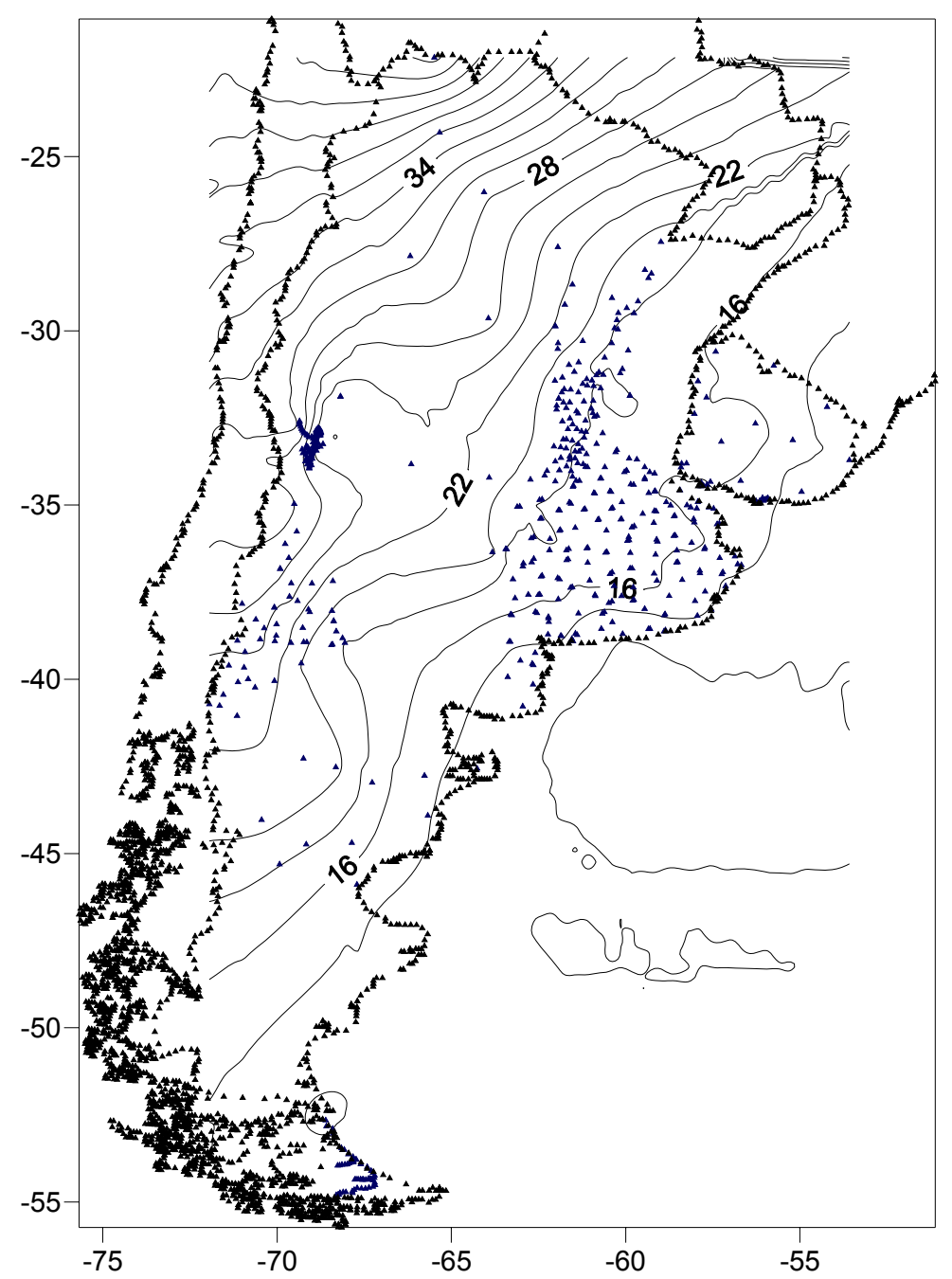

Figure 4.10: GPS/levelling-derived geoid (after blunders removal)

\subsubsection{Global Geopotential Models}

The gravimetric geoid of Argentina will be determined using the remove-computerestore technique where the use of a global geopotential model (GGM) plays an important role. Global geopotential models provide the long-wavelength structure of the

gravity field. They are based on spherical harmonics expansions and they are given as a set of coefficients. The analysis of satellite orbits can determine the low degree coefficients of the geopotential model while higher degrees can be obtained mainly from terrestrial gravity anomalies and satellite altimetry. 
The resolution of the gravity field parameters (e.g., gravity anomalies) computed from a geopotential model is related to its maximum degree and order $\mathrm{n}_{\max }$ and it can be calculated from the following formula:

$\operatorname{res}_{\mathrm{GGM}}=\frac{180^{\circ}}{\mathrm{n}_{\max }}$ in degrees

or by:

$\operatorname{res}_{\mathrm{GGM}}=\frac{20000 \mathrm{~km}}{\mathrm{n}_{\max }}$ in $\mathrm{km}$

The global geopotential models that are derived from only satellite observations are called satellite-only solutions. The first high degree geopotential model was developed to degree 180 for the first time in 1978 (Rapp, 1978). Since then, other models have been computed in 1981 (OSU81) (Rapp, 1981); in 1985 (GPM2) (Wenzel, 1985); in 1986 (OSU86) (Rapp and Cruz, 1986) completed to degree and order 360; in 1990 OSU89 (Rapp and Pavlis, 1990); in 1991 OSU91 (Rapp et al., 1991). In 1996, the Earth Gravity Model (EGM96), complete to degree and order 360 was computed as a National Aeronautics and Space Administration (NASA)/US National Imagery and Mapping Agency (NIMA), and OSU (Ohio State University) effort (Lemoine et al., 1998).

The ultra-high degree geopotential models (GPM98A and GPM98B) were developed to degree and order 1800 , which corresponds to nearly $11 \mathrm{~km}$ spatial resolution by Wenzel in 1998 (Wenzel, 1999).

EGM96 is a spherical harmonic model of the Earth's gravitational potential to degree 360 which incorporates improved surface gravity data, altimeter-derived anomalies from ERS1 and from the GEOSAT Geodetic Mission (GM), extensive satellite tracking data - including new data from Satellite Laser Ranging (SLR), the Global Positioning System (GPS), NASA's Tracking and Data Relay Satellite System (TDRSS), the French Doppler Orbitography and Radiolocation Integrated by Satellite (DORIS) system, and the US Navy TRANET Doppler tracking system - as well as direct altimeter ranges from TOPEX/POSEIDON (T/P), ERS1, and GEOSAT. The final solution blends a low- 
degree combination model to degree 70, a block-diagonal solution from degree 71 to 359 , and a quadrature solution at degree 360 . The model is used to compute geoid undulations globally accurate to better than one meter and realize WGS84 as a true three-dimensional reference system (Lemoine, 1998).

Several global geopotential models listed in Table 4.4 are available for this research.

Table 4.4: Global Geopotential Models available in this research.

\begin{tabular}{c|ccccc}
\hline Geopotential model & $n_{\max }$ & res $_{G G M}(\mathrm{~km})$ & res $_{G G M}(\mathrm{deg})$ & year & Reference \\
\hline GPM98A & 1800 & $\approx 11$ & 0.1 & 1998 & Wenzel (1998) \\
GPM98B & 1800 & $\approx 11$ & 0.1 & 1998 & Wenzel (1998) \\
GPM98CR & 720 & $\approx 28$ & 0.3 & 1998 & Wenzel (1998) \\
EGM96 & 360 & $\approx 55$ & 0.5 & 1996 & Lemoine et al.(1996) \\
OSU91A & 360 & $\approx 55$ & 0.5 & 1991 & Rapp et al. (1991) \\
GPM2 & 200 & $\approx 100$ & 0.9 & 1984 & Wenzel (1985) \\
OSU81 & 180 & $\approx 111$ & 1.0 & 1981 & Rapp (1981) \\
JGM3 & 70 & $\approx 286$ & 2.57 & 1996 & Tapley et.al. (1996) \\
\hline
\end{tabular}

From Table 4.4, we can see that the maximum degree of the geopotential models ranges from 70 to 1800 . It corresponds to a resolution of any gravity quantity computed from a spherical harmonic model of the Earth's gravitational potential between $\sim 11 \mathrm{~km}$ and $\sim 286 \mathrm{~km}$.

The high-resolution global gravity field model EIGEN-CG01C, complete to degree and order 360, was generated using CHAMP (860 days) and GRACE satellite gravity data combined with $0.5 \times 0.5$ degree surface data (gravimetry and altimetry). It was released to the public in October 29, 2004.

EIGEN-CG01C is a combination of 200 days of GRACE mission, 860 days of CHAMP data, and gravimetry and altimetry surface data. The 200 days of GRACE mission were during the months of April, May, August and November 2002 and April, May, August, October and November 2003. The 860 days of CHAMP data were from October 2000 to June 2003. The surface data used to develop the model are described in Reigber et al., (2005).

CHAMP (CHAllenging Minisatellite Payload) is a Gravity And Magnetic Field German satellite Mission. The CHAMP satellite was launched on July 15, 2000 into an 
almost circular, near polar $\left(i=87^{\circ}\right)$ orbit with an initial altitude of $454 \mathrm{~km}$. The design lifetime of the satellite system is 5 years. The Earth's gravity field recovery is the most important scientific objective of CHAMP for this thesis.

The GRACE (Gravity Recover and Climate Experiment) mission was launched in March of 2002. Since then, the GRACE mission is making detailed measurements of the Earth's gravity field. It has a 5-year lifetime. The GRACE mission has two identical spacecrafts flying about 220 kilometers apart in a polar orbit 500 kilometers above the Earth. GRACE is a joint partnership between the National Aeronautics and Space Administration (NASA) in the United States and Deutsche Forschungsanstalt für Luft und Raumfahrt (DLR) in Germany.

\subsubsection{Altimetric data}

\section{- ERS1 data}

The satellite altimetry data were 70510 CORSSHs measurements from the geodetic mission (GM) of the European Remote-Sensing Satellite 1 (ERS1), which are generated by the CLS Space Oceanography Division and provided by AVISO (Archiving, Validation and Interpretation of Satellite Oceanographic data). The ERS1 satellite's main mission is to observe the Earth, in particular its atmosphere and ocean. It was built by the European Space Agency (ESA) and it carried several instruments, including a radar altimeter. ERS1 was launched on July 1991, switched off in June 1996 and it was retired in March 2000. The cross-track spacing of ERS1-GM is about $8 \mathrm{~km}$. The distribution of the ERS1 tracks in the area under study is depicted in Figure 4.11.

\section{- TOPEX/POSEIDON data}

To assess the accuracy of all the marine geoid models computed through this thesis, we will compare them with stacked $3^{\text {rd }}$ year T/P SSHs.

The TOPEX/POSEIDON satellite was launched on 10 August 1992 with the objective of observing and understanding the ocean circulation. It was a joint project between NASA, the US space agency, and Centrale Nationale d' Etudes Speciales (CNES), the French space agency. It carries two radar altimeters and precise orbit determination systems, including the DORIS system. 
The TOPEX/POSEIDON Corrected Sea Surface Heights (CORSSH) are generated by the CLS Space Oceanography Division and distributed by AVISO. The $3{ }^{\text {rd }}$ year of the mission was extracted from the AVISO CORSSH GDRs and provided to us by George Vergos after the stacking of the T/P data was performed. The $3^{\text {rd }}$ year was selected for the comparisons in order to have a common observation period with the ERS1 data.The cross-track spacing of TOPEX/POSEIDON is about $330 \mathrm{~km}$. The stacked T/P tracks can be seen in Figure 4.12.

ERS1 and T/P CORSSHs are generated by AVISO as Geophysical Data Records (GDRs) after quality control, validation of altimetric data and geophysical corrections have been applied.

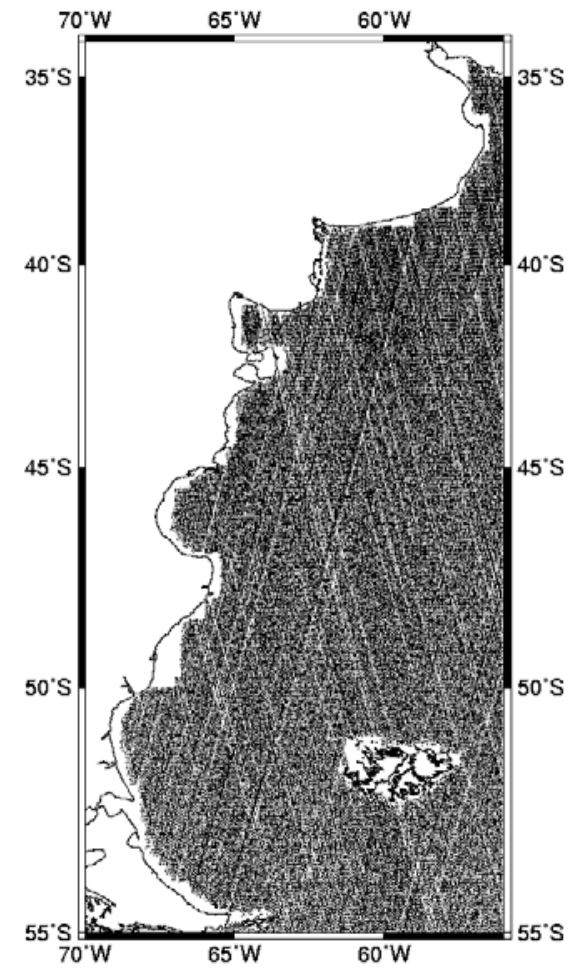

Figure 4.11: Distribution of ERS1-GM SSH

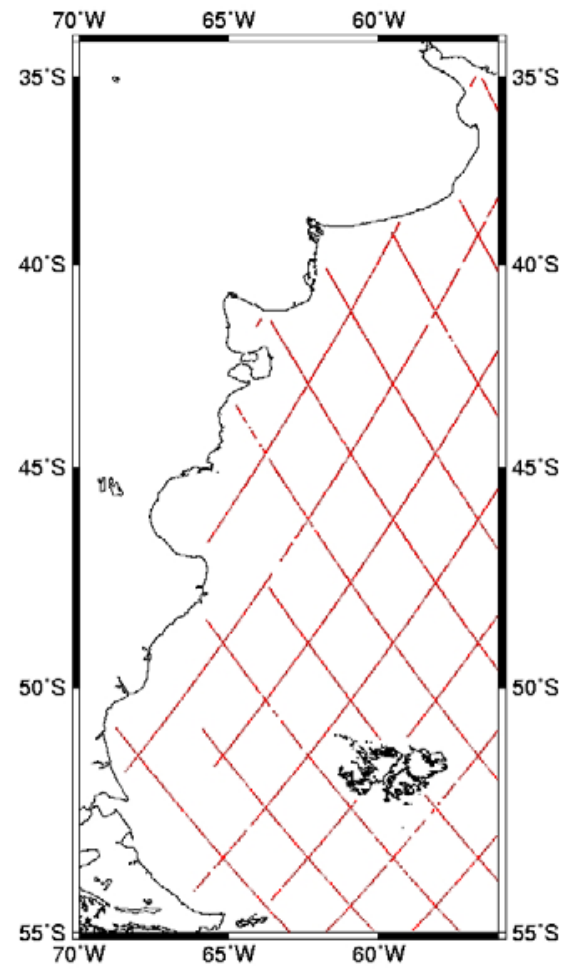

Figure 4.12: TOPEX/POSEIDON tracks

\subsubsection{Quasi Stationary Sea Surface Topography (QSST) models}

The EGM96 DOT model, which is a spherical harmonic expansion of the sea surface topography (SST), complete to degree and order 20 was used. It should be considered as a representation of the mean SST field for the time period that corresponds to TOPEX 
cycles 11 through 84 (December 31, 1992 to January 4, 1995). This estimate was derived from altimeter data from the aforementioned cycles of TOPEX, and altimeter data from ERS1 35-day repeat cycles 6, 8, 11, 14 and 17 (Lemoine et al., 1998). The model was derived during the simultaneous adjustment for the development of the EGM96 geopotential model.

\subsection{Data pre-processing, evaluation and validation}

Surface gravity measurements data have been collected from different universities and organizations. Major part of the gravimetric data in Argentina comes from the database of the Military Geographic Institute (IGM).

Since the point gravity measurements were provided by different sources, they first have to be homogenized. They were provided in different systems so they were unified to the International Gravity Standardization Net 1971 (IGSN71). IGSN71 was introduced by a resolution of the International Union of Geodesy and Geophysics (IUGG) in 1974.

The information given for each data point includes: latitude (degree), longitude (degree), height above sea level (m) and observed gravity (mGal).

Most of the gravity data were generally given in the Potsdam Gravity System established in 1909. The transformation of these values into IGSN71 is

$\mathrm{g}(\mathrm{IGSN71})=\mathrm{g}($ Potsdam $)-14.93 \mathrm{mGal}$

The horizontal geodetic coordinates were converted from the classic Geodetic System Campo Inchauspe 69 (CAI69), used in Argentina for many years, to the Geodetic Reference System 1980 (GRS80). The Geodetic Reference System 1980 has been adopted at the XVII General Assembly of the IUGG in Canberra, December 1979 (Moritz, 2000).

\subsubsection{Gravity reduction and gravity anomaly}

The gravity anomaly $\Delta \mathrm{g}$ is defined as: 
$\Delta \mathrm{g}_{\mathrm{P}}=\mathrm{g}_{\mathrm{P}}-\gamma$

where $\mathrm{P}$ is on the geoid (Stokes's approach) or on the topography (Molodensky's approach) and $\gamma$ is the normal gravity on the ellipsoid $\left(\gamma_{\mathrm{Q}_{0}}\right)$ or on the telluroid $\left(\gamma_{\mathrm{Q}}\right)$, respectively.

The point free-air gravity anomalies used in the classical boundary value problem are computed with equation (2.30), where the gravity on the geoid is computed from the measured gravity (usually measured at the topographic surface) using the actual gradient of gravity and the orthometric height of the point above the geoid. We will refer to these anomalies as the classical free-air anomalies. If $\mathrm{P}$ is on the topographic surface (Molodensky boundary value problem) the free-air gravity anomalies are computed using equation (2.97) where the normal gravity evaluated by equation (2.96) using the normal height $\mathrm{H}^{*}$ is subtracted from the surface gravity. The resulting anomalies are the surface free-air gravity anomalies.

For numerical computations, the classical free-air anomalies can be computed (Featherstone and Denith, 1998) from:

$\Delta \mathrm{g}_{\mathrm{FA}}=\mathrm{g}-0.3086 \mathrm{~h}+0.7210^{-6} \mathrm{~h}^{2}-\gamma_{\mathrm{O}}$

The $0.3086 \mathrm{mGal} / \mathrm{m}$ is the numerical value adopted for the free-air gradient, assuming an spherical Earth with radius R.

The normal gravity on the GRS80 reference ellipsoid $\left(\gamma_{\mathrm{Qo}}\right)$ is evaluated through Somigliana's closed formula, see also equation (2.32).

$\gamma_{\mathrm{Q}_{0}}=\gamma_{\mathrm{a}} \frac{1+\mathrm{k} \sin ^{2} \varphi}{\sqrt{1-\mathrm{e}^{2} \sin ^{2} \varphi}}$

where $\varphi$ is the GRS80 geodetic latitude of the observation point, $\mathrm{k}$ is the normal gravity constant, $\gamma_{a}$ is the normal gravity on the equator, and $\mathrm{e}^{2}$ is the square of the first eccentricity. For GRS80, these constants are:

$\gamma_{\mathrm{a}}=978032.67715 \mathrm{mGal}$ 
$\mathrm{k}=\frac{\mathrm{b} \gamma_{\mathrm{P}}}{\mathrm{a} \gamma_{\mathrm{e}}}-1=0.001931851353$

$\mathrm{e}^{2}=\frac{\mathrm{a}^{2}-\mathrm{b}^{2}}{\mathrm{a}^{2}}=0.0066943800229$

The normal gravity calculated with this equation on GRS80 contains the gravitation of the atmospheric mass but the gravity measured on or near the Earth's surface does not. If this normal gravity is used for the computation of gravity anomalies, an atmospheric gravity correction $\delta g_{a t m}$ has to be added to the observed gravity. The following empirical formula for its calculation is given by Torge, (1989).

$$
\delta \mathrm{g}_{\mathrm{atm}}=0.874-0.9910^{-4} \mathrm{~h}[\mathrm{~m}]+0.35610^{-8} \mathrm{~h}_{[\mathrm{m}]}^{2}[\mathrm{mGal}]
$$

where the height $h$ is in meters.

The atmospherically corrected classical free-air gravity anomaly can be computed using equation (4.13) or equation (4.14), if the second-order free-air reduction is applied

$$
\begin{aligned}
& \Delta \mathrm{g}_{\mathrm{FA}}=\mathrm{g}+\delta \mathrm{g}_{\mathrm{atm}}-0.3086 \mathrm{~h}+0.7210^{-6} \mathrm{~h}^{2}-\gamma_{\mathrm{Q}_{\mathrm{o}}} \\
& \left.\Delta \mathrm{g}_{\mathrm{FA}}=\mathrm{g}+\delta \mathrm{g}_{\mathrm{atm}}-\frac{2 \gamma_{\mathrm{e}}}{\mathrm{a}}\left(1+\mathrm{f}+\mathrm{m}-2 \mathrm{f} \sin ^{2} \varphi\right) \mathrm{h}-3 \frac{\gamma_{\mathrm{e}}}{\mathrm{a}^{2}} \mathrm{~h}^{2}\right)-\gamma_{\mathrm{Q}_{\mathrm{o}}}
\end{aligned}
$$

where $\mathrm{f}$ is the ellipsoidal flattening (for GRS80, 0.0033528106818), $\mathrm{a}$ is the semi-major axis (for GRS80, 6378137m) and

$$
\mathrm{m}=\frac{\omega^{2} \mathrm{a}^{2} \mathrm{~b}}{\mathrm{GM}}=0.00344978600308 \text { for GRS } 80
$$

The point complete Bouguer anomalies are computed through the following equations

$$
\begin{aligned}
& \Delta \mathrm{g}_{\mathrm{B}}=\Delta \mathrm{g}_{\mathrm{FA}}-2 \pi \mathrm{G} \rho \mathrm{h} \quad \text { for } \mathrm{h} \geq 0 \text { land } \\
& \Delta \mathrm{g}_{\mathrm{B}}=\Delta \mathrm{g}_{\mathrm{FA}}+2 \pi \mathrm{G}\left(\rho-\rho_{\mathrm{W}}\right) \mathrm{h} \quad \text { for } \mathrm{h}<0 \text { sea }
\end{aligned}
$$

where $\Delta \mathrm{g}_{\mathrm{FA}}$ is the free-air anomaly, $\rho$ and $\rho_{\mathrm{w}}$ are the densities of the rock and water respectively, $\mathrm{h}$ is the height or the depth of the gravity station. 
During this study, we assume a constant density for the mean crust of $2.67 \mathrm{gr} / \mathrm{cm}^{3}$ and for the seawater $1.03 \mathrm{gr} / \mathrm{cm}^{3}$, so the Bouguer gravity anomalies can be calculated as follows:

$\Delta \mathrm{g}_{\mathrm{B}}=\Delta \mathrm{g}_{\mathrm{FA}}-0.1119 \mathrm{~h} \quad$ for $\mathrm{h} \geq 0$ land $[\mathrm{mGal}]$

$\Delta \mathrm{g}_{\mathrm{B}}=\Delta \mathrm{g}_{\mathrm{FA}}+0.0699 \mathrm{~h} \quad$ for $\mathrm{h}<0$ sea $[\mathrm{mGal}]$

The point refined Bouguer anomalies can be computed after applying the terrain correction to the Bouguer anomaly.

\subsubsection{Terrain corrections}

Terrain corrections were computed using program Tc2DFTPL developed at the Department of Geomatics Engineering at the University of Calgary by Yecai Li in 1993. This program computes terrain corrections via 2D FFT with either a mass prism or a mass line topographic model. First, terrain corrections were computed from the Digital Elevation Model GTOPO30 which has an original grid spacing of 30 arc seconds corresponding to an approximate spacing of 1 kilometre in North-South and East-West directions. But due to the convergence of the meridians, this spacing varies according to latitude. Due to some numerical instabilities, terrain corrections were computed again but this time with the Digital Elevation Model with a grid spacing of 2 arc-minutes by 2 arc-minutes. The maximum, minimum, mean and standard deviation of the heights and terrain corrections for the entire Argentina can be seen in Table 4.5.

Terrain corrections were computed using formulas (2.36) and (2.43), which correspond to the mass line (ML) and the mass prism (MP) topographic models. The computations were done over the whole area without any integration cap size. Figure 4.13 shows a map of terrain corrections for Argentina computed with a mass prism topographic model.

The highest area of Argentina was selected to study terrain corrections computed with different mass representations and their effect on the geoid. This area corresponds to a grid which is bounded between latitudes $29^{\circ} \mathrm{S}$ to $36^{\circ} \mathrm{S}$ and longitudes $73^{\circ} \mathrm{W}$ to $63^{\circ} \mathrm{W}$. 
Table 4.5: Terrain corrections in Argentina in mGal.

\begin{tabular}{c|ll|rrrr}
\hline & & \multicolumn{1}{c|}{ max } & \multicolumn{1}{c}{ min } & mean & \multicolumn{1}{c}{$\sigma$} \\
\cline { 2 - 7 } & Height $[\mathrm{m}]$ & & 6402.69 & 0.00 & 407.11 & 885.54 \\
\cline { 2 - 7 } & $\mathrm{c}_{1}$ & $(\mathrm{MP})$ & 74.30 & 0.00 & 2.89 & 2.70 \\
& $\mathrm{c}_{1}+\mathrm{c}_{2}$ & $(\mathrm{MP})$ & 73.47 & 0.00 & 1.02 & 2.90 \\
& $\mathrm{c}_{1}+\mathrm{c}_{2}+\mathrm{c}_{3}$ & $(\mathrm{MP})$ & 73.48 & 0.00 & 1.02 & 2.90 \\
Latitude & $\left(\mathrm{c}_{1}+\mathrm{c}_{2}+\mathrm{c}_{3}\right)-\left(\mathrm{c}_{1}+\mathrm{c}_{2}\right)$ & $(\mathrm{MP})$ & 0.79 & -0.25 & 0.00 & 0.01 \\
$20^{\circ} \mathrm{S}$ to & $\left(\mathrm{c}_{1}+\mathrm{c}_{2}\right)-\mathrm{c}_{1}$ & $(\mathrm{MP})$ & 0.29 & -3.02 & 0.03 & 0.03 \\
\cline { 2 - 7 } $55^{\circ} \mathrm{S}$ & $(\mathrm{ML})$ & 71.51 & 0.00 & 0.96 & 2.53 \\
Longitude & $\mathrm{c}_{1}$ & $(\mathrm{ML})$ & 70.68 & 0.00 & 0.97 & 2.54 \\
$76^{\circ} \mathrm{W}$ to & $\mathrm{c}_{1}+\mathrm{c}_{2}$ & $(\mathrm{ML})$ & 70.71 & 0.00 & 0.97 & 2.54 \\
$53^{\circ} \mathrm{W}$ & $\mathrm{c}_{1}+\mathrm{c}_{2}+\mathrm{c}_{3}$ & $(\mathrm{ML})$ & 0.22 & -0.09 & 0.00 & 0.00 \\
& $\left(\mathrm{c}_{1}+\mathrm{c}_{2}+\mathrm{c}_{3}\right)-\left(\mathrm{c}_{1}+\mathrm{c}_{2}\right)$ & $(\mathrm{ML})$ & 0.14 & -1.79 & 0.00 & 0.02 \\
\hline & $\left(\mathrm{c}_{1}+\mathrm{c}_{2}\right)-\mathrm{c}_{1}$ & 5.45 & -0.07 & 0.06 & 0.21 \\
\cline { 2 - 7 } & $\left(\mathrm{c}_{1}+\mathrm{c}_{2}+\mathrm{c}_{3}\right) \mathrm{MP}-\left(\mathrm{c}_{1}+\mathrm{c}_{2}+\mathrm{c}_{3}\right) \mathrm{ML}$ & & 6.87 & -0.02 & 0.06 & 0.20 \\
& $\left(\mathrm{c}_{1}+\mathrm{c}_{2}\right) \mathrm{MP}-\left(\mathrm{c}_{1}+\mathrm{c}_{2}\right) \mathrm{ML}$ & & 0.36 & 0.00 & 0.05 & 0.19 \\
\hline
\end{tabular}

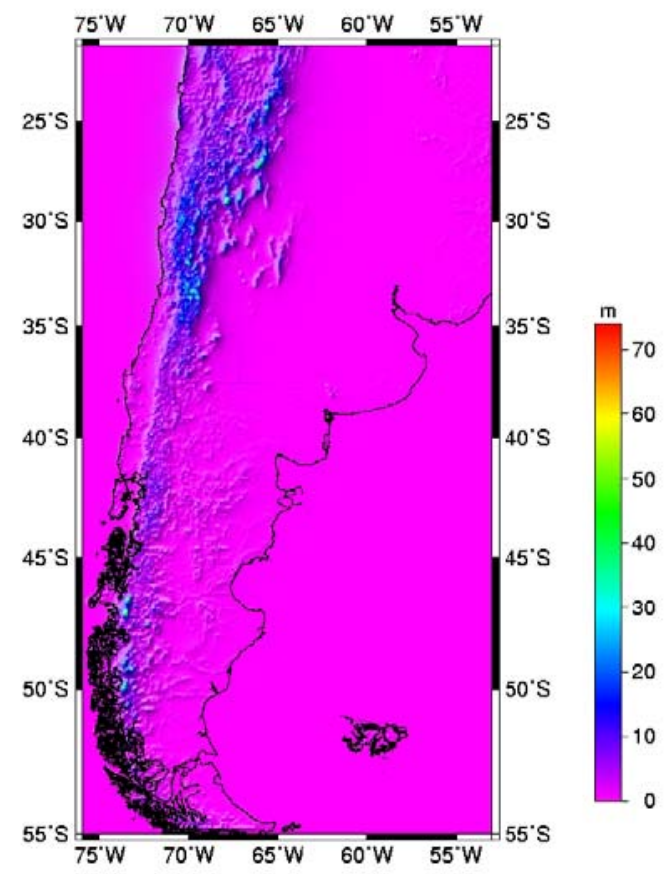

Figure 4.13: Terrain Corrections

Table 4.6 shows the statistics of topographic heights and terrain corrections computed for the whole computation area and with an integration cap size of approximately 100 kilometres and for all the three terms $\left(c_{1}+c_{2}+c_{3}\right)$. MP3 are terrain corrections computed for all three terms using a mass prism representation, ML3 are terrain corrections 
computed for all three terms using a mass line model, w means that the integration was done over the whole area and $\mathrm{c}$ indicates that terrain corrections were computed using a cap size of $100 \mathrm{~km}$ by $100 \mathrm{~km}$.

Table 4.6 indicates that the standard deviation of the differences between computed terrain corrections with a mass line model and a mass prism model is $0.40 \mathrm{mGal}$ and the maximum value is $5.30 \mathrm{mGal}$. Plotting these differences we can see that they are correlated with the topography. The effect of the terrain correction computed with both topographic representations on the geoid can also be seen in Table 4.6. The effect of the terrain correction differences on the geoid has a standard deviation of $4 \mathrm{~cm}$ and a maximum of approximate $20 \mathrm{~cm}$.

Table 4.6: Effect of different models and cap size on terrain corrections and geoid.

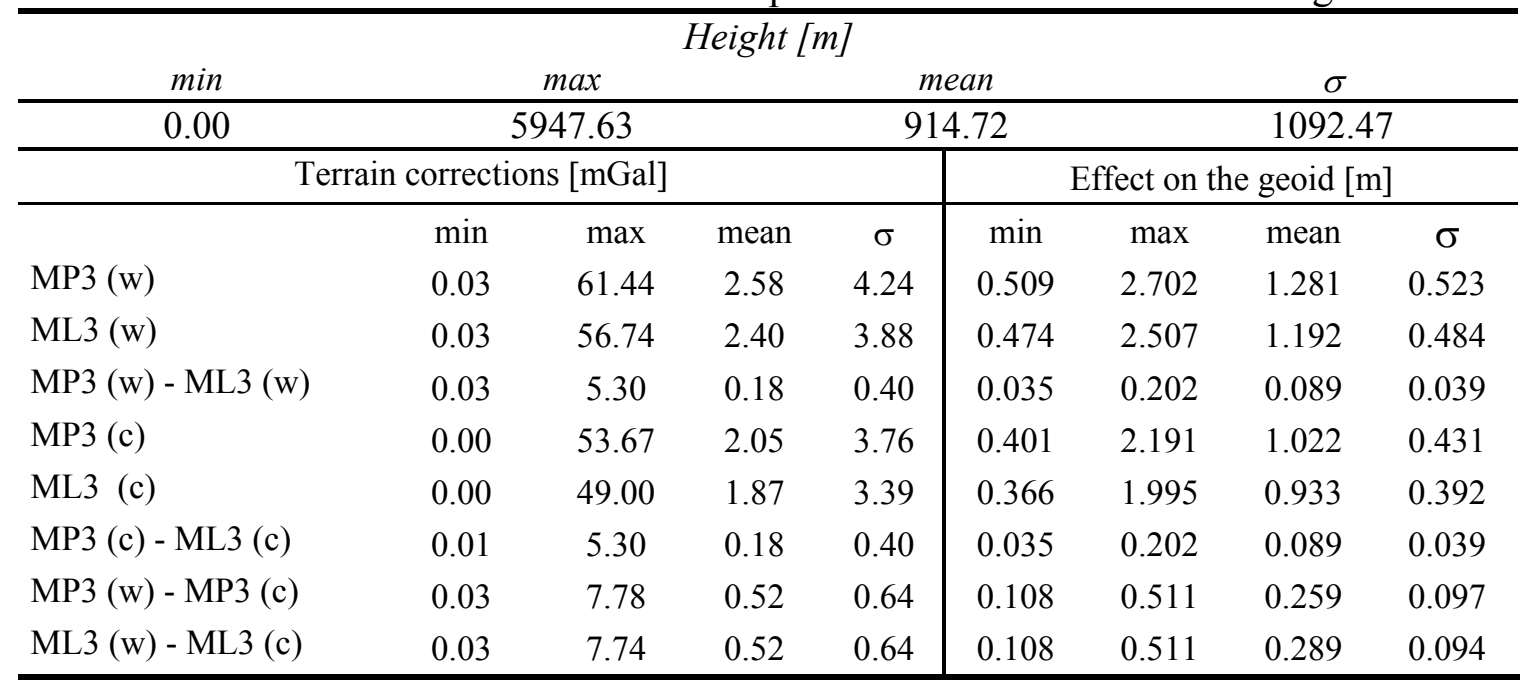

Table 4.6 also shows that the limitation of the integration of the cap size to $100 \mathrm{~km}$ by $100 \mathrm{~km}$ produces an effect on the geoid of about $9 \mathrm{~cm}$ in terms of the standard deviation both mass representations.

Table 4.6 shows that the effect on the geoid when terrain corrections were computed with a limited cap size and using a mass line topographic model instead of a mass prism topographic model is $4 \mathrm{~cm}$ in terms of the standard deviation; this result is the same as when the computation was done over the whole area.

For geoid determination in rough areas, the mass prism topographic model has to be used instead of the mass line topographic model for the computation of terrain 
corrections. The computation of the terrain corrections should be done up to the second term of the terrain correction series for either the mass line or the mass prism topographic model. The effect of the third term is negligible. The integration cap size should be large enough for the computation of terrain corrections. There is a $9 \mathrm{~cm}(\sigma)$ geoid undulation error when the integration cap size is limited to $100 \mathrm{~km}$ by $100 \mathrm{~km}$ instead of using the whole computation area.

We conclude, that for the whole Argentina, we will compute terrain corrections with a mass prism model, without a limited integration radius, and include the second term $\mathrm{c}_{2}$.

\subsubsection{Pre-processing of land gravity data}

The land data described in section 4.1.1 was collected from different data sources, so special care was taken in order to detect and remove data blunders, duplicate points, and all data points that were considered as suspicious observations. Special software was developed to remove repeated points from the database in order to generate the most homogenized gravity database for Argentina.

Point free-air gravity anomalies and point Bouguer gravity anomalies were computed for each observation with equations (4.13) and (4.18), respectively. Table 4.7 shows the statistics after the database was cleaned.

Table 4.7: Statistics of the gravity points of the Argentinean database after data removal.

\begin{tabular}{l|c|cccc}
\hline & Unit & min & max & mean & $\sigma$ \\
\hline \multicolumn{5}{c}{66717 points } \\
\hline latitude & {$[$ degree] } & -54.82 & -20.01 & -29.93 & 7.47 \\
longitude & {$[$ degree $]$} & -74.83 & -53.00 & -63.23 & 5.53 \\
Height & {$[\mathrm{m}]$} & -68.10 & 6204.00 & 842.61 & 1186.16 \\
g IGSN71 & {$[\mathrm{mGal}]$} & 977310.00 & 981469.07 & 979107.27 & 798.95 \\
Free-air gravity anomaly & {$[\mathrm{mGal}]$} & -145.32 & 280.00 & 7.71 & 38.40 \\
Bouguer gravity anomalies & {$[\mathrm{mGal}]$} & -489.95 & 126.87 & -86.56 & 117.98 \\
\hline
\end{tabular}

The gravity anomalies computed from the geopotential model EGM96 were removed from the point free-air gravity anomalies. With this reduced gravity anomalies, a contour map was made and some points with gross errors were detected and removed from the original database. A contour map of Bouguer gravity anomalies was also 
generated and deep holes and steep spikes were considered as suspicious observations. The total area was divided in small areas where 2D contour maps of the Bouguer anomalies were done and a careful visual inspection was performed in order to detect outliers.

\subsubsection{Pre-processing of shipborne data}

The shipborne gravity data described in section 4.1.2 are referred to the Geodetic Reference System 1967 (GRS67), thus they have to be transformed to GRS80. This was done using the following basic formula (Moritz, 2000):

$$
\Delta \mathrm{g}_{\mathrm{GRS} 80}=\Delta \mathrm{g}_{\mathrm{GRS} 67}+\gamma_{\mathrm{GRS} 67}-\gamma_{\mathrm{GRS} 80}
$$

where $\Delta \mathrm{g}_{\mathrm{GRS} 80}$ denotes gravity anomaly in GRS80, $\Delta \mathrm{g}_{\mathrm{GRS} 67}$ gravity anomaly in GRS67 and $\gamma_{\mathrm{GRS} 67}$ and $\gamma_{\mathrm{GRS} 80}$ are the magnitudes of the normal gravity in GRS67 and GRS80, respectively. Normal gravity can be computed for the GRS80 using formula (4.8). For GRS67 (ibid):

$$
\gamma_{\text {GRS67 }}=978031.8459\left(1+0.0052789660 \sin ^{2} \varphi+0.0000232725 \sin ^{4} \varphi\right) \mathrm{mGal}
$$

The statistics of the original shipborne free-air gravity anomalies and the statistics of the shipborne free-air gravity anomalies after they have been transformed to GRS80 is shown in Table 4.8.

Table 4.8: Statistics of shipborne free-air gravity anomalies referred to MSS. Unit [mGal].

\begin{tabular}{l|cccc}
\hline Free-air gravity anomalies & $\min$ & $\max$ & mean & $\sigma$ \\
\hline$\Delta \mathrm{g}_{\mathrm{FA}}$ (17352 values) GRS67 & -132.35 & 532.80 & 24.98 & 97.05 \\
$\Delta \mathrm{g}_{\mathrm{FA}}$ (17352 values) GRS80 & -133.16 & 531.92 & 24.14 & 97.05 \\
\hline
\end{tabular}

Three ship tracks corresponding to a total of 4529 points were removed from the original database as they were considered as blunders; hence the final marine database will consist of 12823 free-air shipborne gravity anomalies is shown in Table 4.9. 
Table 4.9: Statistics of shipborne free-air gravity anomalies referred to MSS. Unit [mGal].

\begin{tabular}{l|cccc}
\hline & $\min$ & $\max$ & mean & $\sigma$ \\
\hline$\Delta \mathrm{g}_{\mathrm{FA}}(12823$ values) GRS80 & -133.16 & 142.38 & 3.96 & 28.64 \\
\hline
\end{tabular}

It is often that the ship gravity anomalies refer to the sea surface and not the geoid itself, thus their use will lead to the determination of a mean sea surface and not a geoid model. These gravity anomalies have to be free-air reduced so as to produce gravity anomalies on the surface of the geoid. The free-air gravity anomalies are computed using the well-known reduction formula

$\Delta \mathrm{g}_{\mathrm{FA}}=\Delta \mathrm{g}-\mathrm{F}$

where $\mathrm{F}$ is the free-air reduction. In marine regions, the height needed for the reduction is that of the QSST, which varies between 0 and $-0.30 \mathrm{~m}$ in the study area. Thus, for practical purposes it is sufficient to use the normal gradient of gravity to compute the free-air reduction as

$\mathrm{F} \approx-\frac{\delta \gamma}{\delta \mathrm{h}} \mathrm{h}_{\mathrm{QSST}} \approx-0.3086 \mathrm{~h}_{\mathrm{QSST}}$

where $h$ is the QSST in meters, derived from a global model.

The statistics of the shipborne gravity anomalies after reducing them to the surface of the geoid can be seen in Table 4.10.

Table 4.10: Statistics of shipborne free-air gravity anomalies referred to the geoid. Unit [mGal].

\begin{tabular}{l|cccc}
\hline & $\min$ & $\max$ & mean & $\sigma$ \\
\hline$\Delta \mathrm{g}_{\mathrm{FA}}(12823$ values) GRS80 & -133.03 & 142.57 & 4.01 & 28.64 \\
\hline
\end{tabular}

These two pre-processing steps are necessary for the data homogenization so that they can be used for the determination of the gravimetric geoid. 


\subsubsection{Validation of altimetry-derived free-air gravity anomalies}

Altimetry-derived gravity anomaly grids offshore Argentina were compared with one another and with shipborne gravity anomalies computed from the shipborne gravity database.

Sub-grids were extracted from the available global marine gravity field grids over the study area bounded by $21^{\circ}$ to $55^{\circ}$ in latitude and $76^{\circ}$ to $53^{\circ}$ in longitude. Some of these grids, like the KMS grids, have been filled in with EGM96 gravity anomalies in the land areas. The statistics of the gravity anomalies for each grid, after land gravity anomalies were removed using the grdlandmask option in GMT (Wessel, 1995) can be seen in Table 4.11 together with the statistics of the gravity anomalies computed from EGM96 computed in the same marine grid.

Table 4.11: Statistics of the gravity anomalies derived from satellite altimetry and EGM96 gravity anomalies.

\begin{tabular}{l|cccc}
\hline Grid & min & max & mean & $\sigma$ \\
\hline CLS_SHOM99 (2'x2') & -270.86 & 226.19 & -3.34 & 41.14 \\
CLS_SHOM99 (1'x1') & -272.39 & 223.53 & -3.31 & 41.02 \\
GSFC (2'x2') & -256.20 & 164.30 & -3.69 & 40.76 \\
GSFC (1'x1') & -254.48 & 137.53 & -3.74 & 40.56 \\
KMS01 (2'x2') & -252.23 & 182.43 & -3.71 & 40.34 \\
KMS01 (1'x1') & -252.84 & 182.44 & -3.71 & 40.34 \\
Sandwell (2'x2') & -260.36 & 150.63 & -4.05 & 40.95 \\
Sandwell (1'x1') & -260.31 & 140.85 & -3.64 & 40.86 \\
KMS02 (2'x2') & -252.57 & 178.16 & -3.69 & 40.56 \\
KMS02 (1'x1') & -252.57 & 183.88 & -3.69 & 40.56 \\
EGM96 (2'x2') & -214.78 & 163.19 & -3.55 & 38.86 \\
\hline
\end{tabular}

It can be seen that the altimetrically derived marine gravity anomalies have similar statistics.

In order to make comparisons among the different grids, the data has to be re-gridded onto one arc-minute by one arc-minute grid using the surface option in GMT (Wessel, 1995) because the Sandwell and CLS_SHOM grids nodes are offset by one minute with respect to the KMS and GSFC grids. The statistics of the differences of the grids around Argentina can be seen in Table 4.12 and their images are shown in Figures 4.14 to 4.23. 
The locations of the shipborne data were bilinear interpolated from the different grids of altimeter-derived gravity anomalies grids. Table 4.13 shows the statistics of the differences between the altimeter data and the shipborne free-air gravity anomalies that can be seen in Figures 4.24 to 4.28 .

Table 4.12: Statistics of the differences between different altimetric gravity anomalies grids around Argentina. Unit [mGal].

\begin{tabular}{l|cccc}
\hline Grid at sea & min & max & mean & $\sigma$ \\
\hline KMS02-KMS01 & -47.68 & 64.58 & 0.01 & 4.65 \\
KMS02-Sandwell & -66.02 & 119.7 & -0.05 & 4.19 \\
KMS02-GSFC & -111.09 & 97.16 & 0.05 & 4.88 \\
KMS02-CLS & -234.96 & 253.43 & -0.38 & 6.80 \\
KMS01-Sandwell & -71.70 & 68.22 & -0.06 & 5.44 \\
KMS01-GSFC & -115.62 & 83.77 & 0.03 & 6.11 \\
KMS01-CLS & -236.98 & 256.97 & -0.38 & 7.53 \\
Sandwell-GSFC & -154.93 & 73.72 & 0.09 & 5.43 \\
Sandwell-cls & 229.77 & 261.07 & -0.33 & 6.78 \\
GSFC-CLS & -245.98 & 249.99 & -0.42 & 7.35 \\
\hline
\end{tabular}

Table 4.13: Statistics of the differences between different altimetric gravity anomalies grids and marine gravity anomalies grids around Argentina. Unit [mGal].

\begin{tabular}{l|cccc}
\hline & $\min$ & $\max$ & mean & $\sigma$ \\
\hline KMS01-shipborne & -61.47 & 67.74 & 0.99 & 10.31 \\
KMS02-shipborne & -63.67 & 66.31 & 1.25 & 9.99 \\
CLS-SHOM99 - shipborne & -154.04 & 162.27 & 0.74 & 11.68 \\
GSFC-shipborne & -57.66 & 77.23 & 1.41 & 10.41 \\
Sandwell-shipborne & -61.21 & 67.92 & 1.13 & 10.11 \\
\hline
\end{tabular}

There are differences between the marine free-air gravity anomalies due to the different computation methods employed. The smaller differences are between the KMS02 and Sandwell grids and the smaller differences in terms of standard deviations between both grids and the shipborne data is achieved with the KMS02. The KMS02 grid will be used, even though some numerical results presented in this research used the KMS01 grid as the KMS02 was delivered for public use after this thesis has started. 

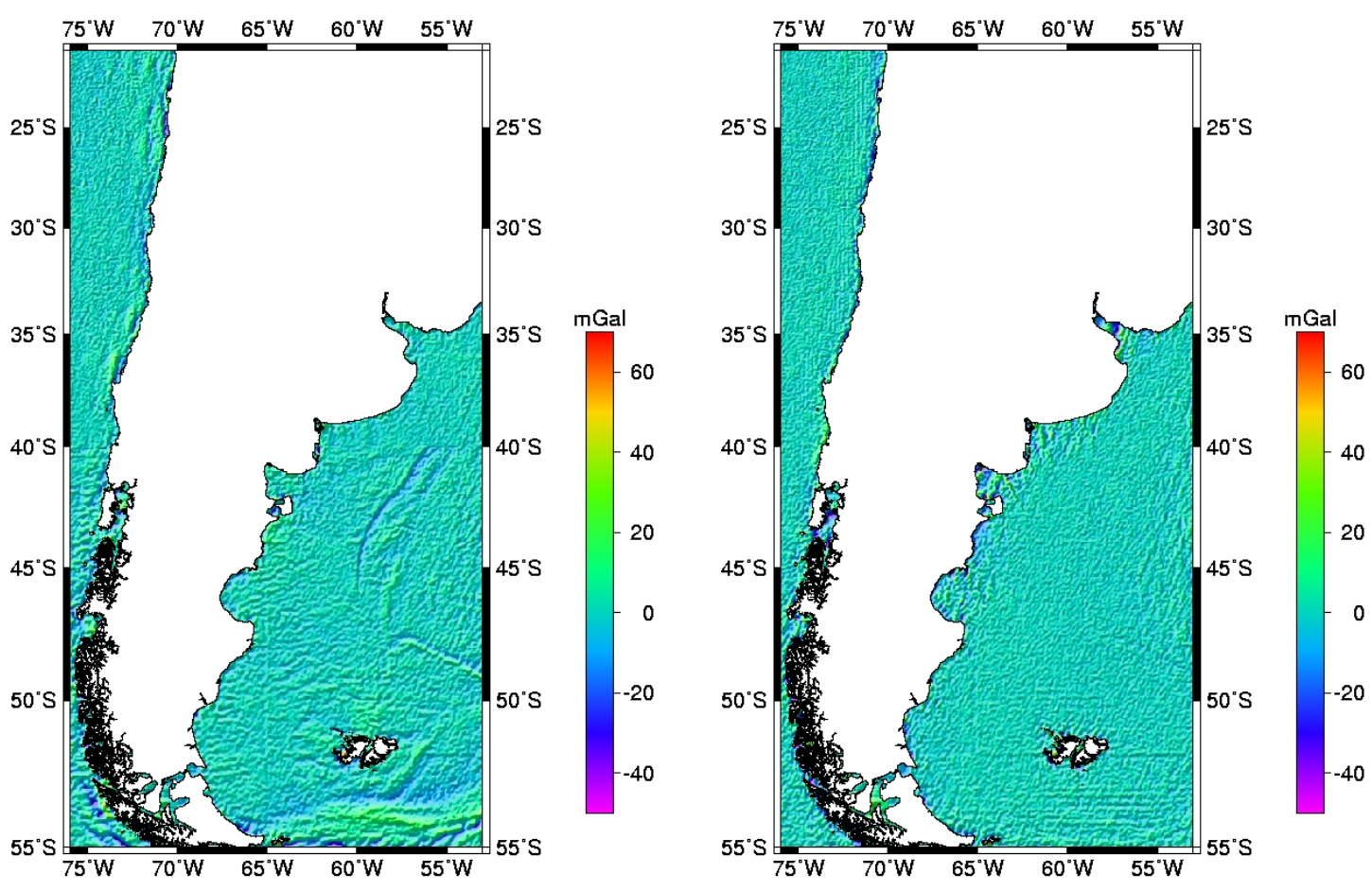

Figure 4.14: Differences between KMS02 and KMS01 gravity anomalies

Figure 4.15: Differences between KMS02 and GSFC gravity anomalies
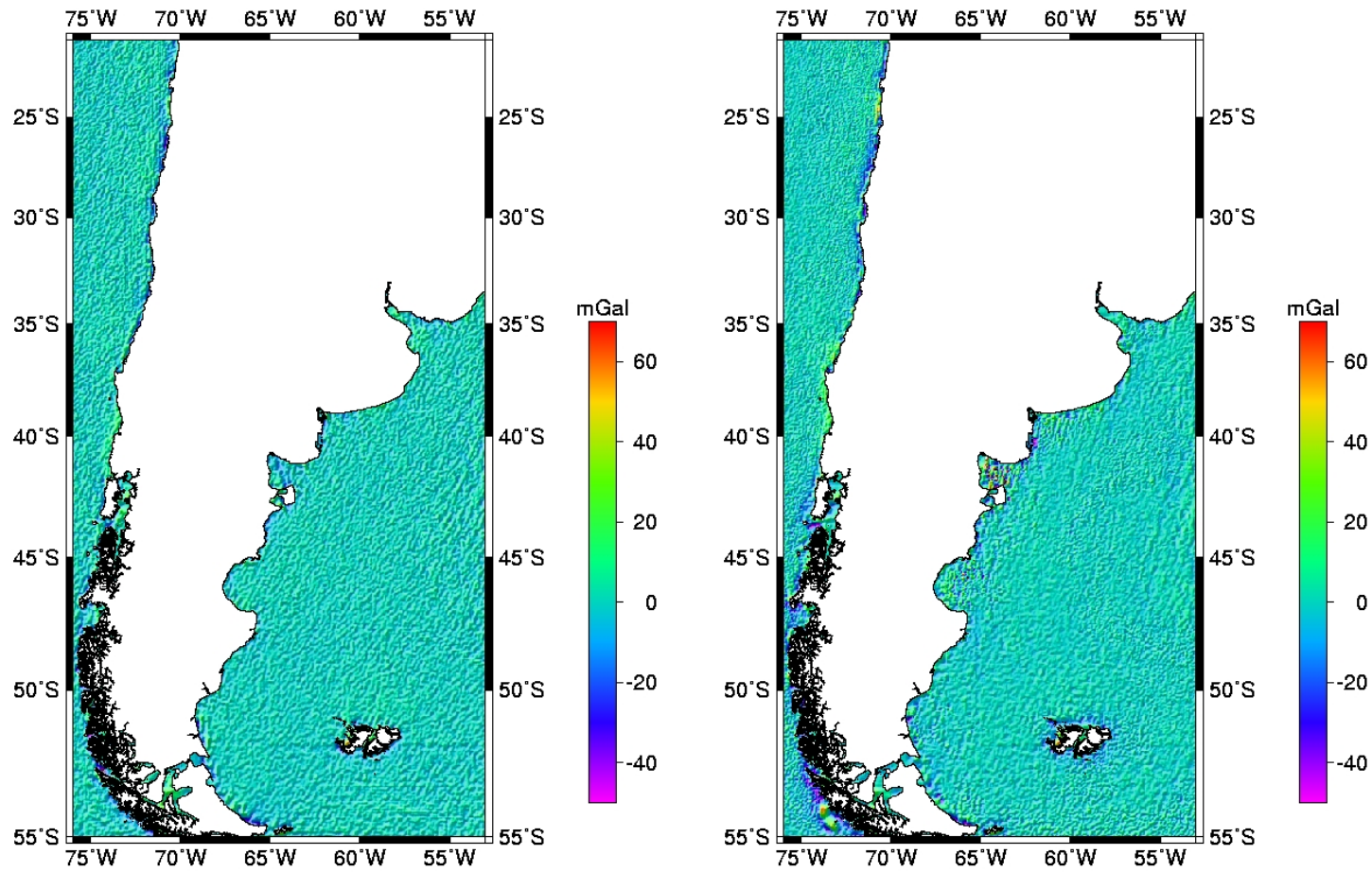

Figure 4.16: Differences between KMS02 and Sandwell gravity anomalies

Figure 4.17: Differences between KMS02 and CLS_SHOM gravity anomalies 

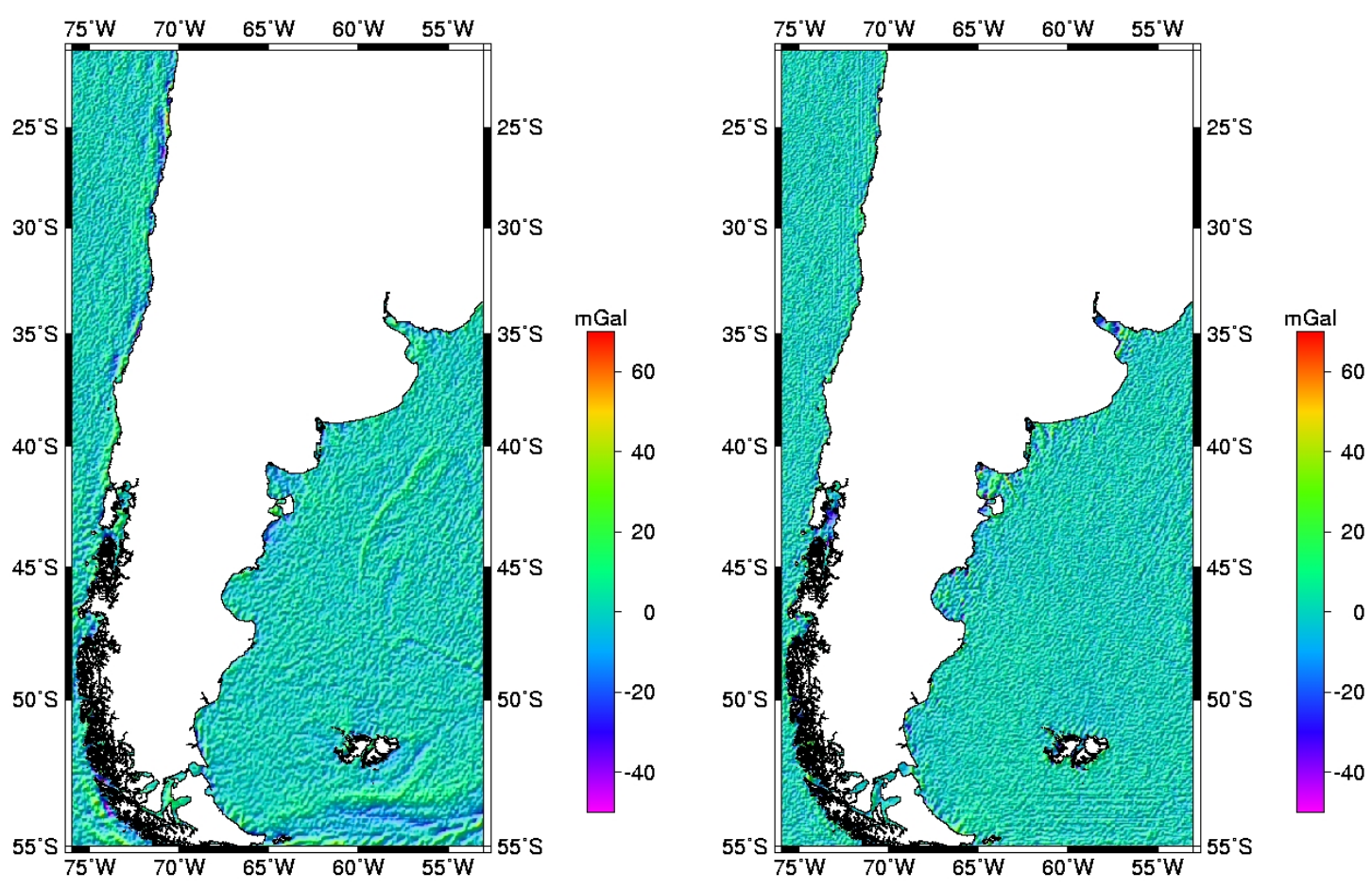

Figure 4.18: Differences between KMS01 and Figure 4.19: Differences between KMS01 and Sandwell gravity anomalies CLS_SHOM gravity anomalies
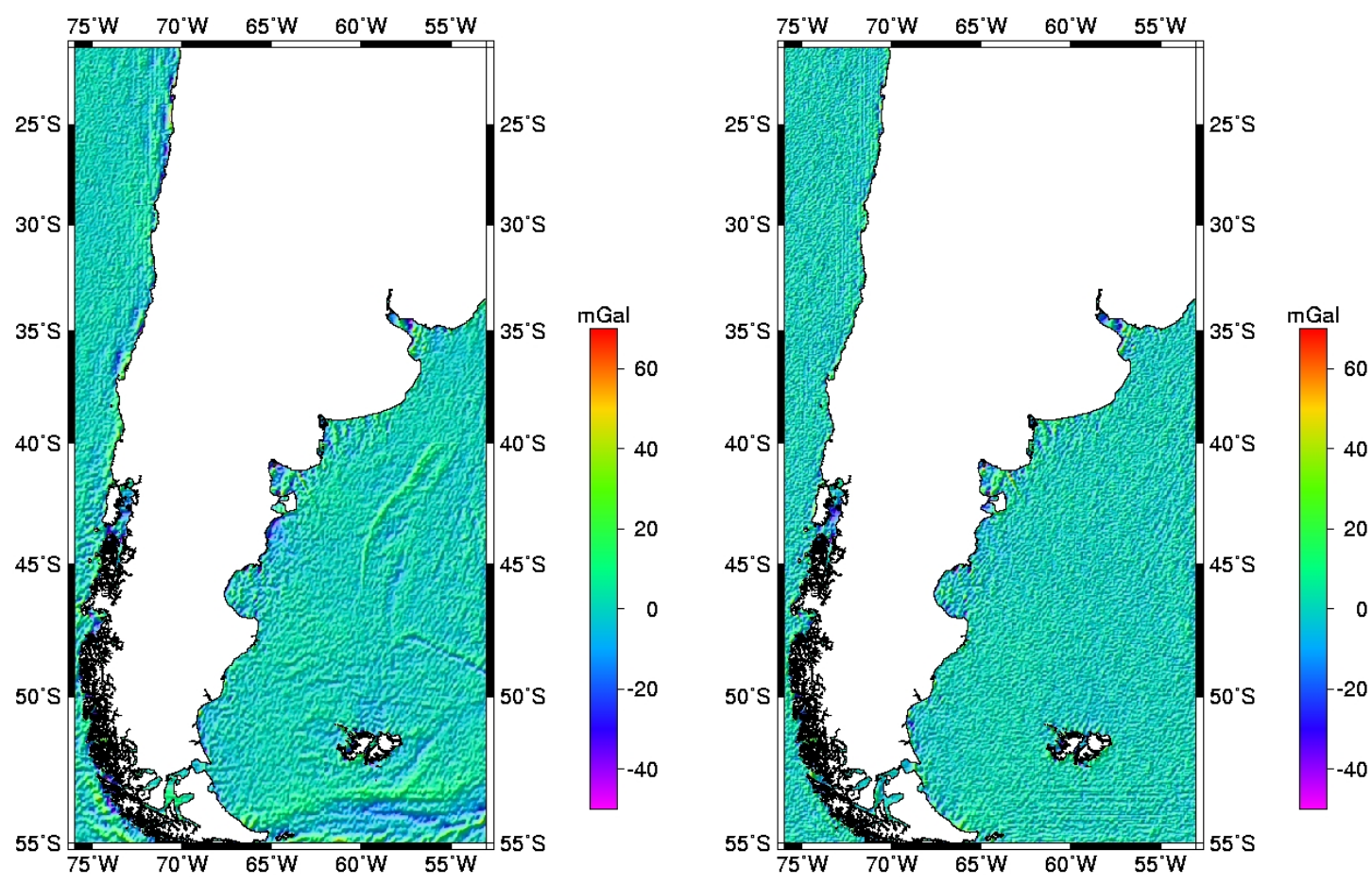

Figure 4.20: Differences between KMS01 and GSFC gravity anomalies

Figure 4.21: Differences between Sandwell and CLS_SHOM gravity anomalies 


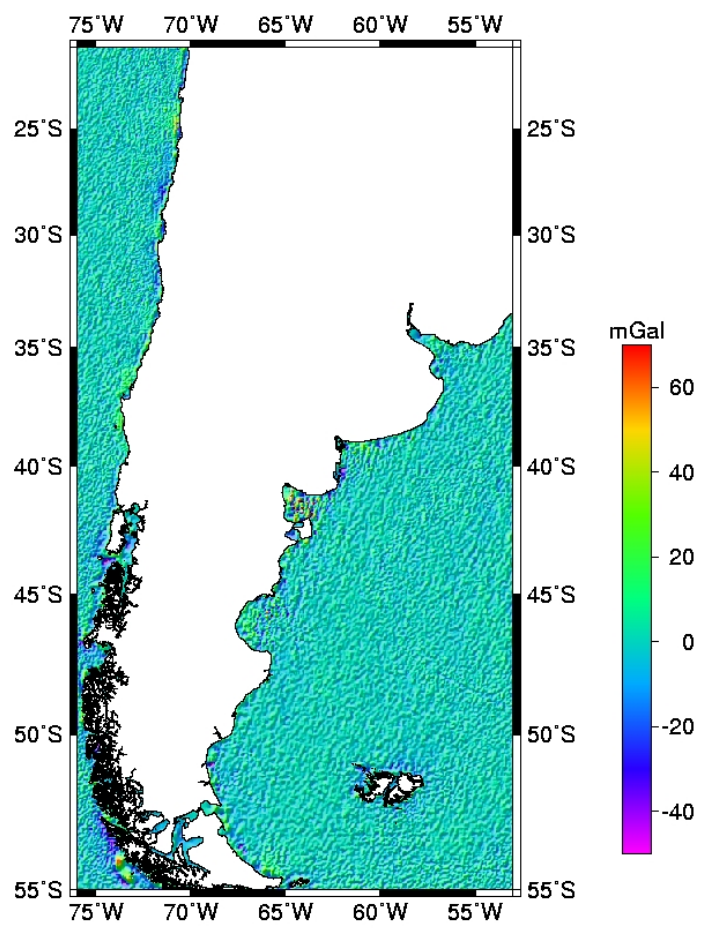

Figure 4.22: Differences between Sandwell and GSFC gravity anomalies
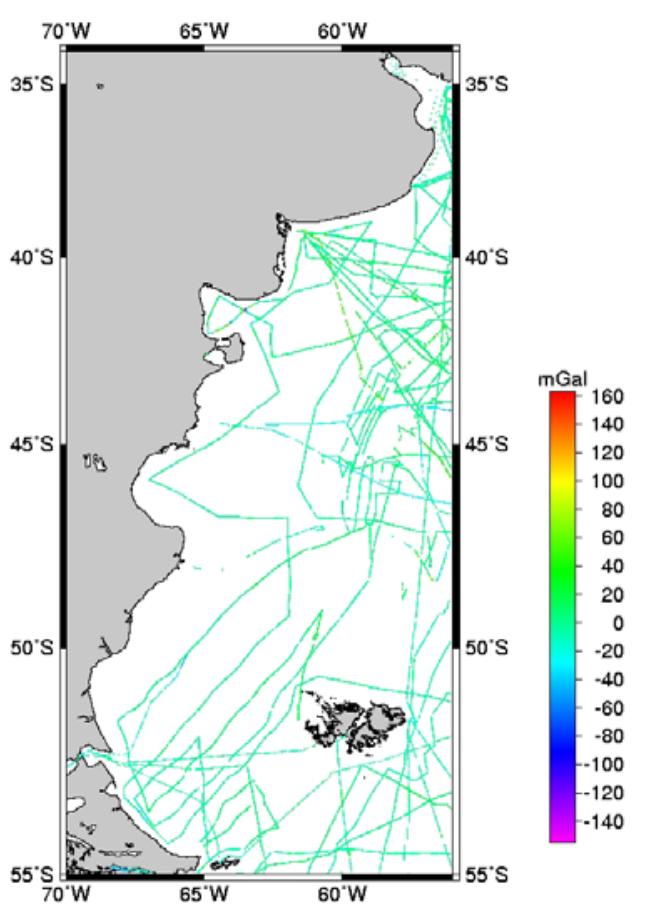

Figure 4.24: Differences between CLS and shipborne gravity anomalies

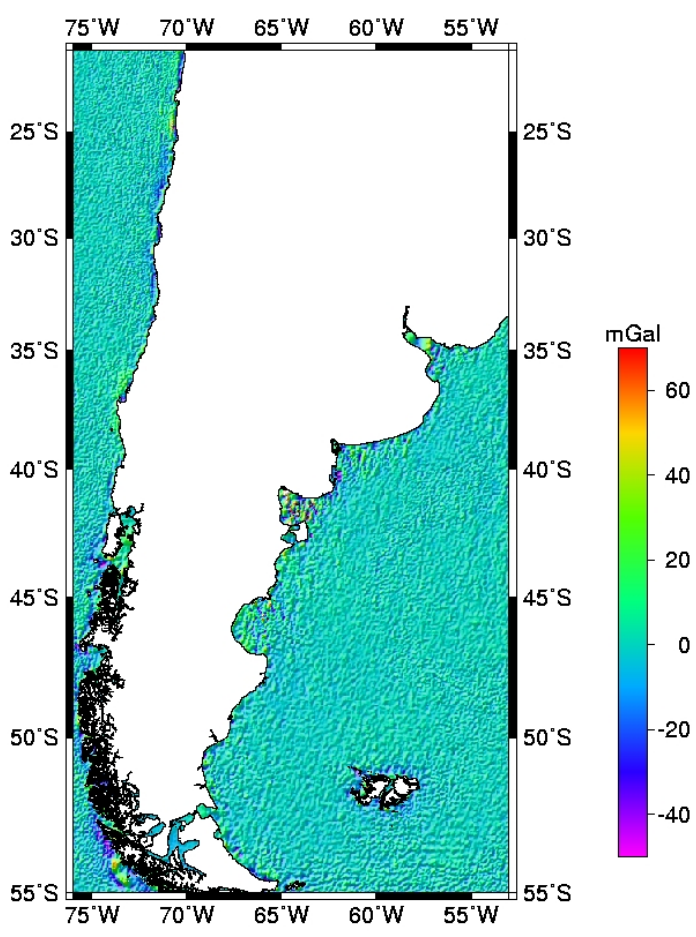

Figure 4.23: Differences between GSFC and CLS gravity anomalies

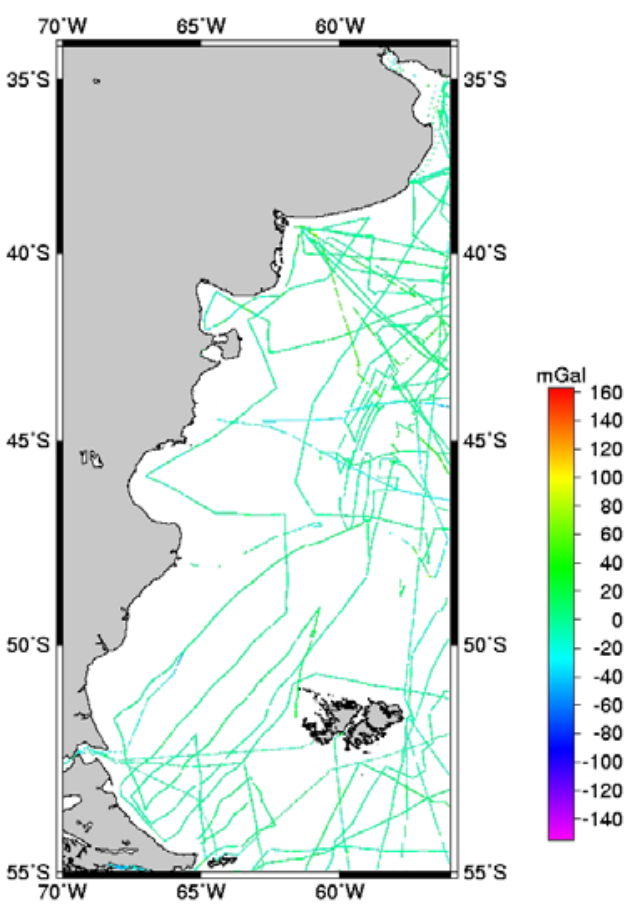

Figure 4.25 Differences between GSFC and shipborne gravity anomalies 

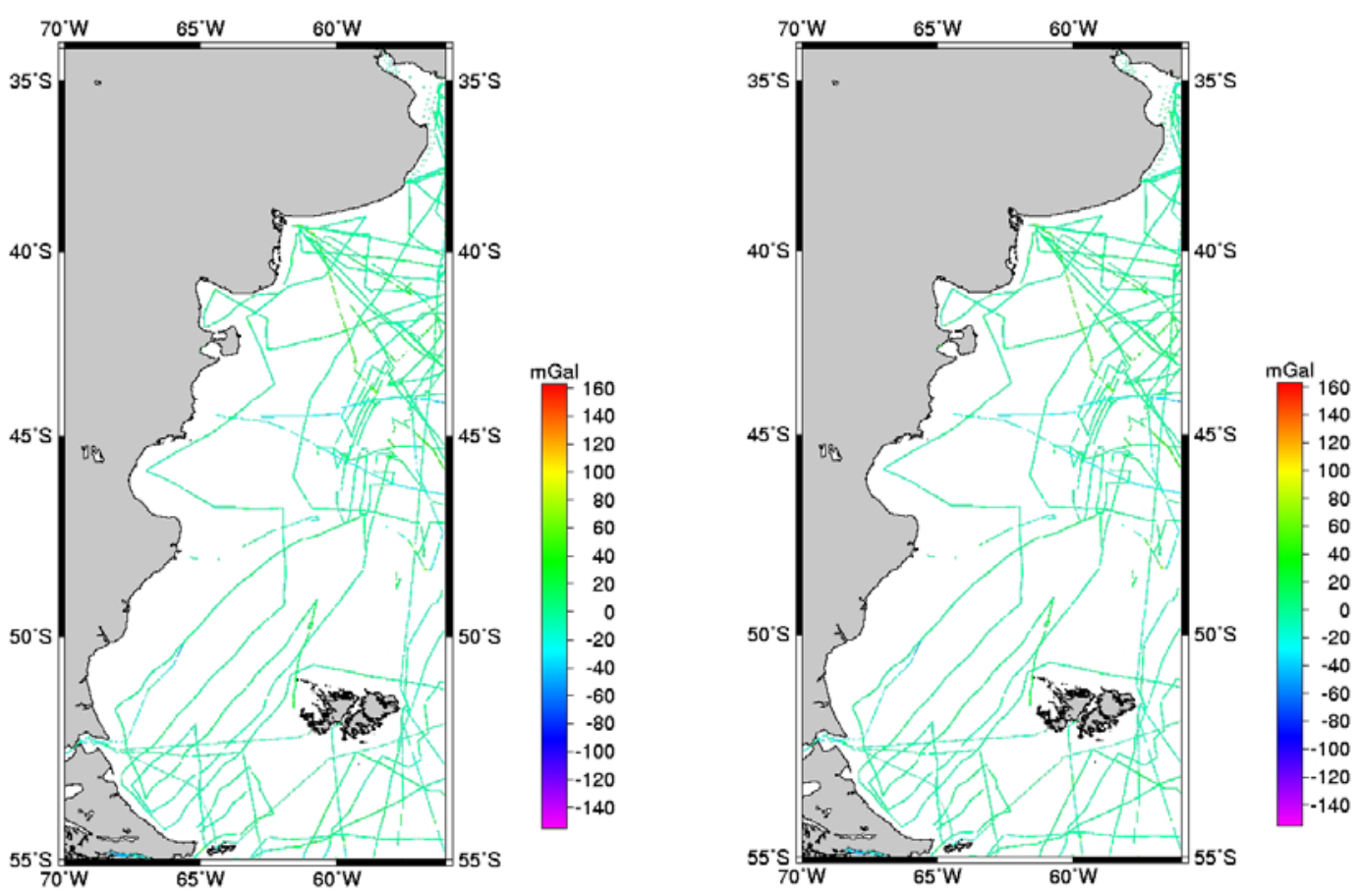

Figure 4.26: Differences between KMS01 and shipborne gravity data

Figure 4.27: Differences between Sandwell and shipborne gravity data

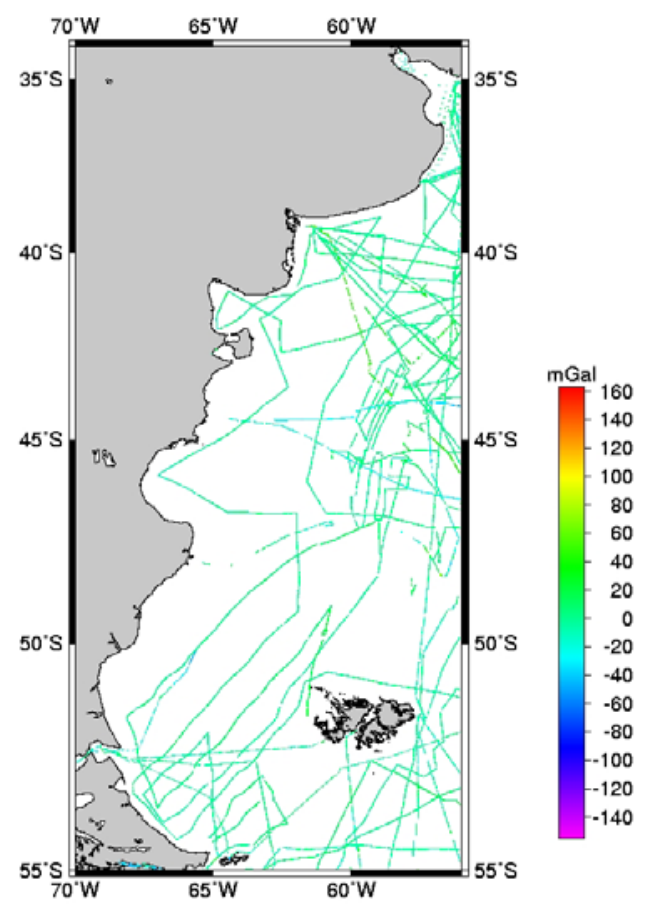

Figure 4.28: Differences between KMS01 and shipborne gravity data 


\subsection{Determination of the best fitting Global Geopotential Model in Argentina}

In order to determine the Argentinean gravimetric geoid it is first necessary to choose the best fitting global geopotential model (GGM) for Argentina.

The best GGM will be the one that best fits the gravity anomalies and the geoid in Argentina, and it will be determined through the following statistical tests:

- Comparisons between geoid undulations computed from different geopotential models and geometrical geoid undulations at GPS/levelling points.

- Comparisons between gravity anomalies computed from different global geopotential models and land, marine and free-air gravity anomalies derived from satellite altimetry.

\subsubsection{Comparisons between geoid undulations computed from different} geopotential models and geoid undulations derived from GPS/levelling points

Geoid undulation values $\left(\mathrm{N}_{\mathrm{GM}}\right)$ are computed from a set of normalized coefficients in spherical harmonic approximation using formula (2.13).

The quality of the geopotential model geoid can be evaluated by comparing the geoid undulations values computed from a geopotential model $\left(\mathrm{N}_{\mathrm{GM}}\right)$ to those from GPS/levelling $\left(\mathrm{N}^{\mathrm{GPS}}\right)$ :

$\mathrm{N}_{\mathrm{i}}^{\mathrm{GPS}}-\mathrm{N}_{\mathrm{GM}_{\mathrm{i}}}=0=\mathrm{h}_{\mathrm{e}_{\mathrm{i}}}-\mathrm{H}_{\mathrm{i}}-\mathrm{N}_{\mathrm{i}}$

In practice, there are a lot factors that affect equation (4.24); these factors have been described by Fotopoulos et al. (1999) and Kotsakis and Sideris (1999). Some of these factors are:

- random errors in the values of $h_{e}, H$ and $\mathrm{N}$

- datum inconsistencies; each data type $\left(h_{e}, H\right.$ and $\left.N\right)$ refers to a different reference surface and the result is a datum shift between the gravimetric geoid and the GPS/levelling derived geoid 
- systematic effects and distortions, like long wavelength errors in $\mathrm{N}_{\mathrm{GM}}$, poorly modeled GPS errors, and distortions in the vertical datum due to over constraining the levelling network

- geodynamics effects (post glacial rebound, land subsidence, monuments instabilities, mean sea level rise)

- theoretical approximations in the computation of either the gravimetric geoid $\mathrm{N}$ or the orthometric height $\mathrm{H}$ (improper terrain modeling in the gravimetric geoid, neglecting the Sea Surface Topography (SST) at the tide gauges, errors in the orthometric correction

Datum inconsistencies and systematic effects are the most important effects that cause discrepancies in equation (4.24). Most of the geoid studies that use GPS/levelling derived geoid as an external evaluation are based in the following corrector surface model:

$\mathrm{h}_{\mathrm{e}_{\mathrm{i}}}-\mathrm{H}_{\mathrm{i}}-\mathrm{N}_{\mathrm{i}}=\mathrm{a}_{\mathrm{i}}^{\mathrm{T}} \mathrm{x}+v_{\mathrm{i}}=\mathrm{N}^{\mathrm{GPS}}-\mathrm{N}_{\mathrm{GM}}=\mathrm{a}_{\mathrm{i}}^{\mathrm{T}} \mathrm{x}+v_{\mathrm{i}}$

where $\mathrm{x}$ is an $\mathrm{n} \times 1$ vector of unknown parameters, $\mathrm{a}_{\mathrm{i}}$ is an $\mathrm{n} \times 1$ vector of known coefficients and $v_{\mathrm{i}}$ is the residual random noise term (Fotopoulos, 1999).

The model of equation (4.25) is applied to all reliable GPS network points and the leastsquares adjusted values for the residuals $v_{\mathrm{i}}$ give a realistic picture of the level of absolute agreement between the GGM geoid or the gravimetric geoid and the GPS/levelling data, and they are taken as the final external indication of the geoid accuracy (Fotopoulos, 1999).

The parametric part $\mathrm{a}_{\mathrm{i}}^{\mathrm{T}} \mathrm{x}$ can describe all possible datum inconsistencies and systematic distortions of the data.

One of the most common models is the four-parameter transformation model given by

$\mathrm{a}_{\mathrm{i}}^{\mathrm{T}} \mathrm{x}=\mathrm{x}_{1}+\mathrm{x}_{2} \cos \varphi_{\mathrm{i}} \cos \lambda_{\mathrm{i}}+\mathrm{x}_{3} \cos \varphi_{\mathrm{i}} \sin \lambda_{\mathrm{i}}+\mathrm{x}_{4} \sin \varphi_{\mathrm{i}}$ 
where $\varphi_{\mathrm{i}}$ and $\lambda_{\mathrm{i}}$ are the latitude and longitude of the GPS/levelling points, $\mathrm{x}_{1}$ is the shift parameter between the vertical datum implied by the GPS/levelling data and the datum of the GGM, $x_{2}, x_{3}$, and $x_{4}$ are the translation parameters implied by the GPS/levelling data and the geopotential model.

Other classes of models are polynomials referred to as the multiple regression formula (MRE) in Fotopoulos (1999):

$a_{i}^{\mathrm{T}} \mathrm{x}=\sum_{\mathrm{m}=0}^{\mathrm{M}} \sum_{\mathrm{n}=0}^{\mathrm{N}}\left(\varphi_{\mathrm{i}}-\varphi_{0}\right)^{\mathrm{n}}\left(\lambda_{\mathrm{i}}-\lambda_{0}\right)^{\mathrm{m}} \mathrm{x}_{\mathrm{q}}$

where $\varphi_{0}, \lambda_{0}$ are the mean values of the latitude and longitude of the GPS/levelling points and $\mathrm{x}_{\mathrm{q}}$ contains the $\mathrm{q}$ unknown coefficients; $\mathrm{q}$ varies according to the number of terms up to a maximum of $\mathrm{q}=(\mathrm{N}+1)(\mathrm{M}+1)$.

Another model is the seven-parameters similarity transformation model given by Kotsakis (2001):

$$
\begin{aligned}
& a_{i}^{T} x=x_{1} \cos \varphi_{i} \cos \lambda_{i}+x_{2} \cos \varphi_{i} \cos \lambda_{i}+x_{3} \sin \varphi_{i}+x_{4}\left(\frac{\sin \varphi_{i} \cos \varphi_{i} \sin \lambda_{i}}{W}\right)+ \\
& x_{5}\left(\frac{\sin \varphi_{i} \cos \varphi_{i} \cos \lambda_{i}}{W}\right)+x_{6}\left(\frac{1-f^{2} \operatorname{sen}^{2} \varphi_{i}}{W}\right)+x_{7}\left(\frac{\sin ^{2} \varphi_{i}}{W}\right)
\end{aligned}
$$

where $\mathrm{W}=\sqrt{1-\mathrm{e}^{2} \sin ^{2} \varphi_{\mathrm{i}}}, \mathrm{e}^{2}$ is the eccentricity and $\mathrm{f}$ is the flattening of the reference ellipsoid. The parametric model corresponds to a parallel datum shift plus two small rotations around the $\mathrm{x}$ - and $\mathrm{y}$-axes, plus one change in the semi-major axis of the reference ellipsoid, plus one change in the flattening of the reference ellipsoid.

During the numerical result carried out through this thesis, these three types of models were used.

\section{National Analysis}

The statistics of the absolute differences between the geoid model derived from different geopotential models and GPS/levelling-derived undulations for the entire Argentinean region can be seen in Appendix 1. Appendix 1 also shows the statistics of 
the discrepancies between the geoid from different geopotential models and GPS/levelling after the fit of a $3^{\text {rd }}$ order polynomial model, the least-square fitting of a four-parameter transformation model and a differential similarity transformation model, with 7 parameters.

Before the least squares fitting was applied, a 3 root-mean-square value (rms) test was employed to remove some remaining outliers that could not be removed by the simple visualization method. The number of points depends on the geopotential model used (for example, 4 points for the EIGEN_CG01C and only 1 point for EGM96).

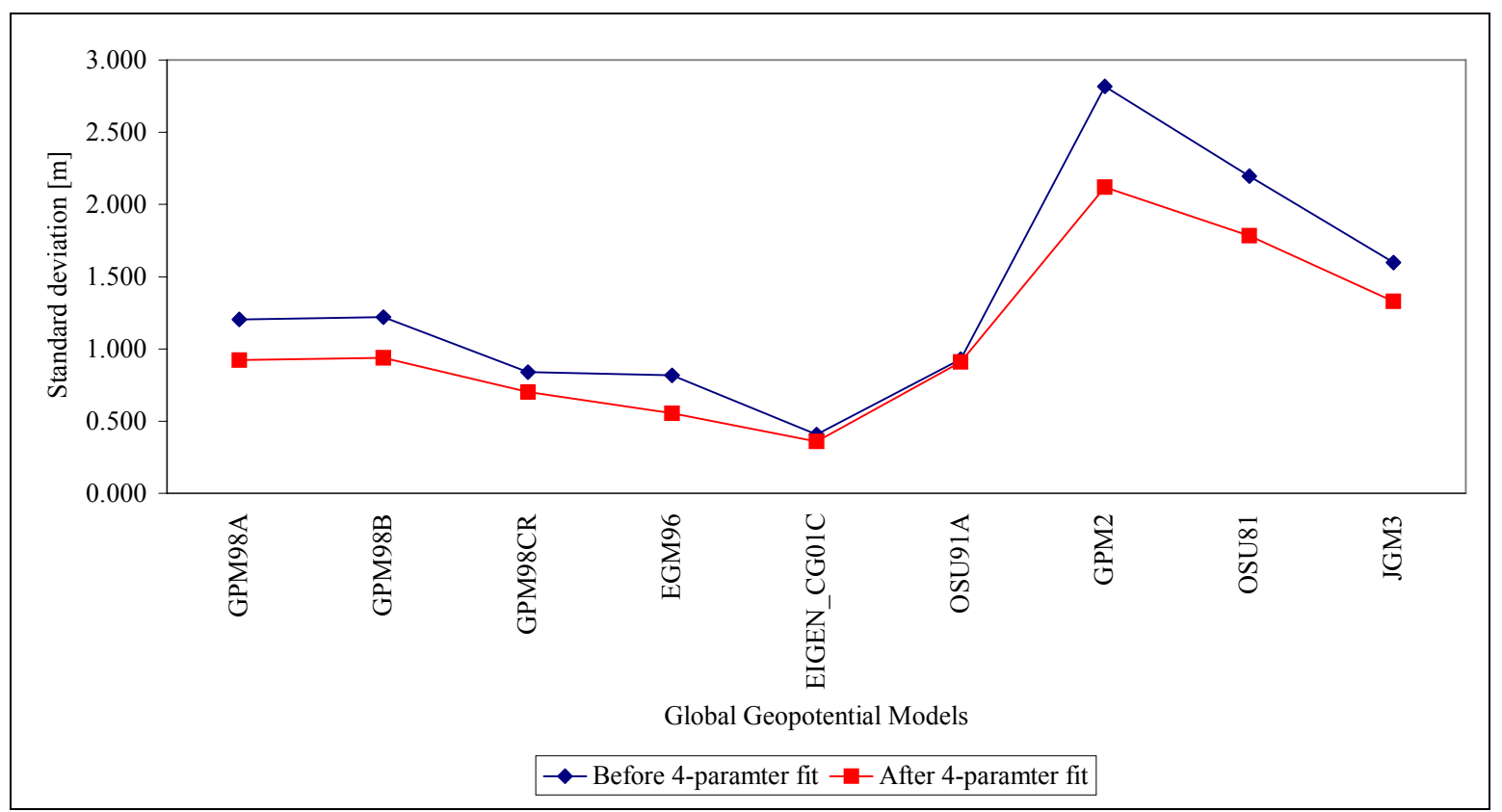

Figure 4.29: Standard deviation of the absolute differences between the different geoid undulations computed from geopotential models with GPS/levelling-derived geoid (before and after fit)

To summarize the results presented in the Appendix 1, the standard deviations of the differences between the geoid undulations computed from the different geopotential models with the GPS/levelling derived geoids before and after fir are plotted in Figure 4.29 .

From the statistics shown in Appendix 1, it can be seen that EIGEN_CG01C and EGM96 are the best global geopotential models that represent the long wavelength gravity field in Argentina. 
For the EIGEN_CG01C, it can be seen from Appendix 1 that there is $5 \mathrm{~cm}, 7 \mathrm{~cm}$ and 6 $\mathrm{cm}$ improvement in the standard deviation of the differences after using a fourparameter, a third polynomial and a seven-parameters similarity transformation model, respectively.

\section{Regional Analysis}

The absolute differences between the geoid undulations computed from different geoid models with GPS/levelling derived geoid undulations at each network are presented in Appendices 2 to 9. From these tables, we can see that the EIGEN_CG01C global gravity model best fits the long-wavelength structure of the gravity field in almost all the GPS/levelling networks, with the exception of the Tierra del Fuego network where the OSU91A $(\sigma \approx 21 \mathrm{~cm})$ model is superior in terms of the standard deviation to the EIGEN_CG01C $(\sigma \approx 27 \mathrm{~cm})$, before and after fitting a four parameter, a seven parameter and third order polynomial model. But in terms of mean values, the results is reverse; $57 \mathrm{~cm}$ for OSU91A and $7 \mathrm{~cm}$ for EIGEN_CG01C.

The differences, after a four-parameter transformation model has been applied to the differences between the geoid computed from the different geopotential models with the geoid derived from GPS/levelling, are depicted in Appendix 10.

After applying the model given in (4.25), the remaining, mostly random errors were not considered. In other studies, these errors are usually modeled by least-squares collocation and added to the corrector surface.

\subsubsection{Comparisons between gravity anomalies computed from different global geopotential models and marine, land and free-air gravity anomalies derived from satellite altimetry}

Gravity anomalies from the geopotential models OSU91A, EGM96, GPM98A and GPM98B and EIGEN-CG01C were computed using formula (2.12) and they were compared with land, sea and altimetry free-air gravity anomalies in Argentina. 
Table 4.14: Statistical comparisons between gravity anomalies computed from GGMs and marine gravity anomalies. Unit: [mGal].

\begin{tabular}{l|cccc}
\hline & min & max & mean & $\sigma$ \\
\hline Marine $\Delta \mathrm{g}$ & -133.03 & 142.57 & 4.01 & 28.64 \\
$\Delta \mathrm{g}$ OSU91A & -98.21 & 104.85 & 2.68 & 24.51 \\
$\Delta \mathrm{g}$ EGM96 & -109.98 & 116.19 & 3.18 & 27.05 \\
$\Delta \mathrm{g}$ GPM98A & -132.83 & 114.74 & 3.09 & 27.19 \\
$\Delta \mathrm{g}$ GPM98B & -133.85 & 116.27 & 3.38 & 27.21 \\
$\Delta \mathrm{g}$ EIGEN-CG01C & -118.97 & 119.71 & 2.95 & 27.51 \\
\hline Marine $\Delta \mathrm{g}-\Delta \mathrm{g}$ OSU91A & -75.87 & 63.89 & 1.33 & 12.79 \\
Marine $\Delta \mathrm{g}-\Delta \mathrm{g}$ EGM96 & -80.51 & 62.15 & 0.83 & 12.54 \\
Marine $\Delta \mathrm{g}-\Delta \mathrm{g}$ GPM98A & -46.78 & 68.64 & 0.92 & 8.79 \\
Marine $\Delta \mathrm{g}-\Delta \mathrm{g}$ GPM98B & -46.31 & 68.40 & 0.63 & 9.00 \\
Marine $\Delta \mathrm{g}-\Delta \mathrm{g}$ EIGEN-CG01C & -81.00 & 71.77 & 1.06 & 13.40 \\
\hline
\end{tabular}

Table 4.15: Statistical comparisons between gravity anomalies computed from GGMs and KMS02 satellite derived free-air gravity anomalies. Unit: [mGal].

\begin{tabular}{|c|c|c|c|c|}
\hline 16961 KMS02 points & $\min$ & $\max$ & mean & $\sigma$ \\
\hline $\mathrm{KMS} 02 \Delta \mathrm{g}$ & -98.37 & 131.47 & 3.46 & 16.96 \\
\hline$\Delta \mathrm{g}$ OSU91A & -87.18 & 105.60 & 1.34 & 14.61 \\
\hline$\Delta \mathrm{g}$ EGM96 & -95.00 & 108.22 & 2.92 & 15.76 \\
\hline$\Delta \mathrm{g}$ GPM98A & -100.88 & 128.94 & 1.90 & 16.71 \\
\hline$\Delta \mathrm{g}$ GPM98B & -100.91 & 127.74 & 1.48 & 16.71 \\
\hline$\Delta \mathrm{g}$ EIGEN-CG01C & -106.71 & 100.14 & 1.70 & 15.16 \\
\hline $\mathrm{KMS} 02 \Delta \mathrm{g}-\Delta \mathrm{g}$ OSU91A & -31.49 & 47.67 & 2.11 & 7.90 \\
\hline KMS02 $\Delta \mathrm{g}-\Delta \mathrm{g}$ EGM96 & -25.88 & 48.33 & 0.54 & 6.79 \\
\hline KMS02 $\Delta \mathrm{g}-\Delta \mathrm{g}$ GPM98A & -140.83 & 103.73 & 1.56 & 6.31 \\
\hline KMS02 $\Delta \mathrm{g}-\Delta \mathrm{g}$ GPM98B & -139.89 & 102.25 & 1.98 & 6.37 \\
\hline KMS02 $\Delta \mathrm{g}-\Delta \mathrm{g}$ EIGEN-CG01C & -27.46 & 61.51 & 1.76 & 6.79 \\
\hline
\end{tabular}

Table 4.16: Statistical comparisons between gravity anomalies computed from GGMs and land gravity anomalies. Unit:[mGal].

\begin{tabular}{l|cccc}
\hline & min & max & mean & $\sigma$ \\
\hline Land $\Delta \mathrm{g}$ & -145.32 & 280.00 & 7.71 & 38.40 \\
$\Delta \mathrm{g}$ OSU91A & -142.27 & 237.91 & 19.26 & 41.73 \\
$\Delta \mathrm{g}$ EGM96 & -112.66 & 247.60 & 13.65 & 41.49 \\
$\Delta \mathrm{g}$ GPM98A & -92.59 & 319.21 & 23.61 & 41.47 \\
$\Delta \mathrm{g}$ GPM98B & -92.71 & 378.56 & 23.87 & 41.76 \\
$\Delta \mathrm{g}$ EIGEN-CG01C & -100.27 & 248.96 & 14.59 & 40.57 \\
\hline Land $\Delta \mathrm{g}-\Delta \mathrm{g}$ OSU91A & -298.85 & 231.12 & -11.56 & 34.62 \\
Land $\Delta \mathrm{g}-\Delta \mathrm{g}$ EGM96 & -321.92 & 216.73 & -5.95 & 28.26 \\
Land $\Delta \mathrm{g}-\Delta \mathrm{g}$ GPM98A & -313.47 & 245.73 & -15.97 & 28.46 \\
Land $\Delta \mathrm{g}-\Delta \mathrm{g}$ GPM98B & -352.46 & 262.40 & -16.09 & 28.26 \\
Land $\Delta \mathrm{g}-\Delta \mathrm{g}$ EIGEN-CG01C & -300.82 & 225.15 & -6.88 & 28.33 \\
\hline
\end{tabular}


The smallest standard deviation in the differences between the gravity anomalies from the database and the gravity anomalies derived from the geopotential model can be taken as an indication of the best geopotential model.

The free-air gravity anomalies were selected from the gravity database. Their statistics can be seen in Tables 4.14, 4.15 and 4.16 for shipborne, KMS02 and land gravity anomalies, respectively.

From the above tables, the GPM98A and GPM98B show better standard deviation in the marine and altimetry comparisons but in the comparisons with land data all models show similar statistics. Considering these results in conjunction with the comparisons made with the GPS/levelling-derived geoid, the EIGEN_CG01C gave better results overall and it is the GGM that best fits the long wavelength structure of the gravity field in Argentina, followed by EGM96. Some of the numerical tests carried out during this research were done before the public distribution of the EIGEN_CG01C global gravity model to the scientific community.

\subsection{Summary}

The following data and models were selected after the evaluations described in this chapter and will be used in the numerical results presented in the following chapters.

\begin{tabular}{|c|c|}
\hline Gravimetric geoid & Altimetric geoid \\
\hline $\begin{array}{c}\text { Gravity data } \\
\text { - } 66717 \text { land free-air gravity anomalies } \\
\text { - } 128717 \text { Bouguer gravity anomalies } \\
\text { anomalies shipborne free-air gravity } \\
\text { KMS01 \& KMS02 global altimetry- } \\
\text { derived marine free-air gravity anomalies }\end{array}$ & $\begin{array}{c}70510 \text { Corrected Sea Surface Heights from } \\
\text { the ERS1 Geodetic Mission }\end{array}$ \\
\hline $\begin{array}{c}\text { EGM96 \& EIGEN_CG01C } \\
\text { Global Gravity Models }\end{array}$ & EGM96 \& CHAMP/GRACE-type EGMs \\
(Vergos et al., 2004)
\end{tabular}




\section{CHAPTER FIVE}

\section{PREDICTION AND STATISTICAL BEHAVIOR OF GRAVITY ANOMALIES}

The gravimetric geoid model for Argentina will be computed by the Fast Fourier Transform. The use of FFT requires that random gravity data points be interpolated on a grid.

The gridding methods of weighted means, continuous curvature in tension and leastsquares collocation will be described. This chapter also presents the basic concepts of covariance, correlation and power spectral density (PSD) functions. The results of a covariance analysis for areas with different topographic schemes in Argentina are also presented in this chapter.

\subsection{Three predictions methods for gravity anomalies}

\subsubsection{Weighted means}

The inverse distance weighting is a deterministic interpolation method where the values at grid points are estimated by values located at arbitrary points.

The original inverse distance weighted interpolation method was given in Shepard, (1968). The basic formula for the prediction of a function $\mathrm{f}(\mathrm{x}, \mathrm{y})$ was given in Morrison and Douglas (1984), and it can be expressed as:

$f(x, y)=\frac{\sum_{k=1}^{N} f\left(x_{k}, y_{k}\right) w\left(x, x_{k}, y, y_{k}\right)}{\sum_{k=1}^{N} w\left(x, x_{k}, y, y_{k}\right)}$

with $\mathrm{w}\left(\mathrm{x}, \mathrm{x}_{\mathrm{k}}, \mathrm{y}, \mathrm{y}_{\mathrm{k}}\right)=\left[\left(\mathrm{x}-\mathrm{x}_{\mathrm{k}}\right)^{2}+\left(\mathrm{y}-\mathrm{y}_{\mathrm{k}}\right)^{2}\right]^{-\mathrm{p} / 2}$ 
where $\mathrm{w}$ is the weighting function and $\mathrm{p}$ is the power of the prediction, $\mathrm{p}>0$. The user specifies the value of $p$. The most common choice is $p=2$. $x_{k}$ and $y_{k}$ are the coordinates of the $\mathrm{N}$ sampling points.

For the prediction of gravity anomalies at a point $(\mathrm{x}, \mathrm{y}),(5.1)$ becomes::

$$
\Delta g(x, y)=\frac{\sum_{k=1}^{N} \Delta g\left(x_{k}, y_{k}\right) w\left(x, x_{k}, y, y_{k}\right)}{\sum_{k=1}^{N} w\left(x, x_{k}, y, y_{k}\right)}
$$

The estimated value $\Delta \mathrm{g}$ is based on the weighted sum of $\mathrm{N}$ close observations $\Delta \mathrm{g}\left(\mathrm{x}_{\mathrm{k}}, \mathrm{y}_{\mathrm{k}}\right)$.

\subsubsection{Continuous curvature splines in tension}

The minimum curvature method interpolates the data to be gridded with a surface having continuous second derivates and minimum total squared curvature (Smith and Wessel, 1990). Minimum curvature surfaces may have large and suspicious inflections points, which are not suitable for gridding, and they can be eliminated adding a tension parameter.

The total squared curvature $\mathrm{C}$ is:

$C=\iint\left(\nabla^{2} z\right)^{2} d x d y$

supposing $z=f(x, y)=\Delta g$

Minimizing equation (5.4) leads to the following differential equation:

$\nabla^{2}\left(\nabla^{2} \Delta \mathrm{g}\right)=\sum_{\mathrm{i}} \mathrm{f}_{\mathrm{i}} \delta\left(\mathrm{x}-\mathrm{x}_{\mathrm{i}}, \mathrm{y}-\mathrm{y}_{\mathrm{i}}\right)$

where $\nabla^{2}$ is the Laplacian operator and $\left(\mathrm{x}_{\mathrm{i}}, \mathrm{y}_{\mathrm{i}}, \Delta \mathrm{g}_{\mathrm{i}}\right)$ are constraining data. The $\mathrm{f}_{\mathrm{i}}$ must be chosen such that $\Delta \mathrm{g} \rightarrow \Delta \mathrm{g}_{\mathrm{i}}$ as $(\mathrm{x}, \mathrm{y}) \rightarrow\left(\mathrm{x}_{\mathrm{i}}, \mathrm{y}_{\mathrm{i}}\right)$ and the boundary conditions along the edges are: 
$\frac{\partial^{2} \Delta \mathrm{g}}{\partial \mathrm{n}^{2}}=0$

$\frac{\partial}{\partial \mathrm{n}}\left(\nabla^{2} \mathrm{z}\right)=0$

where $\frac{\partial}{\partial \mathrm{n}}$ is the derivate normal to an edge, and at the corners

$$
\frac{\partial^{2} z}{\partial x \partial y}=0
$$

Equations (5.6), (5.7) and (5.8) are the free edge conditions and with these conditions, equation (5.5) has a unique solution with continuous second derivates.

Smith and Wessel (1990) expressed equation (5.5) in a general form as follows:

$$
\mathrm{D} \nabla^{2}\left(\nabla^{2} \Delta \mathrm{g}\right)-\left[\mathrm{T}_{\mathrm{xx}} \frac{\partial^{2} \Delta \mathrm{g}}{\partial \mathrm{x}^{2}}+2 \mathrm{~T}_{\mathrm{xy}} \frac{\partial^{2} \Delta \mathrm{g}}{\partial \mathrm{x} \partial \mathrm{y}}+\mathrm{T}_{\mathrm{yy}} \frac{\partial^{2} \Delta \mathrm{g}}{\partial \mathrm{y}^{\prime \prime}}\right]=\mathrm{q}
$$

where $\mathrm{D}$ is the constant flexural rigidity; $\mathrm{q}$ is the normal vertical stress; and $\mathrm{T}_{\mathrm{xx}}, \mathrm{T}_{\mathrm{xy}}$ and $\mathrm{T}_{\mathrm{yy}}$ are the constant horizontal forces per unit length.

When $\mathrm{T}_{\mathrm{xx}}=\mathrm{T}_{\mathrm{yy}}=\mathrm{T}$ and $\mathrm{T}_{\mathrm{xy}}=0$

equation (5.9) becomes:

$$
\mathrm{D} \nabla^{2}\left(\nabla^{2} \Delta \mathrm{g}\right)-\mathrm{T} \nabla^{2} \Delta \mathrm{g}=\mathrm{q}
$$

or according to Smith and Wessel (1990):

$$
(1-\mathrm{T}) \nabla^{2}\left(\nabla^{2} \Delta \mathrm{g}\right)-\mathrm{T} \nabla^{2} \Delta \mathrm{g}=\sum_{\mathrm{i}} \mathrm{f}_{\mathrm{i}} \delta\left(\mathrm{x}-\mathrm{x}_{\mathrm{i}}, \mathrm{y}-\mathrm{y}_{\mathrm{i}}\right)
$$

where $\mathrm{T}$ is the tension parameter between 0 and 1 .

$\mathrm{T}=0$ gives the minimum curvature spline surface solution. 
The adjustable tension continuous curvature surface gridding algorithm is also used in this research. This algorithm is implemented in the surface routine of the Generic Mapping Tools (GMT).

Smith and Wessel recommend, according to their experience, that $\mathrm{T} \approx 0.25$ usually works well for potential field data and a $\mathrm{T}$ larger than $\mathrm{T} \approx 0.35$ for steep topography data. $\mathrm{T}=1$ gives a harmonic surface.

\subsubsection{Least-square collocation}

The method of least-squares collocation can be used for the prediction of gravity anomalies; it uses the statistical information inherent in the covariance function and takes into account the errors of the observations (Torge, 2001).

The interpolated gravity anomaly at a point P (Heiskanen and Moritz, 1967; Torge, 2001) is:

$\Delta \mathrm{g}_{\mathrm{P}}=\mathrm{C}_{\mathrm{P}}^{\mathrm{T}}(\mathrm{C}+\mathrm{D})^{-1} \Delta \mathrm{g}_{\mathrm{i}}$

where $\Delta g_{i}(i=1 \ldots n)$ is the vector of gravity anomalies at $n$ observations points, and

$\mathrm{C}_{\mathrm{P}}{ }^{\mathrm{T}}=\left(\begin{array}{llll}\mathrm{C}_{\mathrm{P} 1} & \mathrm{C}_{\mathrm{P} 2} & \mathrm{C}_{\mathrm{P} 3} \ldots . . & \mathrm{C}_{\mathrm{Pn}}\end{array}\right)$ and $\mathrm{C}=\left(\begin{array}{cccc}\mathrm{C}_{11} & \mathrm{C}_{12} & & \mathrm{C}_{1 \mathrm{n}} \\ \mathrm{C}_{21} & \cdot & \cdot & \mathrm{C}_{2 \mathrm{n}} \\ \cdot & \cdot & \cdot & \cdot \\ \mathrm{C}_{\mathrm{n} 1} & \mathrm{C}_{\mathrm{n} 2} & & \mathrm{C}_{\mathrm{nn}}\end{array}\right)$

$\mathrm{C}_{\mathrm{P}}{ }^{\mathrm{T}}$ is the covariance vector between $\Delta \mathrm{g}_{\mathrm{P}}$ and $\Delta \mathrm{g}_{\mathrm{i}}$ (measured and predicted gravity anomalies) and $\mathrm{C}$ is the covariance matrix of the measurements $\Delta \mathrm{g}_{\mathrm{i}}$. All the covariance elements $\mathrm{C}_{\mathrm{Pi}}$ and $\mathrm{C}_{\mathrm{ij}}$ are obtained from the same covariance function $\mathrm{C}(\mathrm{s})$ or $\mathrm{C}(\psi)$, which is assumed to depend only on the horizontal distance s or the spherical distance $\psi$ of the points under consideration.

$\mathrm{C}_{\mathrm{Pi}}=\mathrm{C}\left(\mathrm{s}_{\mathrm{Pi}}\right)$ or $\mathrm{C}\left(\psi_{\mathrm{Pi}}\right)$ and $\mathrm{C}_{\mathrm{ij}}=\mathrm{C}\left(\mathrm{s}_{\mathrm{ij}}\right)$ or $\mathrm{C}\left(\psi_{\mathrm{ij}}\right)$ 
where $\mathrm{s}_{\mathrm{Pi}}$ or $\psi_{\mathrm{Pi}}$ is the horizontal distance or the spherical distance between $\mathrm{P}$ and $\mathrm{P}_{\mathrm{i}}$ and $\mathrm{s}_{\mathrm{ij}}$ or $\psi_{\mathrm{ij}}$ is the horizontal distance or the spherical distance between $\mathrm{P}_{\mathrm{i}}$ and $\mathrm{P}_{\mathrm{j}}$.

$\mathrm{D}=\left(\begin{array}{cccc}\mathrm{D}_{11} & \mathrm{D}_{12} & & \mathrm{D}_{1 \mathrm{n}} \\ \mathrm{D}_{21} & \cdot & \cdot & \mathrm{D}_{2 \mathrm{n}} \\ \cdot & \cdot & \cdot & \cdot \\ \mathrm{D}_{\mathrm{n} 1} & \mathrm{D}_{\mathrm{n} 2} & & \mathrm{D}_{\mathrm{nn}}\end{array}\right)$

is the covariance matrix of the observation errors.

The prediction error is $\varepsilon=\Delta \mathrm{g}-\overline{\Delta \mathrm{g}}$. The error covariance matrix for the estimate is computed from:

$\mathrm{E}_{\mathrm{PP}}=\mathrm{C}_{\mathrm{PP}}-\mathrm{C}_{\mathrm{P}}^{\mathrm{T}}(\mathrm{C}+\mathrm{D})^{-1} \mathrm{C}_{\mathrm{P}}$

The covariance matrices $C_{P}{ }^{T}, C$ and $D$ are determined from models for covariance functions.

\subsection{Covariance functions}

The knowledge of the covariance function of the gravity anomalies is essential for the gravity anomaly prediction by least-square collocation and it is the basic descriptor of the statistical properties of the variations of the gravity field (Forsberg, 1984). The basic concept of the covariance function will be presented first and then the gravity anomaly covariance function will be discussed.

The covariance function $\mathrm{C}_{\mathrm{gh}}(\mathrm{x}, \mathrm{y})$ of two functions $\mathrm{g}\left(\mathrm{x}_{1}, \mathrm{y}_{1}\right)$ and $\mathrm{h}\left(\mathrm{x}_{2}, \mathrm{y}_{2}\right)$ is defined as:

$$
\mathrm{C}_{\mathrm{gh}}(\Delta \mathrm{x}, \Delta \mathrm{y})=\mathrm{E}\left[\left(\mathrm{g}\left(\mathrm{x}_{1}, \mathrm{y}_{1}\right)-\overline{\mathrm{g}}\right)\left(\mathrm{h}\left(\mathrm{x}_{2}, \mathrm{y}_{2}\right)-\overline{\mathrm{h}}\right)\right]
$$

where $\Delta x=x_{2}-x_{1}, \Delta y=y_{2}-y_{1}, E$ is the mathematical expectation operator, and $\bar{g}$ and $\bar{h}$ are the mean values of the functions $g\left(x_{1}, y_{1}\right)$ and $h\left(x_{2}, y_{2}\right)$, respectively. 
When the two functions are equal, $\mathrm{g}\left(\mathrm{x}_{1}, \mathrm{y}_{1}\right)=\mathrm{h}\left(\mathrm{x}_{2}, \mathrm{y}_{2}\right)$, equation (5.10) gives the autocovariance function and when $\mathrm{g}\left(\mathrm{x}_{1}, \mathrm{y}_{1}\right) \neq \mathrm{h}\left(\mathrm{x}_{2}, \mathrm{y}_{2}\right)$ the covariance is known as the crosscovariance function.

If $\overline{\mathrm{g}}=\overline{\mathrm{h}}=0, \mathrm{~g}\left(\mathrm{x}_{1}, \mathrm{y}_{1}\right)$ and $\mathrm{h}\left(\mathrm{x}_{2}, \mathrm{y}_{2}\right)$ are called centered functions.

\subsection{Gravity anomaly covariance function}

The average product of the gravity anomalies $\Delta g_{i} \Delta g_{j}$ at each pair of points $P_{i}$ and $P_{j}$ that are distance s apart is called the covariance of the gravity anomalies and is defined as:

$\mathrm{C}(\mathrm{s})=\mathrm{C}\left\{\Delta \mathrm{g}_{\mathrm{i}}, \Delta \mathrm{g}_{\mathrm{j}}, \mathrm{s}\right\} \equiv \mathrm{M}\left\{\Delta \mathrm{g}_{\mathrm{i}} \Delta \mathrm{g}_{\mathrm{j}}\right\}_{\mathrm{s}}$

where $\mathrm{M}$ is the averaging operator on the sphere and it is extended over all pair of points $\mathrm{Pi}$ and $\mathrm{P}_{\mathrm{j}}$ for which the distance between $\mathrm{P}_{\mathrm{i}} \mathrm{P}_{\mathrm{j}}$ is $\mathrm{s}=$ constant.

The covariance function represents the statistical behavior of the gravity anomalies It can be can be expressed in spherical coordinates $(\varphi, \lambda)$ by:

$\mathrm{C}(\psi)=\mathrm{C}\left\{\Delta \mathrm{g}_{\mathrm{i}}, \Delta \mathrm{g}_{\mathrm{j}}, \psi\right\} \equiv \mathrm{M}\left\{\Delta \mathrm{g}_{\mathrm{i}} \Delta \mathrm{g}_{\mathrm{j}}\right\}_{\psi}=\frac{1}{4 \pi} \iint_{\sigma} \Delta \mathrm{g}_{\mathrm{i}} \Delta \mathrm{g}_{\mathrm{j}} \mathrm{d} \sigma$

where $\psi$ is the spherical distance on the unit sphere.

For $\mathrm{s}=0$ or $\psi=0, \Delta \mathrm{g}_{\mathrm{i}}=\Delta \mathrm{g}_{\mathrm{j}}=\Delta \mathrm{g}$ and equation (5.21) yields the variance:

$\sigma^{2}(\Delta \mathrm{g})=\mathrm{M}\left\{\Delta \mathrm{g}^{2}\right\}=\frac{1}{4 \pi} \iint_{\sigma} \Delta \mathrm{g}^{2} \mathrm{~d} \sigma$

The covariance function shows the correlation of gravity anomalies with distance. The correlation coefficient $r$ is:

$$
r\left(\Delta g_{i}, \Delta g_{j}, \psi\right)=\frac{C\left\{\Delta g_{i}, \Delta g_{j}, \psi\right\}}{\sigma^{2}(\Delta g)}
$$


Usually, the correlation decreases as the spherical distance increases.

\subsection{Computation of empirical covariance functions}

There are two methods to compute the empirical covariance function; one is the direct method, which computes the empirical covariance function directly from the data and the other is the indirect method, which computes the empirical covariance function from the power spectral density (PSD) function.

\subsubsection{Direct method}

The empirical covariance function estimated directly from the local data in the space domain can be expressed (Esan, 2000) as:

$\mathrm{C}\left(\mathrm{s}_{\mathrm{k}}\right)=\frac{\sum_{\mathrm{k}} \Delta \mathrm{g}_{\mathrm{i}} \Delta \mathrm{g}_{\mathrm{j}}}{\mathrm{n}_{\mathrm{k}}}$ or $\mathrm{C}\left(\psi_{\mathrm{k}}\right)=\frac{\sum_{\mathrm{k}} \Delta \mathrm{g}_{\mathrm{i}} \Delta \mathrm{g}_{\mathrm{j}}}{\mathrm{n}_{\mathrm{k}}}$

where $n_{k}$ are the number of products between all pairs of gravity anomalies according to the class distance $\mathrm{s}_{\mathrm{k}}$ or $\psi_{\mathrm{k}}$.

\subsubsection{Indirect method}

The second method estimates the covariance function using the FFT technique. The covariance function can also be defined (Schwarz et al., 1990) as:

$\left.\mathrm{C}_{\mathrm{gh}}(\Delta \mathrm{x}, \Delta \mathrm{y})=\mathrm{R}_{\mathrm{gh}}(\Delta \mathrm{x}, \Delta \mathrm{y})-\overline{\mathrm{gh}}\right\}$

where $\mathrm{R}_{\mathrm{gh}}(\mathrm{x}, \mathrm{y})$ is the correlation function of $\mathrm{g}\left(\mathrm{x}_{1}, \mathrm{y}_{1}\right)$ and $\mathrm{h}\left(\mathrm{x}_{2}, \mathrm{y}_{2}\right)$ defined as:

$\mathrm{R}_{\mathrm{gh}}(\Delta \mathrm{x}, \Delta \mathrm{y})=\mathrm{E}\left[\mathrm{g}\left(\mathrm{x}_{1}, \mathrm{y}_{1}\right) \mathrm{h}\left(\mathrm{x}_{2}, \mathrm{y}_{2}\right)\right]$

If $\overline{\mathrm{g}}=\overline{\mathrm{h}}=0$, the correlation function is the same as the covariance function.

The power spectral density function is the frequency domain equivalent of the correlation function: 
$\mathrm{P}_{\mathrm{gh}}(\mathrm{u}, \mathrm{v})=\mathrm{F}\left\{\mathrm{R}_{\mathrm{gh}}(\mathrm{x}, \mathrm{y})\right\}$

where $\mathrm{u}$ and $\mathrm{v}$ are the spatial frequencies corresponding to $\mathrm{x}$ and $\mathrm{y}$, respectively. Thus,

$$
\mathrm{R}_{\mathrm{hg}}(\mathrm{x}, \mathrm{y})=\mathrm{F}^{-1}\left\{\mathrm{P}_{\mathrm{hg}}(\mathrm{u}, \mathrm{v})\right\}
$$

For centered data, the inverse Fourier transform of the PSD function provides the covariance function:

$$
\mathrm{C}_{\mathrm{hg}}(\mathrm{x}, \mathrm{y})=\mathrm{F}^{-1}\left\{\mathrm{P}_{\mathrm{hg}}(\mathrm{u}, \mathrm{v})\right\}
$$

\subsection{Local and global covariance functions}

The covariance functions can be either local or global. A local covariance function represents the gravity field structure for a certain area after trend removal (Schwartz et al., 1990).

The essential parameters used to describe the characteristics of the local covariance function of the gravity anomalies are: the variance $C_{0}$, the correlation length $\xi$ and the curvature parameter $\chi$ or the gradient variance $G_{0}$. The variance $C_{o}$ is the value of the covariance value at distance zero.

The correlation length $\xi$ is defined as the distance at which the covariance is half of the variance value:

$\mathrm{C}(\xi)=\frac{1}{2} \mathrm{C}_{\mathrm{o}}$

The variance and correlation length are depicted in Figure 5.1.

The curvature parameter $\chi$ is related to the curvature of the covariance curve at $\psi=0$ by

$\chi=\kappa \xi^{2} / C_{o}$

The gradient variance $G_{o}$ is the variance of the horizontal gradient of $\Delta \mathrm{g}$ or half of the variance of the vertical gradient of $\Delta \mathrm{g}$, and it is related to the curvature parameter by: 


$$
\mathrm{G}_{\mathrm{o}}=\chi \mathrm{C}_{\mathrm{o}} / \xi^{2}=\operatorname{var}\left(\frac{\partial \Delta \mathrm{g}}{\partial \mathrm{x}}\right)=\operatorname{var}\left(\frac{\partial \Delta \mathrm{g}}{\partial \mathrm{y}}\right)=\frac{1}{2} \operatorname{var}\left(\frac{\partial \Delta \mathrm{g}}{\partial \mathrm{z}}\right)
$$

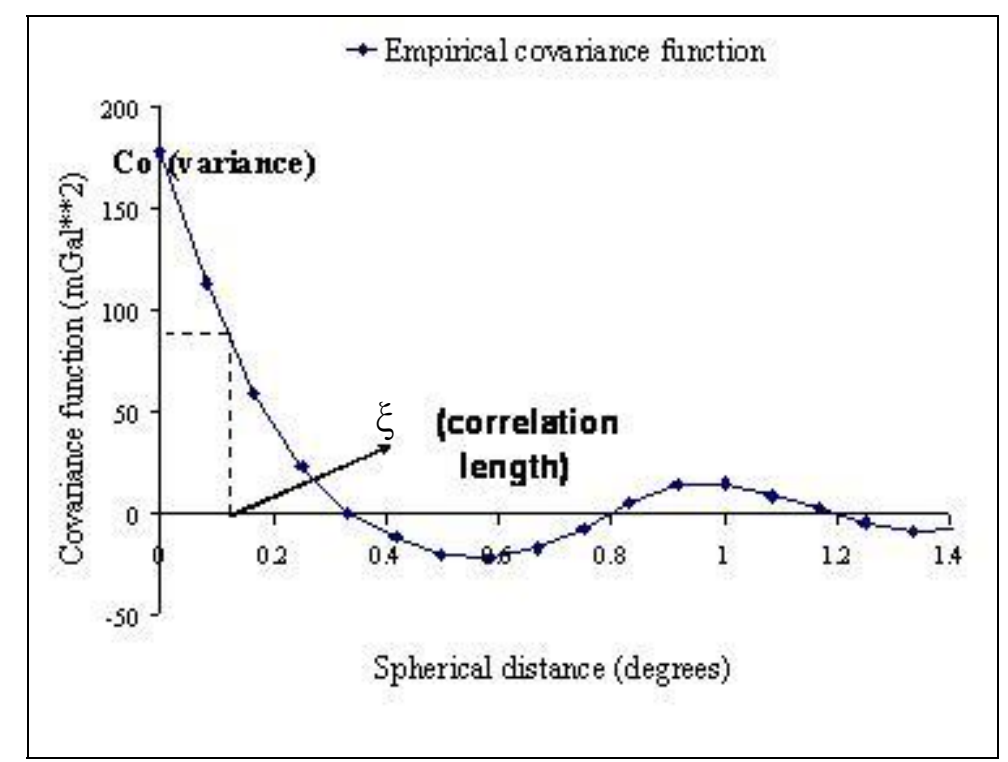

Figure 5.1: Empirical covariance function and essential parameters

Covariance functions with the same essential parameters show a similar interpolation behavior independent of the model.

\subsection{Modeling the empirical covariance function}

Modeling the empirical gravity anomaly covariance function implies the determination of an analytical covariance function that fits the empirical values. The adjustment of the local covariance is done by estimating the values of the three essentials parameters. The information provided by the analytical function is used for the prediction method.

There are various planar covariance models for gravity field modeling used for prediction; several examples of planar covariance functions are described in Moritz (1980). Some of these models are the Gaussian, Hirvonen, and first-order, second order and third order Markov model.

As an example, the second-order Markov model is expressed as

$$
C(s)=C_{0}\left(1+\frac{s}{D}\right) e^{-s / D}
$$


where $\mathrm{s}$ is the distance, $\mathrm{C}_{\mathrm{o}}$ is the variance and $\mathrm{D}$ is a constant parameter.

For spherical Earth, the Tscherning/Rapp model (Tscherning and Rapp, 1974) is a degree variance model and it will be used in this research for covariance modeling.

The gravity anomaly covariance function $\mathrm{C}(\mathrm{P}, \mathrm{Q})$ on the can also be derived by covariance propagation from the basic covariance function $K(P, Q)$ of the disturbing potential T, which can be expressed in terms of Legendre polynomials (Moritz, 1980) as:

$K(P, Q)=K(\psi)=\sum_{n=2}^{n_{\max }} \sigma_{n}(T, T)\left(\frac{R_{B}}{r^{\prime}}\right)^{n+1} P_{n}(\cos \psi)$

where $\sigma_{n}(T, T)$ are the anomalous potential degree variances, $R_{B}$ is the radius of the Bjerhammar sphere, $r$ and $r^{\prime}$ represent the geocentric radial distances of points $\mathrm{P}$ and $\mathrm{Q}$ separated by a spherical distance $\psi$.

The numerical examples carried out in the sequel used residual gravity anomalies observations to compute the empirical covariance function. The empirical covariance function is computed by first removing the gravity anomalies computed from a geopotential model and the direct effect of the terrain.

$$
\begin{aligned}
& \Delta \mathrm{g}=\Delta \mathrm{g}_{\text {obs }}-\Delta \mathrm{g}_{\mathrm{GM}}-\Delta \mathrm{g}_{\mathrm{T}} \\
& \Delta \mathrm{g}=\Delta \mathrm{g}_{\text {obs }}-\mathrm{R} \sum_{\mathrm{n}=2}^{\mathrm{n}=\mathrm{n}_{\max }}(\mathrm{n}-1) \sum_{\mathrm{m}=0}^{\mathrm{n}}\left(\overline{\mathrm{C}_{\mathrm{n}, \mathrm{m}}} \cos \mathrm{m} \lambda_{\mathrm{P}}+\overline{\mathrm{S}_{\mathrm{n}, \mathrm{m}}} \sin \mathrm{m} \lambda_{\mathrm{P}}\right) \overline{\mathrm{P}_{\mathrm{n}, \mathrm{m}}}\left(\operatorname{sen} \phi_{\mathrm{P}}\right)-\Delta \mathrm{g}_{\mathrm{T}}
\end{aligned}
$$

The covariance function of the residual local gravity anomalies can be expresses as:

$$
\mathrm{C}_{\Delta \mathrm{g} \Delta \mathrm{g}}(\mathrm{P}, \mathrm{Q})=\mathrm{a} \sum_{\mathrm{n}=2}^{\mathrm{n}_{\max }} \varepsilon_{\mathrm{n}}(\Delta \mathrm{g}, \Delta \mathrm{g}) \mathrm{S}^{\mathrm{n}+2} \mathrm{P}_{\mathrm{n}} \cos (\psi)+\sum_{\mathrm{n}=\mathrm{n}_{\max }+1}^{\infty} \sigma_{\mathrm{n}}(\Delta \mathrm{g}, \Delta \mathrm{g}) \mathrm{S}^{\mathrm{n}+2} \mathrm{P}_{\mathrm{n}} \cos (\psi)
$$

with:

$$
\mathrm{S}=\left(\frac{\mathrm{R}_{\mathrm{B}}^{2}}{\mathrm{rr}^{\prime}}\right)
$$


where the $\varepsilon_{\mathrm{n}}(\Delta \mathrm{g}, \Delta \mathrm{g})$ are the error anomaly degree variances associated with the coefficients of the geopotential model; $\mathrm{a}$ is a scale factor; and $\sigma_{\mathrm{n}}(\Delta \mathrm{g}, \Delta \mathrm{g})$ are signal gravity anomaly degree variances estimated using the Tscherning/Rapp model as follows:

$\varepsilon_{\mathrm{n}}(\Delta \mathrm{g}, \Delta \mathrm{g})=\frac{(\mathrm{n}-1)^{2}}{\mathrm{R}^{2}} \varepsilon_{\mathrm{n}}(\mathrm{T}, \mathrm{T})$

$\varepsilon_{\mathrm{n}}(\mathrm{T}, \mathrm{T})=\left(\frac{\mathrm{GM}}{\mathrm{R}}\right)^{2} \sum_{\mathrm{m}=0}^{\mathrm{n}}\left(\mathrm{e}_{\mathrm{Cnm}}^{2}+\mathrm{e}_{\mathrm{Snm}}^{2}\right)$

where $\mathrm{e}_{\mathrm{Cnm}}^{2}$ and $\mathrm{e}_{\mathrm{Snm}}^{2}$ are the variances of the fully normalized geopotential coefficients.

The degree variances of the disturbing potential $\sigma_{n}(T, T)$ can be estimated from the Tscherning/Rapp model as:

$\sigma_{n}(T, T)=\frac{A}{(n-1)(n-2)(n+B)}$

where $\mathrm{A}$ is a free parameter to be determined, B was first set at 24 in the original work of Tscherning and Rapp, but in this study we will set it equal to 4 following the recommendations of Tscherning (1997).

The degree variances of the gravity anomalies are related with the degree variances of the disturbing potential by the following relationship:

$\sigma_{\mathrm{n}}(\Delta \mathrm{g}, \Delta \mathrm{g})=\frac{(\mathrm{n}-1)^{2}}{\mathrm{R}^{2}} \sigma_{\mathrm{n}}(\mathrm{T}, \mathrm{T})$

The covariance function given in equation (5.28) is global and it must be adjusted to fit the local characteristics of the field in local gravity field computation. The adjustment of the global model requires the estimation of the parameters: A, the scaling factor a, and the radius of the Bjerhammar sphere. The estimation of these parameters is done by fitting the global model to the empirical covariance values for the local area by least squares in an iterative procedure. 


\subsection{Covariance analysis in Argentina}

The empirical covariance function will be computed in different areas of Argentina with different topographic structures and statistical behavior of free-air anomalies, reduced free-air gravity anomalies by the geopotential model EGM96 complete to degree and order 360, and residual free-air gravity anomalies after removal of the EGM96 and terrain effects. The Residual Terrain Model (RTM) gravity reduction was used to compute the terrain effects of the topography.

Three selected areas were chosen as test areas within the Argentinean territory and their location can be seen in Figure 5.2.

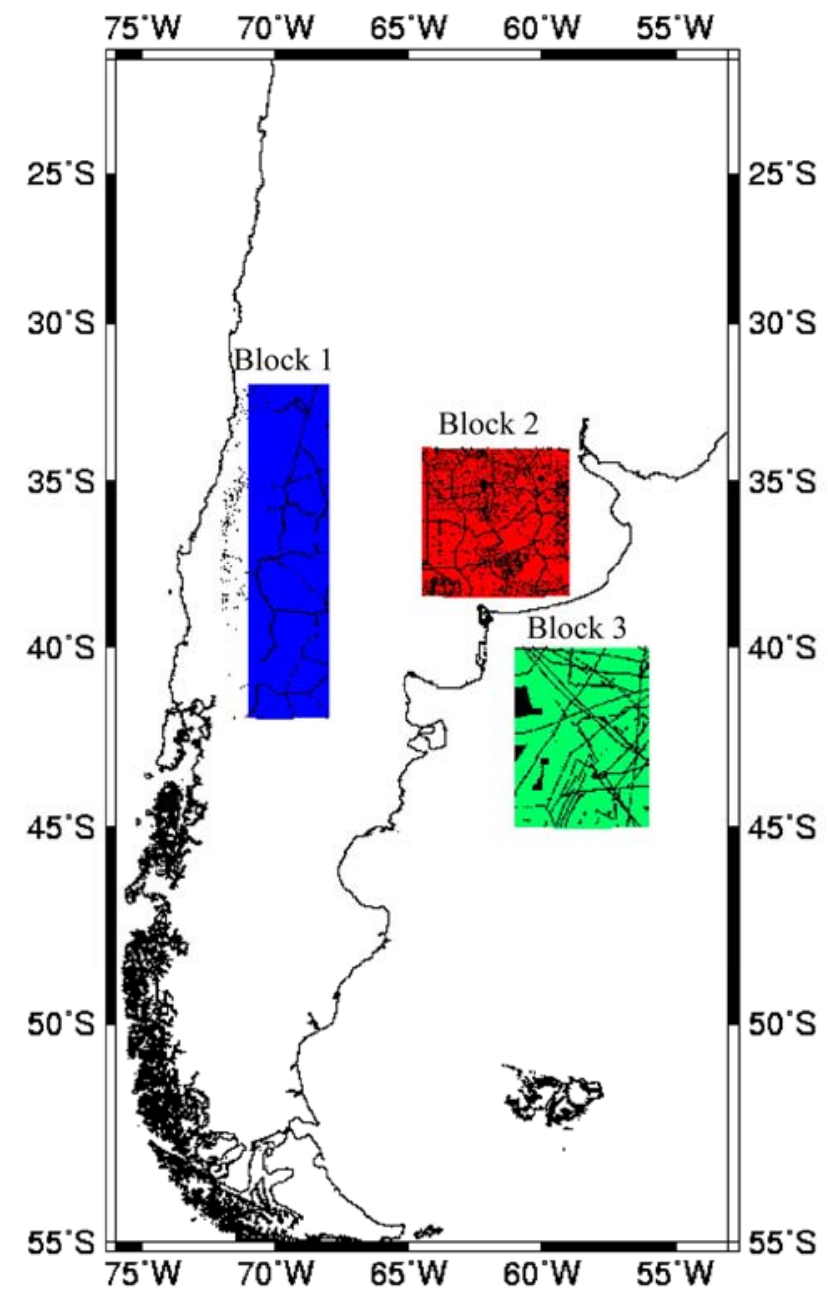

Figure 5.2: Location of test areas and distribution of gravity data 


\subsubsection{Andes Area. Block 1}

The first area is a rough area and we will refer to this area as Block 1. Block 1 is located in the Andes, which are the highest mountain range of the country. Its dimensions are $10^{\circ}$ by $4^{\circ}$ in the latitude and longitude, respectively. The coordinates of the lower-left corner of the area are $42^{\circ} \mathrm{S}$ and $72^{\circ} \mathrm{W}$. The area has 1428 gravity points with a mean elevation height of about 960 meters. The statistical information of this area can be seen in Table 5.1.

Table 5.1: Statistical information for Block 1.

\begin{tabular}{l|cccc}
\hline Rough area & min & max & mean & $\sigma$ \\
\hline Latitude & -42.00 & -32.02 & -36.90 & 2.70 \\
Longitude & -72.00 & -68.00 & -69.76 & 1.15 \\
Observed gravity [mGal] & 978584.68 & 980206.92 & 979607.476 & 317.85 \\
Height [m] & 3.90 & 3362.00 & 959.66 & 551.28 \\
\hline
\end{tabular}

The average inter-point distance (IPD) is calculated from

$$
\mathrm{IPD}=\frac{\mathrm{NP}}{\sqrt{\mathrm{A}}}
$$

where NP is the number of gravity points and A is the area size. NP is equal to 1428 gravity points so an IPD of 3.8 minutes represents the actual data resolution.

The statistics of the free-air anomalies for the Block 1 test area can be seen in Table 5.2. This table also shows the statistics of residual gravity anomalies after the contribution of EGM96 geopotential model has been removed and the statistics of the residual gravity anomalies after the RTM effects have been also removed.

Table 5.2: Statistics for the gravity anomalies for Block 1. Unit:[mGal].

\begin{tabular}{l|cccc}
\hline Rough area & $\min$ & $\max$ & mean & $\sigma$ \\
\hline$\Delta \mathrm{g}_{\mathrm{FA}}$ & -127.45 & 147.53 & 3.79 & 39.08 \\
$\Delta \mathrm{g}_{\mathrm{FA}}-\Delta \mathrm{g}_{\mathrm{GM}}$ & -209.59 & 138.08 & -19.69 & 33.09 \\
$\Delta \mathrm{g}_{\mathrm{FA}}-\Delta \mathrm{g}_{\mathrm{GM}}-\delta \mathrm{A}_{\mathrm{RTM}}$ & -106.50 & 100.68 & 10.54 & 31.14 \\
\hline
\end{tabular}

\subsubsection{Flat area. Block 2}

The second area is a flat area located in the eastern part of the country; we will refer to it as Block 2. Its dimensions are $4.5^{\circ}$ by $5.5^{\circ}$ in latitude and longitude, respectively. The 
coordinates of the lower-left corner of the area are $38.5^{\circ} \mathrm{S}$ and $59^{\circ} \mathrm{W}$. The area has 4276 gravity points with a mean elevation height of about 126 meters. The statistical information of this area can be seen in Table 5.3.

Table 5.3: Statistical information for Block 2.

\begin{tabular}{l|cccc}
\hline Flat Area & min & Max & mean & $\sigma$ \\
\hline Latitude & -38.50 & -34.00 & -36.25 & 1.34 \\
Longitude & -64.50 & -59.00 & -61.66 & 1.61 \\
Observed gravity [mGal] & 979594.81 & 980033.47 & 979812.78 & 105.22 \\
Height [m] & -12.50 & 474.70 & 126.17 & 66.07 \\
\hline
\end{tabular}

The average inter-point distance (IPD) is equal to 14.3 minutes and it represents the actual data resolution.

The statistics of the free-air anomalies for the Block 2 test area can be seen in Table 5.4. This table also shows the statistics of residual gravity anomalies after the contribution of the EGM96 geopotential model has been removed and the statistics of the residual gravity anomalies after the RTM effects have also been removed.

Table 5.4: Statistics for the gravity anomalies for Block 2. Unit:[mGal].

\begin{tabular}{l|cccc}
\hline Flat area & min & $\max$ & mean & $\sigma$ \\
\hline$\Delta \mathrm{g}_{\mathrm{FA}}$ & -23.18 & 52.01 & 9.89 & 11.47 \\
$\Delta \mathrm{g}_{\mathrm{FA}}-\Delta \mathrm{g}_{\mathrm{GM}}$ & -22.93 & 22.76 & 1.69 & 6.80 \\
$\Delta \mathrm{g}_{\mathrm{FA}}-\Delta \mathrm{g}_{\mathrm{GM}}-\delta \mathrm{A}_{\mathrm{RTM}}$ & -22.42 & 30.12 & 1.83 & 7.11 \\
\hline
\end{tabular}

\subsubsection{Marine area. Block 3}

The third area is a marine area located in the Atlantic Ocean near Argentina. We will refer to this area as Block 3. Its dimensions are $5^{\circ}$ by $5^{\circ}$ in latitude and longitude, respectively. The coordinates of the lower-left corner of the area are $45^{\circ} \mathrm{S}$ and $61^{\circ} \mathrm{W}$. The area has 4017 free-air shipborne and KMS02 gravity anomalies. The statistics of the free-air anomalies for the Block 3 test area can be seen in Table 5.5. This table also shows the statistics of residual gravity anomalies after the contribution of EGM96 geopotential model has been removed and the residual anomalies after the RTM effects were also removed.

The average inter-point distance (IPD) is 13.4 minutes. 
Table 5.5: Statistics for the gravity anomalies for Block 3. Unit:[mGal].

\begin{tabular}{l|cccc}
\hline Marine area & $\min$ & $\max$ & mean & $\sigma$ \\
\hline$\Delta \mathrm{g}_{\mathrm{FA}}$ & -62.46 & 76.01 & 4.68 & 24.16 \\
$\Delta \mathrm{g}_{\mathrm{FA}}-\Delta \mathrm{g}_{\mathrm{GM}}$ & -32.80 & 38.27 & 1.82 & 9.36 \\
$\Delta \mathrm{g}_{\mathrm{FA}}-\Delta \mathrm{g}_{\mathrm{GM}}-\delta \mathrm{A}_{\mathrm{RTM}}$ & -28.51 & 32.87 & 2.08 & 8.88 \\
\hline
\end{tabular}

\subsection{Estimation and modeling of empirical local covariance functions}

The empirical gravity anomaly covariance functions for actual data were computed in the space domain using the program empcov of the GRAVSOFT software (Tscherning et al., 1992) for the three test areas. The empirical covariance functions were computed for free-air gravity anomalies, for free-air gravity anomalies minus the gravity anomalies computed from EGM96 and for the anomalies from which the RTM-effects have also been subtracted.

Figure 5.3, Figure 5.4 and Figure 5.5 show the empirical local covariances functions of residual gravity anomaly field after the removal of the long component of the gravity data with the EGM96 geopotential model, complete to degree and order 360 and also after removing the RTM effects. The empirical covariance function is estimated in the space domain with 5 arc-minute spherical distance interval for Block 1, Block 2 and Block 3, respectively. The essential parameters are listed in Table 5.6 for the three areas.

Table 5.6: Essential parameters for the GM and RTM-reduced gravity anomaly empirical covariance function.

\begin{tabular}{l|cccc}
\hline Test Areas & Co: $\left[\mathrm{mGal}^{* * 2} 2\right]$ & $\xi:[$ degrees $]$ & $\xi:[\mathrm{km}]$ & $\mathrm{Co} / \xi:\left[\mathrm{mGal}^{* *} 2 / \mathrm{km}\right]$ \\
\hline Block 1 Rough area & 1078 & 0.40 & 45 & 12.1 \\
Block 2 Flat area & 49 & 0.17 & 19 & 0.8 \\
Block 3 Marine area & 68 & 0.17 & 19 & 0.8 \\
\hline
\end{tabular}

The modeling of the empirically covariance function is done using program covfit from the GRAVSOFT software (Tscherning et al., 1992). The space domain empirical covariance functions are fitted to the Tscherning/Rapp degree-variance model. The factors A, $\alpha$ and the radius of the Bjerhammar sphere must be fixed and gravity error degree variances for the EGM96 coefficients were used. 
The analytical covariance function is also displayed in Figures 5.3 to 5.5. The results presented in Figures 5.3 to 5.5 show that the covariance function varies in the three areas with different topography. The variance is higher in the rough area than the variances in the marine and flat area.

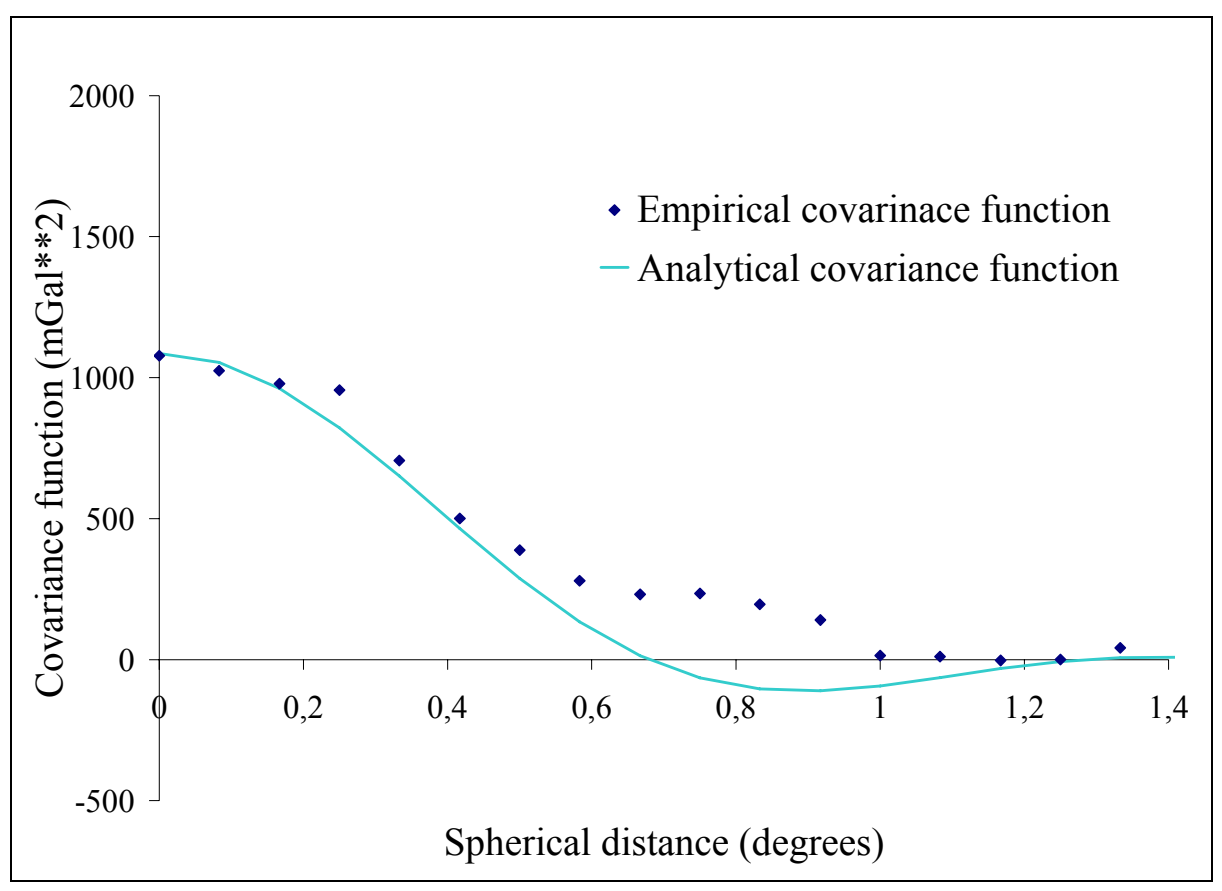

Figure 5.3: The empirical and model covariance function for free-air gravity anomalies reduced from EGM96 and RTM effects (Block 1-rough area)

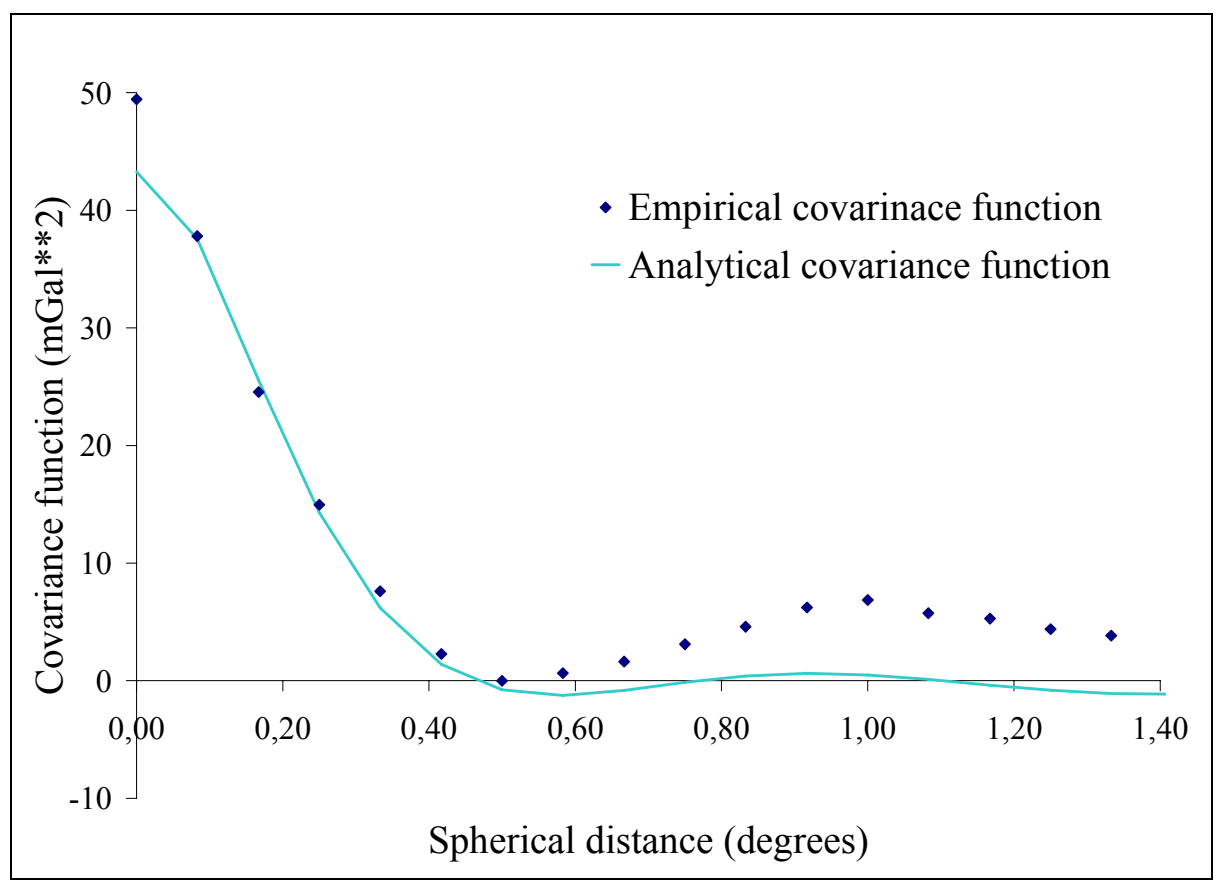

Figure 5.4: The empirical and model covariance function for free-air gravity anomalies reduced from EGM96 and RTM effects (Block 2-flat area) 


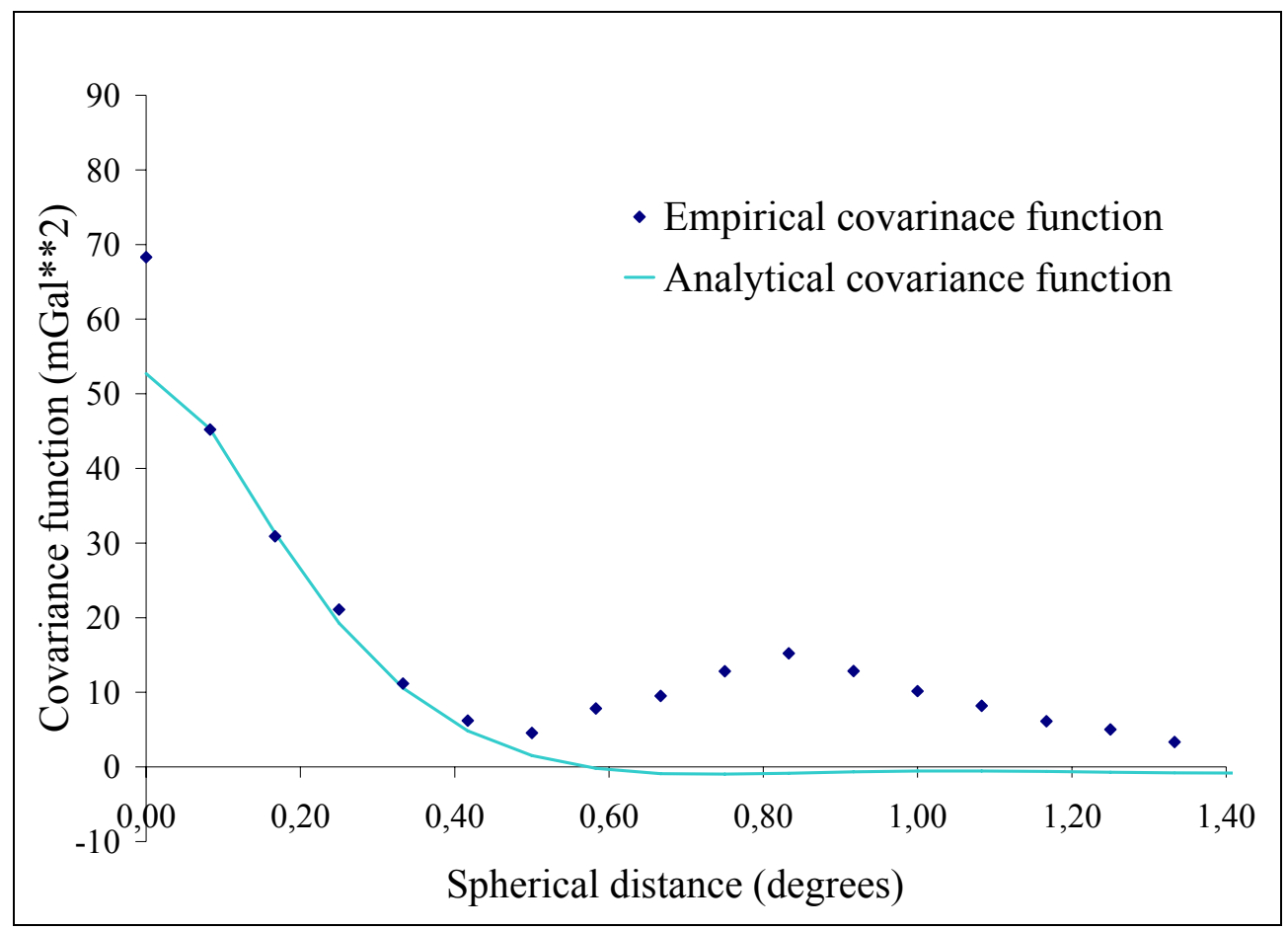

Figure 5.5: The empirical and model covariance function for free-air gravity anomalies reduced from EGM96 and RTM effects (Block 3-marine area)

\subsection{Geoid spectrum}

The geoid spectrum from different gravity field signals can be investigated in order to estimate the best combination of GM and local gravity data.

The power spectrum of the geoid can be represented by the undulation degree variances $\sigma_{\mathrm{n}}(\mathrm{N}, \mathrm{N})$ that are estimated for the different geoid components.

For $\mathrm{T}$, the degree variances are given by:

$$
\sigma_{\mathrm{n}}(\mathrm{T}, \mathrm{T})=\frac{(\mathrm{GM})^{2}}{\mathrm{R}^{2}} \sum_{\mathrm{m}=0}^{\mathrm{n}}\left(\overline{\mathrm{C}}_{\mathrm{nm}}^{2}+\overline{\mathrm{S}}_{\mathrm{nm}}^{2}\right)
$$

The geoid degree variances can then be obtained from:

$$
\sigma_{\mathrm{n}}(\mathrm{N}, \mathrm{N})=\frac{\sigma_{\mathrm{n}}(\mathrm{T}, \mathrm{T})}{\gamma^{2}}
$$

The anomalous potential degree variances $\sigma_{\mathrm{n}}(\mathrm{T}, \mathrm{T})$ will be estimated in the following manner: 
1) The $2 \mathrm{D}$ power spectral density (PSD) function of the gravity anomalies is computed directly from the actual gravity anomaly data grid by Fourier Transform:

$$
\mathrm{P}_{\Delta \mathrm{g} \Delta \mathrm{g}}(\mathrm{u}, \mathrm{v})=\mathrm{F}\{\Delta \mathrm{g}(\mathrm{x}, \mathrm{y})\} \mathrm{F}\{\Delta \mathrm{g}(\mathrm{x}, \mathrm{y})\}^{*}
$$

In general, the estimated 2D PSD is non-isotropic, so the next step is to obtain an isotropic estimate of the PSD.

2) The isotropic estimate of the PSD can be obtained using a circular averaging process (Schwarz et al., 1990):

$$
\mathrm{P}_{\Delta \mathrm{g} \Delta \mathrm{g}}^{\prime}(\mathrm{q})=\frac{1}{2 \pi} \int_{0}^{2 \pi} \mathrm{P}_{\Delta \mathrm{g} \Delta \mathrm{g}}(\mathrm{q} \cos \theta, \mathrm{q} \sin \theta) \mathrm{d} \theta
$$

For the isotropic case,

$$
\mathrm{P}_{\Delta \mathrm{g} \Delta \mathrm{g}}(\mathrm{u}, \mathrm{v})=\mathrm{P}_{\Delta \mathrm{g} \Delta \mathrm{g}}^{\prime}(\mathrm{q}) ; \mathrm{q}=\left(\mathrm{u}^{2}+\mathrm{v}^{2}\right)^{1 / 2}
$$

3) The anomaly degree variances are related to the isotropic PSD by the relationship given by Forsberg, (1984):

$$
\begin{aligned}
& \sigma_{\mathrm{n}}(\Delta \mathrm{g}, \Delta \mathrm{g})=\frac{1}{2 \pi \mathrm{R}^{2}}\left(\mathrm{n}+\frac{1}{2}\right) \mathrm{P}_{\Delta \mathrm{g} \Delta \mathrm{g}}\left(\mathrm{q}_{\mathrm{n}}\right) \\
& \mathrm{q}_{\mathrm{n}}=\frac{\mathrm{n}+\frac{1}{2}}{2 \pi \mathrm{R}}
\end{aligned}
$$

4) The covariance function of the gravity anomalies and the corresponding anomaly degree variances are related by a Legendre transform (Heiskanen and Moritz, 1967; Schwartz et al., 1990).

$$
\begin{aligned}
& \mathrm{C}_{\Delta \mathrm{g}, \Delta \mathrm{g}}(\psi)=\sum_{\mathrm{n}=2}^{\infty} \sigma_{\mathrm{n}}(\Delta \mathrm{g}, \Delta \mathrm{g}) \mathrm{P}_{\mathrm{n}}(\cos \psi) \\
& \sigma_{\mathrm{n}}(\Delta \mathrm{g}, \Delta \mathrm{g})=\frac{2 \mathrm{n}+1}{2} \int_{0}^{\pi} \mathrm{C}_{\Delta \mathrm{g} \Delta \mathrm{g}}(\psi) \mathrm{P}_{\mathrm{n}}(\cos \psi) \sin \psi \mathrm{d} \psi
\end{aligned}
$$


The anomaly degree variances describe the global spectral behavior of the gravity field.

The potential degree variances are related to the gravity anomalies degrees variances by the expression:

$\sigma_{\mathrm{n}}(\mathrm{T}, \mathrm{T})=\frac{\mathrm{R}^{2}}{(\mathrm{n}-1)^{2}} \sigma_{\mathrm{n}}(\Delta \mathrm{g}, \Delta \mathrm{g})$

The undulation degree variances $\sigma_{\mathrm{n}(\mathrm{N})}$ can be obtained from the anomaly degree variance by the expression:

$$
\sigma_{\mathrm{n}}(\mathrm{N})=\frac{\mathrm{R}^{2}}{(\mathrm{n}-1)^{2} \gamma^{2}} \sigma_{\mathrm{n}}(\Delta \mathrm{g}, \Delta \mathrm{g})
$$




\section{CHAPTER SIX}

\section{DIFFERENT TOPOGRAPHIC REDUCTION METHODS IN PRACTICAL GRAVIMETRIC GEOID DETERMINATION}

\subsection{Introduction}

As a preliminary analysis for the development and evaluation of a precise gravimetric geoid for Argentina, different gravimetric geoid solutions were computed using different gravity reduction techniques in three test areas. One area was covering part of Mendoza and Neuquén provinces. This test area was bounded by latitudes $32^{\circ} \mathrm{S}$ to $42^{\circ} \mathrm{S}$ and longitudes $68^{\circ} \mathrm{W}$ and $72^{\circ} \mathrm{W}$, and it was selected due to the presence of GPS/levelling data, sparse gravity coverage coming from different sources and rough topography (Block 1). Another test area was an extension of the pervious one and it was bounded by latitude $20^{\circ} \mathrm{S}$ to $42^{\circ} \mathrm{S}$ and longitude $72^{\circ} \mathrm{W}$ to $67^{\circ} \mathrm{W}$ (Block 2). The other test area was a flat area, with more dense gravity data ranging from $34^{\circ} \mathrm{S}$ to $38.5^{\circ} \mathrm{S}$ in latitude and $59^{\circ} \mathrm{W}$ to $64.5^{\circ} \mathrm{W}$ in longitude (Flat Area). Figure 6.1 shows the location of the three tests areas in rectangular blocks.

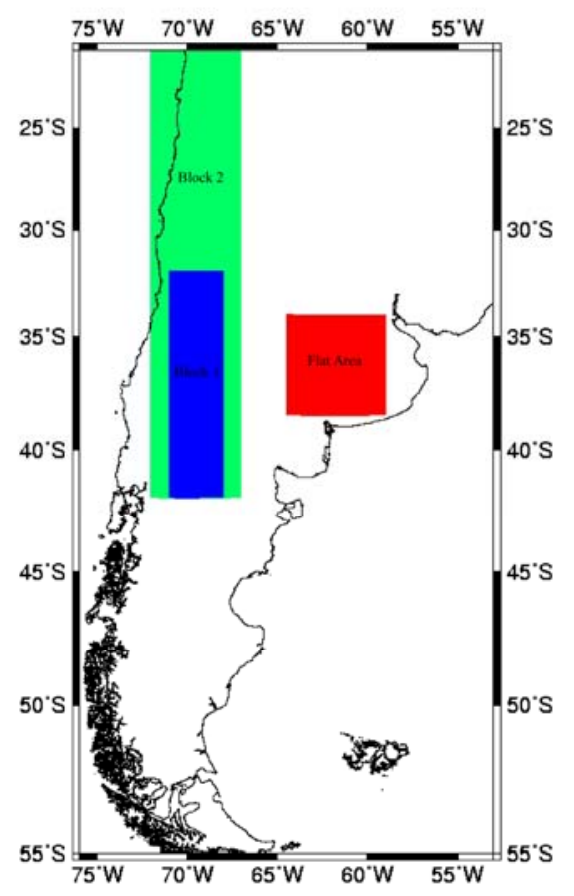

Figure 6.1: Distribution of test areas blocks in Argentina 
These three areas were selected to study gravimetric geoids using different gravity reductions, in planar approximation. The following terrain reductions techniques were used: Helmert's second condensation method, the Airy-Heiskanen topographic-isostatic reduction $(\mathrm{AH})$, the residual terrain model (RTM) method and the Rudzki inversion method.

\subsection{Gravimetric geoid determination in a flat area}

A total of 4276 gravity points, with a spacing of approximately $8 \mathrm{~km}$ were selected in the flat area. The distribution of the gravity points is shown in Figure 6.2.

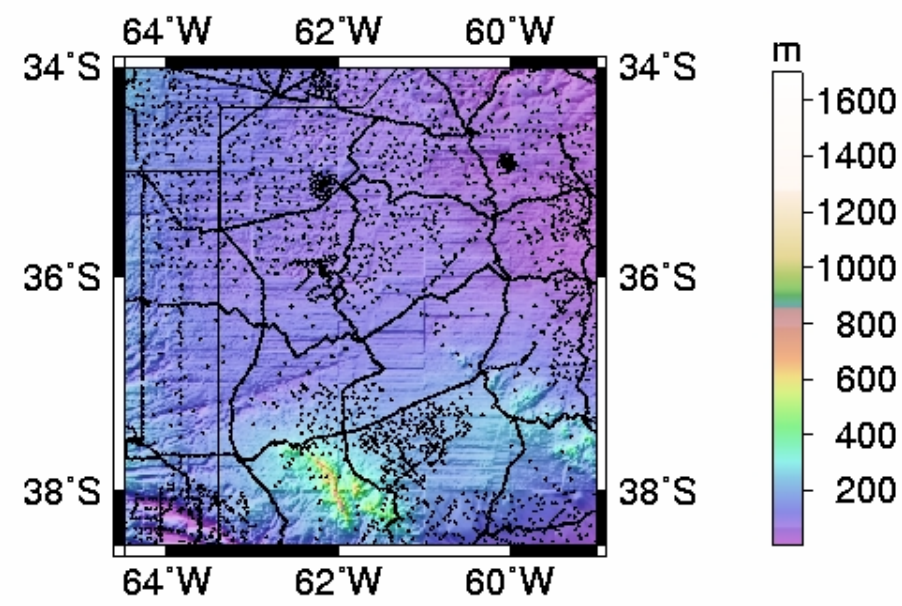

Figure 6.2: Distribution of gravity stations on elevation map

The maximum and minimum values of the observed gravity were $980033.47 \mathrm{mGal}$ and 979594.81 mGal, respectively.

Free-air gravity anomalies were calculated using the parameters of the Geodetic Reference System 1980 (GRS80) and the normal gradient of $0.3086 \mathrm{mGal} / \mathrm{m}$. The atmospheric correction was applied to the observed gravity according to formula (4.12) (Torge, 1989). The statistics of the free-air anomalies can be seen in Table 6.1 and Figure 6.3 shows the free-air anomalies computed with formula (4.14). 


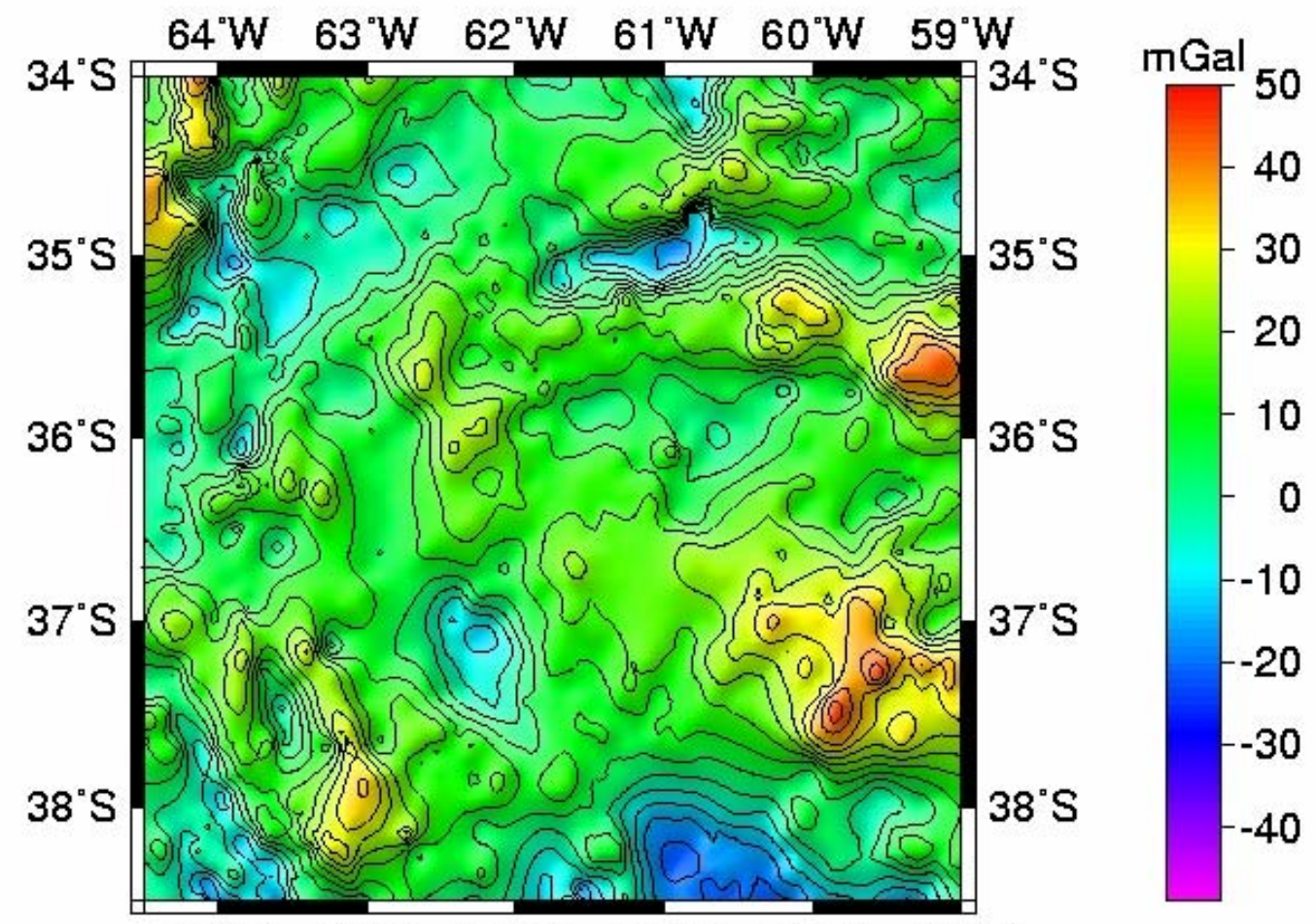

$64^{\circ} \mathrm{W} \quad 63^{\circ} \mathrm{W} \quad 62^{\circ} \mathrm{W} \quad 61^{\circ} \mathrm{W} \quad 60^{\circ} \mathrm{W} \quad 59^{\circ} \mathrm{W}$

Figure 6.3: Free-air gravity anomalies

The global digital elevation model GTOPO30 with a horizontal grid spacing of 30 arc seconds (approximately 0.758 kilometre in the North-South direction at the mean latitude of the area and 0.920 kilometre in the East-West direction) was used to represent the topography in this test area. The maximum, minimum, mean and standard deviation height is $1617 \mathrm{~m}, 1 \mathrm{~m}, 136.109 \mathrm{~m}$ and $115.393 \mathrm{~m}$, respectively.

Terrain corrections $\left(\mathrm{c}_{\mathrm{P}}\right)$ were calculated by FFT from the GTOPO30 DEM using the TC2DFTPL program (Li, 1993; Li and Sideris, 1994). They were computed at all points of a grid of 720 rows by 900 columns with different topographic representations and they were then interpolated from the grids at the gravity stations using the bilinear interpolation of program geoip from GRAVSOFT software (Tscherning et al., 1992). The statistics of terrain corrections in gravity stations up to second order term of a mass line model have a maximum of $0.96 \mathrm{mGal}$, a minimum of $0.00 \mathrm{mGal}$, a mean value of $0.02 \mathrm{mGal}$ and a standard deviation of $0.03 \mathrm{mGal}$. 
The refined Bouguer anomalies were computed using formula (4.18), their statistics are also presented in Table 6.1 and they are shown in Figure 6.4.

The Helmert or Faye gravity anomalies were computed according equation (2.82), their statistics are also presented in Table 6.1 and they are depicted in Figure 6.5.

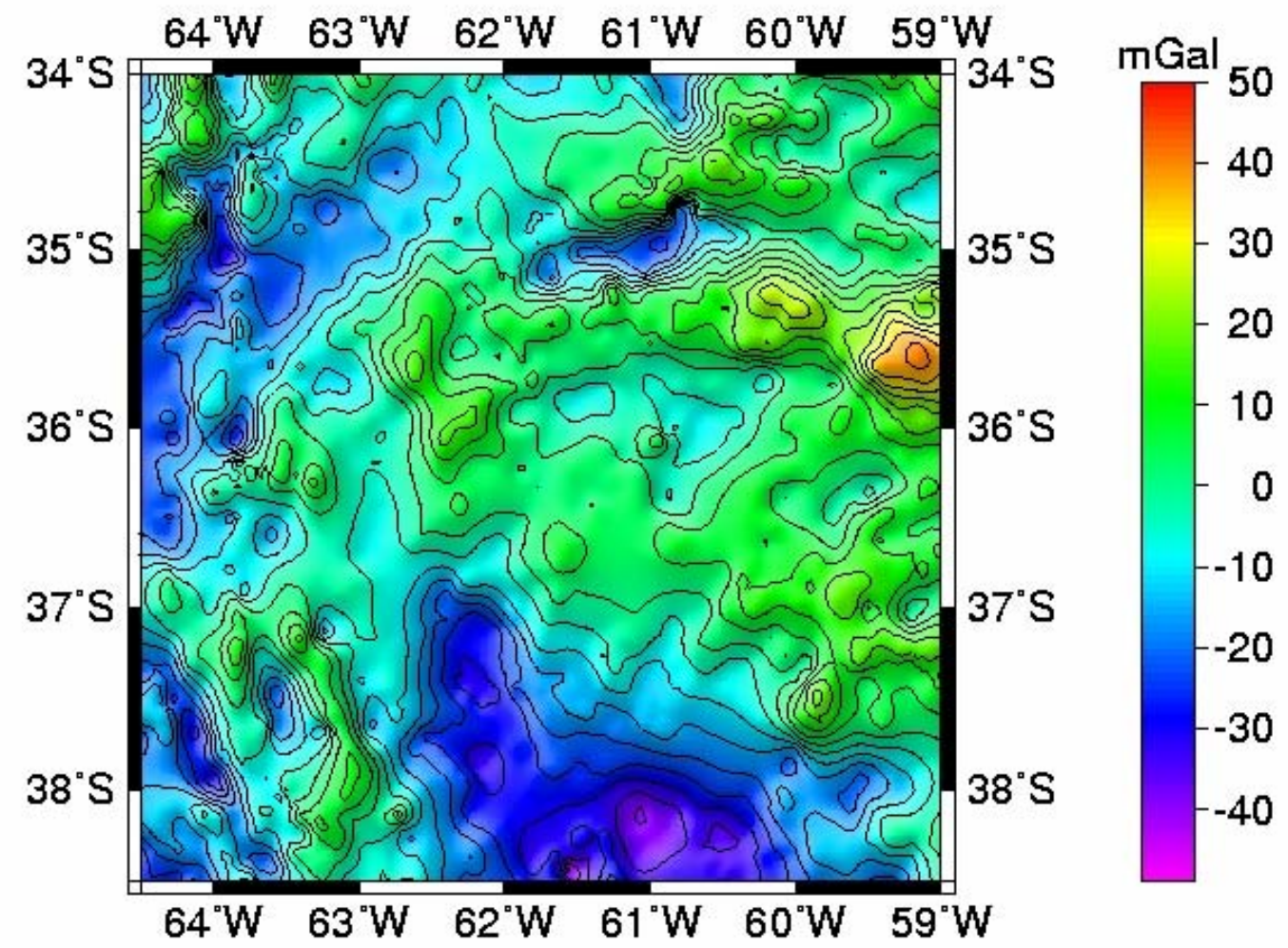

Figure 6.4: Refined Bouguer gravity anomalies

Table 6.1: The statistics of gravity anomalies. Unit: [mGal].

\begin{tabular}{c|cccc}
\hline & min & max & mean & $\sigma$ \\
\hline Free-air anomalies & -23.18 & 52.01 & 9.89 & 11.47 \\
Refined Bouguer anomalies & -48.22 & 41.55 & -4.21 & 13.78 \\
$\Delta \mathrm{g}$ EGM96 & -25.61 & 42.27 & 8.20 & 10.34 \\
Helmert (Faye anomalies) & -23.14 & 52.15 & 9.90 & 11.46 \\
AH anomalies & -30.89 & 45.74 & 8.51 & 11.52 \\
RTM anomalies & -26.15 & 45.62 & 10.03 & 11.20 \\
Rudzki anomalies & -23.33 & 49.95 & 9.89 & 11.47 \\
\hline
\end{tabular}




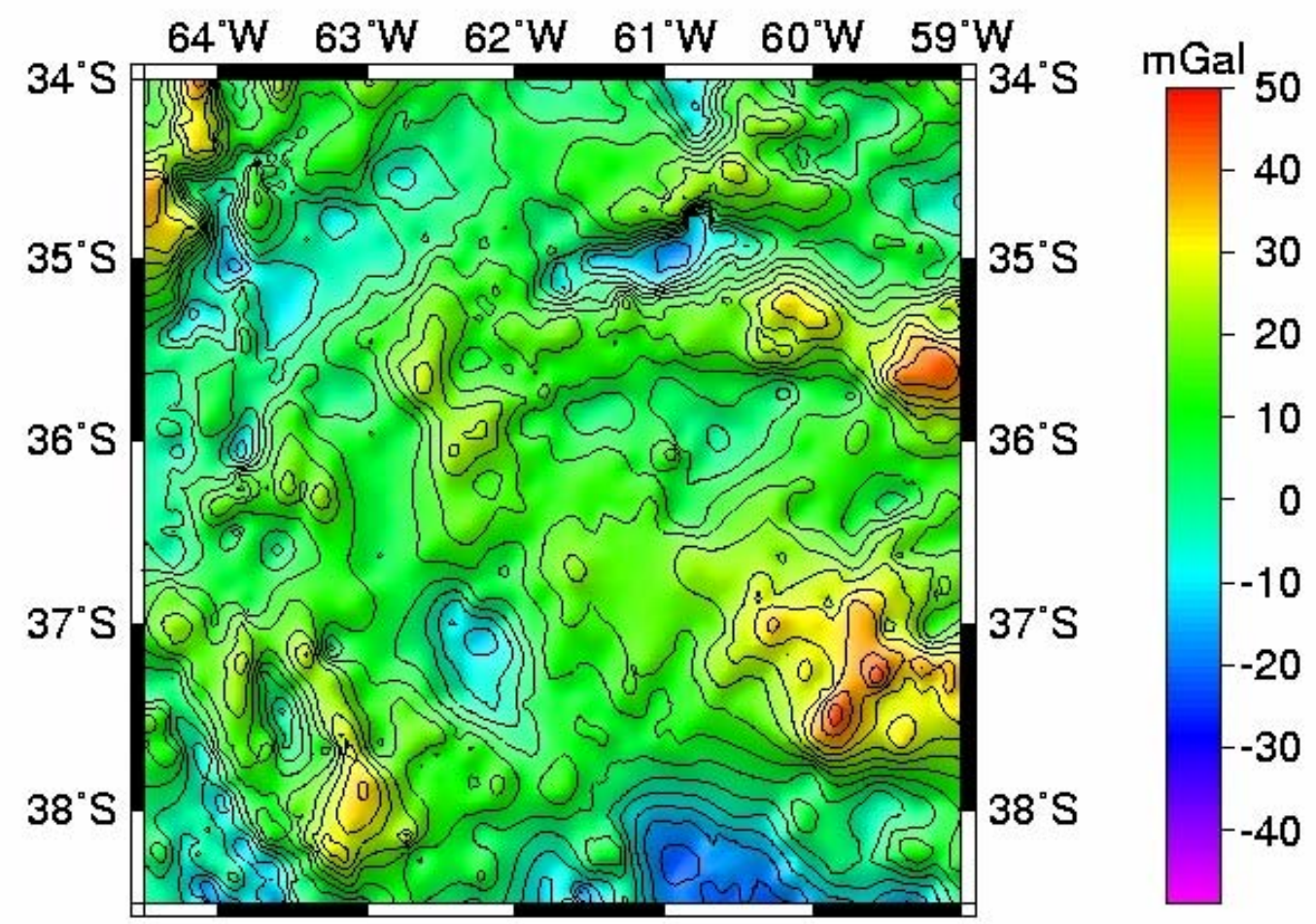

$64^{\circ} \mathrm{W} \quad 63^{\circ} \mathrm{W} \quad 62^{\circ} \mathrm{W} \quad 61^{\circ} \mathrm{W} \quad 60^{\circ} \mathrm{W} \quad 59^{\circ} \mathrm{W}$

Figure 6.5: Faye gravity anomalies

The tc program from GRAVSOFT software (Tscherning et al., 1992) was used to compute the RTM effects and also the geoid RTM effects for use in the restore step (Forsberg, 1984) and it was also used to compute the direct topographical effect on gravity using the Airy-Heiskanen ( $\mathrm{AH}$ ) model (constant density). This program was also used to compute the indirect topographical effect on geoid using the (AH) reduction scheme (constant density assuming the normal thickness of the crust equal to $32 \mathrm{~km}$ and the density of mantle equal to $3.27 \mathrm{~g} / \mathrm{cm}^{3}$ ).

The tcgrid program from GRAVSOFT software (Tscherning et al., 1992) was used to prepare the reference height grid, with a resolution around 100 kilometres.

Airy-Heiskanen and RTM gravity anomalies were computed using formulas (2.59) and (2.103), they are shown in Figures 6.6 and 6.7, respectively and their statistics are in Table 6.1. 


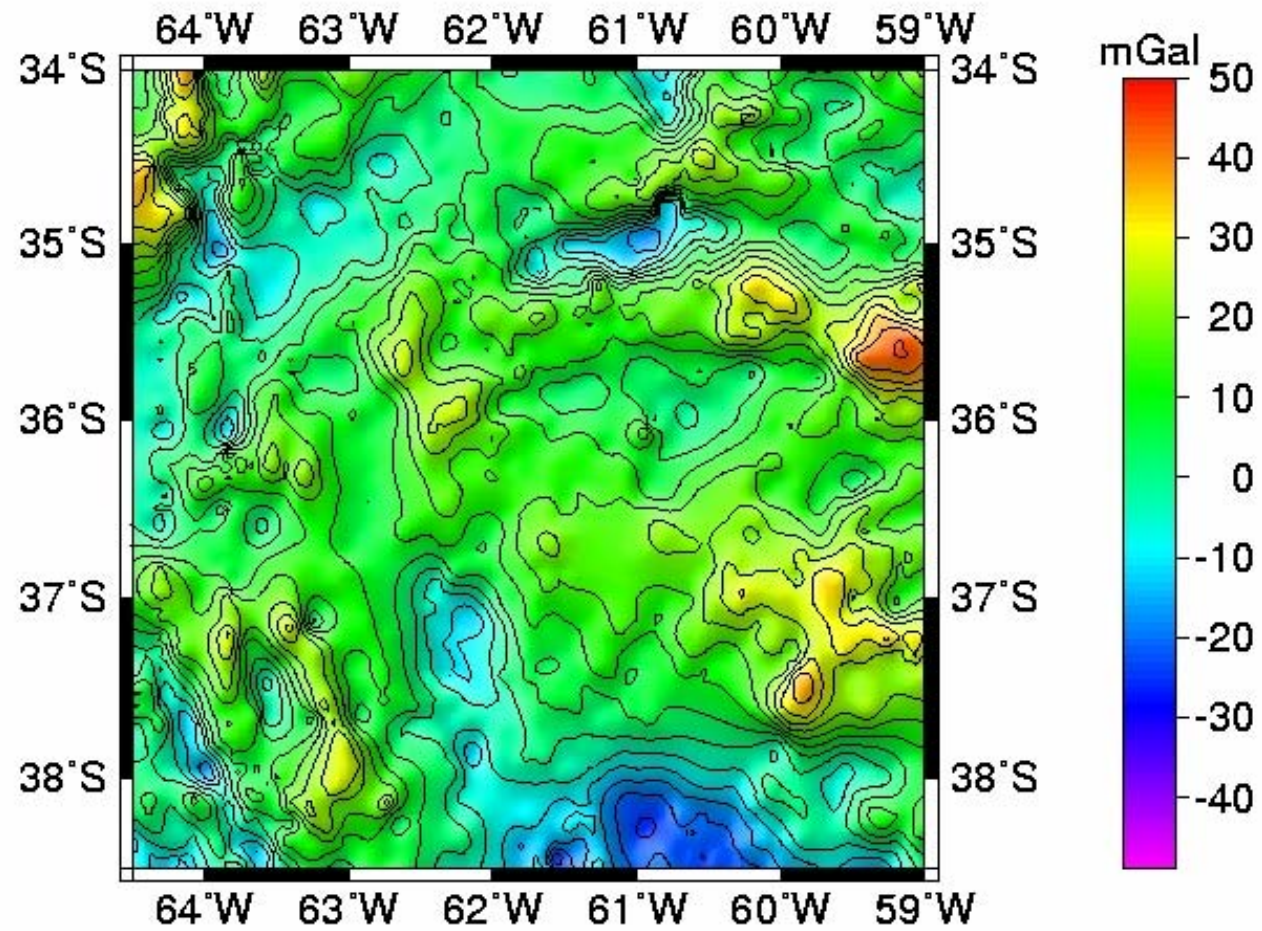

Figure 6.6: Airy-Heiskanen gravity anomalies

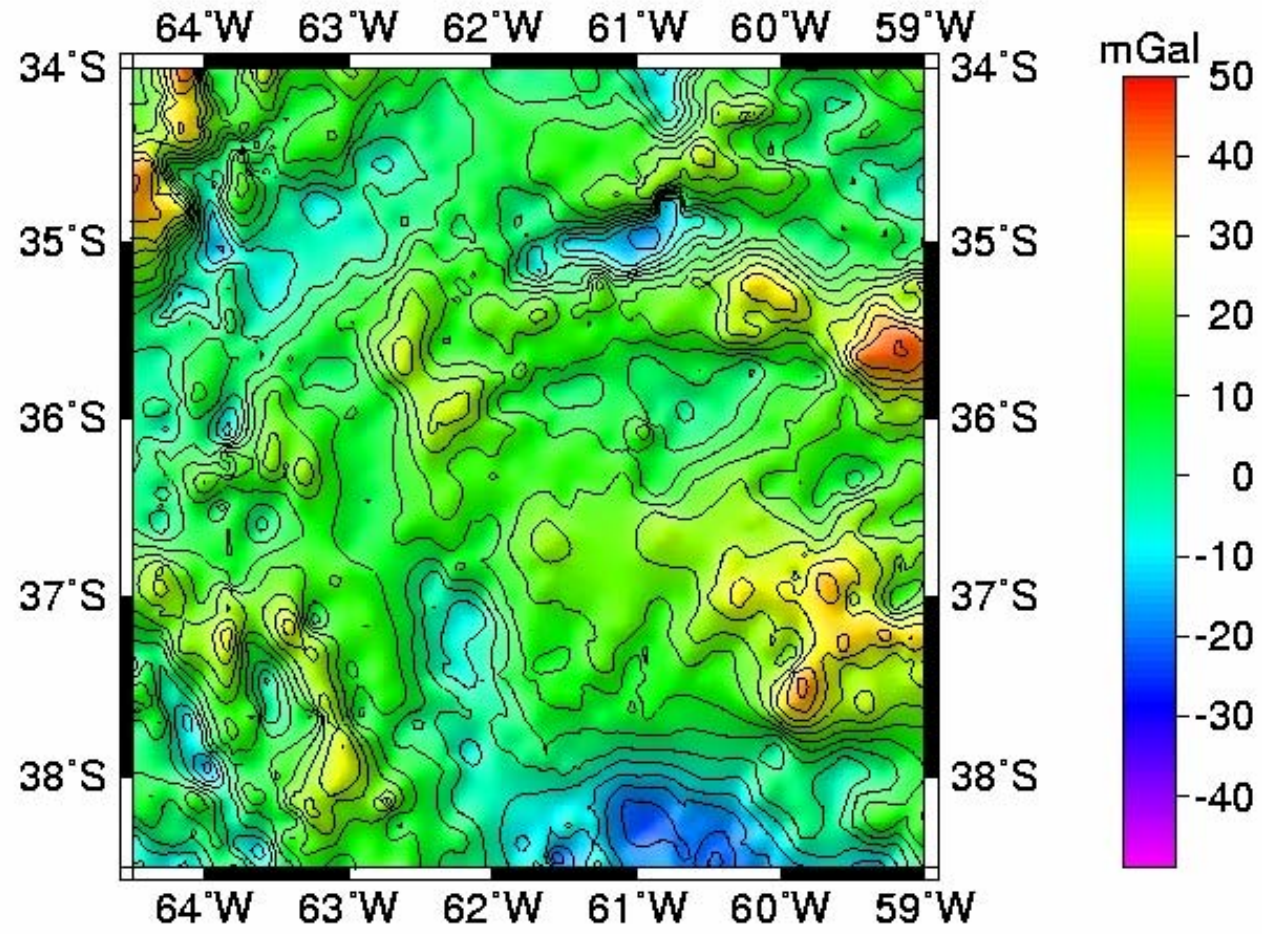

Figure 6.7: RTM gravity anomalies 
Tc was modified to compute the direct topographical effects on gravity using the Rudzki inversion gravimetric reduction scheme using constant density (Bajracharya et al., 2001). Figure 6.8 shows the Rudzki gravity anomalies computed with formula (2.89). Their statistics are also presented in Table 6.1.

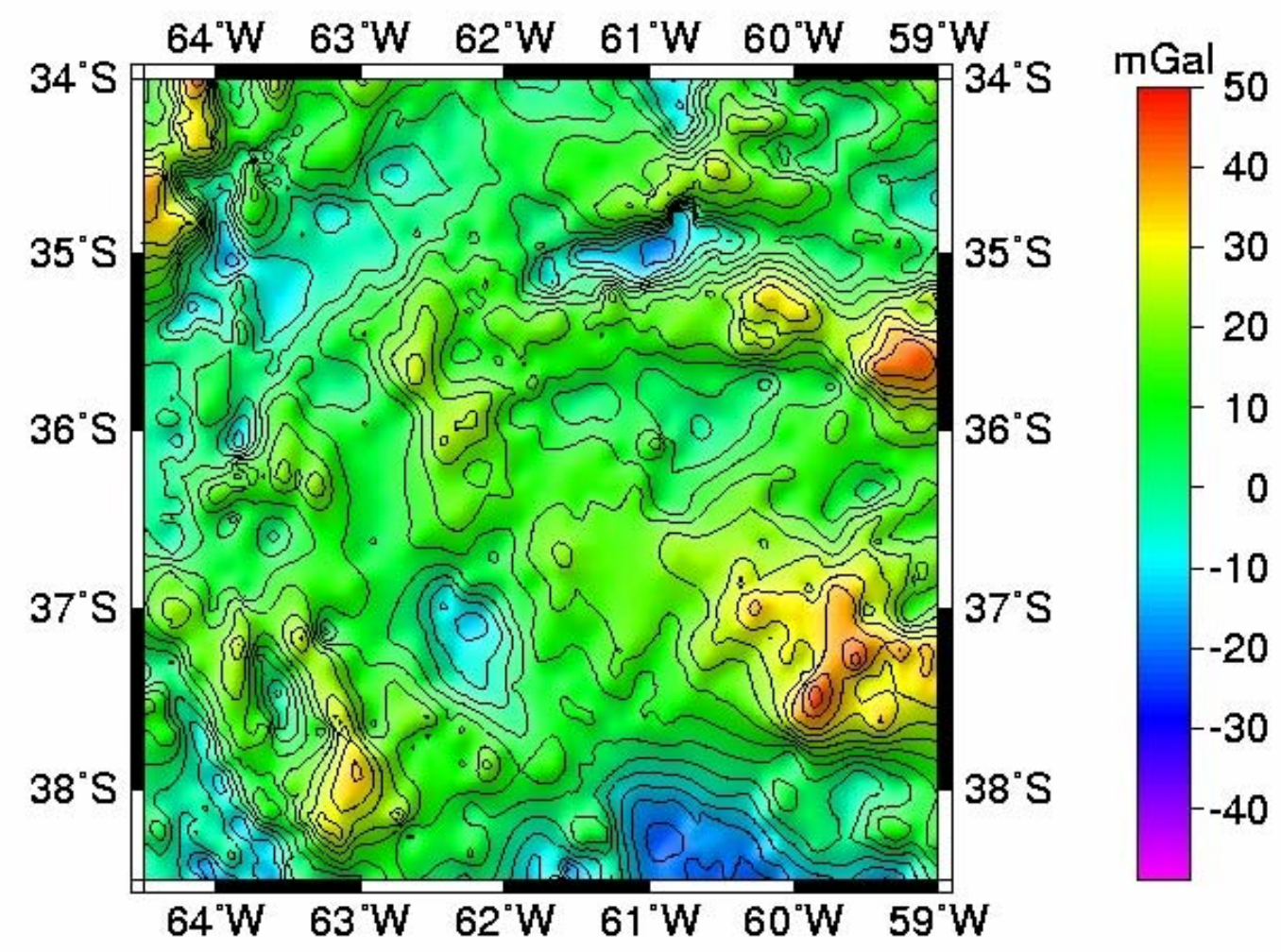

Figure 6.8: Rudzki gravity anomalies

After applying different terrain reductions, the long-wavelength contribution of the geopotential model was removed from the reduced terrain gravity anomalies. The reference gravity field was computed from the EGM96 geopotential model (Lemoine et al., 1998) complete to degree and order 360 . In spherical approximation, the reference gravity anomaly estimated at position $\phi_{\mathrm{P}}, \lambda_{\mathrm{P}}$ is expressed by $(2.12)$; these are depicted in Figure 6.9. The statistics of the gravity anomalies computed from EGM96 are also shown in Table 6.1 and the statistics of the residual gravity anomalies can be seen in Table 6.2. 


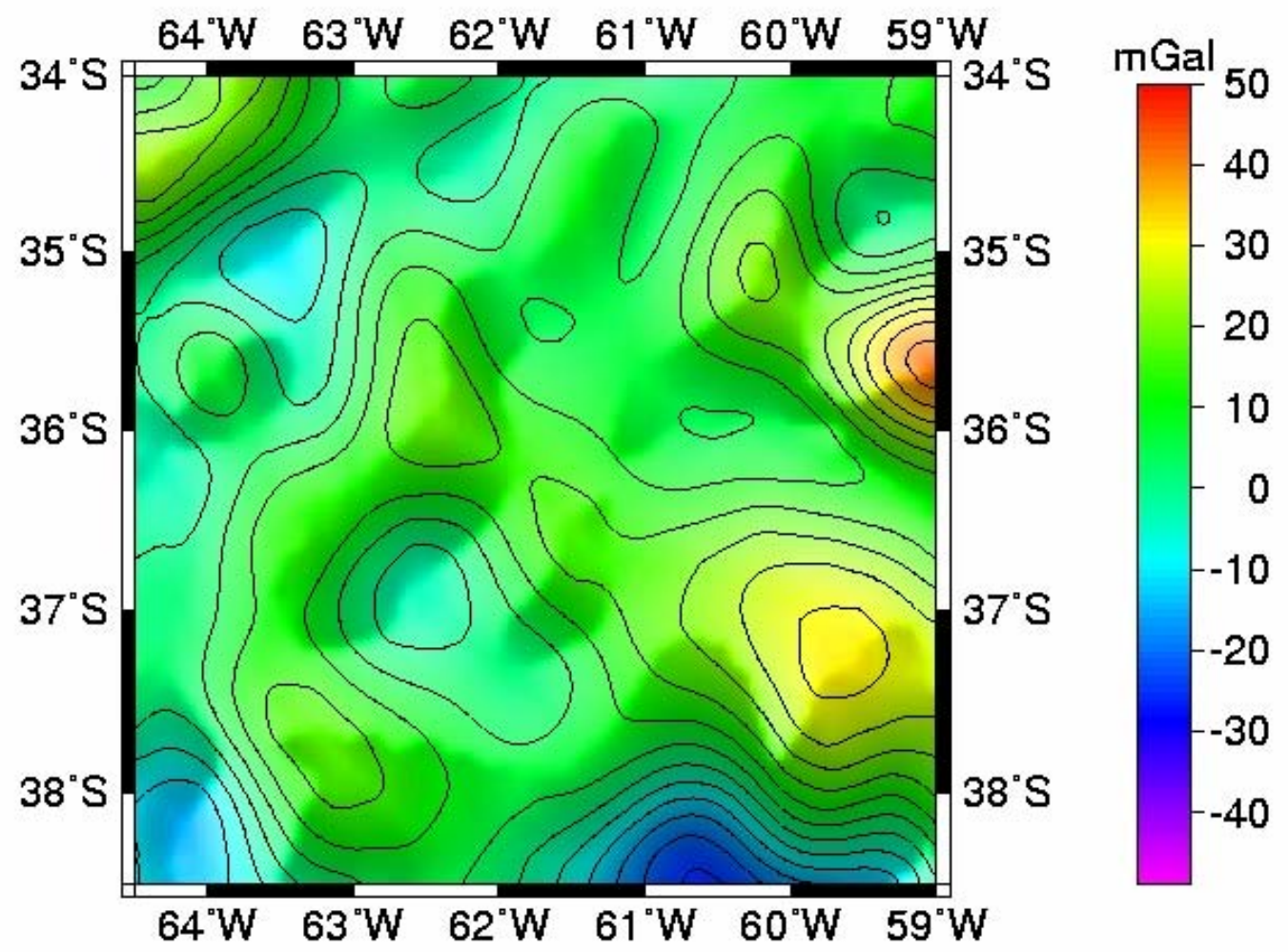

Figure 6.9: EGM96 gravity anomalies

Table 6.2: The statistics of the residual gravity anomalies. Unit: [mGal].

\begin{tabular}{c|cccc}
\hline & min & max & mean & $\sigma$ \\
\hline Free-air anomalies $-\Delta \mathrm{g}^{\text {EGM96 }}$ & 22.77 & -22.99 & 1.69 & 6.81 \\
Bouguer anomalies $-\Delta \mathrm{g}^{\text {EGM96 }}$ & 15.86 & -42.82 & -12.41 & 9.41 \\
Helmert (Faye anomalies) $-\Delta \mathrm{g}^{\text {EGM96 }}$ & 22.78 & -22.98 & 1.70 & 6.81 \\
RTM anomalies - $\Delta \mathrm{g}^{\text {EGM96 }}$ & 30.12 & -22.42 & 1.83 & 7.11 \\
AH anomalies - $\Delta \mathrm{g}^{\text {EGM96 }}$ & 27.00 & -25.71 & 0.18 & 7.20 \\
Rudzki anomalies $-\Delta \mathrm{g}^{\text {EGM96 }}$ & 22.77 & -22.99 & 1.69 & 6.81 \\
\hline
\end{tabular}

The residual geoid undulations were computed using the program fftgeoid developed by Yecai Li at the University of Calgary. This program takes the residual gravity anomaly grid as input and computes the residual geoid undulations on the same grid simultaneously using the Stokes integral by means the Fast Fourier Transform. The rigorous spherical kernel (RSK) and the approximated spherical kernel (ASK) were investigated. 
During these numerical tests, the gridding was performed using a weighted means algorithm implemented in the program geogrid from GRAVSOFT software (Tscherning et al., 1992).

Finally, the gravimetric geoid undulations were computed by restoring the geoid undulations computed from the EGM96 geopotential model and the indirect effect on the geoid due to each reduction scheme.

The indirect effects on gravity were neglected before applying Stokes's formula since the area was very flat. The topographic indirect effect on the geoid due to Helmert's second method of condensation was computed using program ind developed by Yecai $\mathrm{Li}$ at the University of Calgary. This program computes the topographic indirect effect on the geoid undulation due to the second method of Helmert's condensation of the topography with the formula given in (2.86). The topographic indirect effect on the geoid did not add any significant contribution to the gravimetric geoid undulations. The computation was done only considering the first term in equation (2.86) and it has a maximum of $0.004 \mathrm{~m}$ a minimum of $-0.001 \mathrm{~m}$, and a standard deviation of $0.001 \mathrm{~m}$. For the Rudzki geoid the indirect effect on the geoid is zero. The indirect effect on geoid undulations for the $\mathrm{AH}$ isostatic reduction changes the geoid by as much as $1 \mathrm{~m}$.

A total of $125 \mathrm{GPS} /$ levelling points in three different networks were used for comparison with the different gravimetric geoid solutions computed with different terrain reductions. The distributions of the GPS points can be seen in Figure 6.10. There were no GPS/levelling points above the elevation of $308 \mathrm{~m}$.

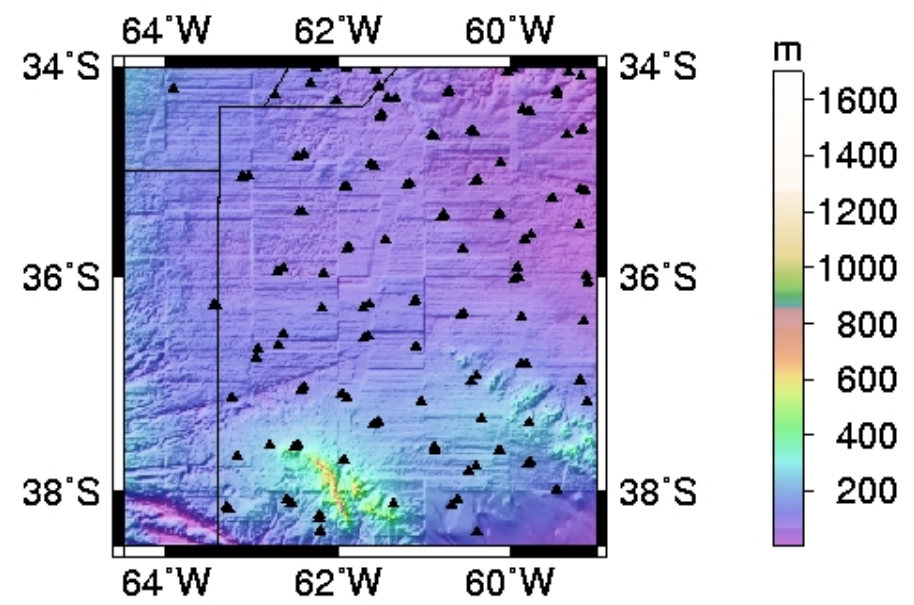

Figure 6.10: Distribution of GPS/levelling benchmarks on elevation map 
In order to get a good agreement of the gravimetric geoid with respect to the GPS/levelling-derived geoid, the systematic datum differences between the gravimetric geoid and the GPS/levelling data and the long wavelengths errors of the geoid were removed by the four-parameter transformation model expressed in equation (4.26), (Heiskanen and Moritz, 1967) and a differential similarity transformation model with seven parameters; see equation (4.28) (Kotsakis, 2001).

The statistics of the absolute differences between the GPS/levelling derived-geoid and the gravimetric geoids computed using different methods of handling the topography are summarized in Table 6.3, where $\mathrm{N}^{\mathrm{RSK}}$ means geoid heights computed with the rigorous spherical kernel and $\mathrm{N}^{\mathrm{ASK}}$ are geoid undulations computed with the approximately spherical kernel.

Table 6.3: Statistics of the differences between gravimetric geoids with GPS/levelling-derived geoid in the flat area. Unit: [m].

\begin{tabular}{|c|c|c|c|c|c|c|}
\hline \multicolumn{2}{|c|}{ Flat Area } & & $\min$ & $\max$ & mean & $\sigma$ \\
\hline $\mathrm{N}^{\mathrm{EGM} 96}-\mathrm{N}^{\mathrm{GPS}}$ & $\begin{array}{c}\text { Original (125 pts) } \\
\text { After fit }\end{array}$ & $\begin{array}{l}\text { Before fit } \\
\text { 4-param } \\
\text { 7-param }\end{array}$ & $\begin{array}{l}-0.431 \\
-0.962 \\
-0.868 \\
\end{array}$ & $\begin{array}{l}1.159 \\
0.318 \\
0.280 \\
\end{array}$ & $\begin{array}{l}0.589 \\
0.000 \\
0.000\end{array}$ & $\begin{array}{l}0.299 \\
0.198 \\
0.189\end{array}$ \\
\hline \multicolumn{2}{|c|}{ Geoid Model: Rudzki } & & $\min$ & $\max$ & mean & $\sigma$ \\
\hline $\mathrm{N}^{\mathrm{RSK}}-\mathrm{N}^{\mathrm{GPS}}$ & $\begin{array}{c}\text { Original (125 pts) } \\
\text { After fit }\end{array}$ & $\begin{array}{l}\text { Before fit } \\
\text { 4-param } \\
\text { 7-param }\end{array}$ & $\begin{array}{r}0.089 \\
-0.873 \\
-0.824 \\
\end{array}$ & $\begin{array}{l}1.270 \\
0.206 \\
0.241\end{array}$ & $\begin{array}{l}0.962 \\
0.000 \\
0.000\end{array}$ & $\begin{array}{l}0.208 \\
0.179 \\
0.157\end{array}$ \\
\hline $\mathrm{N}^{\mathrm{ASK}}-\mathrm{N}^{\mathrm{GPS}}$ & $\begin{array}{c}\text { Original (125 pts) } \\
\text { After fit }\end{array}$ & $\begin{array}{l}\text { Before fit } \\
\text { 4-param } \\
\text { 7-param }\end{array}$ & $\begin{array}{r}0.084 \\
-0.535 \\
-0.823 \\
\end{array}$ & $\begin{array}{l}1.271 \\
0.717 \\
0.242\end{array}$ & $\begin{array}{l}0.962 \\
0.000 \\
0.000\end{array}$ & $\begin{array}{l}0.208 \\
0.151 \\
0.157\end{array}$ \\
\hline \multicolumn{2}{|c|}{ Geoid Model: Helmert } & & $\min$ & $\max$ & mean & $\sigma$ \\
\hline $\mathrm{N}^{\mathrm{RSK}}-\mathrm{N}^{\mathrm{GPS}}$ & $\begin{array}{c}\text { Original (125 pts) } \\
\text { After fit }\end{array}$ & $\begin{array}{l}\text { Before fit } \\
\text { 4-param } \\
\text { 7-param }\end{array}$ & $\begin{array}{l}0.118 \\
-0.895 \\
-0.830 \\
\end{array}$ & $\begin{array}{l}1.360 \\
0.240 \\
0.247\end{array}$ & $\begin{array}{l}1.024 \\
0.000 \\
0.000\end{array}$ & $\begin{array}{l}0.222 \\
0.186 \\
0.167\end{array}$ \\
\hline $\mathrm{N}^{\mathrm{ASK}}-\mathrm{N}^{\mathrm{GPS}}$ & $\begin{array}{c}\text { Original (125 pts) } \\
\text { After fit }\end{array}$ & $\begin{array}{l}\text { Before fit } \\
\text { 4-param } \\
\text { 7-param }\end{array}$ & $\begin{array}{c}0.113 \\
-0.895 \\
0.118 \\
\end{array}$ & $\begin{array}{l}1.362 \\
1.362 \\
1.360\end{array}$ & $\begin{array}{l}1.023 \\
0.000 \\
1.024\end{array}$ & $\begin{array}{l}0.223 \\
0.186 \\
0.222\end{array}$ \\
\hline \multicolumn{2}{|c|}{ Geoid Model: $A H$} & & $\min$ & $\max$ & mean & $\sigma$ \\
\hline $\mathrm{N}^{\mathrm{RSK}}-\mathrm{N}^{\mathrm{GPS}}$ & $\begin{array}{c}\text { Original (125 pts) } \\
\text { After fit }\end{array}$ & $\begin{array}{l}\text { Before fit } \\
\text { 4-param } \\
\text { 7-param }\end{array}$ & $\begin{array}{l}0.127 \\
-0.924 \\
-0.850\end{array}$ & $\begin{array}{l}.0 .289 \\
0.251 \\
0.227\end{array}$ & $\begin{array}{l}1.044 \\
0.000 \\
0.000\end{array}$ & $\begin{array}{l}0.186 \\
0.175 \\
0.163\end{array}$ \\
\hline $\mathrm{N}^{\mathrm{ASK}}-\mathrm{N}^{\mathrm{GPS}}$ & $\begin{array}{c}\text { Original (125 pts) } \\
\text { After fit }\end{array}$ & $\begin{array}{l}\text { Before fit } \\
\text { 4-param } \\
\text { 7-param }\end{array}$ & $\begin{array}{c}0.131 \\
-0.924 \\
-0.849\end{array}$ & $\begin{array}{l}1.289 \\
0.251 \\
0.228\end{array}$ & $\begin{array}{c}1.045 \\
0.00 \\
0.000\end{array}$ & $\begin{array}{l}0.186 \\
0.175 \\
0.163\end{array}$ \\
\hline Geol & el: RTM & & $\min$ & $\max$ & mean & $\sigma$ \\
\hline $\mathrm{N}^{\mathrm{RSK}}-\mathrm{N}^{\mathrm{GPS}}$ & $\begin{array}{c}\text { Original (125 pts) } \\
\text { After fit }\end{array}$ & $\begin{array}{l}\text { Before fit } \\
\text { 4-param } \\
\text { 7-param }\end{array}$ & $\begin{array}{r}0.160 \\
-0.895 \\
-0.836\end{array}$ & $\begin{array}{l}1.353 \\
0.254 \\
0.235\end{array}$ & $\begin{array}{l}1.026 \\
0.000 \\
0.000\end{array}$ & $\begin{array}{l}0.212 \\
0.181 \\
0.164\end{array}$ \\
\hline $\mathrm{N}^{\mathrm{ASK}}-\mathrm{N}^{\mathrm{GPS}}$ & $\begin{array}{c}\text { Original (125 pts) } \\
\text { After fit }\end{array}$ & $\begin{array}{l}\text { Before fit } \\
\text { 4-param } \\
\text { 7-param }\end{array}$ & $\begin{array}{l}0.159 \\
-0.895 \\
-0.836\end{array}$ & $\begin{array}{l}1.356 \\
0.256 \\
0.239\end{array}$ & $\begin{array}{l}1.026 \\
0000 \\
0.000\end{array}$ & $\begin{array}{l}0.212 \\
0.182 \\
0.164\end{array}$ \\
\hline
\end{tabular}


Four different gravity reduction methods have been presented. They treat the topography in a very different way. Helmert's second method of condensation and the RTM method are the most used reduction techniques for the determination of a gravimetric geoid. The Airy-Heiskanen topographic-isostatic reduction and the Rudzki inversion method were applied as well; the latter is not very often used, even though it has the advantage of no indirect effect.

The main conclusion of these results was that the four reduction methods gave almost identical results, as expected for a flat area.

Table 6.3 shows that the agreement between the gravimetric geoid and the GPS/levelling geoid is around 15 to $20 \mathrm{~cm}$ in terms of the standard deviation after fit, and there is no significant difference between the geoid undulations computed with the rigorous spherical kernel $\left(\mathrm{N}^{\mathrm{RSK}}\right)$ and with the approximated spherical kernel $\left(\mathrm{N}^{\mathrm{ASK}}\right)$.

\subsection{Gravimetric geoid determination in a rough area}

A total of 1452 gravity points, with a spacing of approximately $20 \mathrm{~km}$ were selected in the rough area (Block 1). The distribution of the gravity points is shown in Figure 6.11.

The maximum and minimum values of the observed gravity were $980206.92 \mathrm{mGal}$ and 978584.68 mGal, respectively.

Free-air gravity anomalies were calculated using the parameters of the Geodetic Reference System 1980 (GRS80) and the second order free-air reduction. The atmospheric correction was applied to the observed gravity according equation (4.12). The statistics of the Free-air gravity anomalies can be seen in Table 6.4, Figure 6.13 shows the free-air anomalies computed with formula (4.7).

The global digital elevation model GTOPO30 with a horizontal grid spacing of 30 arc seconds (approximately 0.758 kilometre in the North-South direction at the mean latitude of the area and 0.920 in the East-West direction) was used to represent the topography in this test area. The maximum, minimum, mean and standard deviation height was $6795 \mathrm{~m}, 0 \mathrm{~m}, 1125.236 \mathrm{~m}$ and $896.927 \mathrm{~m}$, respectively. 


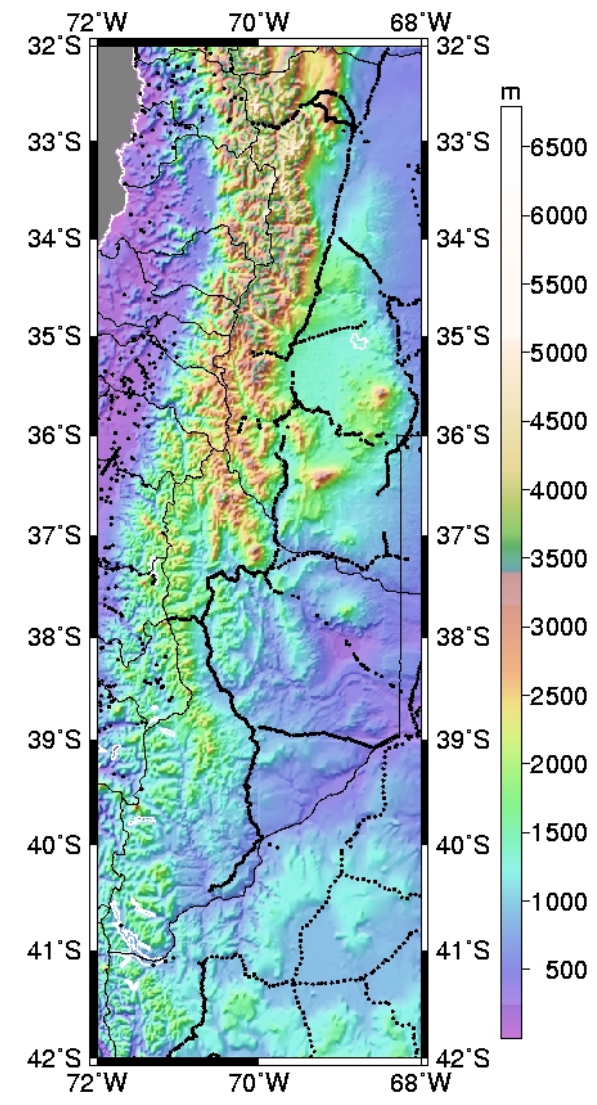

Figure 6.11: Distribution of gravity stations on Figure 6.12: Distribution of GPS/levelling on elevation map

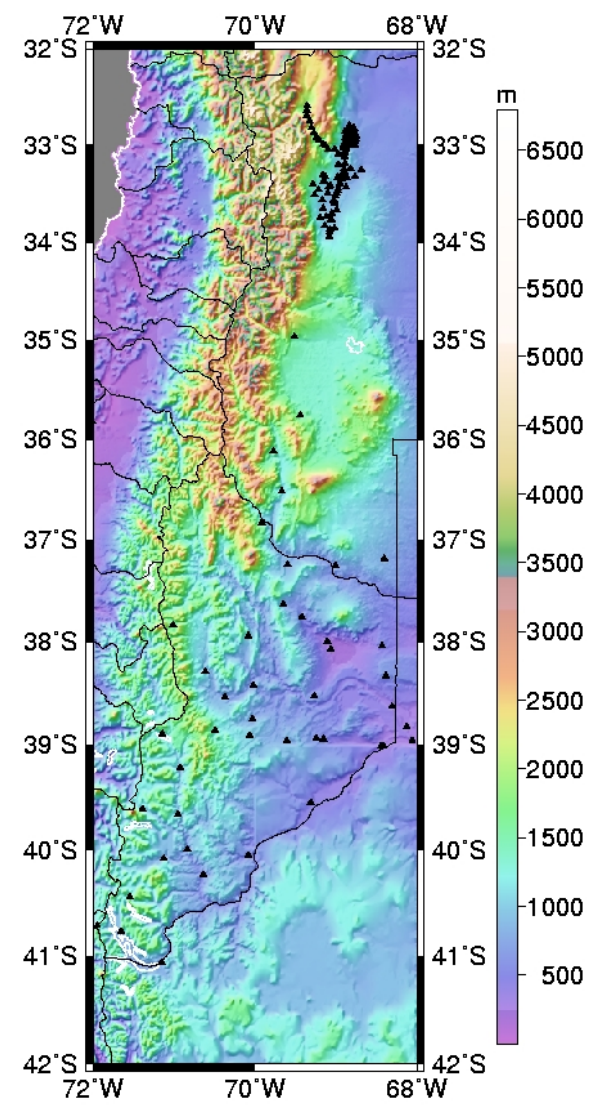

benchmarks on elevation map

Table 6.4: The statistics of gravity anomalies. Unit: [mGal].

\begin{tabular}{l|cccc}
\hline & min & max & mean & $\sigma$ \\
\hline Free-air anomalies & -127.45 & 147.53 & 3.79 & 39.08 \\
Bouguer anomalies & -302.68 & 64.01 & -103.57 & 57.94 \\
Refined Bouguer anomalies & -279.54 & 65.27 & -100.92 & 56.13 \\
Helmert (Faye anomalies) & -124.76 & 173.59 & 6.44 & 39.23 \\
RTM anomalies & -73.26 & 154.67 & 34.01 & 28.30 \\
AH anomalies & -101.67 & 121.56 & 7.22 & 29.53 \\
Rudzki anomalies & -122.73 & 127.09 & 10.55 & 37.80 \\
$\Delta \mathrm{g}^{\text {EGM96 }}$ & -112.66 & 182.71 & 23.26 & 43.21 \\
\hline
\end{tabular}


Terrain corrections $\left(c_{P}\right)$ were calculated by FFT from the GTOPO30 DEM using the TC2DFTPL program ( $\mathrm{Li}, 1993)$; they were computed at all points of a grid of 1440 rows by 600 columns with different topographic representations. Terrain corrections were then interpolated from the grids in the gravity stations using the bilinear interpolation of program geoip from GRAVSOFT software (Tscherning et al., 1992). The statistics of terrain corrections in gravity stations up to third order term of a mass prism model had a maximum of $35.39 \mathrm{mGal}$, a minimum of $0.07 \mathrm{mGal}$, a mean value of $2.65 \mathrm{mGal}$ and a standard deviation of $3.78 \mathrm{mGal}$.

Table 6.4 also shows the statistics of the gravity anomalies computed from EGM96 and the statistics of the Helmert, RTM, Airy-Heiskanen and Rudzki gravity anomalies.

Figures 6.14 to 6.18 show EGM96, Bouguer, Faye, AH, RTM and Rudzki gravity anomalies respectively. The standard constant density of $2.67 \mathrm{~g} / \mathrm{cm}^{3}$ was assumed.

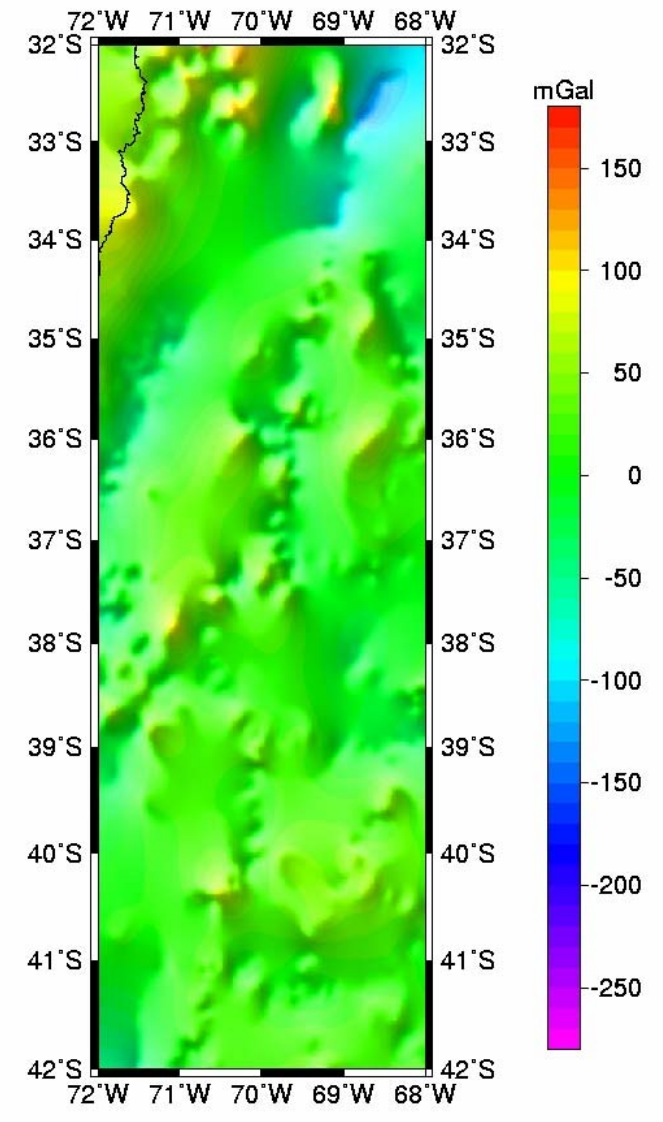

Figure 6.13: Free-air gravity anomalies

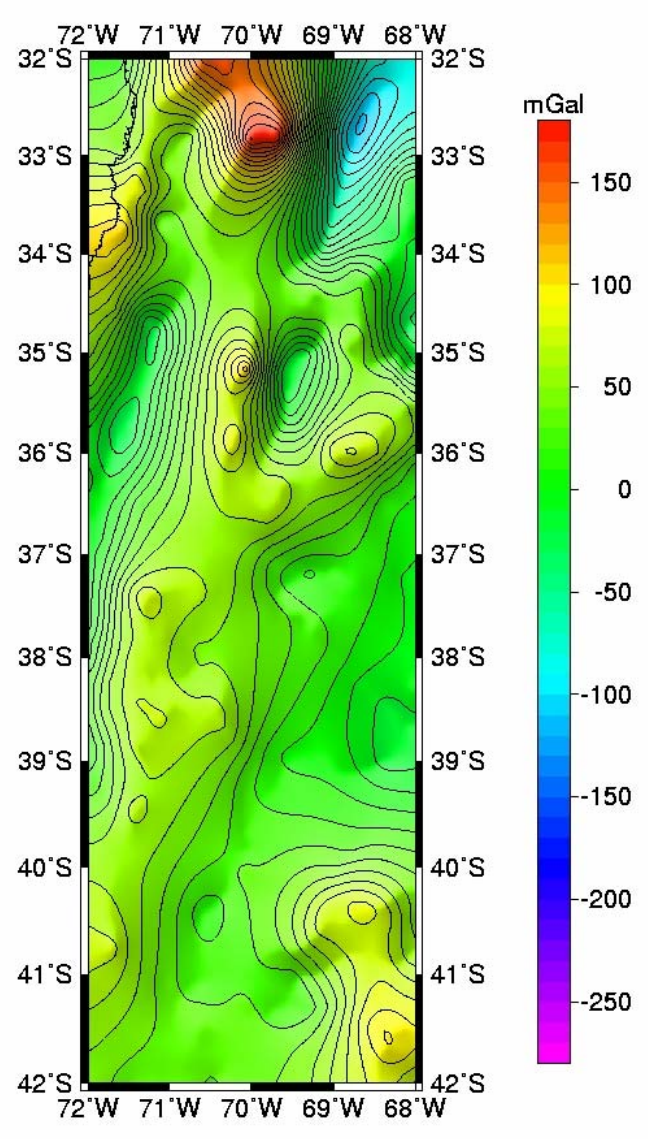

Figure 6.14: EGM96 gravity anomalies 

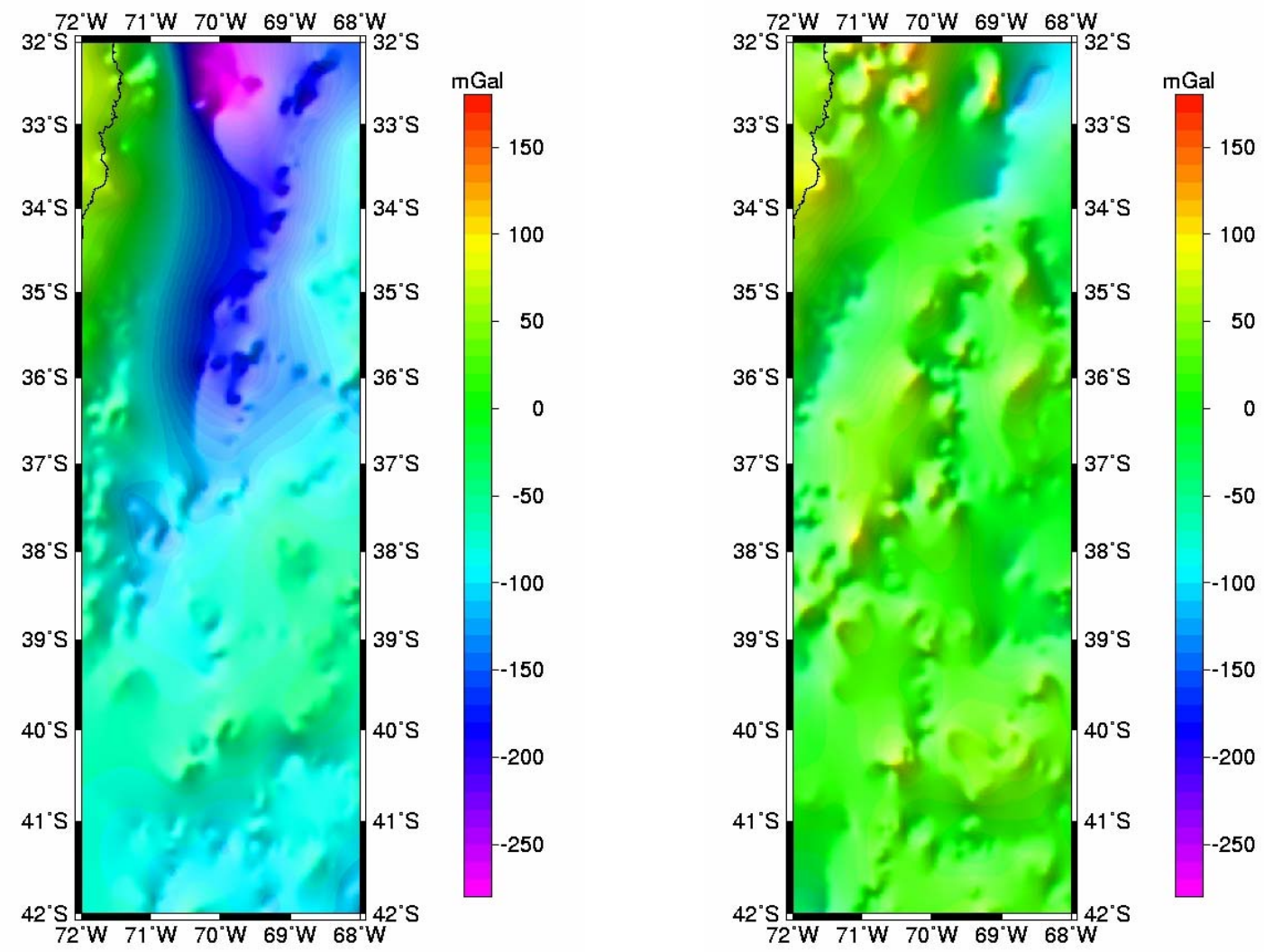

Figure 6.15: Refined Bouguer gravity anomalies

Figure 6.16: Faye gravity anomalies
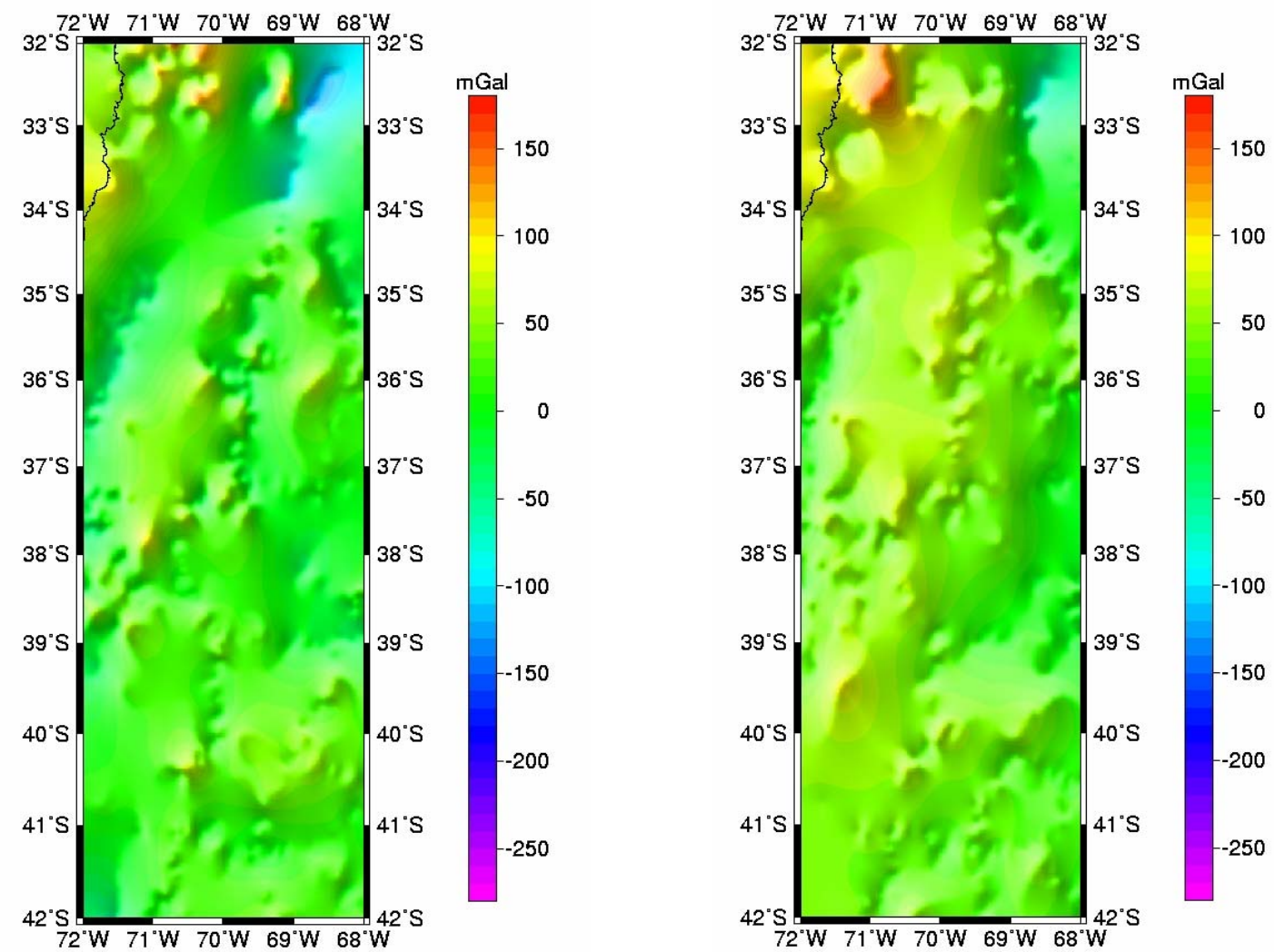

Figure 6.17: Airy-Heiskanen gravity anomalies

Figure 6.18: RTM gravity anomalies 


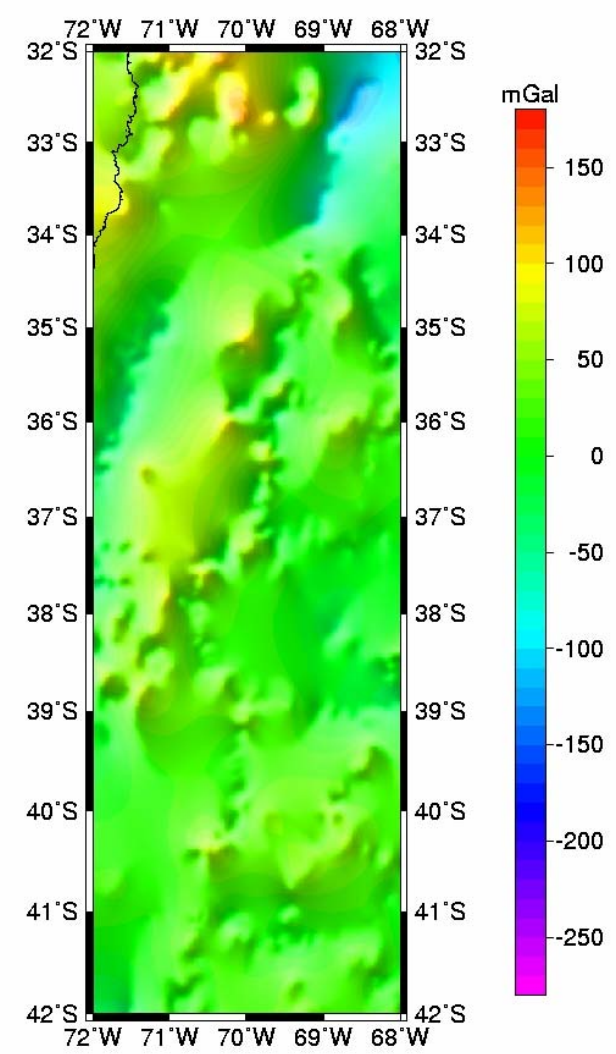

Figure 6.19: Rudzki gravity anomalies

Table 6.4 also shows the statistics of the gravity anomalies computed from EGM96 and the statistics of the Helmert, RTM, Airy-Heiskanen and Rudzki gravity anomalies.

Table 6.4: The statistics of gravity anomalies. Unit: [mGal].

\begin{tabular}{l|cccc}
\hline & $\min$ & $\max$ & mean & $\sigma$ \\
\hline Free-air anomalies & -127.45 & 147.53 & 3.79 & 39.08 \\
Bouguer anomalies & -302.68 & 64.01 & -103.57 & 57.94 \\
Refined Bouguer anomalies & -279.54 & 65.27 & -100.92 & 56.13 \\
Helmert (Faye anomalies) & -124.76 & 173.59 & 6.44 & 39.23 \\
RTM anomalies & -73.26 & 154.67 & 34.01 & 28.30 \\
AH anomalies & -101.67 & 121.56 & 7.22 & 29.53 \\
Rudzki anomalies & -122.73 & 127.09 & 10.55 & 37.80 \\
$\Delta \mathrm{g}$ EGM96 & -112.66 & 182.71 & 23.26 & 43.21 \\
\hline
\end{tabular}

From Table 6.4, we can see that the RTM gravity anomalies are the smoothest gravity anomalies in terms of the standard deviations and also they had the smallest range. 
RTM statistics are similar to those of the AH gravity anomalies. Free-air and Helmert anomalies show similar statistics to each other, as well.

The reference gravity field was computed from the EGM96 geopotential model (Lemoine et al., 1996) complete to degree and order 360. The statistics of the residual gravity anomalies can be seen in Table 6.5. A $3 \mathrm{rms}$ test was performed in order to detect some blunders.

Table 6.5: The statistics of the residual gravity anomalies. Unit: [mGal].

\begin{tabular}{l|cccc}
\hline & min & max & mean & $\sigma$ \\
\hline Free-air anomalies - $\Delta \mathrm{g}^{\text {EGM96 }}$ & -219.75 & 140.46 & -19.47 & 33.96 \\
Bouguer anomalies - $\Delta \mathrm{g}^{\text {EGM96 }}$ & -485.39 & 21.54 & -126.83 & 70.15 \\
Helmert (Faye anomalies) - $\Delta \mathrm{g}^{\text {EGM96 }}$ & -187.47 & 149.65 & -16.82 & 32.75 \\
RTM anomalies - $\Delta \mathrm{g}^{\text {EGM96 }}$ & -106.50 & 100.68 & 10.54 & 31.14 \\
AH anomalies - $\Delta \mathrm{g}^{\text {EGM96 }}$ & -229.63 & 66.98 & -16.04 & 40.10 \\
Rudzki anomalies - $\Delta \mathrm{g}^{\text {EGM96 }}$ & 94.23 & -94.77 & -12.71 & 26.20 \\
\hline
\end{tabular}

The gridding, interpolation, reduction and computational procedures were the same as the ones used in the previous test area.

The indirect effect on gravity due to Helmert's second method of condensation was considered before applying Stokes's formula. The statistics of this effect, together with the indirect effect on the geoid in the rough area, can be seen in Table 6.6. The values of the first, the second and the third term of the indirect effect caused by the second method of Helmert's topographic condensation at 163 GPS/levelling points can be seen in Figure 6.20. In the mountainous area, the computation of the indirect effect on the geoid should be done up to the third order term. The third order term contributes an indirect effect with maximum values of about $20 \mathrm{~cm}$. The maximum indirect effects are correlated with the topography.

Table 6.6: Statistics of indirect effects due to the Helmert's condensation method.

\begin{tabular}{l|cccc}
\hline & $\min$ & $\max$ & mean & $\sigma$ \\
\hline On gravity [mGal] & 0.199 & 0.000 & 0.022 & 0.025 \\
On geoid [m] $1^{\text {st }}+2^{\text {nd }}+3^{\text {rd }}$ terms & -1.171 & 0.000 & -0.111 & 0.225 \\
On geoid [m] 1 ${ }^{\text {st }}$ term & -1.192 & 0.000 & -0.109 & 0.226 \\
On geoid [m] 2 ${ }^{\text {nd }}$ term & -0.023 & 0.025 & 0.000 & 0.006 \\
On geoid [m] 3 $3^{\text {rd }}$ term & -0.174 & 0.147 & -0.002 & 0.026 \\
\hline
\end{tabular}




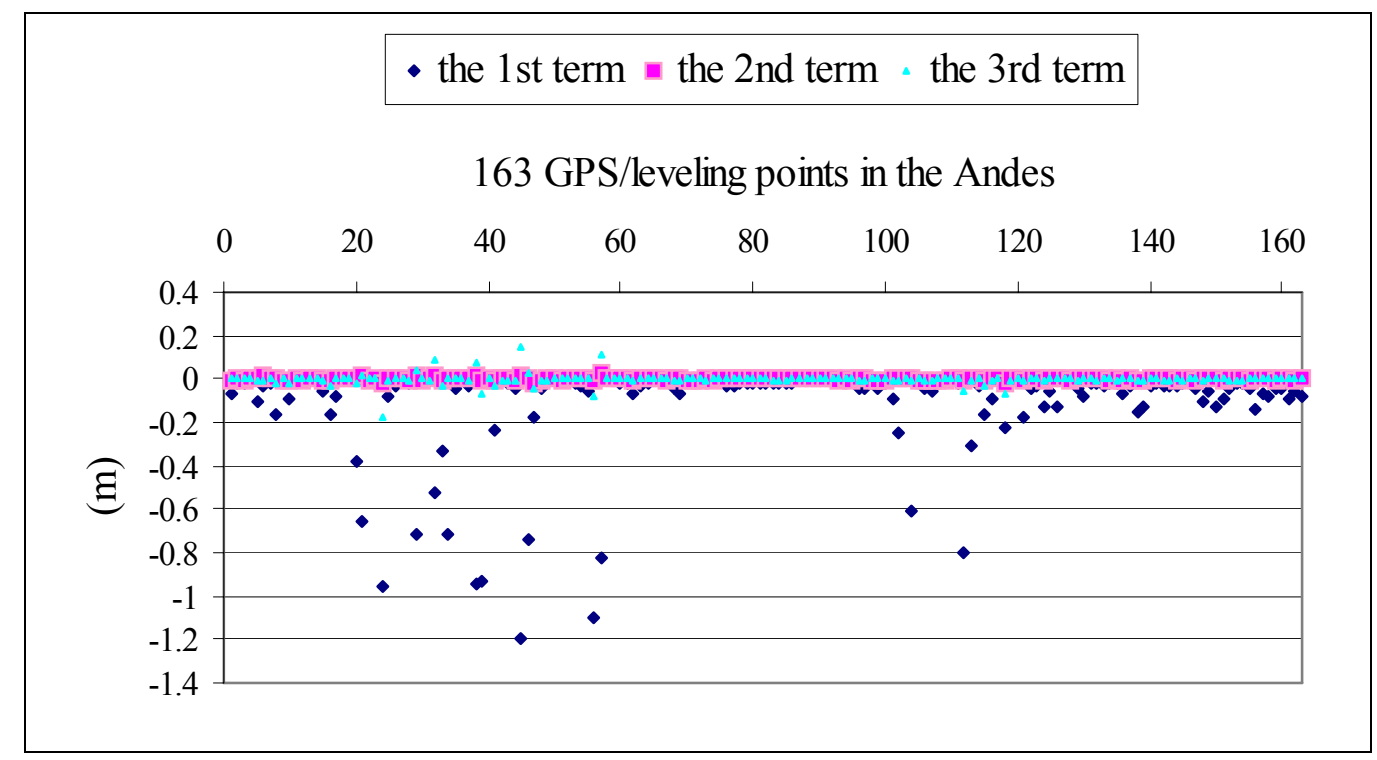

Figure 6.20: Indirect effect on the geoid undulation

For the Rudzki geoid the indirect effect is zero.

A total of $163 \mathrm{GPS} /$ levelling points in three different networks were used for comparison with the different gravimetric geoid solutions computed with different terrain reductions. The distributions of the GPS points can be seen in Figure 6.12. There are no GPS/levelling points above the elevation of $1890 \mathrm{~m}$.

A four-parameter transformation model (Heiskanen and Moritz, 1967) and a differential similarity transformation model with seven parameters (Kotsakis, 2001) were applied to fit the geoid solutions to the GPS/levelling-derived geoid.

The statistics of the absolute differences between the GPS/levelling derived-geoid and the gravimetric geoids computed using different methods of handling the topography are summarized in Table 6.7.

Figure 6.21 shows the graph of the standard deviation of the differences between the different geoid solutions computed with different gravity reduction schemes and with different approximations of the spherical Stokes formula with GPS/levelling-derived geoid. 
Table 6.7: Statistics of the differences between gravimetric geoids with GPS/levelling-derived geoid in the rough Block 1. Unit: [m].

\begin{tabular}{|c|c|c|c|c|c|c|}
\hline \multicolumn{2}{|c|}{ Block 1} & & $\min$ & $\max$ & mean & $\sigma$ \\
\hline \multirow{3}{*}{$\mathrm{N}^{\mathrm{EGM} 96}-\mathrm{N}^{\mathrm{GPS}}$} & Original (163 pts) & \multirow{3}{*}{$\begin{array}{l}\text { Before } \\
\text { fit } \\
\text { 4-param } \\
\text { 7-param }\end{array}$} & -2.43 & 1.88 & 0.62 & 0.91 \\
\hline & Aftor fit & & -1.87 & 1.72 & 0.00 & 0.47 \\
\hline & Aiter I1t & & -1.52 & 1.30 & 0.00 & 0.40 \\
\hline \multicolumn{2}{|c|}{ Geoid Model: Rudzki } & & $\min$ & $\max$ & mean & $\sigma$ \\
\hline \multirow{3}{*}{$\mathrm{N}^{\mathrm{RSK}}-\mathrm{N}^{\mathrm{GPS}}$} & Original (163 pts) & Before fit & 2.60 & 6.47 & 4.19 & 0.60 \\
\hline & 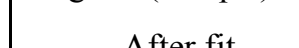 & 4-param & -1.82 & 1.84 & 0.00 & 0.41 \\
\hline & After tit & 7-param & -1.63 & 1.88 & 0.00 & 0.39 \\
\hline \multirow{3}{*}{$\mathrm{N}^{\mathrm{ASK}}-\mathrm{N}^{\mathrm{GPS}}$} & Original (163 pts) & Before fit & 2.65 & 6.45 & 4.21 & 0.60 \\
\hline & & 4-param & -1.82 & 1.85 & 0.00 & 0.41 \\
\hline & Alter 11 & 7-param & -1.63 & 1.89 & 0.00 & 0.39 \\
\hline \multicolumn{2}{|c|}{ Geoid Model: Helmert } & & $\min$ & $\max$ & mean & $\sigma$ \\
\hline \multirow{3}{*}{$\mathrm{N}^{\mathrm{RSK}}-\mathrm{N}^{\mathrm{GPS}}$} & Original (163 pts) & Before fit & 3.12 & 8.00 & 5.46 & 0.81 \\
\hline & $\Delta$ fter fit & 4-param & -2.51 & 2.81 & 0.00 & 0.46 \\
\hline & Atter int & 7-param & -2.23 & 2.46 & 0.00 & 0.42 \\
\hline \multirow{3}{*}{$\mathrm{N}^{\mathrm{ASK}}-\mathrm{N}^{\mathrm{GPS}}$} & Original (163 pts) & Before fit & 3.18 & 7.98 & 5.50 & 0.82 \\
\hline & & 4-param & -2.51 & 2.79 & 0.00 & 0.46 \\
\hline & After tit & 7-param & -2.24 & 2.45 & 0.00 & 0.22 \\
\hline \multicolumn{2}{|c|}{ Geoid Model: RTM } & & $\min$ & $\max$ & mean & $\sigma$ \\
\hline \multirow{3}{*}{$\mathrm{N}^{\mathrm{RSK}}-\mathrm{N}^{\mathrm{GPS}}$} & Original (163 pts) & Before fit & -4.10 & 5.72 & -0.69 & 0.89 \\
\hline & 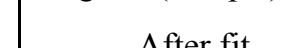 & 4-param & -2.44 & 4.42 & 0.00 & 0.68 \\
\hline & Atter fit & 7-param & -2.69 & 4.39 & 0.00 & 0.64 \\
\hline \multirow{3}{*}{$\mathrm{N}^{\mathrm{ASK}}-\mathrm{N}^{\mathrm{GPS}}$} & Original (163 pts) & Before fit & -4.05 & 5.80 & -0.67 & 0.89 \\
\hline & & 4-param & -2.41 & 4.42 & 0.00 & 0.67 \\
\hline & After in & 7-param & -2.69 & 4.41 & 0.00 & 0.63 \\
\hline \multicolumn{2}{|c|}{ Geoid Model: $A H$} & & $\min$ & $\max$ & mean & $\sigma$ \\
\hline \multirow{3}{*}{$\mathrm{N}^{\mathrm{RSK}}-\mathrm{N}^{\mathrm{GPS}}$} & Original (163 pts) & Before fit & -4.10 & 3.73 & -2.07 & 1.54 \\
\hline & After fit & 4-param & -1.97 & 5.20 & 0.00 & 1.40 \\
\hline & Arter nit & 7-param & -2.19 & 4.32 & 0.00 & 1.02 \\
\hline \multirow{3}{*}{$\mathrm{N}^{\mathrm{ASK}}-\mathrm{N}^{\mathrm{GPS}}$} & Original (163 pts) & Before fit & -4.10 & 3.81 & -2.00 & 1.54 \\
\hline & & 4-param & -2.22 & 5.15 & 0.00 & 1.39 \\
\hline & & 7-param & -2.44 & 4.28 & 0.00 & 1.01 \\
\hline
\end{tabular}

The gravimetric geoid determination based on the Rudzki inversion topographic reduction shows the smallest differences from GPS-levelling before and after fit. The standard deviation of the difference between the gravimetric solution based on AH or the RTM reduction and GPSlevelling is much higher compared to those of Rudzki and Helmert methods. 


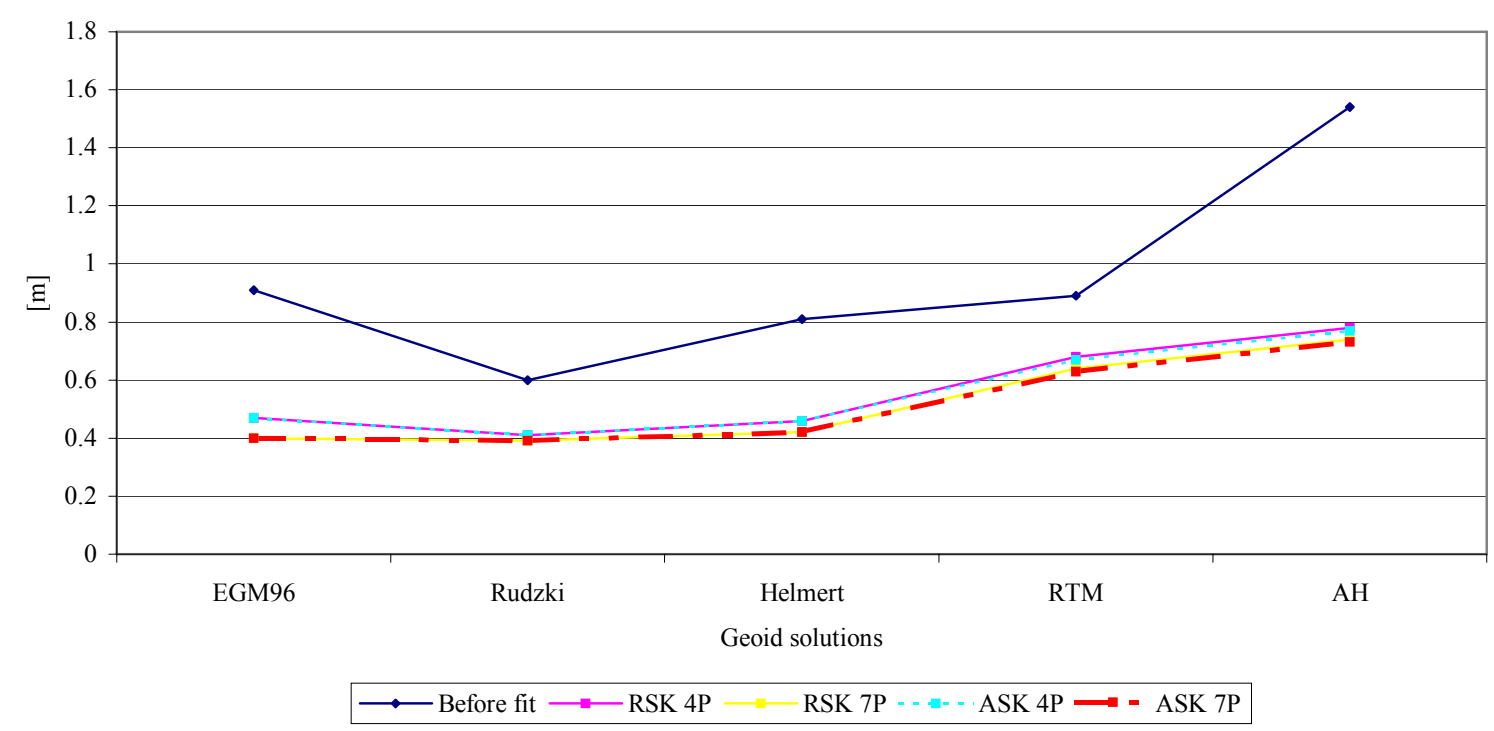

Figure 6.21: Standard deviation of the differences between the geoid undulations from different solutions and the GPS/levelling-derived geoid.(Before fit and after fit with four-parameter transformation model (4P) and with differential similarity transformation model with 7 parameters (7P))

\subsection{Gravimetric geoid determination in the Andes}

A rugged area bounded by latitude $20^{\circ} \mathrm{S}$ to $42^{\circ} \mathrm{S}$ and longitude $72^{\circ} \mathrm{W}$ to $67^{\circ} \mathrm{W}$ was chosen to compute the geoids using the same terrain reductions methods as in the test areas mentioned before.

The interpolation, gridding and computation employed in this area were the same applied in Block 1 and Block 2.

The external accuracy of the gravimetric geoid models was evaluated by comparing them with $166 \mathrm{GPS} /$ levelling points in three different networks. A four-parameter transformation was used again to remove the systematic datum differences between the gravimetric geoid and the GPS/levelling undulations, and the possible long wavelength errors of the geoid.

The point gravity measurements, provided by different sources, were referenced to the International Gravity Standardization Net 1971 (IGSN71). 
A total of 11132 measured gravity points, with a mean data spacing of approximately 12 $\mathrm{km}$ are used in the mountainous area. The distribution of the gravity points is shown in Figure 6.22. Gravity anomalies are computed using the parameters of GRS 80 according to the formulas given in Torge (1989).

The reference gravity field is computed from the EGM96 geopotential model (Lemoine et al., 1998) complete to degree and order 360.

The global digital elevation model GTOPO30 with a horizontal grid spacing of 30 arc seconds (approximately 1 kilometre) is used to represent the topography in this test area.

A total of $166 \mathrm{GPS} /$ levelling points in three different networks were used for comparison with the gravimetric geoid in the rough area. The distribution of the GPS points can be seen in Figure 6.23.

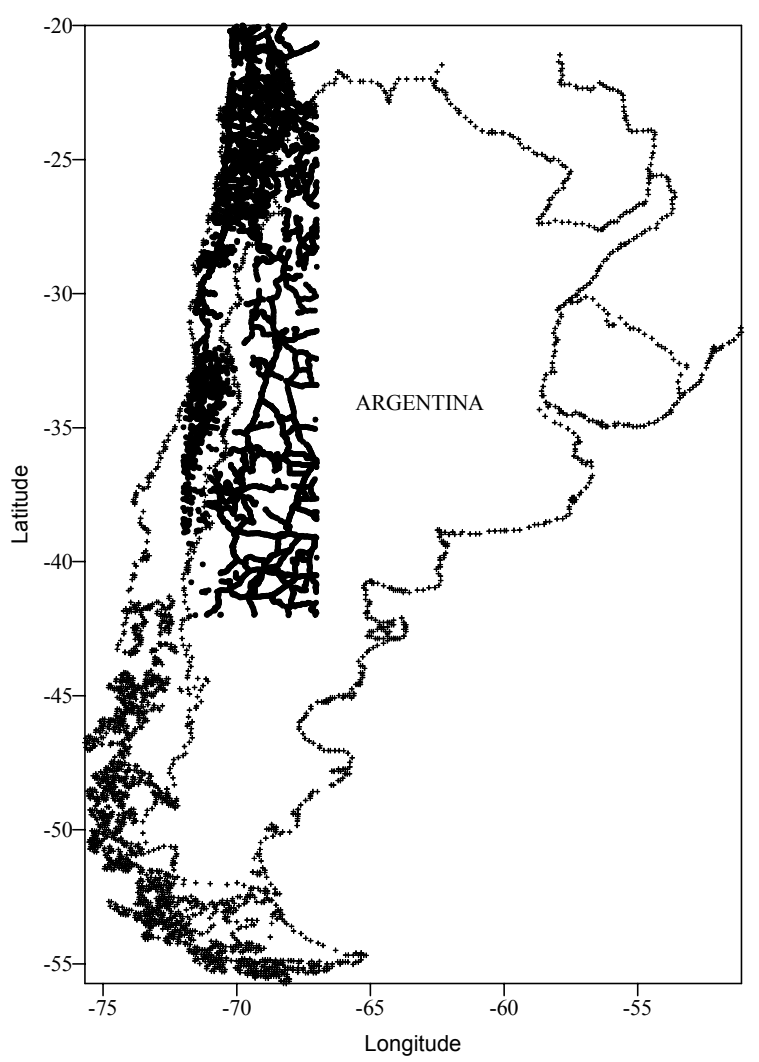

Figure 6.22: Distribution of gravity stations in the area under study

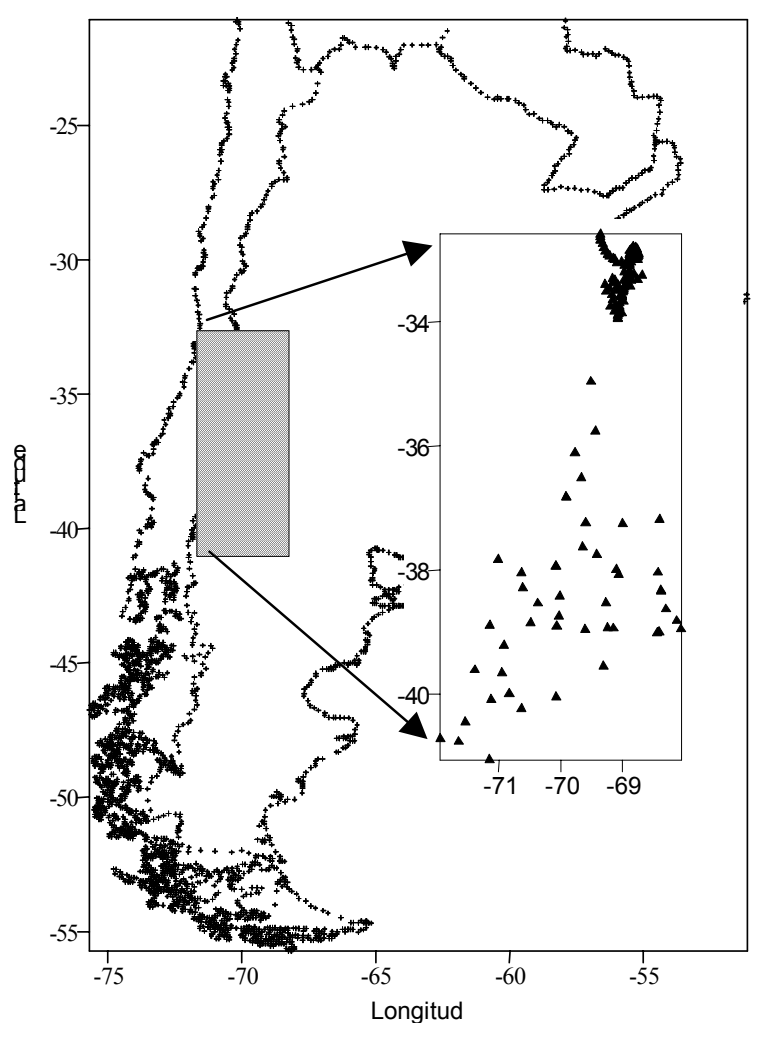

Figure 6.23: Distribution of GPS/levelling points in the area under study 
Terrain corrections $\left(c_{\mathrm{P}}\right)$ were calculated by FFT for each gravity point from the GTOPO30 DEM using the TC2DFTPL program (Li, 1993). A third order term of a mass prism model was used.

The indirect effect on gravity due to Helmert's second method of condensation was considered before applying Stokes's formula. The computation of the indirect effect on the geoid should be considered to, at least, second order term. The maximum indirect effects are correlated with the topography. The statistics of the topographic and data terrain corrections on gravity stations can be seen in Table 6.8 .

Table 6.8: Statistics of the GTOPO30. Unit:[m] and $\mathrm{c}_{\mathrm{P} .}$ Unit:[mGal].

\begin{tabular}{l|llll}
\hline & $\min$ & $\max$ & mean & $\sigma$ \\
\hline GTOPO30 & 0 & 6795 & 1399 & 1465 \\
$\mathrm{c}_{\mathrm{P}}$ & 0.20 & 42.13 & 2.55 & 2.70 \\
\hline
\end{tabular}

The statistics of the gravity anomalies calculated with the four topographic gravity reductions are presented in Table 6.9.

Table 6.9: Statistics of the gravity anomalies calculated with the four topographic reductions. Unit [mGal].

\begin{tabular}{c|ccccc}
\hline & Gravity anomalies & $\min$ & max & mean & $\sigma$ \\
\hline \multirow{2}{*}{ Faye (Helmert) } & $\Delta \mathrm{g}_{\mathrm{FA}}+\mathrm{c}_{\mathrm{P}}$ & -139.09 & 258.63 & 30.53 & 54.95 \\
& $\Delta \mathrm{g}_{\mathrm{FA}}+\mathrm{c}_{\mathrm{P}}-\Delta \mathrm{g}_{\mathrm{EGM} 96}$ & -180.00 & 155.62 & -20.62 & 36.38 \\
& $\Delta \mathrm{g}_{\mathrm{FA}}-\Delta \mathrm{g}_{\mathrm{RU}}$ & -121.55 & 255.70 & 41.77 & 50.87 \\
Rudzki & $\Delta \mathrm{g}_{\mathrm{FA}}-\Delta \mathrm{g}_{\mathrm{RU}}-\Delta \mathrm{g}_{\mathrm{EGM} 96}$ & -113.09 & 112.28 & -9.38 & 27.22 \\
& $\Delta \mathrm{g}_{\mathrm{FA}}-\Delta \mathrm{g}_{\mathrm{RTM}}$ & -71.12 & 285.45 & 64.79 & 38.66 \\
\multirow{2}{*}{$\mathrm{RTM}$} & $\Delta \mathrm{g}_{\mathrm{FA}}-\Delta \mathrm{g}_{\mathrm{RTM}}-\Delta \mathrm{g}_{\mathrm{EGM} 96}$ & -128.37 & 166.00 & 14.04 & 37.58 \\
& $\Delta \mathrm{g}_{\mathrm{FA}}-\Delta \mathrm{g}_{\mathrm{AH}}$ & -74.58 & 185.01 & 42.74 & 51.65 \\
Airy-Heiskanen $(\mathrm{AH})$ & $\Delta \mathrm{g}_{\mathrm{FA}}-\Delta \mathrm{g}_{\mathrm{AH}}-\Delta \mathrm{g}_{\mathrm{EGM} 96}$ & -179.59 & 144.75 & -8.41 & 57.57 \\
\hline
\end{tabular}

The statistics of the absolute differences between the GPS/levelling derived-geoid and the gravimetric geoids computed using different methods of handling the topography are summarized in Table 6.10. The numbers in parentheses refer to the results after the least squares fitting of the four-parameter transformation model has been applied to the original differences. Before applying the four-parameter transformation model, two GPS on benchmark points having large gross error in either the GPS or the levelling data were removed. 
The gravimetric geoid computed with the Rudzki inversion method gave better results compared with the GPS/levelling-derived geoid before and after fit and was the only method that improved the gravimetric geoid compared to the EGM96 results.

The gravimetric data needs to be improved in the area of the Andes in order to see further improvements in the geoid.

Table 6.10: Statistics of different gravimetric geoid solutions (Values in the parentheses are after fit) Unit: [m].

\begin{tabular}{c|cccc}
\hline & $\min$ & $\max$ & mean & $\sigma$ \\
\hline \multirow{2}{*}{ Rudzki } & -1.64 & 2.86 & 0.44 & 0.68 \\
& $(-1.64)$ & $(1.92)$ & $(0.00)$ & $(0.44)$ \\
Helmert & -1.49 & 3.37 & 0.71 & 0.77 \\
& $(-1.63)$ & $(2.11)$ & $(0.00)$ & $(0.54)$ \\
RTM & -1.66 & 2.32 & 1.17 & 1.10 \\
& $(-1.95)$ & $(1.09)$ & $(0.00)$ & $(0.51)$ \\
Airy-Heiskanen & -8.83 & -0.81 & -5.99 & 1.84 \\
& $(3.43)$ & $(-1.75)$ & $(0.00)$ & $(0.61)$ \\
\hline
\end{tabular}

\subsection{Summary}

The flowchart shown in Figure 6.24 describes the computational methodology used in this chapter to compute gravimetric geoid solution with different gravity reduction mass schemes. All solutions were computed with the remove-compute-restore technique, and they only differ in the way they handle the topography.

Three different areas with very different topographies were selected to compute different gravimetric geoid solutions with $\mathrm{AH}$ isostatic reduction, the Rudzki inversion method, Helmert's second method of condensation and the RTM.

In the rough areas, the Rudzki geoid is the best solution compared to other reductions schemes. The major advantage of the Rudzki inversion method is that the indirect effects on the geoid have not to be computed. In the flat area, all the reductions methods gave identical results as expected

A detailed analysis using a remove-restore technique for gravity gridding will be investigated in chapter 8 using digital terrain data in order to diminish aliasing in gravity anomalies, smooth the residual gravity anomalies, and reduce interpolation errors. 


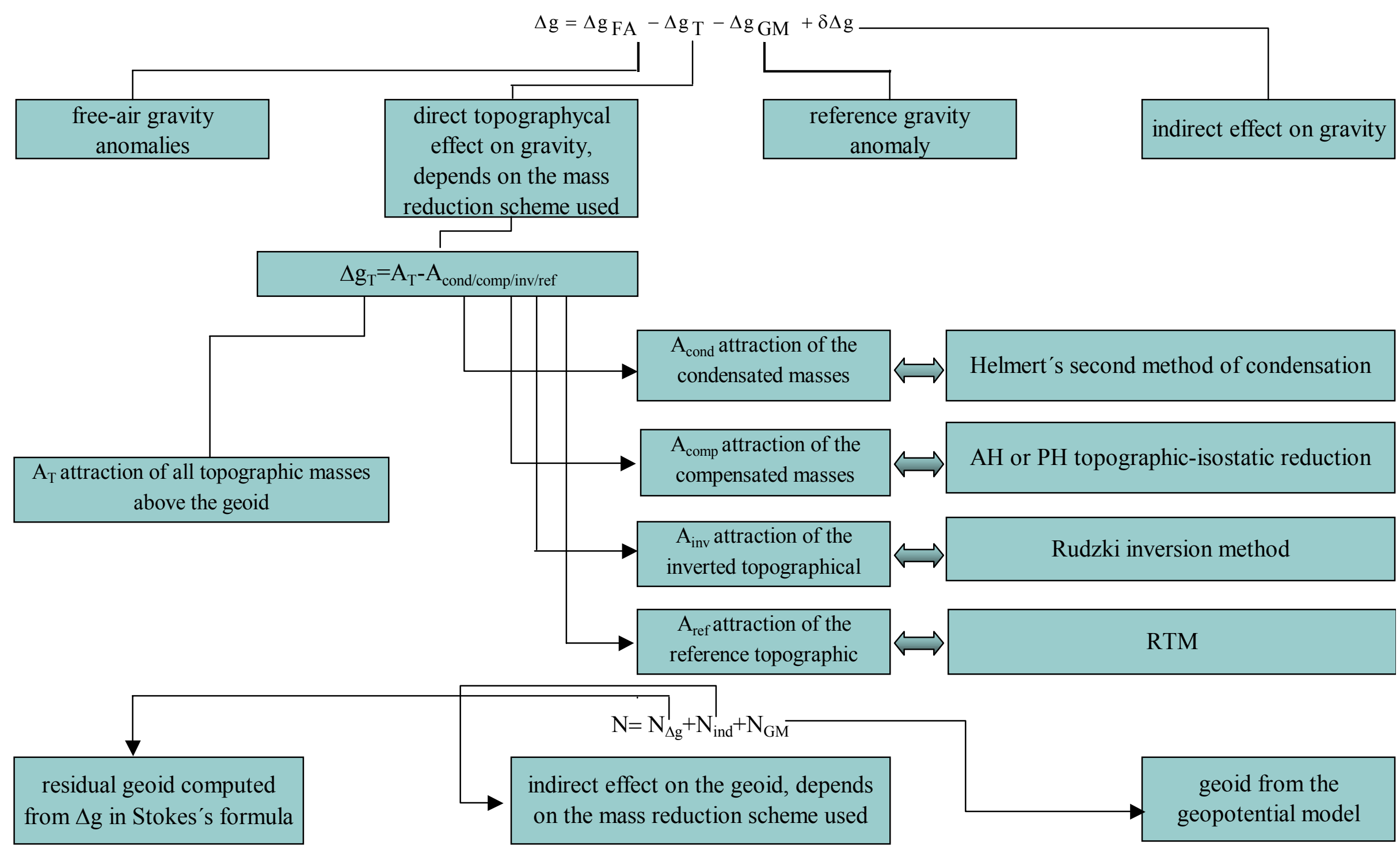

Figure 6.24: Gravimetric geoid solution with different gravity reduction schemes 


\section{CHAPTER SEVEN}

\section{OPTIMAL MARINE GEOID DETERMINATION IN THE ATLANTIC COASTAL REGION OF ARGENTINA}

\subsection{Introduction}

The main objective of this chapter is the determination of a high-accuracy and highresolution marine geoid model in the Atlantic coastal region of Argentina. The theoretical background related to the estimation of the gravimetric and altimetric geoid models (Vergos, 2002) and the combined one using the Multiple Input Multiple Output System Theory (MIMOST) method (Sideris, 1996; Andritsanos and Tziavos, 2002), was outlined in chapter three. In this chapter, some numerical studies that were carried out will be presented, together with the description of the data available in the area under study.

The area under study is located in the Atlantic coastal region of Argentina, bounded by $34^{\circ} \mathrm{S}$ to $55^{\circ} \mathrm{S}$ in latitude and $56^{\circ} \mathrm{W}\left(304^{\circ} \mathrm{E}\right)$ to $70^{\circ} \mathrm{W}\left(290^{\circ} \mathrm{E}\right)$ in longitude. The data available have been described in chapter four and consist of 17352 marine gravity anomalies coming from shipborne campaigns provided by the International Gravimetric Bureau (BGI, 2001) and 2 arc-minute by 2 arc-minute altimetry derived gravity anomalies from the KMS01 and KMS02 global marine free-air gravity fields, computed from ERS1 and GEOSAT satellite altimetry (Andersen and Knudsen, 2005). KMS02 is the newest compilation of a global altimetry-derived marine free-air gravity field by the KMS group at the Danish Surveying and Cadastre.

Gaps in the sparse shipborne data distribution were filled out using $2^{\prime} \times 2^{\prime}$ KMS01 and KMS02 multi-satellite altimetry-derived gravity fields; see Figure 7.1.

The QSST was computed from the EGM96.DOT model and it is shown in Figure 7.2.

The bathymetric data come from the 2' Digital Depth Model (DDM) developed by Smith and Sandwell in 1997. 


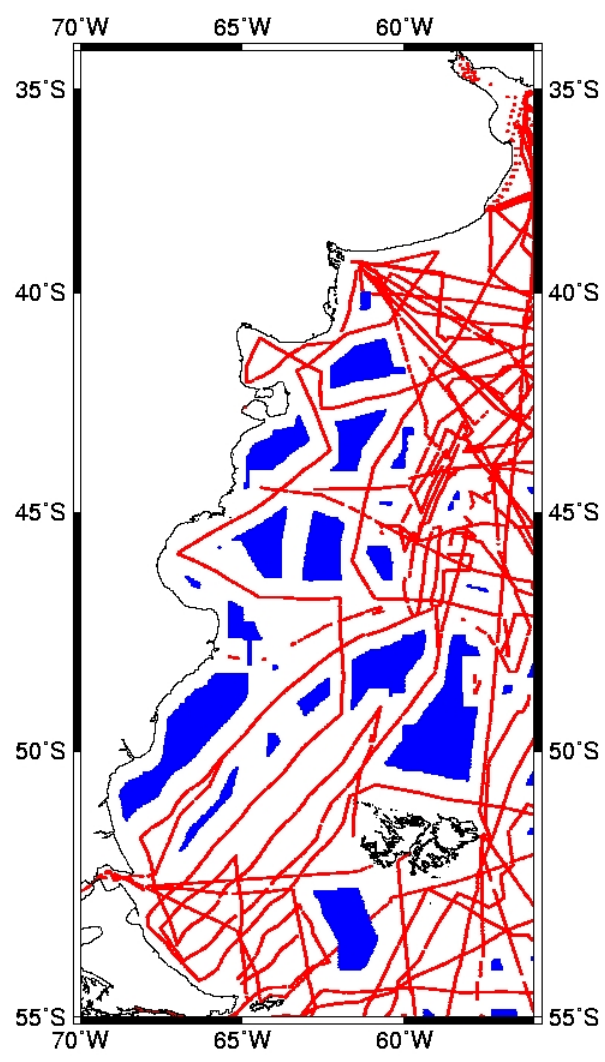

Figure 7.1: Shipborne data (red) filled with KMS in gaps (in blue)

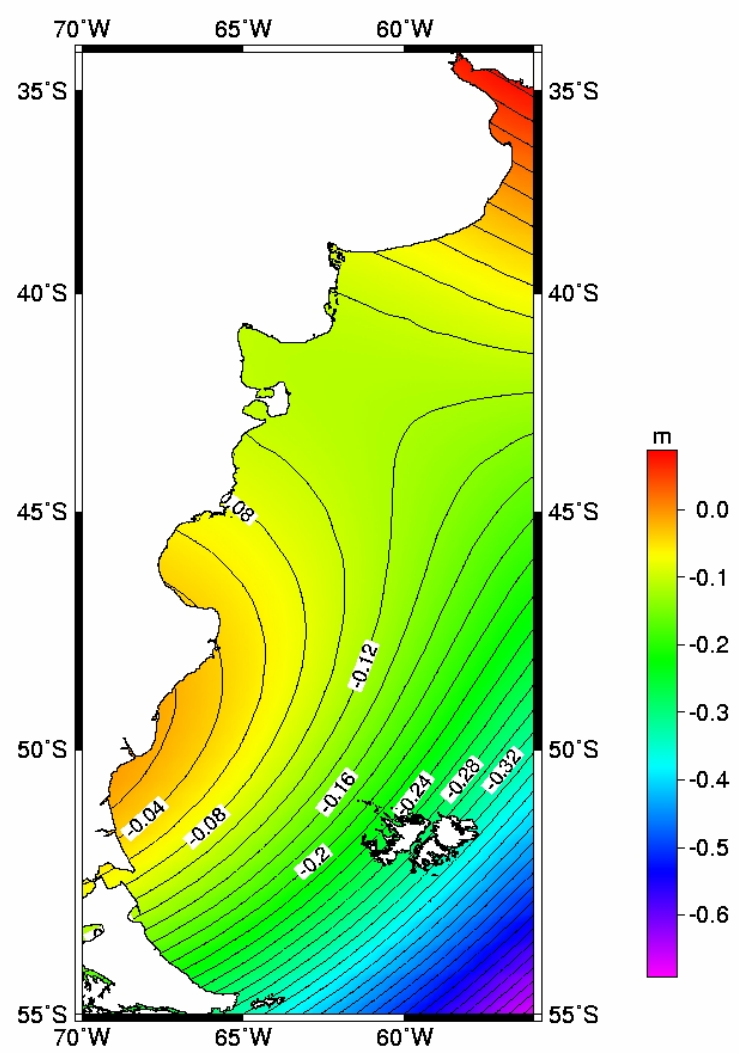

Figure 7.2: The EGM96 QSST in the area under study

The reference gravity field is computed from the EGM96 geopotential model (Lemoine et al., 1998) complete to degree and order 360 and from a "combined" EGM derived from the latest CHAMP and GRACE type of Earth Gravity Models (EGMs) (Vergos et al., 2004). It should be mentioned that this so-called combined EGM is not a new model determined from raw CHAMP and GRACE data, but it is a combination of the harmonic coefficients of a number of new EGMs estimated from CHAMP and GRACE data. Therefore, by inspecting the CHAMP and GRACE degree and error-degree variances, we defined which one was more accurate for different harmonic degrees, and then a "combined" EGM was developed, using the GFZ EIGEN2 for n=2-5, the CSR GGM01C for $\mathrm{n}=6-116$ and EGM96 for $\mathrm{n}=117-360$ (Vergos et al., 2004).

From the contribution of the EGM96 geopotential model and the so-called "combined" EGM, a reference gravity anomaly $\left(\Delta \mathrm{g}_{\mathrm{GM}}\right)$ and a reference geoidal undulation $\left(\mathrm{N}_{\mathrm{GM}}\right)$ can be calculated using equations 2.1 and 2.2 , respectively. 
The next paragraphs will present the first numerical investigations for marine geoid modeling determination using satellite altimetry and shipborne data ever carried out in the Atlantic coastal region of Argentina.

The optimal marine geoid modeling process can be summarizes as follows:

- compute gravimetric and ERS1 altimetric geoid solutions;

- use EGM96 geopotential model and the "combined EGM" to model the lowfrequency part of the gravity field spectrum;

- apply RTM reduction to take into account the high frequency part of the gravity field spectrum due to the bathymetry;

- take into account the high Sea Surface Variability;

- estimate combined solutions using MIMOST; and

- compare the results with T/P SSHs known for to their high accuracy and estimate the accuracy of the final gravimetric, altimetric and combined solution.

The altimetric geoid solutions will be first presented, then the gravimetric ones, and finally the combined solutions using the Input-Output System Theory.

\subsection{Geoid model development}

\subsubsection{Altimetric geoid model with ERS1-GM data}

The ERS1 satellite altimetry CORSSHs were provided in the usual Geophysical Data Records (GDRs) format and were corrected for all geophysical and instrumental errors as well as orbit errors in a pre-processing step according to the models and methods described in the AVISO handbook (AVISO, 1998).

As the ERS1-GM CORSSHs refer to sea surface, they were reduced to the geoid by removing the effect of the QSST. That was performed using equation (3.4) to predict QSST values on the irregular ERS1 points. Then, the corrected ERS1-GM Sea Surface Heights referred to the geoid were ready to be used for the estimation of a purely 
altimetric geoid. The contribution of the EGM96 geopotential model was then removed to derive reduced SSHs (SSHsred). These reduced SSHs may still contain some blunders, which should be removed. A three root mean square $(3 \mathrm{rms})$ test was used for blunder detection. When the $3 \mathrm{rms}$ test is applied, all the points whose absolute value is greater than three times the rms value of the entire dataset is removed as a blunder. To apply the $3 \mathrm{rms}$ test, all biases in the dataset are supposed to be removed so only random errors are remaining. The reduced SSHs were checked for their mean value and after examining the mean value of the reduced field it was not found to be small enough for a $3 \mathrm{rms}$ test to be performed. Thus, the bathymetry was first taken into account with an RTM reduction and after that, a 3 rms test for blunder detection has been applied. After the $3 \mathrm{rms}$ test, 678 points were removed and the resulting point data (Nres) were gridded using the weighted means method on a 3 arc-minute by 3 arc-minute grid.

To reduce the high-frequency Sea Surface Variability effects the data were low-pass filtered using Wiener filtering. The cut-off frequency was determined empirically based on a criterion of maximum noise reduction with minimum signal loss. A number of cutoff frequencies were tested $(14 \mathrm{~km}, 16 \mathrm{~km}, 18 \mathrm{~km}, 20 \mathrm{~km}, 28 \mathrm{~km})$ and finally a cut-off frequency corresponding to a wavelength of $20 \mathrm{~km}$ was chosen. That selection gave the best results as far as both the noise reduction and the minimization of the differences with T/P SSHs are concerned.

Thus the first altimetric geoid solution was obtained by restoring the contribution of the EGM96 geopotential model and that of the RTM effects of the bathymetry. We will refer to this solution as "Altimetric Geoid one" (AG1).

In order to determine a high-accuracy and high-resolution geoid model for the Atlantic coastal region of Argentina, the study was focused on the improvement of our previous results using the "combined EGM". This second solution will be referred as "Altimetric Geoid two"(AG2).

Table 7.1 presents the statistics of the ERS1-GM altimetric geoid processing for the area under study using EGM96 and the so-called "combined EGM", respectively, which is depicted in Figure 7.3.

Due to the very high SSV also present in the residual field of this second solution, the data were low-pass filtered with a Wiener type of filter. A cut-off frequency 
corresponding to $22 \mathrm{~km}$ was selected for AG2, after different cut-off frequencies were empirically tested, for the low-pass filtering procedures using a collocation type of filter assuming Kaula's rule for the geoid spectrum. Figures 7.3 and 7.4 illustrate the altimetric geoid solutions after and before the gridded Nres have been low-pass filtered at $22 \mathrm{~km}$

Table 7.1: Statistics of the ERS1-GM altimetric geoid models. Unit: [m].

\begin{tabular}{l|llll}
\hline & $\min$ & $\max$ & $\operatorname{mean}$ & $\sigma$ \\
\hline Nalt with EGM96. (AG1). Unit: [m]. & 0.447 & 19.665 & 11.406 & \pm 3.026 \\
Nalt with the "combined EGM". (AG2). Unit: [m]. & 0.794 & 19.384 & 11.368 & \pm 3.018 \\
\hline
\end{tabular}

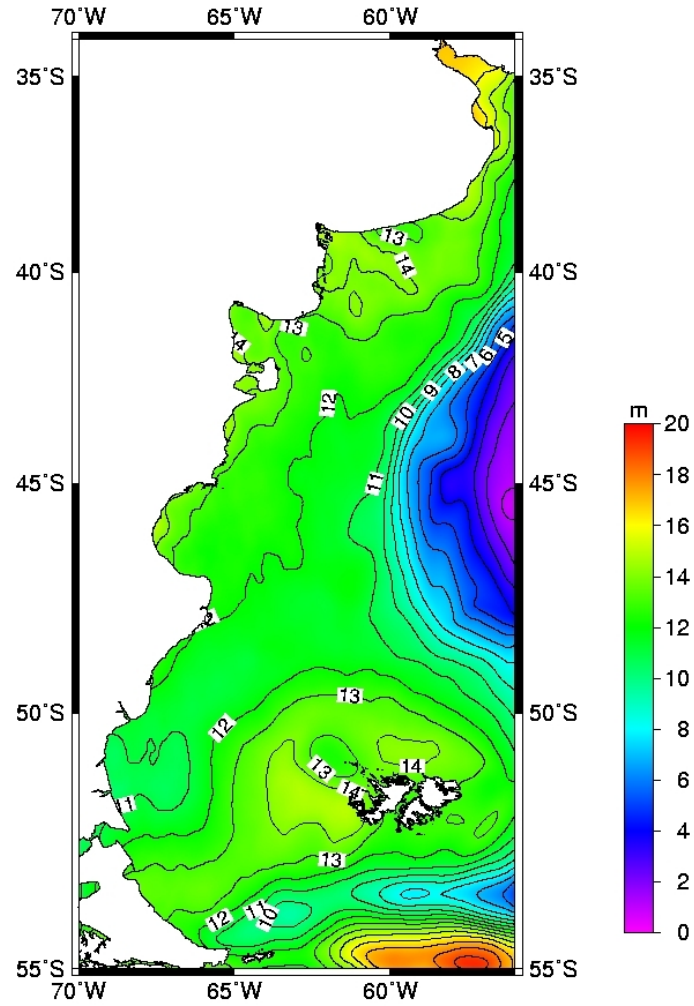

Figure 7.3: Altimetric geoid with Nres after filtering at $22 \mathrm{~km}$

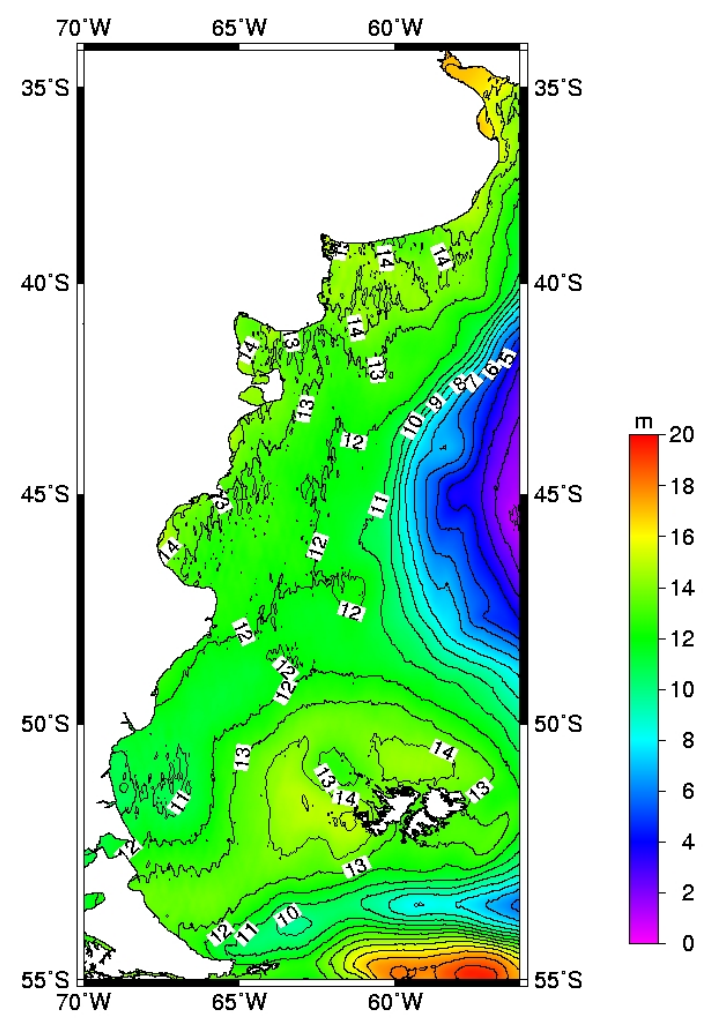

Figure 7.4: Altimetric geoid with Nres without low-pass filtering

The differences between the altimetric geoid computed with the "combined" EGM (AG2) and the solution computed with EGM96 (AG1) have a maximum, a minimum mean and a standard deviation of $1.624 \mathrm{~m},-0.609 \mathrm{~m},-0.038 \mathrm{~m}$ and $0.071 \mathrm{~m}$, respectively. 
From the results shown in Tables 7.1, we cannot conclude about which solution is better but later, we will show that from comparisons made with the solution computed with the EGM96 geopotential model and T/P SSHs and the comparisons between the altimetric solution with the "combined EGM" and T/P SSHs, the use of the "combined EGM" improves the results by $1 \mathrm{~cm}$ in terms of the standard deviation, which is not really significant.

\subsubsection{Gravimetric geoid model}

Three gravimetric geoid models were determined using the computational procedure described in section 3.2.1. One solution was computed with EGM96 and KMS01; we will refer to this solution as "Gravimetric Geoid one" (GG1). The other two solutions were estimated with the "combined EGM" and KMS01; this solution will be referred as "Gravimetric Geoid two" (GG2). The third solution was calculated with the "combined EGM" and KMS02; this will be referred as "Gravimetric Geoid three" (GG3).

Tables 7.2 presents the statistics of the gravimetric geoid processing computed with the "combined EGM" and gaps of shipborne data filled in with KMS01 (GG2) and the statistics for the "Gravimetric Geoid three" (GG3).

The main difference in the processing flow with the altimetric geoid modeling is that the RTM reduction is restored before the prediction of the gravimetric residual geoid heights.. After the pre-processing of the shipborne gravity anomalies (transformation from GRS67 to GRS80, remove data blunders, reduce gravity anomalies from sea surface to geoid with EGM96.DOT and fill gaps with sparse distribution with KMS free-air gravity anomalies derived altimetrically), marine gravity was ready for geoid determination.

The RTM-reduced gravity anomalies, using the Sandwell and Smith bathymetry model to account for bathymetry, were ready for gridding using the same algorithm that was used for the altimetric geoid. After gridding, the contribution of the bathymetry was restored prior to the geoid prediction. The residual geoid prediction was carried out by applying the 2D FFT approximated Stokes convolution on the 3 arc-minute by 3 arc- 
minute grid using program fftgeoid (Li and Sideris, 1993) The final gravimetric geoid solutions were computed by restoring the contribution of the geopotential model.

The statistics of the gravimetric geoid computed with EGM96 as reference field with KMS01 (GG1) for the area under study have a maximum, a minimum, a mean and a standard deviation of $19.333 \mathrm{~m}, 0.628 \mathrm{~m}, 11.309 \mathrm{~m}$ and $2.984 \mathrm{~m}$, respectively.

The gravimetric geoid solution with the "combined EGM" can be seen in Figure 7.5. This solution was computed with the "combined" EGM and KMS02 data (GG3).

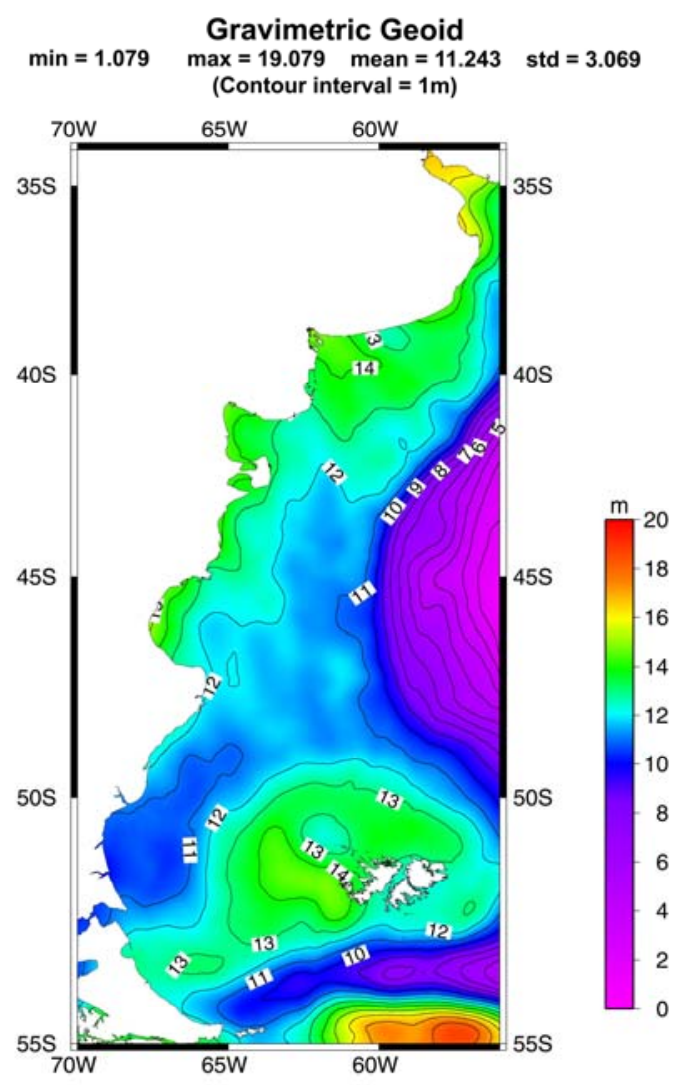

Figure 7.5: Gravimetric geoid in the Atlantic coastal region of Argentina

Table 7.2: Statistics of gravimetric geoid models. Unit:[m]

\begin{tabular}{ll|cccc}
\hline & & $\min$ & $\max$ & mean & $\sigma$ \\
\hline $\begin{array}{l}\text { Ngrav GG2 (with “combined EGM” and } \\
\text { KMS01) }\end{array}$ & 1.079 & 19.079 & 11.249 & \pm 2.869 \\
$\begin{array}{l}\text { Ngrav GG3 (with “combined EGM” and } \\
\text { KMS02) }\end{array}$ & & 1.079 & 19.096 & 11.245 & \pm 2.869 \\
\hline
\end{tabular}


From the statistics shown in Tables 7.2, we can conclude that there is no differences between the "Gravimetric Geoid two" (GG2) and the Gravimetric Geoid three" (GG3). There are no differences in the gravimetric geoid solutions computed using either KMS01 or KMS02 altimetry-derived free-air gravity anomalies.

We can also conclude that there is no significant improvement in the gravimetric geoid solutions computed with the"combined EGM" (solutions GG2 and GG3) compared to the one computed with the EGM96 (solution GG1).

\subsubsection{Validation of KMS01 and KMS02 altimetry-derived free-air gravity anomalies}

KMS01 and KMS02 altimeter-derived gravity anomaly grids offshore Argentina were compared with one another and with ship-track gravity anomalies computed from the BGI gravity database.

Sub-grids were extracted from the global grids over the study area. The statistics of the gravity anomalies for each grid, after land gravity anomalies were removed using the grdlandmask option in GMT (Wessel and Smith, 1998) can be seen in Table 7.3.

Table 7.3: Statistics of KMS01 and KMS02 grids, their differences and shipborne gravity anomalies offshore Argentina Unit: [mGal].

\begin{tabular}{l|cccc}
\hline & $\min$ & $\max$ & mean & $\sigma$ \\
\hline KMS01 & -137.57 & 130.77 & 4.41 & \pm 25.59 \\
KMS02 & -134.26 & 131.47 & 4.39 & \pm 25.90 \\
Shipborne data & -133.03 & 142.57 & 4.01 & \pm 28.64 \\
KMS02-KMS01 & -41.37 & 64.17 & -0.02 & \pm 4.15 \\
\hline
\end{tabular}

From Table 7.3 we can see that both KMS models have similar statistics and the shipborne gravity anomalies data have a comparable range.

The statistics of the differences between KMS02 and KMS01 can also be seen in Table 7.3; these differences are depicted in Figure 7.6. From Figure 7.6, the larger differences occur over the South American-Scotia plate boundary and at the edge of the continental shelf of Argentina. 
The KMS gravity anomalies were bilinearly interpolated to the locations of the shipborne data. Table 7.4 presents the statistics of the differences between both grids and the 12823 shipborne gravity points using program geoip from the GRAVSOFT software (Tscherning et al., 1992). Plotting the differences between the two different KMS grids and the shipborne marine gravity anomalies, we conclude that the large differences correspond to specific ship-tracks, which were removed.. Figure 7.7 shows the differences between shipborne data and KMS02. Due to the uncertain quality of the shipborne data, they should be used with caution to provide any reliable indication of the quality of the altimeter grids.

Table 7.4: Statistics of the differences between KMS grids and the shipborne marine gravity anomalies. Unit: [mGal].

\begin{tabular}{l|cccc}
\hline & $\min$ & Max & mean & $\sigma$ \\
\hline KMS01-shipborne & -61.47 & 67.74 & 0.99 & \pm 10.31 \\
KMS02-shipborne & -63.67 & 66.31 & 1.25 & \pm 9.99 \\
\hline
\end{tabular}

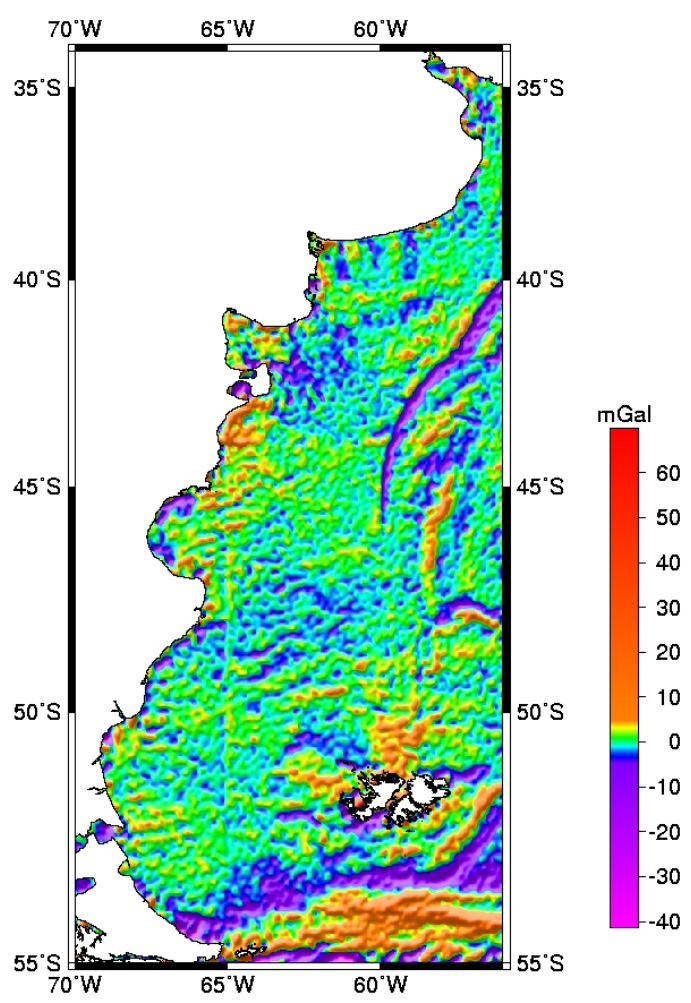

Figure 7.6: KMS02-KMS01 in Argentina

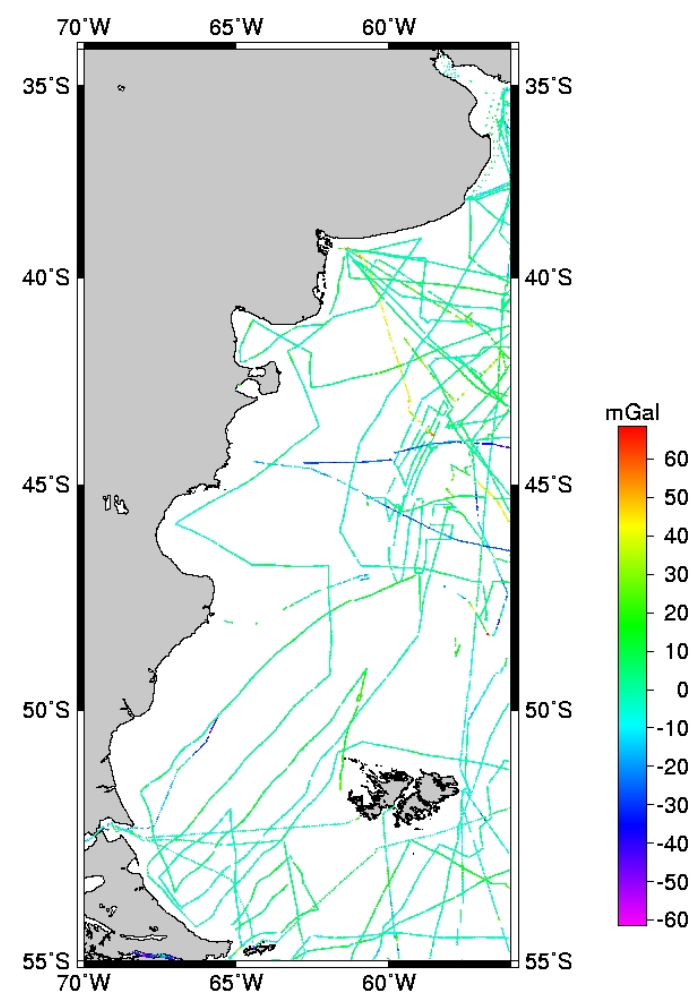

Figure 7.7: Differences between shipborne data and KMS02 


\subsubsection{MIMOST Combined solution}

The combined geoid solutions were estimated using the MIMOST method in a smaller area between $40^{\circ} \mathrm{S}$ to $50^{\circ} \mathrm{S}$ in latitude and $56^{\circ} \mathrm{W}\left(304^{\circ} \mathrm{E}\right)$ to $66^{\circ} \mathrm{W}\left(294^{\circ} \mathrm{E}\right)$ in longitude. The final solution from the combined method was estimated using the formulas described in chapter 3 for two inputs and one output.

Table 7.5 shows the statistics of three gravimetric geoid solutions, one estimated with EGM96 and KMS01 (GG1), other with "combined EGM" and KMS01 (GG2) and the third with "combined EGM" and KMS02 (GG3). The same table also shows the statistics of two ERS1-GM geoid solutions, one with EGM96 (AG1) and the other with the "combined EGM" (AG2), and the statistics of the three combined MIMOST solutions, one (CG1) with AG1 and GG1; the second (CG2) with AG2 and GG2; and the third (CG3) with AG2 and the gravimetric one with KMS02 (GG3). All the geoid solutions can be seen in Figures 7.8 through 7.15.

The inputs of MIMOST were residual gravimetric geoid heights and residual altimetric geoid heights with the contribution of the geopotential model removed in order to avoid long wavelength errors.

The input noises for each dataset were generated using the standard deviation of the differences between T/P SSHs and the gravimetric geoid $(25 \mathrm{~cm})$ and between T/P SSHs and the altimetric geoid $(20 \mathrm{~cm})$ geoid models for the combined solution 1 (CG1) and using the standard deviation of $19 \mathrm{~cm}$ for the altimetric geoid heights and the $21 \mathrm{~cm}$ standard deviation for the gravimetric solutions for the combined solution 2 and 3 (CG2 and CG3).

Table 7.5: Statistics of the geoid models in the smaller area. Unit: [m].

\begin{tabular}{l|cccc}
\hline & Min & max & mean & $\sigma$ \\
\hline Nalt (AG1) & 0.505 & 14.722 & 10.285 & \pm 3.287 \\
Ngrav (GG1) & 0.642 & 14.954 & 10.244 & \pm 3.268 \\
Ncomb (CG1) & 0.574 & 14.912 & 10.257 & \pm 3.275 \\
Nalt (AG2) & 0.794 & 14.663 & 10.246 & \pm 3.279 \\
Ngrav (GG2) & 1.079 & 14.715 & 10.201 & \pm 3.088 \\
Ngrav (GG3) & 1.076 & 14.722 & 10.202 & \pm 3.087 \\
Ncomb (CG2) & 0.788 & 14.618 & 10.247 & \pm 3.278 \\
Ncomb (CG3) & 0.785 & 14.618 & 10.247 & \pm 3.278 \\
\hline
\end{tabular}




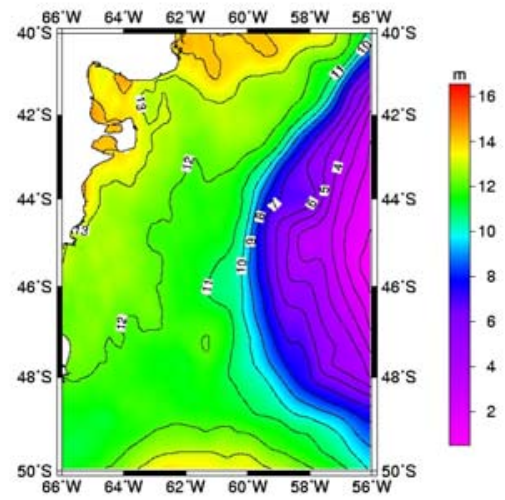

Figure 7.8: ERS1-GM altimetric geoid (AG1)

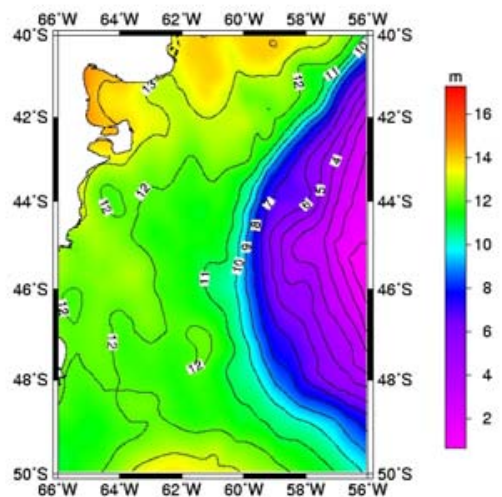

Figure 7.10: Gravimetric geoid (GG1)

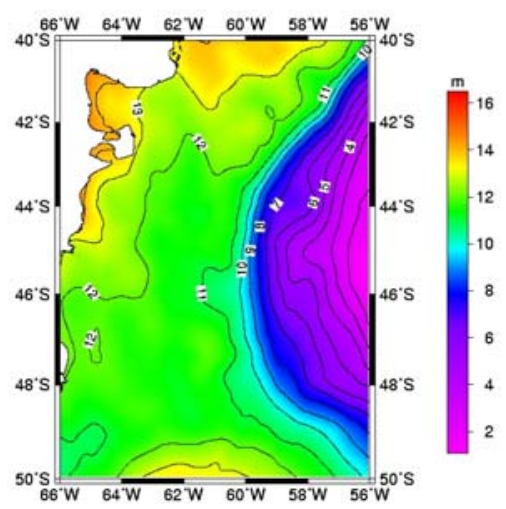

Figure 7.12: Gravimetric geoid (GG3)

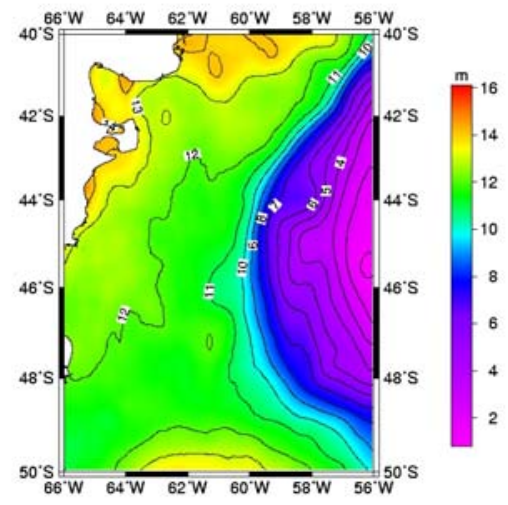

Figure 7.14: MISOT geoid (CG2)

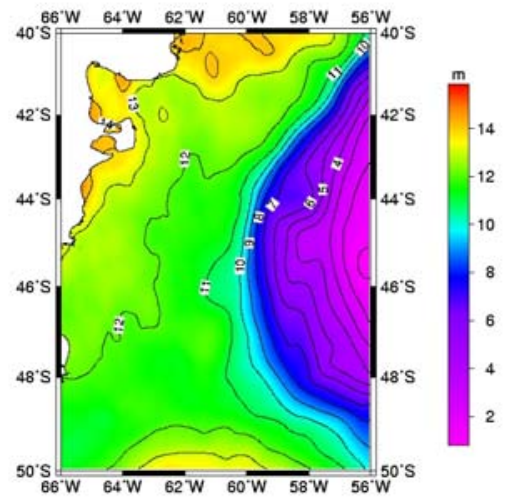

Figure 7.9: ERS1-GM altimetric geoid (AG2)

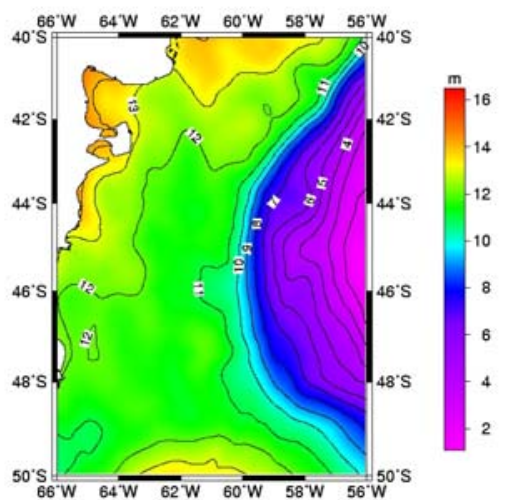

Figure 7.11: Gravimetric geoid (GG2)

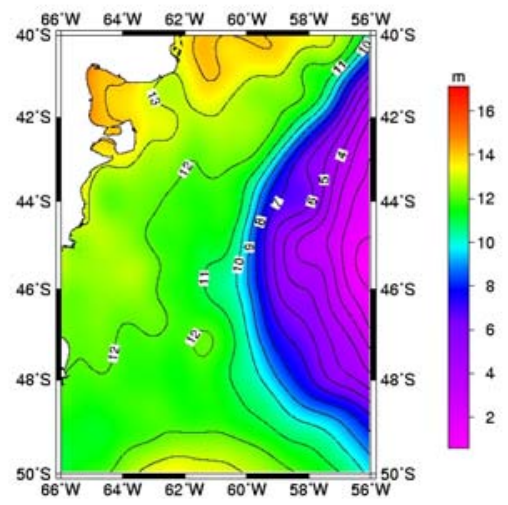

Figure 7.13: MISOT geoid (CG1)

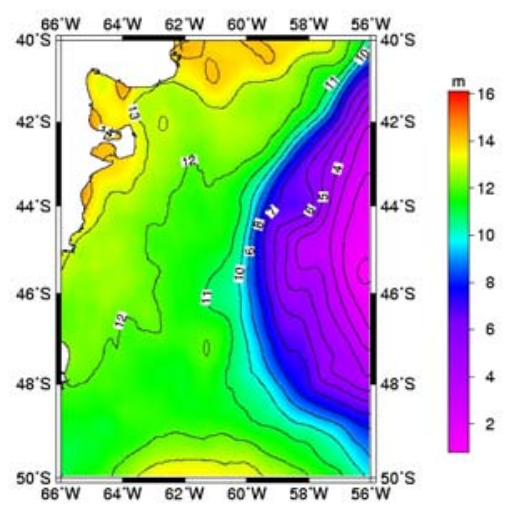

Figure 7.15: MISOT geoid (CG3) 


\subsection{Validation of the estimated geoid models}

The accuracy of the models was assessed through comparisons with stacked T/P SSHs. The computed differences between T/P and each geoid solution were minimized using a 3rd order polynomial model and a four-parameter similarity transformation model. From the results tabulated in Table 7.6, we conclude that the use of a third order polynomial model is preferable compared to the use of the four-parameter transformation.

The statistics of the differences before and after the bias and tilt fit between the T/P SSHs and the estimated geoid solutions are also given in Table 7.6. From that table it can be seen that the overall best agreement is achieved for the altimetric geoid solutions while the data combination improves the gravimetric geoid by about $2 \mathrm{~cm}$.

Table 7.6: Statistics of geoid height differences between the estimated models and T/P SSHs in the test area. Unit: [m]. (before and after bias and tilt fit).

\begin{tabular}{l|cccc}
\hline & min & max & mean & $\sigma$ \\
\hline Nalt (AG1) - T/P SSHs & -1.21 & 1.01 & 0.11 & \pm 0.21 \\
After 3P & -1.07 & 1.11 & 0.00 & \pm 0.20 \\
After 4P & -1.20 & 1.00 & 0.00 & \pm 0.20 \\
\hline Nalt (AG2) - T/P SSHs & -1.15 & 1.15 & 0.15 & \pm 0.20 \\
After 3P & -1.06 & 1.2 & 0.00 & \pm 0.19 \\
After 4P & -1.21 & 1.09 & 0.00 & \pm 0.20 \\
\hline Ngrav (GG1)-T/P SSHs & -0.85 & 1.76 & 0.15 & \pm 0.26 \\
After 3P & -1.00 & 1.35 & 0.00 & \pm 0.23 \\
After 4P & 1.66 & -0.93 & 0.00 & \pm 0.25 \\
\hline Ngrav (GG2)-T/P SSHs & -0.66 & 1.05 & 0.20 & \pm 0.28 \\
After 3P & -0.80 & 0.85 & 0.00 & \pm 0.21 \\
After 4P & -1.18 & 0.57 & 0.00 & \pm 0.23 \\
\hline Ngrav (GG3)-T/P SSHs & -0.67 & 1.05 & 0.20 & \pm 0.28 \\
After 3P & -0.80 & 0.84 & 0.00 & \pm 0.21 \\
After 4P & -1.19 & 0.57 & 0.00 & \pm 0.23 \\
\hline Ncomb (CG1)-T/P SSHs & -0.94 & 1.53 & 0.14 & \pm 0.24 \\
After 3P & -0.80 & 1.39 & 0.00 & \pm 0.22 \\
After 4P & -0.93 & 1.49 & 0.00 & \pm 0.23 \\
\hline Ncomb (CG2)-T/P SSHs & -1.16 & 1.11 & 0.15 & \pm 0.20 \\
After 3P & -1.04 & 1.18 & 0.00 & \pm 0.19 \\
After 4P & -1.20 & 1.05 & 0.00 & \pm 0.20 \\
\hline Ncomb (CG3)-T/P SSHs & -1.16 & 1.11 & 0.15 & \pm 0.20 \\
After 3P & -1.04 & 1.18 & 0.00 & \pm 0.19 \\
After 4P & -1.20 & 1.05 & 0.00 & \pm 0.20 \\
\hline
\end{tabular}


From these results we conclude that there is no differences in the gravimetric geoid solutions computed using either KMS01 (GG2) or KMS02 (GG3) gravity anomalies and this fact is also reflected in the results of the combined solutions using the MIMOST method (CG2 and CG3).

From Table 7.6, we also conclude from comparisons made with the solutions computed with EGM96 geopotential model and T/P SSHs for the same area, that the use of the "combined EGM" improves the results by $1 \mathrm{~cm}$ in terms of the standard deviation for the pure altimetric solutions, $2 \mathrm{~cm}$ in terms of the standard deviation for the pure gravimetric solutions and $3 \mathrm{~cm}$ in terms of the standard deviation for the combined solutions.

We also notice that the combined solution computed with EGM96 geopotential model is worse than, e.g., the altimetric one, this will be an indication of improper weighting of the gravimetric and altimetric data. When the "combined EGM" is used, the combined solution improves the gravimetric ones $\mathrm{n}$ in terms of standard deviation and mean values but it does not improve the altimetric solution.

Figures 7.16 depict the differences between T/P SSHs and the ERS1 altimetric geoid computed with the new EGM. The combined geoid and the gravimetric geoid solution can be seen in Figure 7.17.

It is worth mentioning, though, that the $\sigma$ of the differences for the comparisons with the altimetric models is quite high, at the $20 \mathrm{~cm}$ level, while a value close to $9 \mathrm{~cm}$ would be expected based on previous studies (Li and Sideris 1997; Vergos 2002). Plotting the differences it was noticed that their largest and smallest values are located close to the coastline and more specifically between $-45^{\circ} \leq \varphi \leq-44^{\circ}$ and $294^{\circ} \leq \lambda \leq 296^{\circ}$ where the effects of SSV and other oceanic phenomena are very strong. In the rest of the region, the differences are within their expected values, ranging between -60 and $60 \mathrm{~cm}$. In our opinion, this is an indication that the accuracy of the altimetric geoid models is much better than the comparisons with T/P imply. Neglecting a few T/P points that refer to the aforementioned regions the standard devition of the differences reduces to about 5 to $8 \mathrm{~cm}$ for the altimetric geoid models. The same improvement of more than $9 \mathrm{~cm}$ holds for the gravimetric and combined models, too. So it can be concluded that by only stacking the T/P data, part of the oceanic effects, which clearly influence the SSHs used 
for the comparisons, cannot be removed. Probably, the T/P data had to be low-pass filtered as well in their along-track direction, to further reduce the effect of the SSV and make the comparisons more representative or more simply by rejecting all $\mathrm{T} / \mathrm{P}$ points close to the coasts.

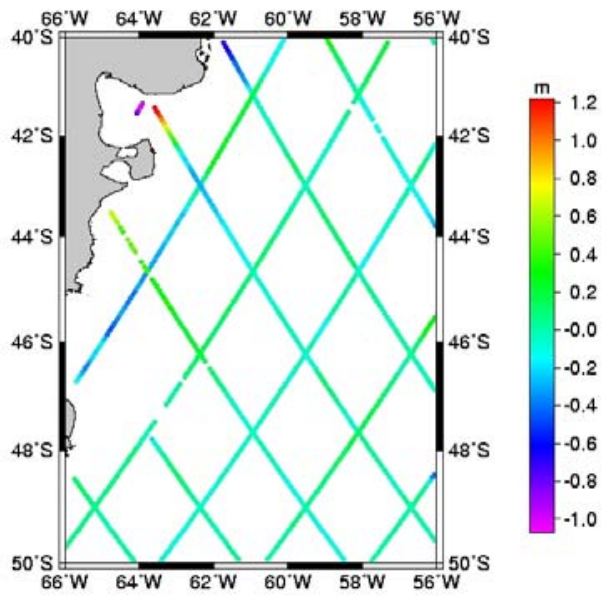

Figure 7.16: Geoid height differences between T/P and the ERS1 altimetric geoid (AG2) solution
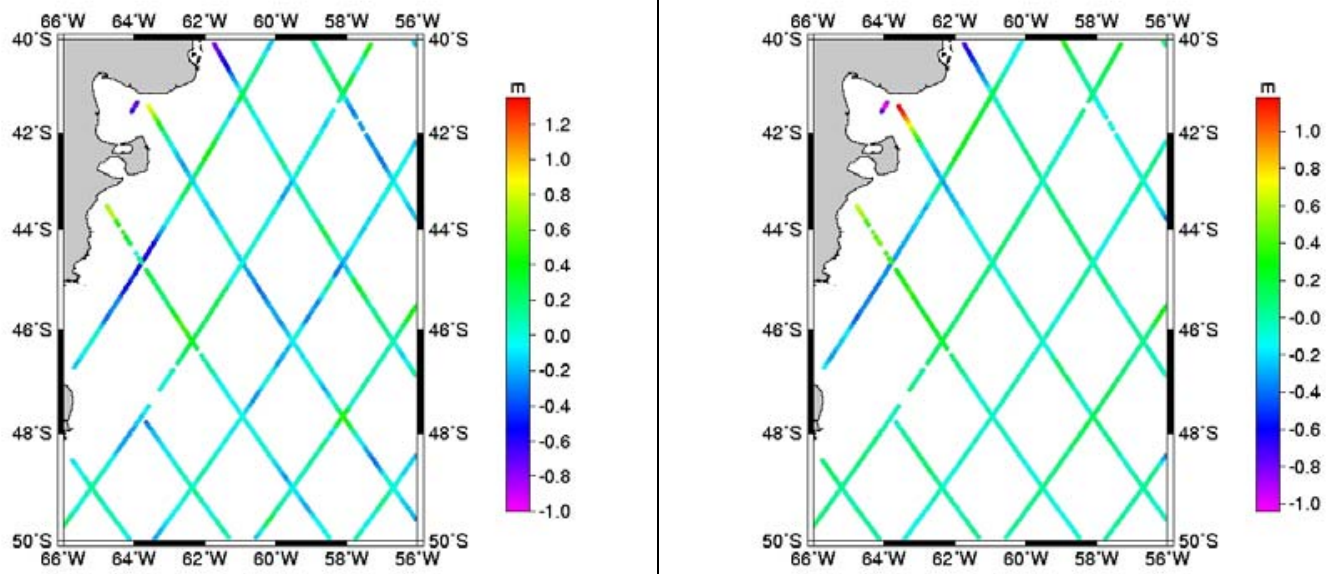

Figure 7.17: Geoid height differences between T/P and the gravimetric (GG2) (left) and the combined (CG2) solutions (right) 


\subsection{Summary}

An altimetric, gravimetric and a combined final geoid height solution have been determined in the Atlantic coastal region of Argentina. The MIMOST theory for the optimal combination of heterogeneous data has been applied to improve the gravimetric geoid solution close to the coastline.

From the results and validation procedures carried out, it is evident that when altimetry and shipborne gravity data are handled properly (i.e., correcting them for all error sources, removing blunders, using accurate geopotential and DOT models, removing the the QSST signal, accounting for the bathymetry using an accurate model, low-pass filtering the altimetry data, etc.), then, altimetric geoid modeling accurate to about $7 \mathrm{~cm}$ is feasible, while the combined solution improves the gravimetric one, by about $2 \mathrm{~cm}$, in terms of the $\sigma$ of the differences with T/P SSHs. These differences refer to purely oceanic areas (not close to the coastline) and regions where the effect of the variability of the oceans is not very strong.

The effect of oceanic phenomena in the densely spaced GM datasets, especially in areas with high ocean dynamics, is profound and should be reduced by low-pass filtering the altimetric datasets. If this step is neglected, then the resulting geoid solutions can be less accurate by about $2-5 \mathrm{~cm}$. A point that needs further research is the use of crossover adjustment for the reduction of such noisy signals. Finally, the altimetry data should be corrected for the QSST signal to refer to the geoid and not the sea surface; the question that arises is not on the necessity of such a correction, but on the selection and the development of accurate DOT models.

From the numerical results presented in this chapter, we conclude that the best pure gravimetric and altimetric geoid solutions are those computed using the "combined EGM" derived from the latest CHAMP and GRACE type of EGMs (Vergos et al., 2004). We also conclude that from comparisons made with the solutions computed with EGM96 geopotential model and T/P SSHs, the use of the "combined EGM" improves the results by $1 \mathrm{~cm}$ in terms of the standard deviation for the pure altimetric solutions, 2 $\mathrm{cm}$ in terms of the standard deviation for the pure gravimetric solutions and $3 \mathrm{~cm}$ in terms of the standard deviation for the combined solutions. From such comparisons, we can also conclude that the use of the "combined EGM" improves the results by $4 \mathrm{~cm}$ in 
terms of the mean differences for the pure altimetric solutions, $5 \mathrm{~cm}$ in terms of the mean differences for the pure gravimetric solutions but for the combined solutions the mean differences increase in $1 \mathrm{~cm}$. 


\section{CHAPTER EIGHT}

\section{A HIGH-PRECISION GRAVIMETRIC GEOID MODEL FOR ARGENTINA}

\subsection{Introduction}

This chapter describes the process selected, based on the tests conducted in the previous chapters, for the determination of a new gravimetric geoid model for Argentina. During the past years, many efforts were carried out to compute a high precision and high accuracy gravimetric geoid model for the whole country. The methodology finally applied for its computation as well as the most recent evaluated data are discussed. Argentina is located in Southern South America; with a total area of $2,766,890 \mathrm{~km}^{2}$ is the second-largest country in South America (after Brazil). It is bounded to the west by the highest mountain range in America, the Andes, so different topographic reduction methods are crucial in practical gravimetric geoid determination. To the east, Argentina borders on the Atlantic Ocean so the combination of shipborne gravity data and altimetry derived free air gravity anomalies was also taken into account.

The remove-compute restore technique was adopted for the geoid determination and the contribution of the local data to the geoid was computed by FFT (Sideris, 1994; Sideris and Li, 1993; Featherstone et al., 1996; Sideris and She, 1995; Li and Sideris 1994; Mainville et al., 1992).

As an external evaluation, the gravimetric geoid was compared with geoid undulations of $539 \mathrm{GPS} /$ levelling points available for the country.

The importance of this new gravimetric geoid lies in the fact that it will be the official gravimetric geoid for the country, and thus it will be of interest to the entire scientific community utilizing geospatial data, like, e.g., GPS users in topographic and cadastral mapping, construction and infrastructure works, vehicle navigation, military operations and floods control. 


\subsection{Area under study and data availability}

The gravimetric geoid model was computed for the whole country, covering both landmasses and the Atlantic Ocean, ranging from $20^{\circ} \mathrm{S}$ to $55^{\circ} \mathrm{S}$ in latitude and $53^{\circ} \mathrm{W}$ $\left(307^{\circ} \mathrm{E}\right)$ to $76^{\circ} \mathrm{W}\left(284^{\circ} \mathrm{E}\right)$ in longitude. Part of this area is offshore, so the KMS02 $2^{\prime} \times 2^{\prime}$ altimetry derived free-air gravity anomaly field (Andersen et al., 2005) has been used to fill in information in the Atlantic and Pacific Oceans with the purpose to improve the quality and accuracy of the geoid.

The distribution of the land gravity data is depicted in Figure 8.1. The input gravity data consisted of: terrestrial, shipborne and altimetry derived gravity measurements. The gravity data were referred to GRS80 (Moritz, 2000). The gravity values were based on the International Gravity Standardization Net 1971 (IGSN71).

To derive the long-wavelength information of the gravity field we used and compared the results of two gravity field models: EGM96 and EIGEN_CG01C.

Two gravimetric geoid solutions will be presented in this chapter; one solution was referenced to the EGM96 global geopotential model (Lemoine et al., 1998) complete to degree and order 360 and the other solution was referenced to the combined global gravity model EIGEN_CG01C (Reigber et al., 2005).

The high-resolution global gravity field model EIGEN-CG01C, complete to degree and order 360, was generated using CHAMP and GRACE satellite gravity data combined with $0.5 \times 0.5$ degree surface data (gravimetry and altimetry). The geopotential model EGM96 and the global gravity model EIGEN-CG01C complete to degree and order 360 were used as reference fields.

The topographic data used to compute terrain corrections (the direct topographical effect on gravity, and indirect effects on the geoid) were those of the GTOPO30 DEM model, with an original grid spacing of approximately $1 \mathrm{~km}$ by $1 \mathrm{~km}$; however, these quantities were computed from the GTOPO30 with a grid spacing $4 \mathrm{~km}$ by $4 \mathrm{~km}$ due to the numerical instabilities encountered as the inclination of the topography increased. These numerical instabilities occur when dense height grids are used in rough topographies (Tziavos, 1992). Table 8.1 shows statistics of the topography and the 
terrain corrections for the area under study. The GTOPO30 DEM has no values at sea, so zeros were used to replace the $\mathrm{NaN}$ numbers in order to compute terrain corrections.

Table 8.1: Statistics of the heights and terrain corrections in Argentina.

\begin{tabular}{l|cccc}
\hline & $\min$ & $\max$ & $\operatorname{mean}$ & $\sigma$ \\
\hline Topographic heights Unit: $[\mathrm{m}]$ & 0.00 & 6402.69 & 407.11 & 885.54 \\
Terrain corrections Unit: $[\mathrm{mGal}]$ & 0.00 & 73.48 & 1.02 & 2.72 \\
\hline
\end{tabular}

A total of $539 \mathrm{GPS} /$ levelling points as well stacked T/P SSHs in the Atlantic Ocean were used for the evaluation and validation of the gravimetric geoid heights.

All these data have been described in chapter four.

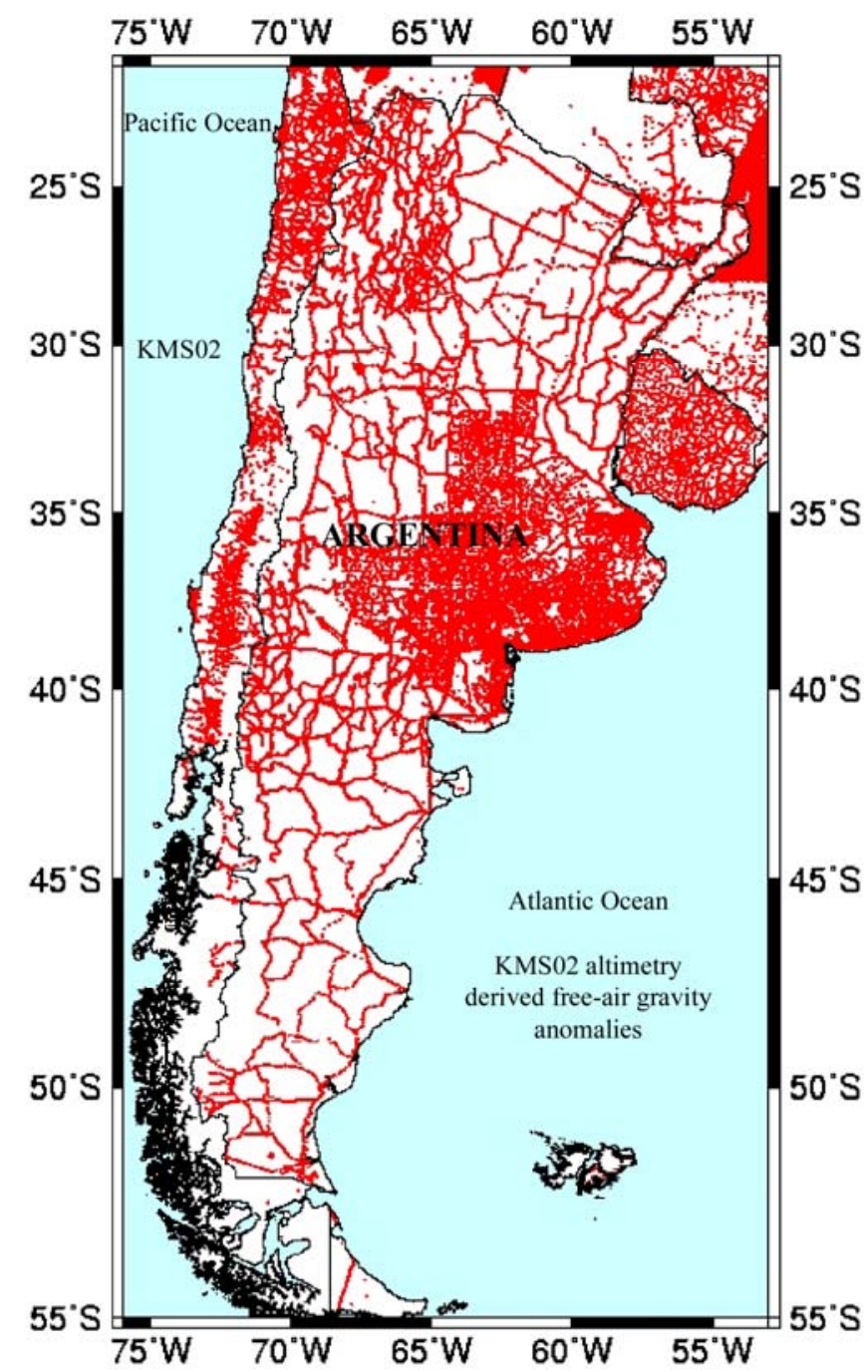

Figure 8.1: Distribution of gravity data in the area under study 


\subsection{Computational methodology}

\subsubsection{Gravimetric geoid modeling}

As it was mentioned before, the gravimetric geoid was computed using the removecompute-restore technique employing Stokes's formula for the prediction of residual geoid heights. Before the prediction of the residual geoid, the free-air gravity anomalies had to be reduced to a geopotential model during the remove step. Furthermore, the effect of the topography had to be taken into account through a topographic reduction. Several gravity terrain reductions have been analyzed during the development of this research for the computation of the gravimetric geoid.

According to the results obtained in chapter 6, the Rudzki inversion method and Helmert's second method of condensation method were the most promising gravity reduction techniques so both will be utilized in this chapter to find the best gravimetric geoid solution for the whole of Argentina.

We will show in this chapter that, even though the best gravimetric geoids solutions were achieved by the Rudzki inversion gravity reduction in the test areas presented in chapter 6 , Helmert's second method of condensation will be finally used because it gave the best results in the final gravimetric solution for all of Argentina.

Stokes's integral formula with the rigorous spherical kernel function evaluated by the one-dimensional spherical Fast Fourier Transform (1D FFT) was used to compute the gravimetric geoid for Argentina (Haagmans et al., 1993).

The indirect effect of Helmert's reduction on the geoid, up the second order was computed, in planar approximation, by equation (2.78) (Wichiencharoen, 1982), which was evaluated by FFT (Li, 1993).

The direct topographical effect on gravity using the Rudzki inversion gravimetric reduction scheme with constant density was computed using program Rudzki (Bajracharya, 2003), which it is a modified version of the program $t c$ from GRAVSOFT software (Tscherning et al., 1992). 


\subsubsection{Gravity gridding}

During the past years, many studies were carried out in order to reduce the effect of aliasing in gravity and geoid heights, using digital terrain data (Sideris and Forsberg, 1991, Featherstone and Kirby, 2000; Li et al., 1995; Bajracharya, 2003; Bajracharya and Sideris, 2005). Terrain reductions were used to generate a grid of free-air gravity anomalies in rough areas like the West part of Argentina in order to avoid aliasing problems due to the high-correlation between the free-air gravity anomalies with the gravity station heights. Three different procedures were used to grid free-air gravity anomalies on land.

\section{Procedure 1}

The free-air gravity anomalies on land were gridded in the following way:

1) Simple Bouguer anomalies $\left(\Delta g_{B}\right)$ were computed at each of the gravity observations by $\Delta \mathrm{g}_{\mathrm{B}}=\Delta \mathrm{g}_{\mathrm{FA}}-2 \pi \mathrm{G} \rho \mathrm{h}$.

2) The simple Bouguer anomalies were interpolated at the grid nodes that define the DEM, in this study, 2 arc-minute by 2 arc-minute, yielding a grid of simple Bouguer anomalies denoted by $\left(\Delta \mathrm{g}_{\mathrm{B}}\right)^{\text {grid }}$.

3) Free-air anomalies were reconstructed at each point of the grid where the simple Bouguer anomalies were interpolated by adding the Bouguer plate term. The Bouguer plate was computed using the height of the DEM in each cell and the same topographic density used to compute the simple Bouguer anomalies. The reconstructed free-air anomalies were on a grid of 2 arc-minute by 2 arc-minute and they were computed by $\left(\Delta \mathrm{g}_{\mathrm{FA}}\right)^{\text {grid }}=\left(\Delta \mathrm{g}_{\mathrm{B}}\right)^{\text {grid }}+\left(2 \pi \mathrm{G} \rho \mathrm{h}_{\mathrm{DEM}}\right)^{\text {grid }}$.

The $\left(\Delta \mathrm{g}_{\mathrm{FA}}\right)^{\text {grid }}$ values at sea were eliminated and filled in with KMS02 free-air gravity anomalies. No smoothing conditions were applied to remove inconsistencies along the coastline. 
The area was bounded between latitudes $20^{\circ} \mathrm{S}$ to $55^{\circ} \mathrm{S}$ (1051 rows) and longitudes $284^{\circ} \mathrm{E}$ to $307^{\circ} \mathrm{E}$ (691 columns). The grid has 706241 points, from which 407313 were computed as described above and 318928 were KMS02 gravity anomalies.

4) The free-air anomalies were still not ready for the geoid computation and they had to be terrain-corrected. Following Featherstone and Kirby, (2000) we called these anomalies reconstructed terrain-corrected free-air (TCFA) anomalies. They were calculated by:

$\Delta \mathrm{g}_{\mathrm{TCFA}}\left(\mathrm{h}_{\mathrm{DEM}}\right)=\Delta \mathrm{g}_{\mathrm{FA}}\left(\mathrm{h}_{\mathrm{DEM}}\right)+\mathrm{TC}\left(\mathrm{h}_{\mathrm{DEM}}\right)$

where $\mathrm{TC}\left(\mathrm{h}_{\mathrm{DEM}}\right)$ were the gravimetric terrain corrections computed from the DEM heights, $\Delta \mathrm{g}_{\mathrm{FA}}\left(\mathrm{h}_{\mathrm{DEM}}\right)$ were the reconstructed free-air anomalies on land and $\Delta \mathrm{g}_{\mathrm{FA}}(\mathrm{KMS} 02)$ at sea.

5) The reconstructed TCFA anomalies in each cell were averaged into a coarser grid of 5 arc-minute by 5 arc-minute. This was done in order to diminish the errors present in the DEM that could propagate into the reconstructed TCFA grid.

At this point, a grid of mean TCFA of 5 arc-minute by 5 arc-minute (grid 1) was constructed and it could be used to compute the gravimetric geoid. Table 8.2 shows the statistics of the reconstructed terrain-corrected free-air gravity anomalies.

Table 8.2: Statistics of the Terrain Corrected reconstructed Free-Air gravity anomalies (TCFA) $\left(5^{\prime} \times 5^{\prime}\right)$. Unit:[mGal].

\begin{tabular}{l|llll}
\hline Grid 1 & $\min$ & $\max$ & mean & $\sigma$ \\
\hline$\Delta \mathrm{g}_{\text {TCFA }}$ (land \& KMS02) & -249.46 & 454.56 & 10.16 & 47.08 \\
\hline
\end{tabular}

\section{Procedure 2}

The free-air gravity anomalies on land were gridded in the following way:

The three first stages were similar than in the procedure 1; but in this procedure stage 4 was not applied. 
The free-air gravity anomalies in each cell were averaged into a coarser grid of 5 arcminute by 5 arc-minute. At this point, a mean free-air gravity anomaly grid of 5 arcminute by 5 arc-minute (grid 2) was obtained to be used in the computation of the geoid. Table 8.3 shows the statistics of the reconstructed free-air gravity anomalies.

Table 8.3: Statistics of the free-air gravity anomalies (5' x 5'). Unit: [mGal]

\begin{tabular}{l|cccc}
\hline Grid 2 & $\min$ & $\max$ & mean & $\sigma$ \\
\hline$\Delta \mathrm{g}_{\mathrm{FA}}$ (land \& KMS02) & -250.50 & 400.75 & 9.13 & 45.65 \\
\hline
\end{tabular}

Terrain corrections were computed using program Tc2DFTPL developed at the Department of Geomatics Engineering at the University of Calgary by Yecai Li in 1993. Terrain corrections were computed with the GTOPO30 Digital Elevation Model with a grid spacing of 2 arc-minutes by 2 arc-minutes. The topographic indirect effect on the geoid due to Helmert's second method of condensation was computed using program ind developed by Yecai Li at the University of Calgary using the same GTOPO30 grid.

\section{Procedure 3}

In order to quantify the effect of the aliasing on the gravity anomalies, terrain corrections were interpolated at each gravity station and added to the free-air gravity anomalies. Then the free-air gravity anomalies plus the terrain correction were arithmetically averaged to form a grid of 2 arc-minutes by 2 arc-minutes. The resultant gravity anomalies grid had values on both land and sea, so the values at sea had to be eliminated and filled in with KMS02 free-air gravity anomalies.

The free-air gravity anomalies terrain corrected on land and KMS02 at sea were averaged into a coarser grid of 5 arc-minute by 5 arc-minute.

At this point, we had a 5'x 5' grid of mean free-air gravity anomalies terrain corrected on land and KMS02 at sea (grid 3). Table 8.4 shows the statistics of the reconstructed free-air gravity anomalies.

Table 8.4: Statistics of the Terrain Corrected free-air gravity anomalies ( $5^{\prime}$ x $\left.5^{\prime}\right)$. Unit: [mGal].

\begin{tabular}{lcccc}
\hline Grid 3 & Min & max & mean & $\sigma$ \\
\hline$\Delta \mathrm{g}_{\mathrm{FA}}+\mathrm{c}$ (land \& KMS02) & -250.50 & 275.69 & 3.50 & 36.82 \\
\hline
\end{tabular}


These three procedures were investigated in order to explore the effect of gravity reduction on gravity gridding and how the gridding affects the geoid prediction accuracy.

\subsection{Analysis of the geoid power spectrum}

All the residual geoid undulations presented in this chapter were computed with the one-dimensional FFT implemented in the computer software fftgeoid developed at the University of Calgary (Li and Sideris, 1993). As fftgeoid can evaluate the contribution of residual gravity anomalies for the whole integration area or within a specified cap size, several computations using different cap sizes were computed in order to select the one that best fits the differences between the gravimetric geoid and the GPS/levellingderived geoid. Finally, the geoid computation was performed using the modified kernel over a two-degree integration spherical cap size.

The geoid power spectrum was computed for Argentina, in order to choose the best way to combine global data from the geopotential model (GM data) and local data (Essan, 2000).

The geoid power spectrum derived from the EGM96 geopotential model (NDV_EGM96) using formula (5.8) is shown in Figure 8.2, together with the power spectrum of the geoid represented by the geoid degree variances from the local gravity data (NDV_grav) and the geoid spectrum of the terrain correction (NDV_TC) and of the geoid indirect effect (NDV_ind); see formula (5.39).

The GM geoid degree variances were computed up to degree and order 360 . The local gravity anomalies consisted of a grid of residual gravity anomalies and a grid of terrain corrections.

In Figure 8.3, the cap sizes in degrees are represented by the vertical lines. The geoid power spectrum from local gravity data was higher than the geoid power spectrum from the EGM96 for frequencies corresponding to a cap size of $1.2^{\circ} \times 1.2^{\circ}$.

For frequencies below the cap size of $1.2^{\circ}$, the geoid power spectrum was dominated by the contribution of the EGM96. 
The residual geoid heights were computed with cap sizes of $1^{\circ}$ and $2^{\circ}$, with the latter yielding slightly better results than the former one.

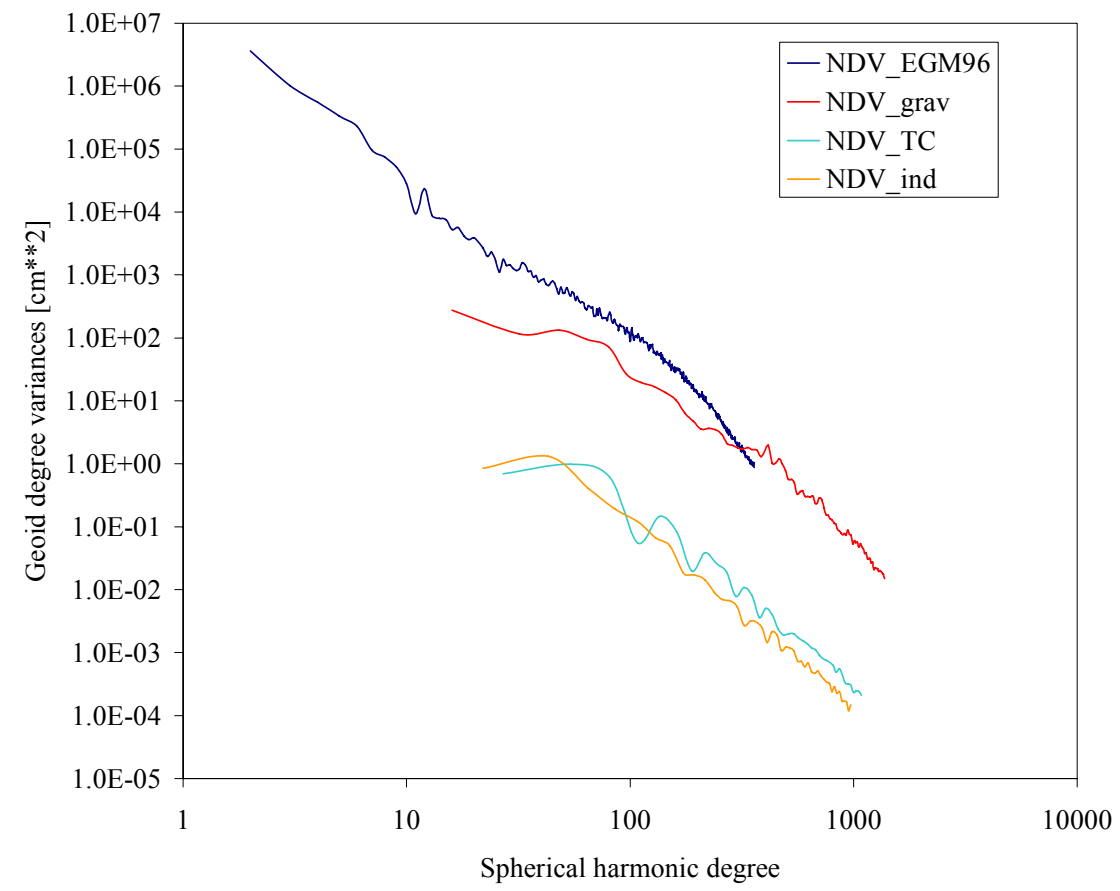

Figure 8.2: Geoid power spectrum for the different gravity field signals involucrate in the gravimetric geoid determination

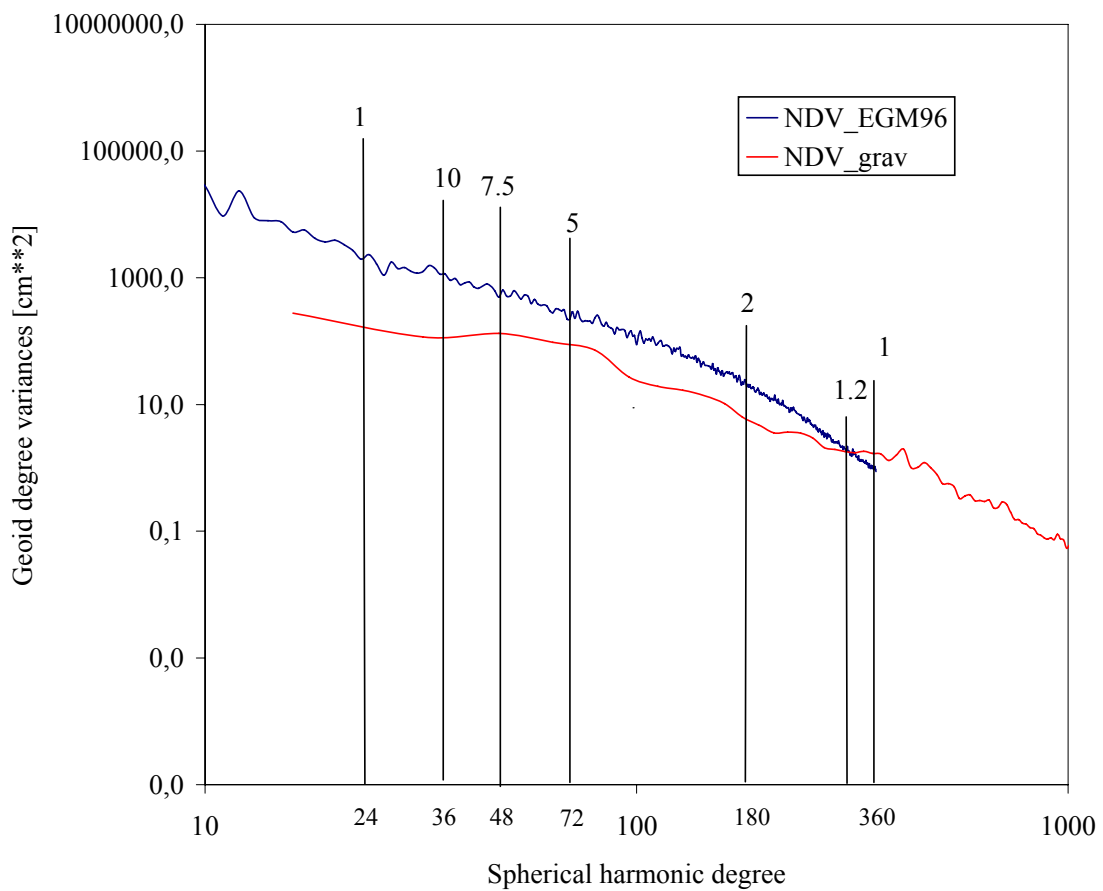

Figure 8.3: Geoid power spectrum from EGM96 and local gravity data 


\subsection{Gravimetric geoid model development}

Different gravimetric geoid solutions were determined using the computational procedure described in section 2.1, introducing some modifications when grid 1 or grid 3 was used. Grid 1 and grid 3 were grids of Faye gravity anomalies.

Six gravimetric geoid solutions were computed, by a combination of the three different grids of free-air gravity anomalies explained in the former section with the two global gravity models, namely the EGM96 (complete to degree and order 360) and the EIGEN_CG01C (complete to degree and order 360) which were used to model the long wavelength part of the geoid.

Two more geoid solutions were also computed using a Rudzki inversion method.

The geoid heights were referred to the Geodetic Reference System 1980 (GRS80) ellipsoid and were computed on a 5' by 5' grid.

Table 8.5: Names of the different geoid solutions presented in this chapter.

\begin{tabular}{l|clc}
\hline Geoid name & Solution & & $G M$ \\
\hline ARG05_procedure 1_egm96 & solution 1 & Procedure 1 & EGM96 \\
ARG05_procedure 2_egm96 & solution 2 & Procedure 2 & EGM96 \\
ARG05_procedure 3_egm96 & solution 3 & Procedure 3 & EGM96 \\
ARG05_procedure 1_eigen_cg01c & solution 4 & Procedure 1 & EIGEN_CG01C \\
ARG05_procedure 2_eigen_cg01c & solution 5 & Procedure 2 & EIGEN_CG01C \\
ARG05_procedure 3_eigen_cg01c & solution 6 & Procedure 3 & EIGEN_CG01C \\
ARG05_Rudzki_egm96 & solution 7 & & EGM96 \\
ARG05_Rudzki_eigen_cg01c & solution 8 & & EIGEN_CG01C \\
\hline
\end{tabular}

\subsection{Validation of the estimated geoid models}

\subsubsection{Comparisons at GPS benchmarks}

The accuracy of the computed models was assessed through comparisons with interpolated values of the gravimetric geoid $\left(\mathrm{N}^{\mathrm{GRAV}}\right)$ at a network of GPS/levelling points $\left(\mathrm{N}^{\mathrm{GPS}}\right)$. The computed differences between GPS/levelling and each geoid solution were minimized using the four-parameter transformation model given in equation (4.26). This model absorbs all the systematic differences between the gravimetric geoid and the GPS/levelling data as well as all possible long wavelength errors and biases of the geoid (Sideris et al., 1992). 
A total of 539 GPS/levelling points with the outliers removed were used as an external control for the quality of the gravimetric geoid solutions. These GPS/levelling points belong to eight GPS/levelling networks, which are located in different topographies. The distribution of GPS/levelling points in Argentina is shown in Figure 8.4.

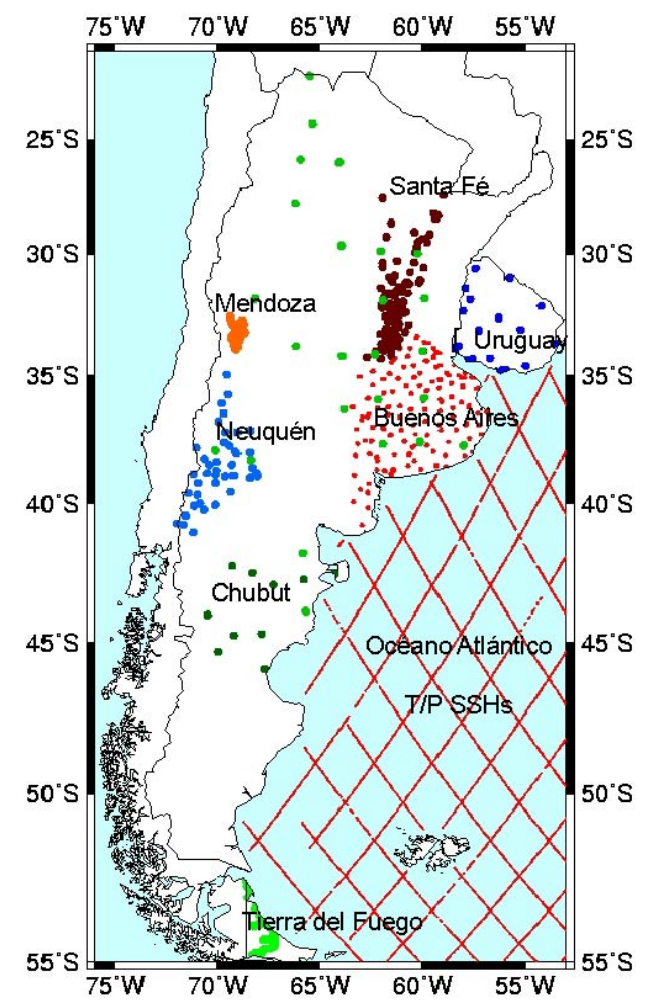

Figure 8.4: Distribution of GPS/levelling points (land) and T/P SSHs (ocean)

\subsubsection{Absolute differences between gravimetric geoid models and GPS/levelling}

The statistics of the absolute differences before and after the bias and tilt fit between the GPS/levelling derived-geoid and the estimated gravimetric geoid solutions for the entire Argentina are given in Table 8.6. The values in parentheses are the results after the fourparameter transformation model has been fitted.

Table 8.6 shows that solution 3 and solution 6 gave the worst results before and after fit, while the overall best agreement is achieved in the solutions 2 and 5. In both solutions, the gravimetrically derived geoid with support of the EGM96 and the one derived with the EIGEN_CG01C present nearly the same external accuracy, which is at the 0.41-0.42 m level 
before fit and at the $0.32-0.33 \mathrm{~m}$ level after fit. This result suggests that the accuracy and resolution of the gravity data have to still be improved in Argentina.

Table 8.6: Geoid height difference between various geoid models and GPS/levelling-derived geoid model (All of Argentina). Unit: [m].

\begin{tabular}{l|cccc}
\hline Geoid model & min & max & mean & $\sigma$ \\
\hline & \multicolumn{4}{c}{ All of Argentina } \\
\hline EGM96 - N & $-2.434(-2.180)$ & $1.888(2.000)$ & $0.155(0.000)$ & $0.805(0.537)$ \\
EIGEN-CG01C - NGPS & $-1.370(-1.738)$ & $1.605(1.209)$ & $0.485(0.000)$ & $0.401(0.359)$ \\
Solution 1 - N & $-1.746(-1.870)$ & $1.742(1.260)$ & $0.491(0.000)$ & $0.437(0.360)$ \\
Solution 2 - N & $-0.663(1.740)$ & $2.693(0.990)$ & $1.381(0.000)$ & $0.412(0.317)$ \\
Solution 3 - N & $-17.165(-6.820)$ & $1.373(6.180)$ & $-2.786(0.000)$ & $5.134(2.404)$ \\
Solution 4 - N & $-1.940(2.060)$ & $1.859(1.070)$ & $0.507(0.000)$ & $0.472(0.395)$ \\
Solution 5 - N & $-0.830(-1.930)$ & $3.017(1.150)$ & $1.426(0.000)$ & $0.419(0.334)$ \\
Solution 6 - N & $-17.493(-7.190)$ & $1.475(6.290)$ & $-2.775(0.000)$ & $5.091(2.347)$ \\
Solution 7 - N & $-0.574(-1.640)$ & $5.699(2.390)$ & $1.246(0.000)$ & $1.323(0.493)$ \\
Solution 8 - N & $-1.932(-2.340)$ & $3.458(1.810)$ & $0.994(0.000)$ & $0.946(0.580$ \\
\hline
\end{tabular}

Table 8.6 also shows that the global gravity field EIGEN_CG01C describes better than EGM96 the long-wavelength structure of the gravity field in Argentina. After fit, EGM96 alone fits the GPS/levelling derived geoid with a standard deviation $(\sigma)$ of near $54 \mathrm{~cm}$ while the EIGEN_CG01C alone fits with a standard deviation of $36 \mathrm{~cm}$. Before the fit, EIGEN_CG01C alone reduces to half the standard deviation of the differences compared to EGM96 alone.

From the statistics shown in Table 8.6, it can be seen that solutions 2 and 5 are the best gravimetric geoid solutions in a national scale in Argentina. From this point on, only these solutions are considered for analysis. Both gravimetric geoid solutions are depicted in Figures 8.5 and 8.6, respectively.

A regional analysis of the differences between both solutions (2 and 5) was carried out for each of the GPS/levelling networks. The standard deviations of the absolute differences before and after fit) between the gravimetrically geoids and the GPS/levelling-derived geoid at each GPS/levelling network can be seen in Figure 8.7 and Figure 8.8 , respectively.

Buenos Aires, Santa Fe and Uruguay networks are located in flat areas. Both global models (EGM96 and EIGEN_CG01C) have similar representation of the gravity field in each of these areas, but the agreement level is different for the three different flat areas. In Buenos Aires, the agreement level is approximately $15 \mathrm{~cm}$ in terms of the standard deviation for both EGM96 and EIGEN_CG01C; in Santa Fe, is around $32 \mathrm{~cm}$ and in Uruguay, is of the order of $50 \mathrm{~cm}$. Both gravimetric geoids (solution 2 and solution 5) show an improvement of about $8 \mathrm{~cm}$ in Buenos Aires; in Santa Fe the best agreement 
was achieved with solution $5(20 \mathrm{~cm})$ rather than solution $2(30 \mathrm{~cm})$; in Uruguay, the differences in the standard deviation between solution 5 and solution 2 is around $4 \mathrm{~cm}$.

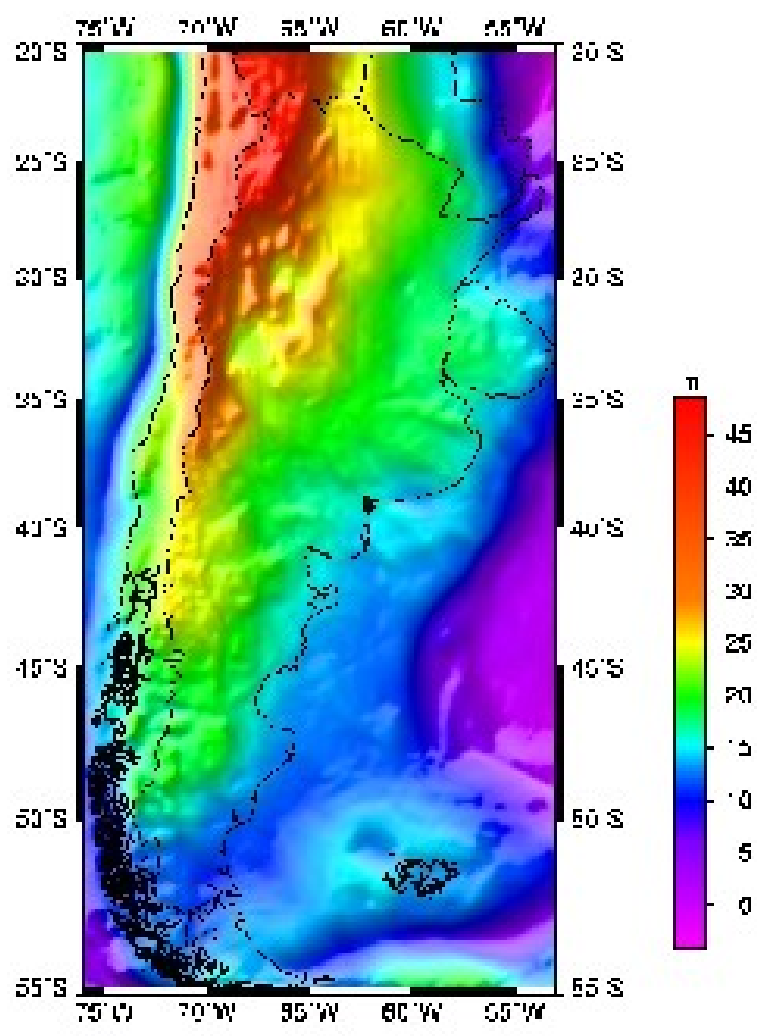

Figure 8.5: Gravimetric geoid. Solution 2

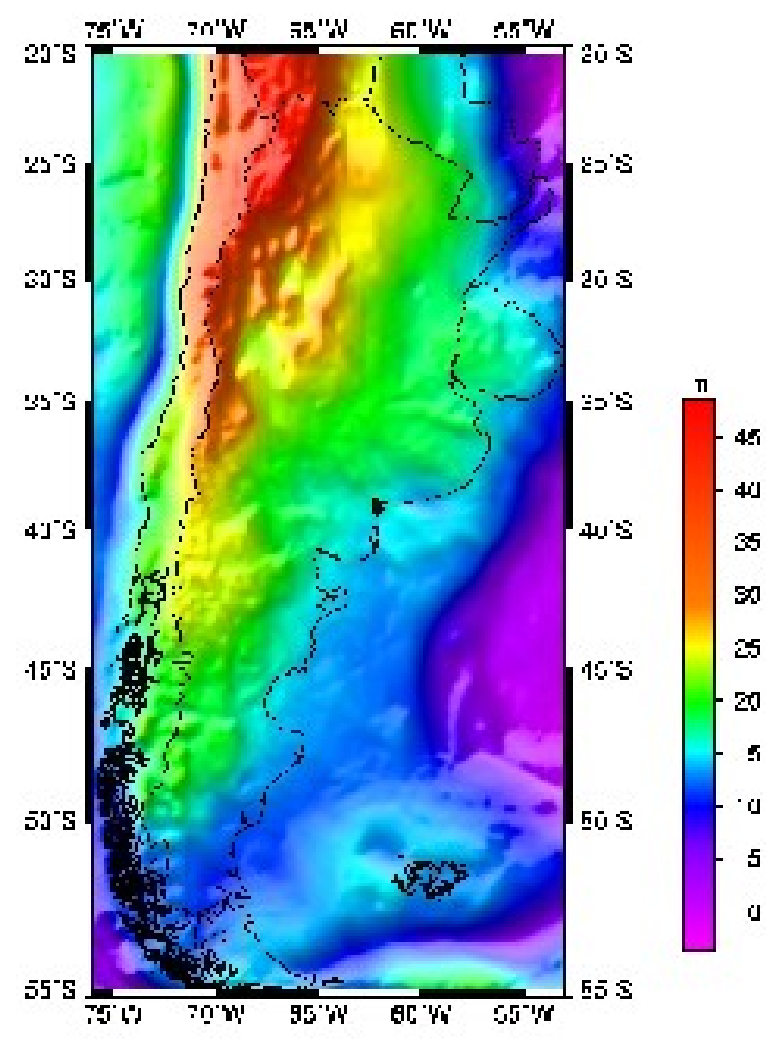

Figure 8.6: Gravimetric geoid. Solution 5

Mendoza and Neuquén are GPS/levelling networks located in the rough areas in Western Argentina. In the Neuquén area, both global models have similar standard deviation agreement with the GPS/levelling data $(44 \mathrm{~cm})$, but in Mendoza, the global gravity field EIGEN_CG01C is superior by $7 \mathrm{~cm}$ compared to EGM96. This result is reflected in the corresponding gravimetric geoids: solution 2 was computed using EGM96 as reference field in contrast to solution 5 that was calculated with EIGEN_CG01C. In Neuquén, even though both global model present similar behavior, solution 2 is better than solution 5 by $2 \mathrm{~cm}$.

The Chubut GPS/levelling network shows a very different behavior with respect to the global models. This network will not be used from this point on because the ellipsoid heights were not referred to the same datum as the other GPS points. 
The Tierra del Fuego network is located in the Southern part of Argentina; both gravimetric geoid solutions have the same level of agreement $(15 \mathrm{~cm})$ but these results are slightly worst than the ones obtain with the global models alone.

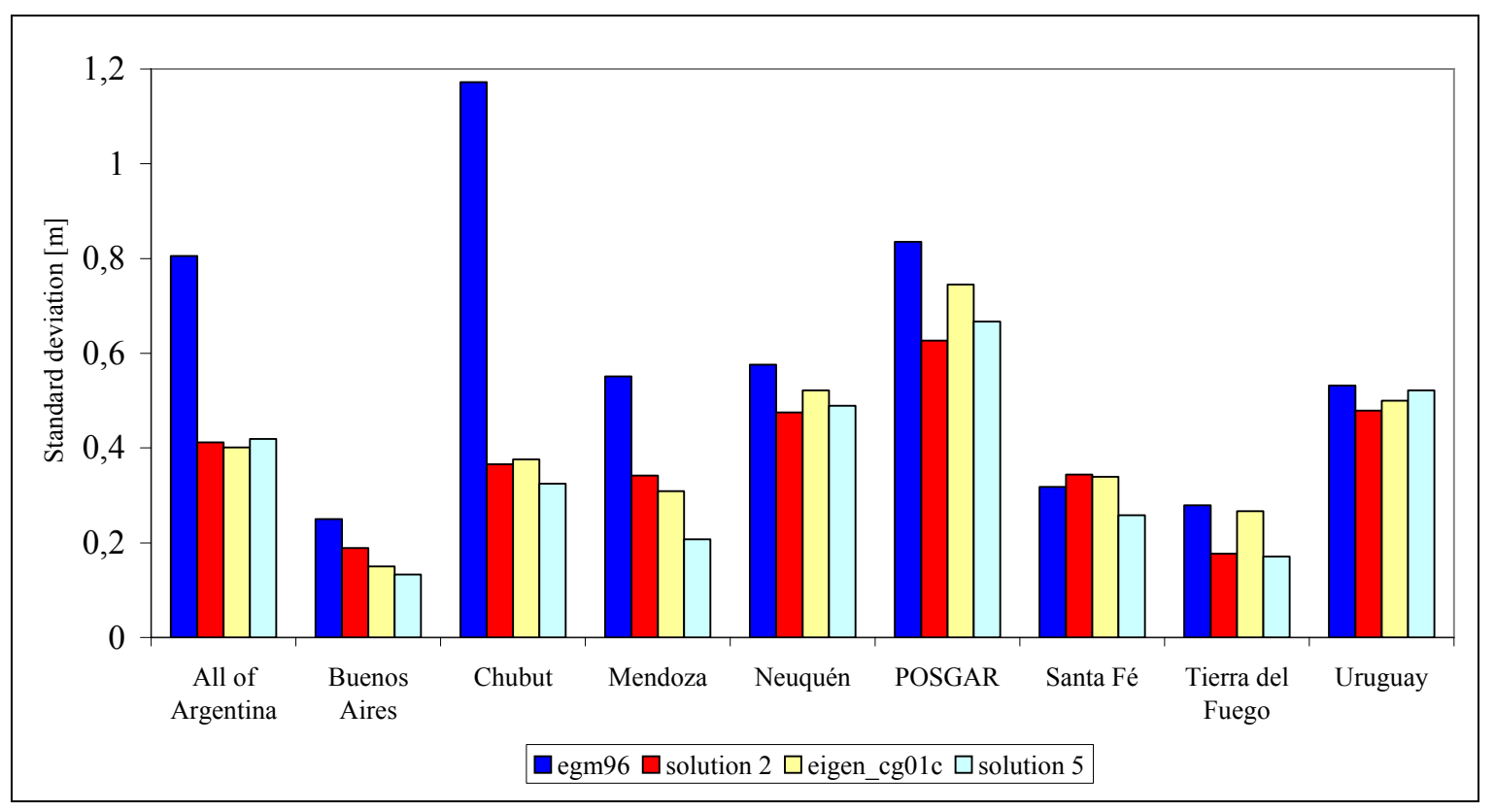

Figure 8.7: standard deviation of the absolute differences (before fit) between the gravimetrically geoids and the GPS/levelling-derived geoid

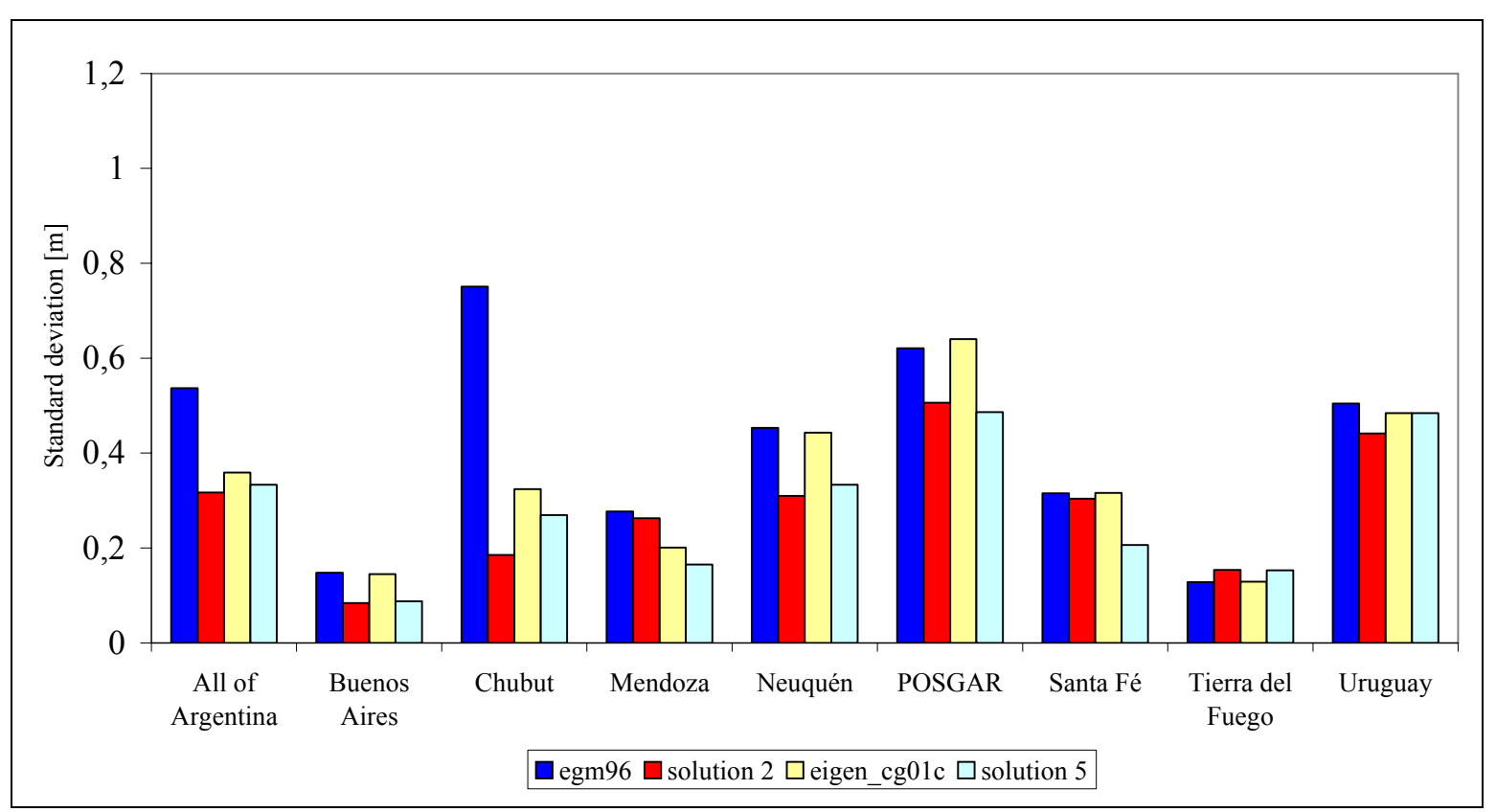

Figure 8.8: standard deviation of the absolute differences (after fit) between the gravimetrically geoids and the GPS/levelling-derived geoid 


\subsubsection{Relative agreement of geoid models with respect to GPS/levelling}

To evaluate the relative accuracy of the best four geoid models with respect to the GPS/levelling-derived geoid, relative geoid heights differences $\left(\Delta \mathrm{N}^{\mathrm{GRAV}}-\Delta \mathrm{N}^{\mathrm{GPS}}\right)$ were formed for all the baselines and plotted as a function of the baseline length (spherical distance in $\mathrm{km}$ ) in parts per million (ppm). The relative differences in ppm were formed after all outliers were removed. Figure 8.9 and Figure 8.10 show the relative differences across the entire Argentina before and after fit, respectively.

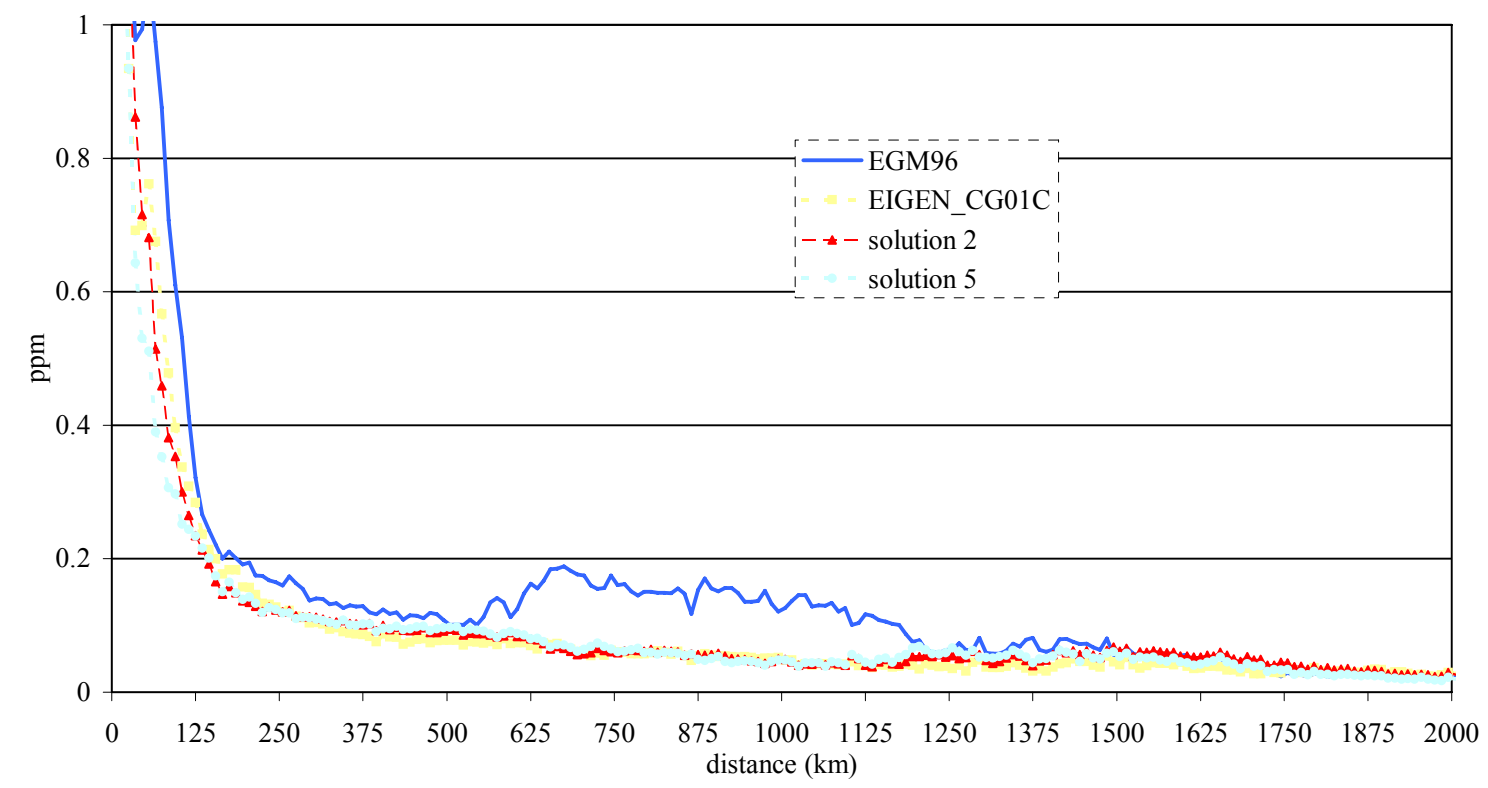

Figure 8.9: Relative accuracy between geoid models and GPS/levelling-derived geoid across

Argentina (before fit)

The two global gravity field models have the same relative accuracies up to baseline lengths of $15 \mathrm{~km}$, ranging from $8.5 \mathrm{ppm}$ to $1.6 \mathrm{ppm}$. For larger baseline lengths ranging from 15 to $125 \mathrm{~km}$, we can see an improvement in the long wavelength structure of the EIGEN_CG01C global model compared to the EGM96. For baseline lengths larger than $125 \mathrm{~km}$ to near $500 \mathrm{~km}$, both models show similar relative accuracies. For $500 \mathrm{~km}$ to $1200 \mathrm{~km}$, we can observe again an improvement of the EIGEN_CG01C global model compared to the EGM96, tending to 0 ppm for lengths over $1800 \mathrm{~km}$.

The two new geoid models (solution 2 and solution 5) present for the entire country, similar behavior for all baseline lengths, except for baselines between 15 to $115 \mathrm{~km}$ 
where EIGEN_CG01C is slightly better than EGM96 and for baselines $115 \mathrm{~km}$ to 700 km where EGM96 performs slightly better than EIGEN_CG01C.

Comparing Figure 8.9 and Figure 8.10, we can appreciate that there is a significant improvement in the relative agreement after the fit, especially for distances greater than $225 \mathrm{~km}$ where both gravimetric geoid models perform better than the global geopotential models. This demonstrated the importance of using local gravity data to improve the relative accuracy.

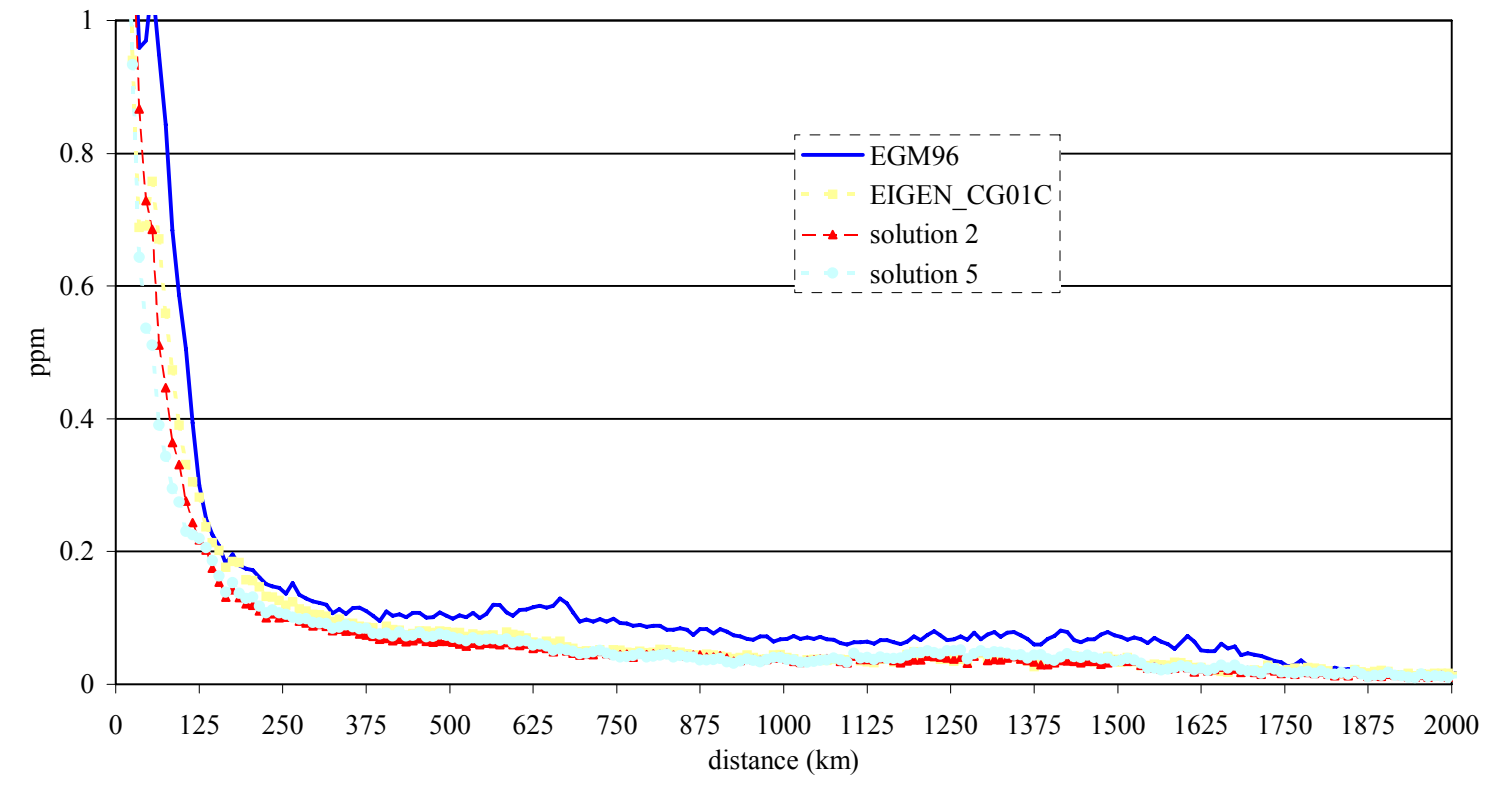

Figure 8.10: Relative accuracy between geoid models and GPS/levelling-derived geoid across

Argentina (after fit)

\subsubsection{Comparison of geoid height solutions with T/P SSHs.}

The four-geoid solutions considered in the previous section were compared with stacked T/P SSHs from the third year of the satellite mission, considered as geoid heights when the dynamic ocean topography was accounted for, and known for their high accuracy. Figure 8.4 shows the geographical distribution of the T/P SSHs used as control points in the area under study, in the Atlantic ocean region of Argentina. Table 8.7 shows the statistics of the differences between the different geoid solutions with T/P SSHs. As with the GPS/levelling benchmarks, a four-parameter transformation model was used to 
minimize the differences. The values in parentheses correspond to values after bias and tilt fit.

Table 8.7: Geoid height difference between various geoid models and T/P SSHs. Unit: [m].

\begin{tabular}{l|cccc}
\hline Geoid model & min & $\max$ & mean & $\sigma$ \\
\hline EGM96 - T/P SSHs & $-1.680(-1.521)$ & $0.888(1.053)$ & $-0.199(0.000)$ & $0.257(0.256)$ \\
EIGEN-CG01C - T/P SSHs & $-1.503(-1.096)$ & $1.051(1.350)$ & $-0.226(0.000)$ & $0.315(0.286)$ \\
Solution 2 - T/P SSHs & $-0.332(-0.714)$ & $1.959(1.327)$ & $0.324(0.000)$ & $0.242(0.197)$ \\
Solution 5 - T/P SSHs & $-0.541(-0.844)$ & $1.788(1.028)$ & $0.327(0.000)$ & $0.294(0.214)$ \\
\hline
\end{tabular}

Comparing the use of the two reference gravity models, it can be concluded that the gravimetric geoid solution 2 that was computed using EGM96 gives $5 \mathrm{~cm}$ (before fit) and $1 \mathrm{~cm}$ (after fit) better agreement that the gravimetric geoid solution 5 computed using EIGEN_CG01C.

The differences between both gravimetric geoid solutions (solution 2 and solution 5) are plotted in Figures 8.11 and 8.12, respectively.
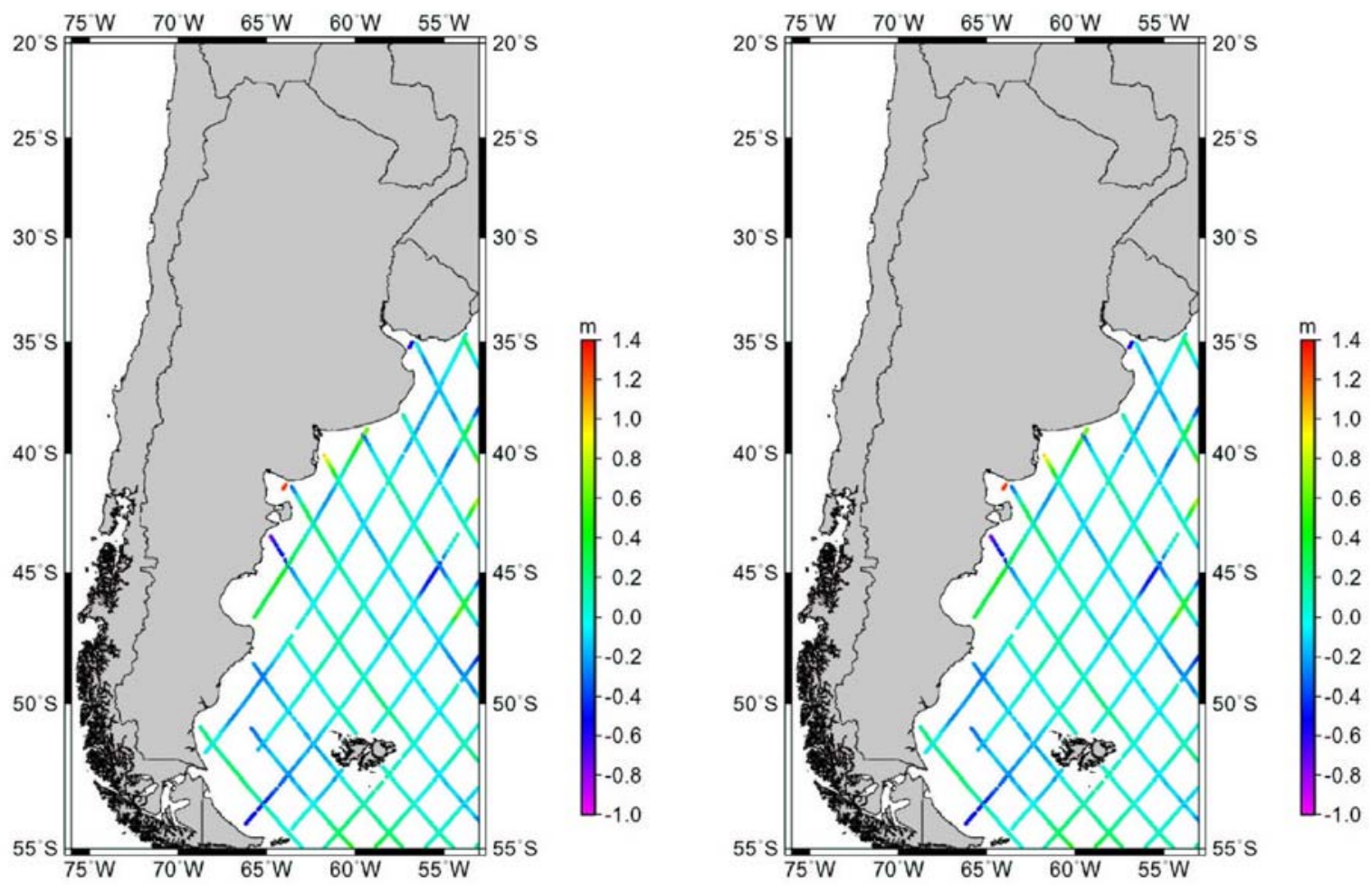

Figure 8.11: Differences solution 2 and stacked Figure 8.12: Differences between solution 5 and T/P SSHs. Unit: [m] stacked T/P SSHs. Unit: [m] 
The standard deviation between the gravimetric solution 2 and the stacked T/P SSHs, improves the gravimetric geoid solutions presented in that chapter 7 by $5 \mathrm{~cm}$ after applying the four-parameter transformation model.

One of the main differences between the gravimetric geoids computed in this chapter with the ones obtained in chapter 7 was the way that the topography/bathymetry was handled. Again, it is worth to mention the importance of the treatment of the gravity reductions in geoid computations.

\subsubsection{Comparisons between geoid models}

Comparisons between the models EGM96 and EIGEN_CG01C, as well as solution 2 and solution 5 were also performed in order to investigate the accuracy of the two new gravimetric geoid models. Table 8.8 presents the statistics of the four gravimetric geoid solutions and their differences for the area under study.

Table 8.8: Statistics for various geoid models and their differences. Unit: [m].

\begin{tabular}{l|cccc}
\hline Geoid model & $\min$ & $\max$ & mean & $\sigma$ \\
\hline EGM96 & -4.737 & 47.673 & 16.681 & 8.820 \\
EIGEN_CG01C & -4.430 & 46.281 & 16.696 & 8.747 \\
EGM96-EIGEN_CG01C & -5.845 & 6.636 & -0.793 & 1.110 \\
Solution 2 & -4.125 & 48.533 & 17.470 & 8.938 \\
Solution 5 & -3.361 & 48.569 & 17.474 & 8.952 \\
Solution 2 - Solution 5 & -1.534 & 1.007 & -0.005 & 0.246 \\
\hline
\end{tabular}

A comparison between the two gravimetric geoid models shows that the main differences are located along the Andes, especially in the south part of the country called Patagonia. These differences are correlated with the differences between the geoid undulations from EIGEN_CG01C and EGM96. Figure 8.1 shows the sparse gravity measurements located in southern Argentina, where the largest discrepancies between the models are located.

\subsection{Summary}

Eight new gravimetric geoid models for Argentina were developed during my stay at the Department of Geomatics Engineering at the University of Calgary. The area 
covered by these solutions is from $20^{\circ} \mathrm{S}$ to $55^{\circ} \mathrm{S}$ in latitude and $53^{\circ} \mathrm{W}\left(307^{\circ} \mathrm{E}\right)$ to $76^{\circ} \mathrm{W}$ $\left(284^{\circ} \mathrm{E}\right)$ in longitude with a grid spacing of $5^{\prime}$.

The gravimetric geoid models have been computed for Argentina using global geopotential models and terrestrial gravity and satellite derived marine gravity anomalies and heights. The differences between the eight models were in the use of two geopotential models, namely, EGM96 and EIGEN_CG01C, in the treatment of the gravity data, and also in the way how the topography was handled. Three procedures were investigated. Two of these procedures used mean free-air gravity anomalies reconstructed using a digital elevation model but differed in the way that terrain corrections were taken into account, and the last procedure used point free-air gravity anomalies.

From these eight solutions, we selected only solutions 2 and 5 because they were the ones that show the best agreement with GPS/levelling-derived geoid.

The two new gravimetric Argentinean geoids model were renamed as ARG05_egm96 (solution 2) and ARG05_eigen_cg01c (solution 5).

They were based on the classical remove-compute-restore technique using the most accurate current gravity database for Argentina, which includes land; marine and satellite derived marine gravity anomalies from KMS02. Marine data was finally excluded for the final solutions because they did not yield any geoid improvement.

The gravity data in Argentina is not homogeneous. There are some areas such as Buenos Aires where the gravity distribution is very dense but areas like Patagonia, located in the south part of the country, has sparse gravity observations. Due to the very high topography in the west part of the country, it is usual that gravity stations were observed in lowlands and valleys. That is why the reconstruction method of free-air gravity anomalies from Bouguer anomalies and the use of the DEM minimize aliasing effects.

The comparison of both geoid solutions with the GPS/levelling data show that the absolute agreement with respect to the GPS/levelling-derived undulations (after the 
systematic datum differences were removed) is $32 \mathrm{~cm}$ in terms of standard deviation for ARG05_egm96 and $33 \mathrm{~cm}$ for ARG05_eigen_cg01c.

A regional analysis was carried out and the statistics shows that the absolute agreement level of the differences between the gravimetric solutions and the GPS/levelling-derived undulations for each network is different for areas of flat terrain like the Buenos Aires province than mountainous areas located in the Andes. The lack of gravity data and the roughness of the topography are similar in the areas where these GPS networks are located so it is necessary to investigate the accuracy of the GPS/leveling-derived geoid heights especially in rough areas where the accuracy of the leveling heights is much poorer.

The overall best absolute agreement for the whole Argentina is achieved by the ARG05_egm96 gravimetric geoid, with a standard deviation of $0.32 \mathrm{~m}$. It will be named ARG05. 


\section{CHAPTER NINE}

\section{CONCLUSIONS AND RECOMMENDATIONS}

This chapter summarizes the most important investigations carried out in this research: (i) compilation, generation, editing and evaluation of a new gravity anomaly database and all other data necessary for the estimation of a regional marine and land geoid model; (ii) a covariance analysis for different areas across Argentina; (iii) the investigation of different gravity reduction methods to handle topography in practical geoid computation; (iv) the computation of a marine geoid model; and (v) the computation of a regional gravimetric model for Argentina.

A new database of gravity anomalies has been created from land, marine and satellite derived free-air gravity anomalies towards the determination of a high-accuracy and high-resolution gravimetric geoid model in Argentina.

Local empirical covariance functions were estimated, in the space domain, for selected areas with different topographies of Argentina. The numerical results carried out in a mountainous, flat and marine areas showed a non uniform signal covariance function and the existence of correlation with the topography.

Different topographic terrain reductions were used in the determination of the gravimetric geoid in different areas, with very different topographies, across Argentina. These methods were the usual Helmert second method of condensation, the RTM, the $\mathrm{AH}$ and the $\mathrm{PH}$ topographic-isostatic gravity reductions, and the Rudzki inversion method. The Rudzki inversion is not a traditional method used for the determination of geoid, even though it has the main advantage that the indirect effect on the geoid is zero thus it does not need to be computed.

Although the Rudzki inversion method performed better than other methods in some rough test areas presented in chapter 6 , for the whole Argentina, the best agreement with the GPS/levelling derived geoid was achieved with the Helmert's second method of condensation.

ARG05 is a new gravimetric geoid model for the whole of Argentina that was 
developed at the Department of Gravity of the University of La Plata in Argentina and at the Department of Geomatics Engineering of the University of Calgary. The area covered by the gravimetric geoid solution is from $20^{\circ} \mathrm{S}$ to $55^{\circ} \mathrm{S}$ in latitude and $53^{\circ} \mathrm{W}$ $\left(307^{\circ} \mathrm{E}\right)$ to $76^{\circ} \mathrm{W}\left(284^{\circ} \mathrm{E}\right)$ in longitude.

The ARG05 geoid undulations refer to the geocentric GRS80 ellipsoid. ARG05 was computed on a 5 arc-minute x 5 arc-minute grid, covering all of Argentina.

The computation of the new gravimetric Argentinean geoid model was based on the classical Remove-Compute-Restore (RCR) technique using the most accurate current gravity database for Argentina. The fast Fourier transform technique was applied to compute residual geoid heights and terrain effects. The classical Helmert condensation method was used to handle the topography in the geoid determination.

The long, medium and short wavelengths components of the ARG05 geoid were determined from EGM96 global geopotential model, 5' x 5' residual gravity anomalies and 2' x 2' digital elevations heights from GTOPO30 global DEM. The residual gravity anomalies consisted of a combination with land free-air gravity anomalies and KMS02 free-air gravity anomalies derived from satellite altimetry.

The Global Gravity Model EIGEN_CG01C was the model that best fits the long wavelength data in Argentina but when it was combined with residual gravity anomalies and digital elevation heights, EGM96 gave a slightly better gravimetric geoid.

For absolute geoid determination, the original rigorous spherical kernel function should be used instead of the approximate ones, with best (in Argentina) integration cap size of 2 degrees.

The topographic indirect effect adds significant contribution to the gravimetric geoid undulations, especially in mountainous areas. The first order term is the dominant term. On the 163 benchmarks in the Andes, the maximum contribution of the first term is 22 $\mathrm{cm}$.

As Helmert's condensation method is not a very good smoothing method, other terrain reductions methods have to be used in a remove-restore fashion in order to obtain 
smooth data easy to grid. Free-air gravity anomalies were reconstructed from a grid of simple Bouguer anomalies using the digital elevation model. Their effect on the geoid together with the effect computed from the grid of terrain corrections yielded the best improvements on geoid computation. This "reconstruction" technique was employed for gravity gridding in order to minimize the aliasing effect, especially when most gravity observations are made in valleys.

The main advantage of FFT-spectral methods like the ones used in this research is that they can efficiently handle large files of gridded data and give results on all grid points simultaneously. FFT spectral methods were used to compute residual geoid heights, terrain corrections, and indirect effects on the geoid due to the second method of Helmert's condensation. Even though FFT methods present some problems like phase shifting, edge effects or circular convolution and planar approximation ( $\mathrm{Li}, 1994)$, they can all be corrected or eliminated. To avoid planar approximation, FFT can be evaluated on the sphere (Strang van Hess, 1990; Forsberg and Sideris, 1993; Haagmans et al., 1992). The phase shifting can be corrected using the shifting property of the Fourier transform and the effect of circular convolution was corrected using zero padding. FFT is the most efficient technique to compute large regional gravimetric geoid models, like the Argentinean geoid.

The overall agreement of ARG05 and the GPS/levelling-derived geoid is approximately $32 \mathrm{~cm}$, after datum inconsistencies and bias as have been removed using a fourparameter transformation model and outliers have been removed from the GPS/levelling data.

The comparison of the gravimetric geoid solution referenced to EIGEN_CG01C with the GPS/levelling data showed that the absolute agreement with respect to the GPS/levelling-derived undulations (after the systematic datum differences were removed) is near $33 \mathrm{~cm}$ in terms of standard deviation.

It is possible to determine absolute gravimetric geoid undulations in flat areas with an accuracy of $8 \mathrm{~cm}$ with respect to geoid undulations derived from GPS/levelling after removing the systematic biases. In mountainous areas, the standard deviation discrepancies between the two geoid representations on 115 benchmarks in Mendoza is about $26 \mathrm{~cm}$, and on 45 benchmarks in Neuquén is about $31 \mathrm{~cm}$. 
The relative agreement for the whole Argentina is 1.4 to $0.2 \mathrm{ppm}$ for baselines between $15 \mathrm{~km}$ and $115 \mathrm{~km}$.

Marine geoid solutions were computed by combining altimetric data and shipborne gravity (Tocho et al., 2005). Pure altimetric and pure gravimetric geoid solutions were computed in the Atlantic coastal region of Argentina. Marine geoid modeling in the Atlantic coastal region of Argentina is problematic. Firstly, because of the insufficient amount of available shipborne gravity data, which renders a purely gravimetric solution not feasible. Secondly, because of the very strong ocean currents, which affect the quality of satellite altimetry data, so that a purely altimetric model is too noisy even after low-pass filtering the Sea Surface Heights (SSHs) to remove (part of) the influence of the oceanographic signals. Thus, the recommended solution is to employ a combination method and use all the available gravity and altimetry data together. This is a suitable solution since (i) combination methods such as least-squares collocation and Input Output System Theory (IOST) inherently low-pass filter and weigh the data, and (ii) will make use of the altimetric heights to fill the gaps of the shipborne gravity data. Following this idea, purely altimetric, gravimetric and combined (using the IOST method) marine geoid models have been estimated for Argentina employing all available shipborne gravity data, satellite altimetry SSHs, EGM96 and the latest Earth Gravity Models (EGMs) developed from the missions of CHAMP and GRACE. The MIMOST theory used for the combination of heterogeneous data was applied for the first times in Argentina with the aim of determining a final marine geoid model. From the comparison of the estimated geoid models to stacked TOPEX/POSEIDON SSHs, we found that the altimetric model provides the best agreement while the combined use of satellite altimetry and shipborne gravity data improved the accuracy of the results by $2 \mathrm{~cm}$ in terms of the standard deviation compared to the purely gravimetric solution with the use a new "combined EGM". From comparisons made with the older solutions computed with the EGM96 geopotential model and T/P SSHs for the same area, the use of the new "combined EGM" improves the results by $1 \mathrm{~cm}$ in terms of the $\sigma$ for the pure altimetric solutions, $2 \mathrm{~cm}$ in terms of the $\sigma$ for the pure gravimetric solutions and $3 \mathrm{~cm}$ in terms of the $\sigma$ for the combined solutions.

The Generic Mapping Tools (GMT) was a potent tool used for the manipulation of large grids of data. It was used, not only for obtaining final illustrations but also for the 
processing and treatment of the data across the land/sea boundary (select data on sea or on land; create "wet-dry" mask grid files from shoreline data base; resample a grid file onto a new grid, etc).

Two geopotential models were used to compute geoid undulations, and comparisons between interpolated GM geoid undulations on GPS benchmarks and GPS/leveling undulations were made The computed differences reflected datum inconsistencies between the different types of heights data, long-wavelength geoid errors, GPS and levelling errors. In order to minimize these deviations, a four-parameter model, a sevenparameter similarity transformation model, and a third order polynomial were used

We used these three types of models in order to assess possible improvements between them. From the statistics of the computed differences for all of Argentina, the best agreement, at the $0.41 \mathrm{~m}$ level, before the bias and tilt fit, was offered by the EIGEN_CG01C model while for the EGM96 model it was $0.81 \mathrm{~m}$. After the bias and tilt fit the improvement was at the $4 \mathrm{~cm}$ for the EIGEN_CG01C and $27 \mathrm{~cm}$ for the EGM96, using a four-parameter model.

The effects of gravity reduction procedures play an important role not only in gravity gridding but as well in geoid modelling.

To predict accurate values in a regular grid from randomly distributed observations, an optimal procedure needs to be chosen. This procedure includes two aspects: the best gridding method based on efficiency and accuracy, and a reduction of aliasing in gravity anomalies and geoid heights using digital terrain data.

Three procedures were used to grid the free-air gravity anomalies on land. The best one used to develop the ARG05 was the procedure 2 that was described in chapter 8 .

Several methods of handling topography in geoid determination were investigated. Gravity is usually measured at the surface of the Earth and in order to compute geoid undulations using Stokes formula gravity anomalies should be boundary values at the geoid with no masses external to the geoid. The gravity must be reduced to the geoid and this was done using the following methods: the Helmert condensation method, residual Terrain Model (RTM), Rudzki inversion method, and topographic-isostatic reductions. These methods treat the topography in a different way and all methods gave 
comparable results at the 15 to $20 \mathrm{~cm}$ level in the flat area. The Rudzki inversion method gave good results in some tests areas located in rough areas, while for the whole country the Helmert second method of condensation presented the best results.

\section{Recommendations and future work}

Gravity data coverage, density and quality have to be improved in Argentina, especially in rough areas like the Andes. The densification of gravity data in the Andes can be carried out with modern measurement techniques like airborne gravimetry. This will make possible to improve the accuracy of the geoid in order to meet the requirements needed nowadays for modern geodetic, oceanographic and geophysical applications.

As digital elevation models play an important role in the remove-compute-restore technique and they represent an essential type of data used in gravity field modeling, principally in mountain areas like the ones located in the west part of Argentina, it is necessary to evaluate the use of global DEM models like the SRTM3 (JPL, 2004) model, which has been released to the public for evaluation by the research and applications user community. The SRTM3 data from the Shuttle Topography Mission, has a resolution of 3" (90 meters) and covers the $80 \%$ of the land masses between latitudes $60^{\circ} \mathrm{N}$ to $54^{\circ} \mathrm{S}$.

A numerical solution for the altimetry-gravimetry boundary value problem (AGBVP) should be evaluated in order to combine different types of gravity data along the coastline. Also, the effect on geoid modeling of applying smoothing conditions along the coastline to remove data discontinuities has to be investigated (Grebenitcharsky, 2004).

More work has to be done in order to estimate an accurate and precise marine geoid model in the Atlantic coastal region of Argentina. The use of heterogeneous data, new results using more recent altimetry data and the use of combined methods like the traditional least-squares collocation for the optimal combination of heterogeneous data need to be investigated.

Different Earth Gravitational Models, such as the upcoming EGM05 (Pavlis, 2004) need to be evaluated in future work. EGM05, complete to degree and order 2160 is 
expected to be a composite model like the EGM96, and it will combine information of the GRACE satellite mission with terrestrial gravity and satellite altimetry. 


\section{References}

Andersen OB and Knudsen P (1998): Global gravity field from ERS1 and Geosat geodetic mission altimetry, Journal Geophysical Research, vol. 103, no. C4, pp. 8129-8137.

Andersen OB, Knudsen P, Trimmer R (2005): Improved high-resolution altimetric gravity field mapping (KMS02 Global marine gravity field), International Association of Geodesy Symposia, vol. 128, Sanso F (Ed.), Springer. Proceedings of the Symposium 128: A window on the future of Geodesy, Sapporo, Japan, June 30July 11, 2003, pp. 326-331.

Andritsanos VD and Tziavos IN (2002): Estimation of gravity field parameters by a multiple input/output system, Physics and Chemistry of the Earth, Part A, vol. 25, no. 1, pp. 39-46.

Andritsanos VD, Sideris MG and Tziavos IN (2000): A survey of gravity filed modeling applications of the Input-Output system Theory (IOST), International Geoid Service Bulletin no. 10, pp. 1-17.

AVISO User Handbook (1998): Corrected Sea Surface Heights (CORSSHs) AVI-NT011-311-CN Edition 31.

Bajracharya S (2003): Terrain effects on geoid determination, MSc. Thesis, University of Calgary, Department of Geomatics Engineering, UCGE Reports Number 20181.

Bajracharya S and Sideris MG (2004): The Rudzki inversion gravimetric scheme in geoid determination, Journal of Geodesy, vol. 78, pp. 272-282.

Bajracharya S and Sideris MG (2005): Terrain aliasing effects on gravimetric geoid determination Geodesy and Cartography, vol. 54, no. 1, pp. 3-16.

Bajracharya S, Kotsakis C and Sideris MG (2002): Aliasing effects on terrain correction computation, International Geoid Service, Bulletin no. 12.

Bendat JS and Piersol AG (1986): Random data: Analysis and measurement procedures, Second edition, John Wiley and Sons, New York. 
Bureau Gravimétrique International (2001): Shipborne gravity data for the Argentina, Personal communication.

Dahl OC and Forsberg R (1998): Geoid models around Sognefjord using depth data, Journal of Geodesy, vol. 72, pp. 547-556.

Esan O (2000): Spectral analysis of gravity field data and errors in view of subdecimetre geoid determination in Canada, University of Calgary, Department of Geomatics Engineering, UCGE Reports Number 20137.

Featherstone WE, Ken A, Sideris MG (1996): Gravimetric geoid refinement using highresolution gravity and terrain data, Geomatica Research Australasia, no. 64, pp. 7599.

Featherstone WE and Kirby JF (2000): The reduction of alliasing in gravity anomalies and geoid heights using digital terrain data, Geophysical Journal Research, vol. 141, pp. 204-214.

Featherstone WE and Denith MC (1998): A geodetic approach to gravity data reduction for geophysics, Computers and Geosciences, no. 23 (10), pp. 1063-1070.

Forsberg R (1984): A study of terrain corrections density anomalies and geophysical inversion methods in gravity field modeling, Report of the Department of Geodetic Science and Surveying no. 355, The Ohio State University, Columbus, Ohio.

Forsberg R and Sideris MG (1993): Geoid computation by multi-band FFT approach, Manuscripta Geodaetica vol. 18, no. 2.

Forsberg R (1997): Terrain effects in geoid computations, in Lectures Notes for the IAG’s International Geoid School, Rio de Janeiro, Brazil.

Fotopoulos G (2003): An analysis on the optimal combination of geoid, orthometric and ellipsoidal height data, $\mathrm{PhD}$. Thesis, University of Calgary, Department of Geomatics Engineering, UCGE Reports Number 20185.

Fotopoulos G, Kotsakis C and Sideris MG (1999): Evaluation of Geoid Models and their use in the combined GPS/levelling/Geoid height network adjustment, Technical 
reports Department of Geodesy and Geoinformatics, University Stuttgart, Report no. 19994.

Fotopoulos G, Kotsakis C and Sideris MG (1999): A new Canadian geoid model in support of levelling by GPS, Geomatica, vol. 53, no. 4, pp. 53-62.

GLOBE Task Team and others (Hastings, David A, Paula K Dunbar, Gerald M Elphingstone, Mark Bootz, Hiroshi Murakami, Hiroshi Maruyama, Hiroshi Masaharu, Peter Holland, John Payne, Nevin A Bryant, Thomas L Logan, J-P Muller, Gunter Schreier, and John S MacDonald), Eds., (1999): The Global Land Onekilometer Base Elevation (GLOBE) Digital Elevation Model, Version 1.0, National Oceanic and Atmospheric Administration, National Geophysical Data Center, 325 Broadway, Boulder, Colorado 80303, U.S.A. Digital data base on the World Wide Web (URL: http://www.ngdc.noaa.gov/mgg/topo/globe.html) and CD-ROMs.

Goldar J (2001): Personal communication.

Grebenitcharsky R (2004): Numerical solutions to altimetry gravimetry Boundary Value Problem in coastal region. UCGE Reports, Number 20195, The University of Calgary.

GTOPO30, (2005): http://edcdaacusgsgov/gtopo30/gtopo30html

Haagmans R, de Min E and van Gelderen M (1993): Fast evaluation of convolution integrals on the sphere using 1D FFT and a comparison with existing methods for Stokes' integral, Manuscripta Geodaetica, vol. 18, pp. 227-241.

Heiskanen WA and Moritz H (1967): Physical Geodesy, W. H. Freeman and Company, San Francisco.

Hernandez and Schaeffer (2000): Altimetric Mean Sea Surfaces and Gravity Anomaly maps inter-comparisons. Rapport no. AVI-NT-011-5242-CLS, édité par CLS, Ramonville St Agne. pp. 48.

JPL (2004): SRTM-The mission to map the World, Jet Propulsion Laboratory, California Institute of technology. http://www2.jpl.nasa.gov./srtm/index.html. 
Kellogg OD (1929): Foundations of Potential Theory, Frederick Ungar Publishing Company New York Distributions.

Kotsakis C (2001): Personal communication.

Kotsakis C and Sideris MG (1999): On the adjustment of combined GPS/leveling/geoid networks, Journal of Geodesy, vol. 73, pp. 412-421.

Lenzano L (2001): Personal communication.

Lemoine FG, Kenyon SC, Factim JK, Trimmer RG, Pavlis NK, Chinn DS, Cox CM, Klosko SM, Luthcke SB, Torrence MH, Wang YM, Williamson RG, Pavlis EC, Rapp $\mathrm{H}$ and Olson TR (1998): The development of the joint NASA, GSFC and the National Imagery and Mapping Agency (NIMA) Geopotential Model EGM96, NASA, Technical Publication-1998-206861, July, 1998.

Levitus S and Boyer TP (1994): World ocean atlas, vol. 4: Temperature NOAA Atlas NESDIS 4, pp. 117.

Levitus S, Burgett R and Boyer TP (1994): World ocean atlas, vol. 3: Salinity NOAA Atlas NESDIS 3, pp. 99.

Li J (1996): Detailed marine gravity field determination by combination of heterogeneous data, UCGE Reports Number 20102, The University of Calgary.

Li YC and Sideris MG (1993): HFTGVBP Software package for the solution of GVBP by means of fast Hartley/Fourier Transform TOPOGEOP Software packages to evaluate the TOPOgraphic effects on GEOdetic /GEOPhysical Observation Department of Geomatics Engineering The University of Calgary.

Li YC (1993):Optimized spectral geoid determination, UCGE Reports Number 20050, The University of Calgary.

Li YC and Sideris MG (1994): Minimization and estimation of geoid undulation errors, Bulletin Géodésique, vol. 68, pp. 201-219.

Li YC and Sideris MG (1994): Improved gravimetric terrain corrections, Geophysical Journal International, vol. 119, pp. 740-752. 
Li YC, Sideris MG and Schwarz KP (1995): A numerical investigation on height anomaly prediction, Bulletin Géodésique, vol. 69, pp. 143-156.

Li YL and Sideris MG (1997): Marine gravity and geoid determination by optimal combination of satellite altimetry and shipborne gravimetry data, Journal of Geodesy, vol. 71, pp. 209-216.

Li Z (1996): Multiresolution in Gravity Field modeling, MSc. Thesis, University of Calgary, Department of Geomatics Engineering, UCGE Reports Number 20103.

Mainville A R, Forsberg R and Sideris MG (1992): Global Positioning System testing of geoids Computed From Geopotential Models and Local Gravity Data: A Case Study, Journal of Geophysical Research, vol. 97, no. B7, pp. 11137-11147.

Moritz H (1980): Advanced Physical Geodesy, Herbert Wichmann Verlag, Karlsruhe, Abacus Press, Tunbridge Wells, Kent.

Moritz H. (2000): Geodetic Reference System 1980, Journal of Geodesy, vol. 74, pp. 128-162.

Morrison FF and Douglas BC (1984): A comparison of gravity prediction methods on actual and simulated data, Geophysics, vol. 49, no. 10, pp. 1774-1780.

Nagy D (1966): The prism method for terrain corrections using digital computers. Pure Applied Geophysics, vol. 63, pp 31-39.

Omang OCD and Forsberg R (2000): How to handle topography in practical geoid determination: three examples, Journal of Geodesy, vol. 74, no. 6, pp. 478-488.

Orellano MA (2002): Personal communication.

Pavlis NK, Holmes SA, Kenyon SC, Schmidt D, Trimmer R (2004): A preliminary Gravitational Model to Degree 2160, International Association of Geodesy Symposia, vol. 129, Jekeli C, Bastos L and Fernandes J (Eds.), Springer. Proceedings of the Symposium 129: Gravity, Geoid and Space Missions, Porto, Portugal, August 30-September 3, 2004, pp. 18-23. 
Perdomo R and Del Cogliano D (1999): The geoid in Buenos Aires region, International Geoid Service Bulletin no. 9, pp. 109-121.

Perdomo R and Hormaechea JL (1999): A preliminary analysis of the geoid in Tierra del Fuego, International Geoid Service, Bulletin no. 9, pp. 121-123.

Querejeta D (2001): Personal communication.

Reigber CH, Schwintzer P, Stubenvoll R, Schmidt R, Flechtner F, Meyer U , König R, Neumayer H, Förste Ch, Barthelmes F, Zhu SY, Balmino G, Biancale R, Lemoine J , Meixner H, Raimondo JC (2004): A High Resolution Global Gravity Field Model Combining CHAMP and GRACE Satellite Mission and Surface Gravity Data: EIGEN-CG01C accepted by Journal of Geodesy and abstract from Joint CHAMP/GRACE Science Meeting, GFZ, July 5-7, 2004 (page 16, no. 24 in Solid Earth Abstracts (pdf file).

Rapp RH (1978): A global $1^{\circ} \times 1^{\circ}$ anomaly field combining satellite, GEOS-3 altimeter and terrestrial data, Report of the Department of Geodetic Science and Surveying no. 278, The Ohio State University, Columbus.

Rapp RH (1981): The earth gravity field to degree and order 180, using SEASAT altimeter and terrestrial data, Report of the Department of Geodetic Science and Surveying no. 322, The Ohio State University, Columbus.

Rapp RH and Cruz J (1986): Spherical harmonic expansions of the Earth's gravitational potential to degree 360 using mean 30' gravity anomalies, Report of the Department of Geodetic Science and Surveying no. 376, The Ohio State University, Columbus.

Rapp RH and Pavlis NK (1990): The development and analysis of geopotential coefficient models to spherical harmonic degree 360, Journal of Geophysical Research, vol. 95, no. B13, pp. 21885-21911.

Rapp RH, Wang YM and Pavlis NK (1991): The Ohio State 1991 geopotential model and sea surface topography harmonic coefficient models, Report of the Department of Geodetic Science and Surveying no. 410, The Ohio State University, Columbus, Ohio. 
Rodriguez R and Pacino MC (1999): Un modelo de geoide de precisión para la provincia de Santa Fé-Argentina, International Geoid Service, Bulletin no. 9, pp. 123135.

Rudzki MP (1911): Physik der Erde, Leipzig 1911, Chr. Herm. Tauchnitz.

Schwarz KP and Sideris MG (1985): Precise geoid heights and their use in GPS interferometry, Geodetic Survey of Canada, Contract Report 85-004.

Schwarz KP, Sideris MG and Forsberg R (1990): The use of FFT techniques in physical geodesy, Geophysical Journal International, vol. 100, pp. 485-514.

Shepard D (1968): A two dimensional interpolation function for irregularly spaced data, Proc. 23th Nat. Conf. ACM, pp. 517-523.

Sideris MG (1984): Computation of gravimetric terrain corrections using fast Fourier transform techniques, UCSE Report no. 20007, Department of Surveying Engineering, The University of Calgary, Calgary, Alberta, Canada.

Sideris MG and Forsberg R (1991): Review of geoid prediction methods in mountainous regions, International Association of Geodesy Symposia, vol. 106, Rapp RH and Sanso F (Eds.), Springer-Verlag, Proceedings of the Symposium 106: Determination of the Geoid: Present and Future, Milan, Italy, June 11-13,1990, pp. $51-62$.

Sideris MG and Li YC (1993): Gravity field convolutions without windowing and edge effects Bulletin Géodésique, vol. 67, pp. 107-118.

Sideris MG, Mainville A and Forsberg R (1992): Geoid testing using GPS and levelling (or GPS testing using leveling and the geoid?), Aust. J. Geod. Photogram. Surv., no. 57, pp. 62-77.

Sideris MG (1996): On the use of heterogeneous noisy data in spectral gravity field modeling methods, Journal of Geodesy, vol. 70, pp. 470-479.

Sideris MG (1994): Regional geoid determination, Geoid and its geophysical interpretations, CRC Press, pp. 77-94. 
Sideris MG (1997): Geoid Determination by FFT Technique, In Lecture Notes of IAG's Geoid School, Rio de Janeiro, Brazil.

Sideris MG and She BB (1995): A new high-resolution geoid for Canada and part of the U.S. by 1D-FFT method, Bulletin Géodésique, no. 69, pp. 92-108.

Smith WHF and Sandwell DT (1997): Global sea floor topography from satellite altimetry and ship depth soundings, Science Magazine, vol. 277, issue 5334.

Smith DA and Roman DR (2000): Recent Advances in the Acquisition and Use of Terrain Data for Geoid Modelling over the United States. http://www.ngs.noaa.gov/GEOID/geolib.html

Smith WHF and Wessel P (1990): Gridding with continuous curvature splines in tension, Geophysics vol. 55, no. 3, pp. 293-305.

Strang van Hees G (1990): Stokes' formula using fast Fourier techniques, Manuscripta Geodaetica, vol. 15, pp. 235-239.

Subiza Piña WH (1999): Avances en la determinación de un geoide de precisión para Uruguay, International Geoid Service, Bulletin no. 9, pp. 99-109.

Subiza Piña WH (1999): GPS/levelling data for Uruguay, personal communication.

Tapley B, Watkins M, Ries J, Davis G, Eanes R, Poole S, Rim H, Shutz B, Shum S, Nerem R, Lerch F, Marshall J, Klosko S, Pavlis N, Williamson R, (1996): The Joint Gravity Model 3, Journal of Geophysical Research, vol. 101, no. B12, pp. 2802928049.

Tocho C., Vergos G.S., Sideris M.G., (2003): Optimal marine geoid determination in the Atlantic coastal region of Argentina, International Association of Geodesy Symposia, vol. 128, Sanso F (Ed.), Springer. Proceedings of the Symposium 128: $A$ window on the future of Geodesy, Sapporo, Japan, June 30-July 11, 2003, pp. 380385.

Torge W (1989) Gravimetry Walter de Gruyter Verlag Berlin.

Torge W (2001): Geodesy, Walter de Gruyter Verlag Berlin, New York. 
Tscherning CC and Rapp RH (1974): Closed covariance expression for gravity, geoid undulations and deflections of the vertical implied by anomalies degree-variance models, Report of the Department of Geodetic Science and Surveying no. 208, The Ohio State University, Columbus, Ohio.

Tscherning CC (1997) in Lectures Notes for the IAG's International Geoid School, Rio de Janeiro, Brazil.

Tscherning CC, Forsberg R, Knudsen P, (1992): The GRAVSOFT package for geoid determination, in Holota P, Vermeer M (Eds), $1^{\text {st }}$ Continental Workshop for the Geoid in Europe: Towards a precise European geoid in the nineties, Prague, June 79, pp. 327-334.

Tziavos IN (1992): Alternative numerical techniques for the efficient computation of terrain corrections and geoid undulations, in Holota $\mathrm{P}$, Vermeer $\mathrm{M}$ (Eds), $1^{\text {st }}$ Continental Workshop for the geoid in Europe: Towards a precise European geoid in the nineties, Prague, June 7-9, pp. 312-326.

Vergos G (2002): Sea surface topography bathymetry and marine gravity field modeling, MSc. Thesis, University of Calgary, Department of Geomatics Engineering, UCGE Reports Number 20157.

Vergos GS, Tziavos IN, Sideris MG (2004): On the validation of CHAMP- and GRACE-type EGMs and the construction of a combined model, Presented at the Joint CHAMP/GRACE Science Meeting, July 6-8, Potsdam, Germany.

Wang YM: (2001): GSFC00 mean sea surface gravity anomaly and vertical gravity gradient from satellite altimeter data, Journal Geophysical Research, vol.106, no. C12, pp. 31167-31174.

Wenzel HG (1985): Hochauflösende Kugelfunktionsmodelle für das Gravitationspotential der Erde, Wissenschaftliche. Arbeiten d. Fachrichtung Vermessungswesen der Universität. Hannover, no. 135, Hannover.

Wenzel HG (1999): Global models of the gravity field of high and ultra-high resolution, in Lecture Notes of IAG's International Geoid School, Milano, Italy. 
Wessel P and Smith WHF. (1998): New improved version of The Generic Mapping Tools released. EOS Trans 79(47): 579.

Wichiencharoen C (1982): The indirect effects on the computation of geoid undulations, Report of the Department of Geodetic Science and Surveying no. 336, The Ohio State University, Columbus, Ohio.

Wu L (1996): Spectral methods for post processing of airborne vector gravity data, MSc. Thesis, University of Calgary, Department of Geomatics Engineering, UCGE Reports Number 20104.

Zhang K (1997): An evaluation of FFT geoid determination techniques and their application to height determination using GPS in Australia, Phd thesis Department School of Surveying and Land Information. http://adt.curtin.edu.au/theses/available/adt-WCU20020807.170615/. 
Appendix 1: Statistics of the differences between geoids derived from global geopotential models with GPS/leveling-derived geoid. (All of Argentina). Unit: [m]

\begin{tabular}{|c|c|c|c|c|c|c|}
\hline GPM98A & \multicolumn{2}{|c|}{ All of Argentina } & $\min$ & $\max$ & mean & $\sigma$ \\
\hline $\mathrm{N}^{\mathrm{GPM} 98 \mathrm{~A}}-\mathrm{N}^{\mathrm{GPS}}$ & $\begin{array}{c}\text { Original (552pts) } \\
\text { After } 3 \text { rms (550 pts) } \\
\text { After fit }\end{array}$ & $\begin{array}{l}\text { Before fit } \\
\text { Before fit } \\
4 \text {-param } \\
3^{\text {rd }} \text { pol } \\
\text { 7-param } \\
\end{array}$ & $\begin{array}{l}-4.528 \\
-3.132 \\
-2.961 \\
-3.021 \\
-3.107 \\
\end{array}$ & $\begin{array}{l}3.696 \\
3.696 \\
3.451 \\
4.074 \\
2.991 \\
\end{array}$ & $\begin{array}{l}0.691 \\
0.701 \\
0.000 \\
0.000 \\
0.000 \\
\end{array}$ & $\begin{array}{l}1.223 \\
1.204 \\
0.922 \\
0.638 \\
0.671 \\
\end{array}$ \\
\hline GPM98B & \multicolumn{2}{|c|}{ All of Argentina } & $\min$ & $\max$ & mean & $\sigma$ \\
\hline $\mathrm{N}^{\mathrm{GPM} 98 \mathrm{~B}}-\mathrm{N}^{\mathrm{GPS}}$ & $\begin{array}{c}\text { Original (552 pts) } \\
\text { After } 3 \text { rms (550 pts) } \\
\text { After fit }\end{array}$ & $\begin{array}{l}\text { Before fit } \\
\text { Before fit } \\
4 \text {-param } \\
3^{\text {rd }} \text { pol } \\
\text { 7-param } \\
\end{array}$ & $\begin{array}{l}-5.000 \\
-3.269 \\
-2.960 \\
-3.027 \\
-3.117 \\
\end{array}$ & $\begin{array}{l}3.784 \\
3.784 \\
3.507 \\
4.169 \\
3.074 \\
\end{array}$ & $\begin{array}{l}0.702 \\
0.722 \\
0.000 \\
0.000 \\
0.000 \\
\end{array}$ & $\begin{array}{l}1.264 \\
1.221 \\
0.938 \\
0.646 \\
0.679 \\
\end{array}$ \\
\hline GPM98CR & \multicolumn{2}{|c|}{ All of Argentina } & $\min$ & $\max$ & mean & $\sigma$ \\
\hline $\mathrm{N}^{\mathrm{GPM} 98 \mathrm{CR}}-\mathrm{N}^{\mathrm{GPS}}$ & $\begin{array}{c}\text { Original (552 pts) } \\
\text { After } 3 \text { rms (551 pts) } \\
\text { After fit }\end{array}$ & \begin{tabular}{|l} 
Before fit \\
Before fit \\
4 -param \\
$3^{\text {rd }}$ pol \\
7-param \\
\end{tabular} & $\begin{array}{l}-2.799 \\
-2.497 \\
-2.648 \\
-2.836 \\
-2.806 \\
\end{array}$ & $\begin{array}{l}2.375 \\
2.375 \\
2.772 \\
2.876 \\
2.878 \\
\end{array}$ & $\begin{array}{l}0.251 \\
0.256 \\
0.000 \\
0.000 \\
0.000 \\
\end{array}$ & $\begin{array}{l}0.849 \\
0.840 \\
0.700 \\
0.648 \\
0.684 \\
\end{array}$ \\
\hline EGM96 & \multicolumn{2}{|c|}{ All of Argentina } & $\min$ & $\max$ & mean & $\sigma$ \\
\hline $\mathrm{N}^{\mathrm{EGM} 96}-\mathrm{N}^{\mathrm{GPS}}$ & $\begin{array}{c}\text { Original (552 pts) } \\
\text { After } 3 \text { rms (551 pts) } \\
\text { After fit }\end{array}$ & $\begin{array}{l}\text { Before fit } \\
\text { Before fit } \\
4 \text {-param } \\
3^{\text {rd }} \text { pol } \\
\text { 7-param } \\
\end{array}$ & $\begin{array}{l}-2.598 \\
-2.440 \\
-2.714 \\
-2.955 \\
-2.953 \\
\end{array}$ & $\begin{array}{l}1.880 \\
1.880 \\
1.978 \\
1.936 \\
1.910 \\
\end{array}$ & $\begin{array}{l}0.135 \\
0.140 \\
0.000 \\
0.000 \\
0.000 \\
\end{array}$ & $\begin{array}{l}0.823 \\
0.816 \\
0.554 \\
0.454 \\
0.504 \\
\end{array}$ \\
\hline EIGEN-CG01C & \multicolumn{2}{|c|}{ All of Argentina } & $\min$ & $\max$ & mean & $\sigma$ \\
\hline $\mathrm{N}^{\text {EIGEN-CG01C }}-\mathrm{N}^{\mathrm{GPS}}$ & $\begin{array}{c}\text { Original (552 pts) } \\
\text { After } 3 \text { rms (548 pts) } \\
\text { After fit }\end{array}$ & $\begin{array}{l}\text { Before fit } \\
\text { Before fit } \\
4 \text {-param } \\
3^{\text {rd }} \text { pol } \\
\text { 7-param } \\
\end{array}$ & $\begin{array}{l}-2.878 \\
-1.362 \\
-1.729 \\
-1.822 \\
-1.791 \\
\end{array}$ & $\begin{array}{l}2.131 \\
1.604 \\
1.220 \\
1.283 \\
1.211 \\
\end{array}$ & $\begin{array}{c}0.459 \\
-0.472 \\
0.000 \\
0.000 \\
0.000 \\
\end{array}$ & $\begin{array}{l}0.463 \\
0.407 \\
0.358 \\
0.341 \\
0.350 \\
\end{array}$ \\
\hline OSU91A & \multicolumn{2}{|c|}{ All of Argentina } & $\min$ & $\max$ & mean & $\sigma$ \\
\hline $\mathrm{N}^{\mathrm{OSU} 91 \mathrm{~A}}-\mathrm{N}^{\mathrm{GPS}}$ & $\begin{array}{r}\text { Original (552 pts) } \\
\text { After } 3 \text { rms (548 pts) } \\
\text { After fit }\end{array}$ & $\begin{array}{l}\text { Before fit } \\
\text { Before fit } \\
4 \text {-param } \\
3^{\text {rd }} \text { pol } \\
\text { 7-param } \\
\end{array}$ & $\begin{array}{l}-7.817 \\
-2.776 \\
-3.518 \\
-3.438 \\
-3.583 \\
\end{array}$ & $\begin{array}{l}4.751 \\
3.792 \\
3.209 \\
2.972 \\
2.999 \\
\end{array}$ & $\begin{array}{l}0.755 \\
0.770 \\
0.000 \\
0.000 \\
0.000 \\
\end{array}$ & $\begin{array}{l}1.058 \\
0.928 \\
0.909 \\
0.852 \\
0.866 \\
\end{array}$ \\
\hline GPM2 & \multicolumn{2}{|c|}{ All of Argentina } & $\min$ & $\max$ & mean & $\sigma$ \\
\hline $\mathrm{N}^{\mathrm{GPM} 2}-\mathrm{N}^{\mathrm{GPS}}$ & $\begin{array}{c}\text { Original (552 pts) } \\
\text { After } 3 \text { rms (551 pts) } \\
\text { After fit }\end{array}$ & $\begin{array}{l}\text { Before fit } \\
\text { Before fit } \\
\text { 4-param } \\
3^{\text {rd }} \text { pol } \\
\text { 7-param } \\
\end{array}$ & $\begin{array}{c}-7.582 \\
-7.582 \\
-10.975 \\
-9.833 \\
-9.975 \\
\end{array}$ & $\begin{array}{l}9.285 \\
9.226 \\
5.373 \\
5.602 \\
5.858 \\
\end{array}$ & $\begin{array}{l}1.225 \\
1.211 \\
0.000 \\
0.000 \\
0.000 \\
\end{array}$ & $\begin{array}{l}2.838 \\
2.819 \\
2.121 \\
1.563 \\
1.623\end{array}$ \\
\hline OSU81 & \multicolumn{2}{|c|}{ All of Argentina } & $\min$ & $\max$ & mean & $\sigma$ \\
\hline $\mathrm{N}^{\mathrm{OSU} 81}-\mathrm{N}^{\mathrm{GPS}}$ & $\begin{array}{c}\text { Original (552 pts) } \\
\text { After } 3 \text { rms (552 pts) } \\
\text { After fit }\end{array}$ & $\begin{array}{l}\text { Before fit } \\
\text { Before fit } \\
4 \text {-param } \\
3^{\text {rd }} \text { pol } \\
\text { 7-param }\end{array}$ & $\begin{array}{l}-3.483 \\
-3.483 \\
-7.747 \\
-8.761 \\
-8.923 \\
\end{array}$ & $\begin{array}{l}8.567 \\
8.567 \\
4.386 \\
6.248 \\
6.049 \\
\end{array}$ & $\begin{array}{l}2.596 \\
2.596 \\
0.000 \\
0.000 \\
0.000 \\
\end{array}$ & $\begin{array}{l}2.196 \\
2.196 \\
1.784 \\
1.450 \\
1.462 \\
\end{array}$ \\
\hline JGM3 & \multicolumn{2}{|c|}{ All of Argentina } & $\min$ & $\max$ & mean & $\sigma$ \\
\hline $\mathrm{N}^{\mathrm{JGM} 3}-\mathrm{N}^{\mathrm{GPS}}$ & $\begin{array}{c}\text { Original (552 pts) } \\
\text { After } 3 \text { rms (551 pts) } \\
\text { After fit }\end{array}$ & $\begin{array}{l}\text { Before fit } \\
\text { Before fit } \\
\text { 4-param } \\
3^{\text {rd }} \text { pol } \\
\text { 7-param }\end{array}$ & $\begin{array}{l}-9.583 \\
-4.301 \\
-6.522 \\
-6.733 \\
-6.662\end{array}$ & $\begin{array}{l}4.591 \\
4.591 \\
3.201 \\
2.965 \\
3.141\end{array}$ & $\begin{array}{l}1.161 \\
1.180 \\
0.000 \\
0.000 \\
0.000\end{array}$ & $\begin{array}{l}1.661 \\
1.598 \\
1.329 \\
1.116 \\
1.181\end{array}$ \\
\hline
\end{tabular}


Appendix 2: Statistics of the differences between geoids derived from global geopotential models with GPS/leveling-derived geoid in Buenos Aires province. Unit: [m]

\begin{tabular}{|c|c|c|c|c|c|c|}
\hline GPM98A & \multicolumn{2}{|c|}{ Buenos Aires } & $\min$ & $\max$ & mean & $\sigma$ \\
\hline $\mathrm{N}^{\mathrm{GPM} 98 \mathrm{~A}}-\mathrm{N}^{\mathrm{GPS}}$ & $\begin{array}{c}\text { Original (180 pts) } \\
\text { After } 3 \text { rms (180 pts) } \\
\text { After fit }\end{array}$ & $\begin{array}{l}\text { Before fit } \\
\text { Before fit } \\
4 \text {-param } \\
3^{\text {rd }} \text { pol } \\
\text { 7-param }\end{array}$ & $\begin{array}{l}-0.130 \\
-0.850 \\
-0.883 \\
-0.854 \\
\end{array}$ & $\begin{array}{l}0.690 \\
0.633 \\
0.744 \\
\end{array}$ & $\begin{array}{l}0.000 \\
0.000 \\
0.000\end{array}$ & $\begin{array}{l}0.342 \\
0.287 \\
0.298 \\
\end{array}$ \\
\hline GPM98B & \multicolumn{2}{|c|}{ Buenos Aires } & $\min$ & $\max$ & mean & $\sigma$ \\
\hline $\mathrm{N}^{\mathrm{GPM} 98 \mathrm{~B}}-\mathrm{N}^{\mathrm{GPS}}$ & $\begin{array}{c}\text { Original (180 pts) } \\
\text { After } 3 \text { rms (180 pts) } \\
\text { After fit }\end{array}$ & $\begin{array}{l}\text { Before fit } \\
\text { Before fit } \\
4 \text {-param } \\
3^{\text {rd }} \text { pol } \\
7 \text {-param } \\
\end{array}$ & $\begin{array}{l}-0.115 \\
-0.853 \\
-0.872 \\
-0.850 \\
\end{array}$ & $\begin{array}{l}0.680 \\
0.639 \\
0.742 \\
\end{array}$ & $\begin{array}{l}0.000 \\
0.000 \\
0.000 \\
\end{array}$ & $\begin{array}{l}0.342 \\
0.287 \\
0.297 \\
\end{array}$ \\
\hline GPM98CR & \multicolumn{2}{|c|}{ Buenos Aires } & $\min$ & $\max$ & mean & $\sigma$ \\
\hline $\mathrm{N}^{\mathrm{GPM} 98 \mathrm{C}}-\mathrm{N}^{\mathrm{GPS}}$ & $\begin{array}{c}\text { Original (180 pts) } \\
\text { After } 3 \text { rms (180 pts) } \\
\text { After fit }\end{array}$ & $\begin{array}{l}\text { Before fit } \\
\text { Before fit } \\
\text { 4-param } \\
3^{\text {rd }} \text { pol } \\
\text { 7-param } \\
\end{array}$ & $\begin{array}{l}-0.173 \\
-0.603 \\
-0.513 \\
-0.490 \\
\end{array}$ & $\begin{array}{l}0.462 \\
0.461 \\
0.439 \\
\end{array}$ & $\begin{array}{l}0.000 \\
0.000 \\
0.000 \\
\end{array}$ & $\begin{array}{l}0.187 \\
0.167 \\
0.171 \\
\end{array}$ \\
\hline EGM96 & \multicolumn{2}{|c|}{$\begin{array}{r}\text { Buenos Aires } \\
\end{array}$} & $\min$ & $\max$ & mean & $\sigma$ \\
\hline $\mathrm{N}^{\mathrm{EGM} 96}-\mathrm{N}^{\mathrm{GPS}}$ & $\begin{array}{c}\text { Original (180 pts) } \\
\text { After } 3 \text { rms (180 pts) } \\
\text { After fit }\end{array}$ & $\begin{array}{l}\text { Before fit } \\
\text { Before fit } \\
4 \text {-param } \\
3^{\text {rd }} \text { pol } \\
\text { 7-param } \\
\end{array}$ & $\begin{array}{r}0.029 \\
-0.504 \\
-0.333 \\
-0.337 \\
\end{array}$ & $\begin{array}{l}1.159 \\
0.299 \\
0.244 \\
0.264 \\
\end{array}$ & $\begin{array}{l}0.000 \\
0.000 \\
0.000 \\
\end{array}$ & $\begin{array}{l}0.250 \\
0.147 \\
0.115 \\
0.122 \\
\end{array}$ \\
\hline$E I G E N-C G 01 C$ & \multicolumn{2}{|c|}{$\begin{array}{r}\text { Buenos Aires } \\
\end{array}$} & $\min$ & $\max$ & mean & $\sigma$ \\
\hline $\mathrm{N}^{\text {EIGEN-CG01C }}-\mathrm{N}^{\mathrm{GPS}}$ & $\begin{array}{c}\text { Original (180 pts) } \\
\text { After } 3 \text { rms (180 pts) } \\
\text { After fit }\end{array}$ & $\begin{array}{l}\text { Before fit } \\
\text { Before fit } \\
4 \text {-param } \\
3^{\text {rd }} \text { pol } \\
7 \text {-param } \\
\end{array}$ & $\begin{array}{r}0.181 \\
-0.493 \\
-0.402 \\
-0.391 \\
\end{array}$ & $\begin{array}{l}1.103 \\
0.350 \\
0.329 \\
0.367 \\
\end{array}$ & $\begin{array}{l}0.000 \\
0.000 \\
0.000 \\
\end{array}$ & $\begin{array}{l}0.145 \\
0.128 \\
0.135 \\
\end{array}$ \\
\hline OSU91A & \multicolumn{2}{|c|}{ Buenos Aires } & $\min$ & $\max$ & mean & $\sigma$ \\
\hline $\mathrm{N}^{\mathrm{OSU} 91 \mathrm{~A}}-\mathrm{N}^{\mathrm{GPS}}$ & $\begin{array}{l}\text { Original (180 pts) } \\
\text { After } 3 \text { rms (180 pts) } \\
\text { After fit }\end{array}$ & $\begin{array}{l}\text { Before fit } \\
\text { Before fit } \\
4 \text {-param } \\
3^{\text {rd }} \text { pol } \\
7 \text {-param } \\
\end{array}$ & $\begin{array}{r}0.335 \\
-0.881 \\
-0.663 \\
-0.658 \\
\end{array}$ & $\begin{array}{l}2.086 \\
0.718 \\
0.462 \\
0.568 \\
\end{array}$ & $\begin{array}{l}1.128 \\
0.000 \\
0.000 \\
0.000 \\
\end{array}$ & $\begin{array}{l}0.336 \\
0.286 \\
0.229 \\
0.254 \\
\end{array}$ \\
\hline GPM2 & \multicolumn{2}{|c|}{ Buenos Aires } & $\min$ & $\max$ & mean & $\sigma$ \\
\hline $\mathrm{N}^{\mathrm{GPM} 2}-\mathrm{N}^{\mathrm{GPS}}$ & $\begin{array}{c}\text { Original (180 pts) } \\
\text { After } 3 \text { rms (180 pts) } \\
\text { After fit }\end{array}$ & $\begin{array}{l}\text { Before fit } \\
\text { Before fit } \\
4 \text {-param } \\
3^{\text {rd }} \text { pol } \\
7 \text {-param }\end{array}$ & $\begin{array}{r}-1.149 \\
-1.093 \\
-0.868 \\
-0.918 \\
\end{array}$ & $\begin{array}{l}1.375 \\
0.990 \\
0.565 \\
0.634 \\
\end{array}$ & $\begin{array}{l}0.198 \\
0.000 \\
0.000 \\
0.000 \\
\end{array}$ & $\begin{array}{l}0.410 \\
0.354 \\
0.275 \\
0.276 \\
\end{array}$ \\
\hline OSU81 & \multicolumn{2}{|c|}{ Buenos Aires } & $\min$ & $\max$ & mean & $\sigma$ \\
\hline $\mathrm{N}^{\mathrm{OSU} 81}-\mathrm{N}^{\mathrm{GPS}}$ & $\begin{array}{c}\text { Original (180 pts) } \\
\text { After } 3 \text { rms (180 pts) } \\
\text { After fit }\end{array}$ & $\begin{array}{l}\text { Before fit } \\
\text { Before fit } \\
4 \text {-param } \\
3^{\text {rd }} \text { pol } \\
\text { 7-param } \\
\end{array}$ & $\begin{array}{l}1.255 \\
-1.022 \\
-0.904 \\
-0.839 \\
\end{array}$ & $\begin{array}{l}3.448 \\
1.332 \\
0.599 \\
0.757 \\
\end{array}$ & $\begin{array}{l}2.353 \\
0.000 \\
0.000 \\
0.000 \\
\end{array}$ & $\begin{array}{l}0.475 \\
0.437 \\
0.310 \\
0.339 \\
\end{array}$ \\
\hline$J G M 3$ & \multicolumn{2}{|c|}{$\begin{array}{r}\text { Buenos Aires } \\
\end{array}$} & $\min$ & $\max$ & mean & $\sigma$ \\
\hline $\mathrm{N}^{\mathrm{JGM} 3}-\mathrm{N}^{\mathrm{GPS}}$ & $\begin{array}{c}\text { Original (180 pts) } \\
\text { After } 3 \text { rms (180 pts) } \\
\text { After fit }\end{array}$ & $\begin{array}{l}\text { Before fit } \\
\text { Before fit } \\
4 \text {-param } \\
3^{\text {rd }} \text { pol } \\
\text { 7-param }\end{array}$ & $\begin{array}{r}-1.014 \\
-1.500 \\
-0.866 \\
-1.358 \\
\end{array}$ & $\begin{array}{l}3.684 \\
2.445 \\
1.217 \\
1.763\end{array}$ & $\begin{array}{l}0.000 \\
0.000 \\
0.000\end{array}$ & $\begin{array}{l}0.973 \\
0.733 \\
0.407 \\
0.634\end{array}$ \\
\hline
\end{tabular}


Appendix 3: Statistics of the differences between geoids derived from global geopotential models with GPS/leveling-derived geoid in Chubut. Unit: [m]

\begin{tabular}{|c|c|c|c|c|c|c|}
\hline GPM98A & \multicolumn{2}{|c|}{ Chubut } & $\min$ & $\max$ & mean & $\sigma$ \\
\hline $\mathrm{N}^{\mathrm{GPM} 98 \mathrm{~A}}-\mathrm{N}^{\mathrm{GPS}}$ & $\begin{array}{r}\text { Original (10 pts) } \\
\text { After } 3 \text { rms (10 pts) } \\
\text { After fit }\end{array}$ & $\begin{array}{l}\text { Before fit } \\
\text { Before fit } \\
\text { 4-param } \\
\text { 7-param } \\
\end{array}$ & $\begin{array}{r}-1.342 \\
-0.934 \\
-0.142 \\
\end{array}$ & $\begin{array}{l}1.307 \\
0.709 \\
0.138 \\
\end{array}$ & $\begin{array}{l}0.043 \\
0.000 \\
0.000 \\
\end{array}$ & $\begin{array}{l}0.846 \\
0.594 \\
0.100 \\
\end{array}$ \\
\hline$G P M 98 B$ & \multicolumn{2}{|c|}{ Chubut } & $\min$ & $\max$ & mean & $\sigma$ \\
\hline $\mathrm{N}^{\mathrm{GPM} 98 \mathrm{~B}}-\mathrm{N}^{\mathrm{GPS}}$ & $\begin{array}{r}\text { Original (10 pts) } \\
\text { After } 3 \text { rms (10 pts) } \\
\text { After fit }\end{array}$ & $\begin{array}{l}\text { Before fit } \\
\text { Before fit } \\
\text { 4-param } \\
\text { 7-param }\end{array}$ & $\begin{array}{l}-1.278 \\
-0.935 \\
-0.139\end{array}$ & $\begin{array}{l}1.368 \\
0.705 \\
0.130\end{array}$ & $\begin{array}{l}0.097 \\
0.000 \\
0.000\end{array}$ & $\begin{array}{l}0.842 \\
0.595 \\
0.096\end{array}$ \\
\hline GPM98CR & \multicolumn{2}{|c|}{$\begin{array}{r}\text { Chubut } \\
\end{array}$} & $\min$ & $\max$ & mean & $\sigma$ \\
\hline $\mathrm{N}^{\mathrm{GPM} 98 \mathrm{CR}}-\mathrm{N}^{\mathrm{GPS}}$ & $\begin{array}{r}\text { Original (10 pts) } \\
\text { After } 3 \text { rms (10 pts) } \\
\text { After fit }\end{array}$ & $\begin{array}{l}\text { Before fit } \\
\text { Before fit } \\
\text { 4-param } \\
\text { 7-param } \\
\end{array}$ & $\begin{array}{l}-1.742 \\
-1.222 \\
-0.363 \\
\end{array}$ & $\begin{array}{l}1.687 \\
1.186 \\
0.372 \\
\end{array}$ & $\begin{array}{l}-0.147 \\
0.000 \\
0.000 \\
\end{array}$ & $\begin{array}{l}1.169 \\
0.798 \\
0.258 \\
\end{array}$ \\
\hline EGM96 & \multicolumn{2}{|c|}{$\begin{array}{r}\text { Chubut } \\
\end{array}$} & $\min$ & $\max$ & mean & $\sigma$ \\
\hline $\mathrm{N}^{\mathrm{EGM} 96}-\mathrm{N}^{\mathrm{GPS}}$ & $\begin{array}{r}\text { Original (10 pts) } \\
\text { After } 3 \text { rms (10 pts) } \\
\text { After fit }\end{array}$ & $\begin{array}{l}\text { Before fit } \\
\text { Before fit } \\
\text { 4-param } \\
\text { 7-param } \\
\end{array}$ & $\begin{array}{l}-1.810 \\
-0.956 \\
-0.341 \\
\end{array}$ & $\begin{array}{l}1.685 \\
1.377 \\
0.456 \\
\end{array}$ & $\begin{array}{l}-0.101 \\
0.000 \\
0.000 \\
\end{array}$ & $\begin{array}{l}1.174 \\
0.753 \\
0.286 \\
\end{array}$ \\
\hline$E I G E N-C G 01 C$ & \multicolumn{2}{|c|}{ Chubut } & $\min$ & $\max$ & mean & $\sigma$ \\
\hline $\mathrm{N}^{\mathrm{EIGEN}-\mathrm{CG} 01 \mathrm{C}}-\mathrm{N}^{\mathrm{GPS}}$ & $\begin{array}{r}\text { Original (10 pts) } \\
\text { After } 3 \mathrm{rms}(10 \mathrm{pts}) \\
\text { After fit }\end{array}$ & $\begin{array}{l}\text { Before fit } \\
\text { Before fit } \\
\text { 4-param } \\
\text { 7-param } \\
\end{array}$ & $\begin{array}{l}-0.184 \\
-0.688 \\
-0.416 \\
\end{array}$ & $\begin{array}{l}1.025 \\
0.373 \\
0.529 \\
\end{array}$ & $\begin{array}{l}0.387 \\
0.000 \\
0.000 \\
\end{array}$ & $\begin{array}{l}0.377 \\
0.325 \\
0.264 \\
\end{array}$ \\
\hline OSU91A & \multicolumn{2}{|c|}{ Chubut } & $\min$ & $\max$ & mean & $\sigma$ \\
\hline $\mathrm{N}^{\mathrm{OSU} 91 \mathrm{~A}}-\mathrm{N}^{\mathrm{GPS}}$ & $\begin{array}{r}\text { Original (10 pts) } \\
\text { After } 3 \text { rms (10 pts) } \\
\text { After fit }\end{array}$ & $\begin{array}{l}\text { Before fit } \\
\text { Before fit } \\
\text { 4-param } \\
\text { 7-param } \\
\end{array}$ & $\begin{array}{l}-1.097 \\
-0.830 \\
-0.287 \\
\end{array}$ & $\begin{array}{l}1.140 \\
0.844 \\
0.388\end{array}$ & $\begin{array}{l}0.200 \\
0.000 \\
0.000\end{array}$ & $\begin{array}{l}0.818 \\
0.541 \\
0.187\end{array}$ \\
\hline GPM2 & \multicolumn{2}{|c|}{ Chubut } & $\min$ & $\max$ & mean & $\sigma$ \\
\hline $\mathrm{N}^{\mathrm{GPM} 2}-\mathrm{N}^{\mathrm{GPS}}$ & $\begin{array}{l}\text { Original (10 pts) } \\
\text { After } 3 \mathrm{rms}(10 \mathrm{pts}) \\
\text { After fit }\end{array}$ & $\begin{array}{l}\text { Before fit } \\
\text { Before fit } \\
\text { 4-param } \\
\text { 7-param } \\
\end{array}$ & $\begin{array}{l}-3.662 \\
-2.030 \\
-0.591 \\
\end{array}$ & $\begin{array}{l}4.102 \\
2.538 \\
0.684 \\
\end{array}$ & $\begin{array}{l}-0.167 \\
0.000 \\
0.000 \\
\end{array}$ & $\begin{array}{l}2.631 \\
1.463 \\
0.396 \\
\end{array}$ \\
\hline OSU81 & \multicolumn{2}{|c|}{$\begin{array}{r}\text { Chubut } \\
\end{array}$} & $\min$ & $\max$ & mean & $\sigma$ \\
\hline $\mathrm{N}^{\mathrm{OSU} 81}-\mathrm{N}^{\mathrm{GPS}}$ & $\begin{array}{l}\text { Original (10 pts) } \\
\text { After } 3 \text { rms (10 pts) } \\
\text { After fit }\end{array}$ & $\begin{array}{l}\text { Before fit } \\
\text { Before fit } \\
\text { 4-param } \\
\text { 7-param } \\
\end{array}$ & $\begin{array}{l}-3.004 \\
-4.038 \\
-0.593 \\
\end{array}$ & $\begin{array}{l}5.654 \\
3.153 \\
0.645 \\
\end{array}$ & $\begin{array}{l}1.123 \\
0.000 \\
0.000 \\
\end{array}$ & $\begin{array}{l}2.819 \\
2.217 \\
0.437 \\
\end{array}$ \\
\hline$J G M 3$ & \multicolumn{2}{|c|}{ Chubut } & $\min$ & $\max$ & mean & $\sigma$ \\
\hline $\mathrm{N}^{\mathrm{JGM} 3}-\mathrm{N}^{\mathrm{GPS}}$ & $\begin{array}{r}\text { Original (10 pts) } \\
\text { After } 3 \text { rms (10 pts) } \\
\text { After fit }\end{array}$ & $\begin{array}{l}\text { Before fit } \\
\text { Before fit } \\
\text { 4-param } \\
\text { 7-param }\end{array}$ & $\begin{array}{l}-1.644 \\
-0.872 \\
-0.644\end{array}$ & $\begin{array}{l}2.083 \\
0.812 \\
0.377\end{array}$ & $\begin{array}{l}-0.018 \\
0.000 \\
0.000\end{array}$ & $\begin{array}{l}1.237 \\
0.599 \\
0.291\end{array}$ \\
\hline
\end{tabular}


Appendix 4: Statistics of the differences between geoids derived from global geopotential models with GPS/leveling-derived geoid in Mendoza. Unit: [m]

\begin{tabular}{|c|c|c|c|c|c|c|}
\hline GPM98A & \multicolumn{2}{|c|}{ Mendoza } & $\min$ & $\max$ & mean & $\sigma$ \\
\hline $\mathrm{N}^{\mathrm{GPM} 98 \mathrm{~A}}-\mathrm{N}^{\mathrm{GPS}}$ & $\begin{array}{l}\text { Original (116 pts) } \\
\text { After } 3 \text { rms (115 pts) } \\
\text { After fit }\end{array}$ & $\begin{array}{l}\text { Before fit } \\
\text { Before fit } \\
4 \text {-param } \\
3^{\text {rd }} \text { pol } \\
7 \text {-param }\end{array}$ & $\begin{array}{l}-4.684 \\
-2.873 \\
-0.546 \\
-0.460 \\
-0.553 \\
\end{array}$ & $\begin{array}{l}1.142 \\
1.142 \\
1.424 \\
1.040 \\
1.026 \\
\end{array}$ & $\begin{array}{c}-0.739 \\
-0.704 \\
0.000 \\
0.000 \\
0.015 \\
\end{array}$ & $\begin{array}{l}0.955 \\
0.884 \\
0.259 \\
0.165 \\
0.177 \\
\end{array}$ \\
\hline GPM98B & \multicolumn{2}{|c|}{ Mendoza } & $\min$ & $\max$ & mean & $\sigma$ \\
\hline $\mathrm{N}^{\mathrm{GPM} 98 \mathrm{~B}}-\mathrm{N}^{\mathrm{GPS}}$ & $\begin{array}{c}\text { Original (116 pts) } \\
\text { After } 3 \text { rms (115 pts) } \\
\text { After fit }\end{array}$ & $\begin{array}{l}\text { Before fit } \\
\text { Before fit } \\
4 \text {-param } \\
3^{\text {rd }} \text { pol } \\
\text { 7-param } \\
\end{array}$ & $\begin{array}{l}-5.000 \\
-3.269 \\
-0.575 \\
-0.483 \\
-0.650 \\
\end{array}$ & $\begin{array}{l}1.116 \\
1.116 \\
1.426 \\
1.025 \\
1.015 \\
\end{array}$ & $\begin{array}{c}-0.764 \\
-0.727 \\
0.000 \\
0.000 \\
0.016 \\
\end{array}$ & $\begin{array}{l}0.986 \\
0.907 \\
0.261 \\
0.171 \\
0.186 \\
\end{array}$ \\
\hline GPM98CR & \multicolumn{2}{|c|}{ Mendoza } & $\min$ & $\max$ & mean & $\sigma$ \\
\hline $\mathrm{N}^{\mathrm{GPM} 98 \mathrm{CR}}-\mathrm{N}^{\mathrm{GPS}}$ & $\begin{array}{c}\text { Original (116 pts) } \\
\text { After } 3 \text { rms (116 pts) } \\
\text { After fit }\end{array}$ & $\begin{array}{l}\text { Before fit } \\
\text { Before fit } \\
\text { 4-param } \\
3^{\text {rd }} \text { pol } \\
\text { 7-param } \\
\end{array}$ & $\begin{array}{l}-2.497 \\
-1.689 \\
-1.493 \\
-1.639 \\
\end{array}$ & $\begin{array}{l}1.648 \\
1.051 \\
1.056 \\
\end{array}$ & $\begin{array}{c}-0.592 \\
0.000 \\
0.000 \\
-0.015 \\
\end{array}$ & $\begin{array}{l}0.354 \\
0.228 \\
0.248 \\
\end{array}$ \\
\hline EGM96 & \multicolumn{2}{|c|}{ Mendoza } & $\min$ & $\max$ & mean & $\sigma$ \\
\hline $\mathrm{N}^{\mathrm{EGM} 96}-\mathrm{N}^{\mathrm{GPS}}$ & $\begin{array}{c}\text { Original (116 pts) } \\
\text { After } 3 \text { rms (116 pts) } \\
\text { After fit }\end{array}$ & $\begin{array}{l}\text { Before fit } \\
\text { Before fit } \\
4 \text {-param } \\
3^{\text {rd }} \text { pol } \\
\text { 7-param } \\
\end{array}$ & $\begin{array}{l}-2.426 \\
-1.363 \\
-1.410 \\
-1.488 \\
\end{array}$ & $\begin{array}{l}0.977 \\
1.469 \\
1.082 \\
1.123 \\
\end{array}$ & $\begin{array}{c}-1.063 \\
0.000 \\
0.000 \\
-0.044 \\
\end{array}$ & $\begin{array}{l}0.584 \\
0.310 \\
0.234 \\
0.247 \\
\end{array}$ \\
\hline$E I G E N-C G 01 C$ & \multicolumn{2}{|c|}{ Mendoza } & $\min$ & $\max$ & mean & $\sigma$ \\
\hline $\mathrm{N}^{\text {EIGEN-CG01C }}-\mathrm{N}^{\mathrm{GPS}}$ & $\begin{array}{c}\text { Original (116 pts) } \\
\text { After } 3 \text { rms (115 pts) } \\
\text { After fit }\end{array}$ & $\begin{array}{l}\text { Before fit } \\
\text { Before fit } \\
4 \text {-param } \\
3^{\text {rd }} \text { pol } \\
7 \text {-param } \\
\end{array}$ & $\begin{array}{l}-1.120 \\
-1.120 \\
-1.412 \\
-1.415 \\
-1.510 \\
\end{array}$ & $\begin{array}{l}2.131 \\
1.190 \\
0.624 \\
0.654 \\
0.562 \\
\end{array}$ & $\begin{array}{c}0.402 \\
0.387 \\
0.000 \\
0.000 \\
-0.002 \\
\end{array}$ & $\begin{array}{l}0.376 \\
0.341 \\
0.247 \\
0.215 \\
0.224 \\
\end{array}$ \\
\hline OSU91A & \multicolumn{2}{|c|}{ Mendoza } & $\min$ & $\max$ & mean & $\sigma$ \\
\hline $\mathrm{N}^{\mathrm{OSU} 91 \mathrm{~A}}-\mathrm{N}^{\mathrm{GPS}}$ & $\begin{array}{l}\text { Original (116 pts) } \\
\text { After } 3 \text { rms (116 pts) } \\
\text { After fit }\end{array}$ & $\begin{array}{l}\text { Before fit } \\
\text { Before fit } \\
4 \text {-param } \\
3^{\text {rd }} \text { pol } \\
\text { 7-param } \\
\end{array}$ & $\begin{array}{r}-1.351 \\
-1.588 \\
-1.395 \\
-1.474 \\
\end{array}$ & $\begin{array}{l}4.751 \\
1.779 \\
1.112 \\
1.085 \\
\end{array}$ & $\begin{array}{l}1.006 \\
0.000 \\
0.000 \\
0.006 \\
\end{array}$ & $\begin{array}{l}1.524 \\
0.381 \\
0.237 \\
0.248 \\
\end{array}$ \\
\hline GPM2 & \multicolumn{2}{|c|}{ Mendoza } & $\min$ & $\max$ & mean & $\sigma$ \\
\hline $\mathrm{N}^{\mathrm{GPM} 2}-\mathrm{N}^{\mathrm{GPS}}$ & $\begin{array}{c}\text { Original (116 pts) } \\
\text { After } 3 \text { rms (116 pts) } \\
\text { After fit }\end{array}$ & $\begin{array}{l}\text { Before fit } \\
\text { Before fit } \\
4 \text {-param } \\
3^{\text {rd }} \text { pol } \\
7 \text {-param }\end{array}$ & $\begin{array}{r}-0.732 \\
-0.998 \\
-1.407 \\
-1.350 \\
\end{array}$ & $\begin{array}{l}9.285 \\
2.196 \\
1.082 \\
1.090 \\
\end{array}$ & $\begin{array}{r}6.114 \\
0.000 \\
0.000 \\
-0.019 \\
\end{array}$ & $\begin{array}{l}2.128 \\
0.445 \\
0.238 \\
0.241 \\
\end{array}$ \\
\hline OSU81 & \multicolumn{2}{|c|}{ Mendoza } & $\min$ & $\max$ & mean & $\sigma$ \\
\hline $\mathrm{N}^{\mathrm{OSU} 81}-\mathrm{N}^{\mathrm{GPS}}$ & $\begin{array}{c}\text { Original (116 pts) } \\
\text { After } 3 \text { rms (116 pts) } \\
\text { After fit }\end{array}$ & $\begin{array}{l}\text { Before fit } \\
\text { Before fit } \\
\text { 4-param } \\
3^{\text {rd }} \text { pol } \\
\text { 7-param } \\
\end{array}$ & $\begin{array}{r}-0.291 \\
-0.856 \\
-1.395 \\
-1.391 \\
\end{array}$ & $\begin{array}{l}8.567 \\
1.507 \\
1.100 \\
1.116 \\
\end{array}$ & $\begin{array}{r}0.000 \\
0.000 \\
-0.026 \\
\end{array}$ & $\begin{array}{l}0.361 \\
0.238 \\
0.241 \\
\end{array}$ \\
\hline JGM3 & \multicolumn{2}{|c|}{ Mendoza } & $\min$ & $\max$ & mean & $\sigma$ \\
\hline $\mathrm{N}^{\mathrm{JGM} 3}-\mathrm{N}^{\mathrm{GPS}}$ & $\begin{array}{c}\text { Original (116 pts) } \\
\text { After } 3 \text { rms (116 pts) } \\
\text { After fit }\end{array}$ & $\begin{array}{l}\text { Before fit } \\
\text { Before fit } \\
4 \text {-param } \\
3^{\text {rd }} \text { pol } \\
7 \text {-param }\end{array}$ & $\begin{array}{r}-3.430 \\
-1.904 \\
-1.388 \\
-1.482 \\
\end{array}$ & $\begin{array}{l}4.591 \\
1.899 \\
1.112 \\
1.035\end{array}$ & $\begin{array}{l}3.270 \\
0.000 \\
0.000 \\
0.071 \\
\end{array}$ & $\begin{array}{l}1.449 \\
0.471 \\
0.237 \\
0.241\end{array}$ \\
\hline
\end{tabular}


Appendix 5: Statistics of the differences between geoids derived from global geopotential models with GPS/leveling-derived geoid in Neuquén. . Unit: [m]

\begin{tabular}{|c|c|c|c|c|c|c|}
\hline GPM98A & \multicolumn{2}{|c|}{ Neuquén } & $\min$ & $\max$ & mean & $\sigma$ \\
\hline $\mathrm{N}^{\mathrm{GPM} 98 \mathrm{~A}}-\mathrm{N}^{\mathrm{GPS}}$ & $\begin{array}{l}\text { Original (45 pts) } \\
\text { After } 3 \text { rms (45 pts) } \\
\text { After fit }\end{array}$ & $\begin{array}{l}\text { Before fit } \\
\text { Before fit } \\
4 \text {-param } \\
3^{\text {rd }} \text { pol } \\
7 \text {-param }\end{array}$ & $\begin{array}{l}-1.687 \\
-1.320 \\
-1.000 \\
-0.932 \\
\end{array}$ & $\begin{array}{l}1.543 \\
0.771 \\
1.003 \\
\end{array}$ & $\begin{array}{l}0.000 \\
0.000 \\
0.000\end{array}$ & $\begin{array}{l}0.511 \\
0.359 \\
0.415\end{array}$ \\
\hline GPM98B & \multicolumn{2}{|c|}{ Neuquén } & $\min$ & $\max$ & mean & $\sigma$ \\
\hline $\mathrm{N}^{\mathrm{GPM} 98 \mathrm{~B}}-\mathrm{N}^{\mathrm{GPS}}$ & $\begin{array}{r}\text { Original (45 pts) } \\
\text { After } 3 \text { rms (45 pts) } \\
\text { After fit }\end{array}$ & $\begin{array}{l}\text { Before fit } \\
\text { Before fit } \\
4 \text {-param } \\
3^{\text {rd }} \text { pol } \\
\text { 7-param } \\
\end{array}$ & $\begin{array}{l}-1.645 \\
-2.833 \\
-2.132 \\
-0.929 \\
\end{array}$ & $\begin{array}{l}2.736 \\
2.139 \\
1.000 \\
\end{array}$ & $\begin{array}{l}0.000 \\
0.000 \\
0.000 \\
\end{array}$ & $\begin{array}{l}0.970 \\
0.882 \\
0.415 \\
\end{array}$ \\
\hline GPM98CR & \multicolumn{2}{|c|}{ Neuquén } & $\min$ & $\max$ & mean & $\sigma$ \\
\hline $\mathrm{N}^{\mathrm{GPM} 98 \mathrm{CR}}-\mathrm{N}^{\mathrm{GPS}}$ & $\begin{array}{r}\text { Original (45 pts) } \\
\text { After } 3 \text { rms (45 pts) } \\
\text { After fit }\end{array}$ & $\begin{array}{l}\text { Before fit } \\
\text { Before fit } \\
4 \text {-param } \\
3^{\text {rd }} \text { pol } \\
7 \text {-param }\end{array}$ & $\begin{array}{l}-0.947 \\
-1.430 \\
-1.154 \\
-1.261 \\
\end{array}$ & $\begin{array}{l}2.020 \\
1.432 \\
1.437 \\
0.760 \\
\end{array}$ & $\begin{array}{l}0.000 \\
0.000 \\
0.000 \\
\end{array}$ & $\begin{array}{l}0.560 \\
0.507 \\
0.439 \\
\end{array}$ \\
\hline$\overline{E G M 96}$ & \multicolumn{2}{|c|}{ Neuquén } & $\min$ & $\max$ & mean & $\sigma$ \\
\hline $\mathrm{N}^{\mathrm{EGM} 96}-\mathrm{N}^{\mathrm{GPS}}$ & $\begin{array}{r}\text { Original (45 pts) } \\
\text { After } 3 \text { rms (45 pts) } \\
\text { After fit }\end{array}$ & $\begin{array}{l}\text { Before fit } \\
\text { Before fit } \\
4 \text {-param } \\
3^{\text {rd }} \text { pol } \\
\text { 7-param } \\
\end{array}$ & $\begin{array}{r}-1.008 \\
-1.605 \\
-1.179 \\
-1.019 \\
\end{array}$ & $\begin{array}{l}1.880 \\
1.377 \\
1.306 \\
0.970 \\
\end{array}$ & $\begin{array}{l}0.000 \\
0.000 \\
0.000 \\
\end{array}$ & $\begin{array}{l}0.577 \\
0.575 \\
0.486 \\
0.429 \\
\end{array}$ \\
\hline$E I G E N-C G 01 C$ & \multicolumn{2}{|c|}{ Neuquén } & $\min$ & $\max$ & mean & $\sigma$ \\
\hline $\mathrm{N}^{\text {eigen-cg01c }}-\mathrm{N}^{\mathrm{GPS}}$ & $\begin{array}{l}\text { Original (45 pts) } \\
\text { After } 3 \text { rms (45 pts) } \\
\text { After fit }\end{array}$ & $\begin{array}{l}\text { Before fit } \\
\text { Before fit } \\
4 \text {-param } \\
3^{\text {rd }} \text { pol } \\
7 \text {-param } \\
\end{array}$ & $\begin{array}{l}-1.195 \\
-1.352 \\
-1.072 \\
-0.965 \\
\end{array}$ & $\begin{array}{l}1.391 \\
0.870 \\
0.791 \\
0.871 \\
\end{array}$ & $\begin{array}{l}0.000 \\
0.000 \\
0.000 \\
\end{array}$ & $\begin{array}{l}0.445 \\
0.396 \\
0.419 \\
\end{array}$ \\
\hline OSU91A & \multicolumn{2}{|c|}{ Neuquén } & $\min$ & $\max$ & mean & $\sigma$ \\
\hline $\mathrm{N}^{\mathrm{OSU} 91 \mathrm{~A}}-\mathrm{N}^{\mathrm{GPS}}$ & $\begin{array}{l}\text { Original (45 pts) } \\
\text { After } 3 \text { rms ( } 45 \text { pts) } \\
\text { After fit }\end{array}$ & $\begin{array}{l}\text { Before fit } \\
\text { Before fit } \\
4 \text {-param } \\
3^{\text {rd }} \text { pol } \\
7 \text {-param } \\
\end{array}$ & $\begin{array}{l}-2.009 \\
-1.636 \\
-1.655 \\
-1.904 \\
\end{array}$ & $\begin{array}{l}2.494 \\
1.994 \\
1.980 \\
1.756 \\
\end{array}$ & $\begin{array}{l}0.095 \\
0.000 \\
0.000 \\
0.000 \\
\end{array}$ & $\begin{array}{l}0.930 \\
0.779 \\
0.730 \\
0.659 \\
\end{array}$ \\
\hline GPM2 & \multicolumn{2}{|c|}{ Neuquén } & $\min$ & $\max$ & mean & $\sigma$ \\
\hline $\mathrm{N}^{\mathrm{GPM} 2}-\mathrm{N}^{\mathrm{GPS}}$ & $\begin{array}{r}\text { Original (45 pts) } \\
\text { After } 3 \text { rms ( } 45 \text { pts) } \\
\text { After fit }\end{array}$ & $\begin{array}{l}\text { Before fit } \\
\text { Before fit } \\
4 \text {-param } \\
3^{\text {rd }} \text { pol } \\
7 \text {-param }\end{array}$ & $\begin{array}{r}-1.669 \\
-1.922 \\
-1.956 \\
-1.539 \\
\end{array}$ & $\begin{array}{l}2.587 \\
2.298 \\
2.291 \\
1.334 \\
\end{array}$ & $\begin{array}{l}0.129 \\
0.000 \\
0.000 \\
0.000 \\
\end{array}$ & $\begin{array}{l}1.094 \\
0.972 \\
0.924 \\
0.710 \\
\end{array}$ \\
\hline OSU81 & \multicolumn{2}{|c|}{ Neuquén } & $\min$ & $\max$ & mean & $\sigma$ \\
\hline $\mathrm{N}^{\mathrm{OSU} 81}-\mathrm{N}^{\mathrm{GPS}}$ & $\begin{array}{l}\text { Original (45 pts) } \\
\text { After } 3 \text { rms (45 pts) } \\
\text { After fit }\end{array}$ & $\begin{array}{l}\text { Before fit } \\
\text { Before fit } \\
\text { 4-param } \\
3^{\text {rd }} \text { pol } \\
7 \text {-param } \\
\end{array}$ & $\begin{array}{l}-1.372 \\
-2.133 \\
-2.095 \\
-1.375 \\
\end{array}$ & $\begin{array}{l}3.084 \\
2.431 \\
2.581 \\
1.311 \\
\end{array}$ & $\begin{array}{l}0.000 \\
0.000 \\
0.000 \\
\end{array}$ & $\begin{array}{l}1.065 \\
1.025 \\
0.767 \\
\end{array}$ \\
\hline$J G M 3$ & \multicolumn{2}{|c|}{ Neuquén } & $\min$ & $\max$ & mean & $\sigma$ \\
\hline $\mathrm{N}^{\mathrm{JGM} 3}-\mathrm{N}^{\mathrm{GPS}}$ & $\begin{array}{r}\text { Original (45 pts) } \\
\text { After } 3 \text { rms (45 pts) } \\
\text { After fit }\end{array}$ & $\begin{array}{l}\text { Before fit } \\
\text { Before fit } \\
4 \text {-param } \\
3^{\text {rd }} \text { pol } \\
7 \text {-param }\end{array}$ & $\begin{array}{l}-2.851 \\
-3.182 \\
-2.339 \\
-1.094 \\
\end{array}$ & $\begin{array}{l}2.625 \\
1.925 \\
1.959 \\
0.805 \\
\end{array}$ & $\begin{array}{l}0.616 \\
0.000 \\
0.000 \\
0.000\end{array}$ & $\begin{array}{l}1.152 \\
1.152 \\
1.022 \\
0.383 \\
\end{array}$ \\
\hline
\end{tabular}


Appendix 6: Statistics of the differences between geoids derived from global geopotential models with GPS/leveling-derived geoid in Santa Fe. Unit: [m]

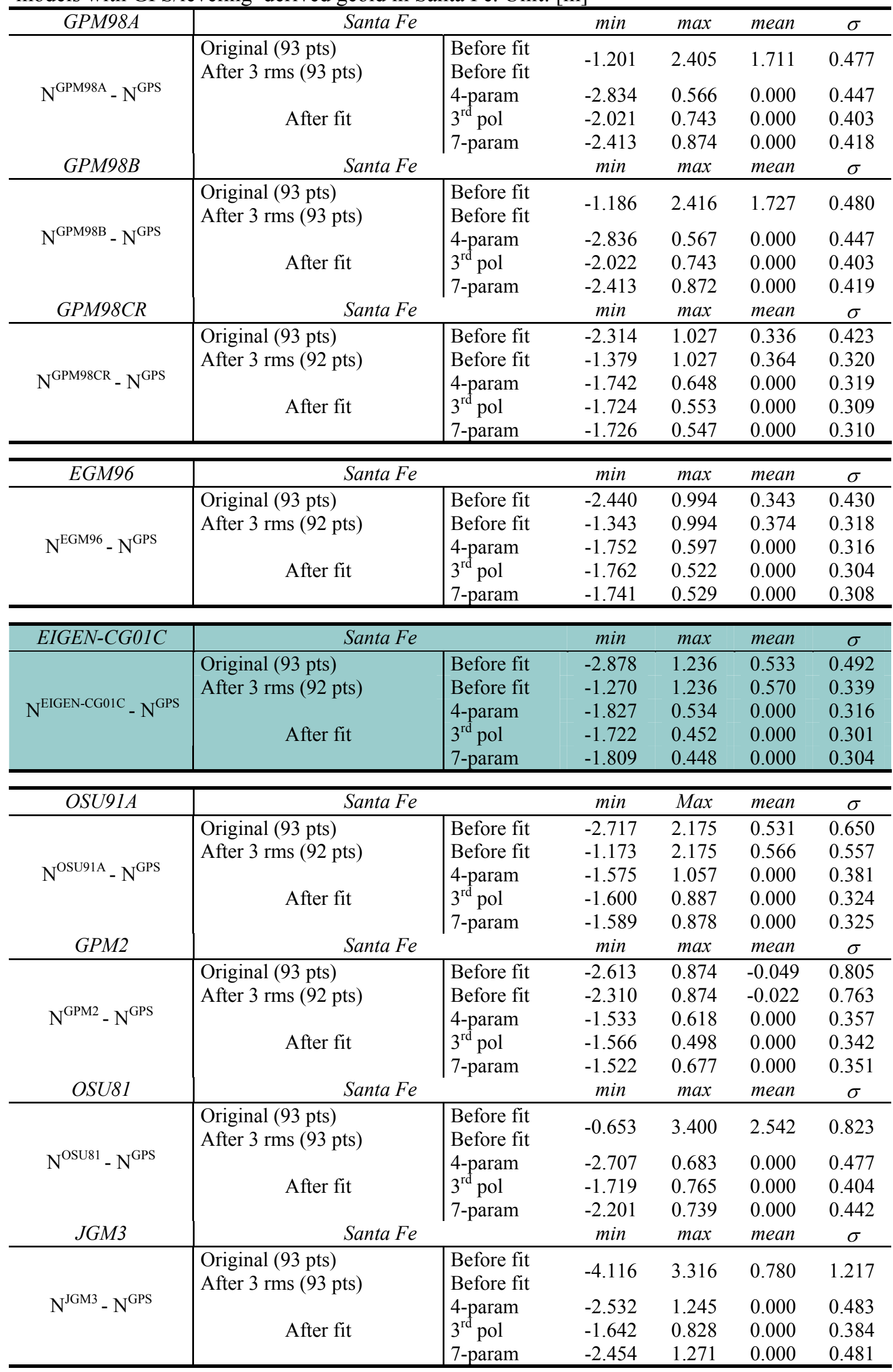


Appendix 7: Statistics of the differences between geoids derived from global geopotential models with GPS/leveling-derived geoid in Uruguay. Unit: [m]

\begin{tabular}{|c|c|c|c|c|c|c|}
\hline GPM98A & \multicolumn{2}{|c|}{ Uruguay } & $\min$ & $\max$ & mean & $\sigma$ \\
\hline $\mathrm{N}^{\mathrm{GPM} 98 \mathrm{~A}}-\mathrm{N}^{\mathrm{GPS}}$ & $\begin{array}{r}\text { Original (28 pts) } \\
\text { After } 3 \text { rms (28 pts) } \\
\text { After fit }\end{array}$ & $\begin{array}{l}\text { Before fit } \\
\text { Before fit } \\
\text { 4-param } \\
3^{\text {rd }} \text { pol } \\
\text { 7-param } \\
\end{array}$ & $\begin{array}{l}-0.819 \\
-0.922 \\
-1.024 \\
\end{array}$ & $\begin{array}{r}-0.963 \\
0.865 \\
0.878 \\
\end{array}$ & $\begin{array}{l}0.000 \\
0.000 \\
0.000 \\
\end{array}$ & $\begin{array}{l}0.468 \\
0.380 \\
0.401 \\
\end{array}$ \\
\hline$G P M 98 B$ & \multicolumn{2}{|c|}{ Uruguay } & $\min$ & $\max$ & mean & $\sigma$ \\
\hline $\mathrm{N}^{\mathrm{GPM} 98 \mathrm{~B}}-\mathrm{N}^{\mathrm{GPS}}$ & $\begin{array}{r}\text { Original (28 pts) } \\
\text { After } 3 \mathrm{rms}(28 \mathrm{pts}) \\
\text { After fit }\end{array}$ & $\begin{array}{l}\text { Before fit } \\
\text { Before fit } \\
\text { 4-param } \\
3^{\text {rd }} \text { pol } \\
\text { 7-param } \\
\end{array}$ & $\begin{array}{r}0.075 \\
-0.813 \\
-0.922 \\
-1.019 \\
\end{array}$ & $\begin{array}{l}0.966 \\
0.865 \\
0.875 \\
\end{array}$ & $\begin{array}{l}0.000 \\
0.000 \\
0.000 \\
\end{array}$ & $\begin{array}{l}0.468 \\
0.330 \\
0.401 \\
\end{array}$ \\
\hline GPM98CR & \multicolumn{2}{|c|}{ Uruguay } & $\min$ & $\max$ & mean & $\sigma$ \\
\hline $\mathrm{N}^{\mathrm{GPM} 98 \mathrm{CR}}-\mathrm{N}^{\mathrm{GPS}}$ & $\begin{array}{r}\text { Original (28 pts) } \\
\text { After } 3 \text { rms (28 pts) } \\
\text { After fit }\end{array}$ & $\begin{array}{l}\text { Before fit } \\
\text { Before fit } \\
\text { 4-param } \\
3^{\text {rd }} \text { pol } \\
\text { 7-param } \\
\end{array}$ & $\begin{array}{l}-0.283 \\
-0.754 \\
-0.961 \\
-0.891 \\
\end{array}$ & $\begin{array}{l}1.023 \\
0.896 \\
0.987 \\
\end{array}$ & $\begin{array}{l}0.000 \\
0.000 \\
0.000 \\
\end{array}$ & $\begin{array}{l}0.442 \\
0.390 \\
0.398 \\
\end{array}$ \\
\hline EGM96 & \multicolumn{2}{|c|}{ Uruguay } & $\min$ & $\max$ & mean & $\sigma$ \\
\hline $\mathrm{N}^{\mathrm{EGM} 96}-\mathrm{N}^{\mathrm{GPS}}$ & $\begin{array}{r}\text { Original (28 pts) } \\
\text { After } 3 \text { rms ( } 28 \text { pts }) \\
\text { After fit }\end{array}$ & $\begin{array}{l}\text { Before fit } \\
\text { Before fit } \\
4 \text {-param } \\
3^{\text {rd }} \text { pol } \\
\text { 7-param } \\
\end{array}$ & $\begin{array}{r}-0.420 \\
-0.919 \\
-1.089 \\
-1.125 \\
\end{array}$ & $\begin{array}{l}1.171 \\
1.055 \\
1.059 \\
\end{array}$ & $\begin{array}{l}0.000 \\
0.000 \\
0.000 \\
\end{array}$ & $\begin{array}{l}0.497 \\
0.442 \\
0.443 \\
\end{array}$ \\
\hline EIGEN-CG01C & \multicolumn{2}{|c|}{ Uruguay } & $\min$ & $\max$ & mean & $\sigma$ \\
\hline $\mathrm{N}^{\mathrm{EIGEN}-\mathrm{CG} 01 \mathrm{C}}-\mathrm{N}^{\mathrm{GPS}}$ & $\begin{array}{r}\text { Original (28 pts) } \\
\text { After } 3 \text { rms ( } 28 \text { pts }) \\
\text { After fit }\end{array}$ & $\begin{array}{l}\text { Before fit } \\
\text { Before fit } \\
\text { 4-param } \\
3^{\text {rd }} \text { pol } \\
\text { 7-param } \\
\end{array}$ & $\begin{array}{l}-0.625 \\
-2.188 \\
-1.679 \\
-1.114 \\
\end{array}$ & $\begin{array}{l}1.203 \\
1.059 \\
1.170 \\
\end{array}$ & $\begin{array}{l}0.000 \\
0.000 \\
0.000 \\
\end{array}$ & $\begin{array}{l}0.475 \\
0.442 \\
0.449 \\
\end{array}$ \\
\hline OSU91A & \multicolumn{2}{|c|}{ Uruguay } & $\min$ & $\operatorname{Max}$ & mean & $\sigma$ \\
\hline $\mathrm{N}^{\mathrm{OSU} 91 \mathrm{~A}}-\mathrm{N}^{\mathrm{GPS}}$ & $\begin{array}{r}\text { Original (28 pts) } \\
\text { After } 3 \text { rms (28 pts) } \\
\text { After fit }\end{array}$ & $\begin{array}{l}\text { Before fit } \\
\text { Before fit } \\
\text { 4-param } \\
3^{\text {rd }} \text { pol } \\
\text { 7-param } \\
\end{array}$ & $\begin{array}{l}-0.519 \\
-0.899 \\
-1.063 \\
-1.154 \\
\end{array}$ & $\begin{array}{l}1.816 \\
0.903 \\
0.997 \\
1.004 \\
\end{array}$ & $\begin{array}{l}0.960 \\
0.000 \\
0.000 \\
0.000 \\
\end{array}$ & $\begin{array}{l}0.635 \\
0.534 \\
0.427 \\
0.441 \\
\end{array}$ \\
\hline GPM2 & \multicolumn{2}{|c|}{ Uruguay } & $\min$ & $\operatorname{Max}$ & mean & $\sigma$ \\
\hline $\mathrm{N}^{\mathrm{GPM} 2}-\mathrm{N}^{\mathrm{GPS}}$ & $\begin{array}{r}\text { Original (28 pts) } \\
\text { After } 3 \text { rms ( } 28 \text { pts }) \\
\text { After fit }\end{array}$ & $\begin{array}{l}\text { Before fit } \\
\text { Before fit } \\
\text { 4-param } \\
3^{\text {rd }} \text { pol } \\
\text { 7-param } \\
\end{array}$ & $\begin{array}{l}-1.316 \\
-1.162 \\
-1.061 \\
-1.165 \\
\end{array}$ & $\begin{array}{l}1.083 \\
1.379 \\
1.196 \\
1.288 \\
\end{array}$ & $\begin{array}{l}-0.059 \\
0.000 \\
0.000 \\
0.000 \\
\end{array}$ & $\begin{array}{l}0.618 \\
0.486 \\
0.450 \\
0.481 \\
\end{array}$ \\
\hline OSU81 & \multicolumn{2}{|c|}{\begin{tabular}{|r|} 
Uruguay \\
\end{tabular}} & $\min$ & $\max$ & mean & $\sigma$ \\
\hline $\mathrm{N}^{\mathrm{OSU} 81}-\mathrm{N}^{\mathrm{GPS}}$ & $\begin{array}{r}\text { Original (28 pts) } \\
\text { After } 3 \text { rms ( } 28 \text { pts) } \\
\text { After fit }\end{array}$ & $\begin{array}{l}\text { Before fit } \\
\text { Before fit } \\
4 \text {-param } \\
3^{\text {rd }} \text { pol } \\
\text { 7-param } \\
\end{array}$ & $\begin{array}{l}-0.560 \\
-0.848 \\
-1.025 \\
-1.040 \\
\end{array}$ & $\begin{array}{l}2.128 \\
1.674 \\
1.163 \\
1.279 \\
\end{array}$ & $\begin{array}{l}1.255 \\
0.000 \\
0.000 \\
0.000 \\
\end{array}$ & $\begin{array}{l}0.748 \\
0.569 \\
0.443 \\
0.535 \\
\end{array}$ \\
\hline$J G M 3$ & \multicolumn{2}{|c|}{\begin{tabular}{|l} 
Uruguay \\
\end{tabular}} & $\min$ & $\max$ & mean & $\sigma$ \\
\hline $\mathrm{N}^{\mathrm{JGM} 3}-\mathrm{N}^{\mathrm{GPS}}$ & $\begin{array}{r}\text { Original (28 pts) } \\
\text { After } 3 \text { rms (28 pts) } \\
\text { After fit }\end{array}$ & $\begin{array}{l}\text { Before fit } \\
\text { Before fit } \\
\text { 4-param } \\
3^{\text {rd }} \text { pol } \\
\text { 7-param } \\
\end{array}$ & $\begin{array}{l}-0.860 \\
-1.413 \\
-0.953 \\
-1.085 \\
\end{array}$ & $\begin{array}{l}2.039 \\
0.827 \\
1.027 \\
1.054 \\
\end{array}$ & $\begin{array}{l}0.752 \\
0.000 \\
0.000 \\
0.000 \\
\end{array}$ & $\begin{array}{l}0.677 \\
0.593 \\
0.437 \\
\end{array}$ \\
\hline
\end{tabular}


Appendix 8: Statistics of the differences between geoids derived from global geopotential models with GPS/leveling-derived geoid in Tierra del Fuego. Unit: [m]

\begin{tabular}{|c|c|c|c|c|c|c|}
\hline GPM98A & \multicolumn{2}{|c|}{ Tierra del Fuego } & $\frac{\min }{-1.200}$ & & $\begin{array}{l}\text { mean } \\
-0.251\end{array}$ & \multirow[b]{2}{*}{$\begin{array}{c}\sigma \\
0.561 \\
0.239 \\
0.148 \\
0.173 \\
\end{array}$} \\
\hline $\mathrm{N}^{\mathrm{GPM} 98 \mathrm{~A}}-\mathrm{N}^{\mathrm{GPS}}$ & $\begin{array}{r}\text { Original (56 pts) } \\
\text { After } 3 \text { rms (56 pts) } \\
\text { After fit }\end{array}$ & $\begin{array}{l}\text { Before fit } \\
\text { Before fit } \\
4 \text {-param } \\
3^{\text {rd }} \text { pol } \\
7 \text {-param } \\
\end{array}$ & $\begin{array}{l}-1.200 \\
-0.484 \\
-0.397 \\
-0.585 \\
\end{array}$ & $\begin{array}{l}0.473 \\
0.364 \\
0.296 \\
\end{array}$ & $\begin{array}{r}0.000 \\
0.000 \\
-0.001 \\
\end{array}$ & \\
\hline GPM98B & \multicolumn{2}{|c|}{ Tierra del Fuego } & $\min$ & $\max$ & mean & $\sigma$ \\
\hline $\mathrm{N}^{\mathrm{GPM} 98 \mathrm{~B}}-\mathrm{N}^{\mathrm{GPS}}$ & $\begin{array}{r}\text { Original (56 pts) } \\
\text { After } 3 \text { rms (56 pts) } \\
\text { After fit }\end{array}$ & \begin{tabular}{|l} 
Before fit \\
Before fit \\
4 -param \\
$3^{\text {rd }}$ pol \\
7-param \\
\end{tabular} & $\begin{array}{l}-1.151 \\
-0.481 \\
-0.392 \\
-0.578 \\
\end{array}$ & $\begin{array}{l}0.626 \\
0.475 \\
0.364 \\
0.295 \\
\end{array}$ & $\begin{array}{r}0.000 \\
0.000 \\
-0.001 \\
\end{array}$ & $\begin{array}{l}0.241 \\
0.147 \\
0.172 \\
\end{array}$ \\
\hline GPM98CR & \multicolumn{2}{|c|}{ Tierra del Fuego } & $\min$ & $\max$ & mean & $\sigma$ \\
\hline $\mathrm{N}^{\mathrm{GPM} 98 \mathrm{CR}}-\mathrm{N}^{\mathrm{GPS}}$ & $\begin{array}{r}\text { Original (56 pts) } \\
\text { After } 3 \text { rms (56 pts) } \\
\text { After fit }\end{array}$ & \begin{tabular}{|l} 
Before fit \\
Before fit \\
4 -param \\
$3^{\text {rd }}$ pol \\
7-param \\
\end{tabular} & $\begin{array}{l}-0.510 \\
-0.515 \\
-0.398 \\
-0.635 \\
\end{array}$ & $\begin{array}{l}1.045 \\
0.532 \\
0.395 \\
0.320 \\
\end{array}$ & $\begin{array}{l}0.244 \\
0.000 \\
0.000 \\
0.000 \\
\end{array}$ & $\begin{array}{l}0.476 \\
0.258 \\
0.156 \\
0.189 \\
\end{array}$ \\
\hline EGM96 & \multicolumn{2}{|c|}{ Tierra del Fuego } & $\min$ & $\max$ & mean & $\sigma$ \\
\hline $\mathrm{N}^{\mathrm{EGM} 96}-\mathrm{N}^{\mathrm{GPS}}$ & $\begin{array}{r}\text { Original (56 pts) } \\
\text { After } 3 \text { rms (56 pts) } \\
\text { After fit }\end{array}$ & $\begin{array}{l}\text { Before fit } \\
\text { Before fit } \\
4 \text {-param } \\
3^{\text {rd }} \text { pol } \\
\text { 7-param } \\
\end{array}$ & $\begin{array}{l}-0.367 \\
-0.350 \\
-0.210 \\
-0.398 \\
\end{array}$ & $\begin{array}{l}0.724 \\
0.382 \\
0.334 \\
0.257 \\
\end{array}$ & $\begin{array}{r}0.000 \\
0.000 \\
-0.001 \\
\end{array}$ & $\begin{array}{l}0.301 \\
0.162 \\
0.103 \\
0.142 \\
\end{array}$ \\
\hline EIGEN-CG01C & \multicolumn{2}{|c|}{ Tierra del Fuego } & $\min$ & $\max$ & mean & $\sigma$ \\
\hline $\mathrm{N}^{\mathrm{EIGEN}-\mathrm{CG} 01 \mathrm{C}}-\mathrm{N}^{\mathrm{GPS}}$ & $\begin{array}{r}\text { Original (56 pts) } \\
\text { After } 3 \text { rms (56 pts) } \\
\text { After fit }\end{array}$ & $\begin{array}{l}\text { Before fit } \\
\text { Before fit } \\
4 \text {-param } \\
3^{\text {rd }} \text { pol } \\
\text { 7-param } \\
\end{array}$ & $\begin{array}{c}-0.339 \\
-0.395 \\
0.214 \\
-0.410 \\
\end{array}$ & $\begin{array}{l}0.493 \\
0.395 \\
0.334 \\
0.255 \\
\end{array}$ & $\begin{array}{l}0.000 \\
0.000 \\
0.000 \\
\end{array}$ & $\begin{array}{l}0.171 \\
0.109 \\
0.147 \\
\end{array}$ \\
\hline OSU91A & \multicolumn{2}{|c|}{ Tierra del Fuego } & $\min$ & $\operatorname{Max}$ & mean & $\sigma$ \\
\hline $\mathrm{N}^{\mathrm{OSU} 91 \mathrm{~A}}-\mathrm{N}^{\mathrm{GPS}}$ & $\begin{array}{r}\text { Original (56 pts) } \\
\text { After } 3 \text { rms ( } 56 \text { pts) } \\
\text { After fit }\end{array}$ & $\begin{array}{l}\text { Before fit } \\
\text { Before fit } \\
4 \text {-param } \\
3^{\text {rd }} \text { pol } \\
7 \text {-param } \\
\end{array}$ & $\begin{array}{l}-0.175 \\
-0.311 \\
-0.230 \\
-0.287 \\
\end{array}$ & $\begin{array}{l}0.872 \\
0.261 \\
0.321 \\
0.229 \\
\end{array}$ & $\begin{array}{r}0.546 \\
0.000 \\
0.000 \\
-0.001 \\
\end{array}$ & $\begin{array}{l}0.209 \\
0.135 \\
0.091 \\
0.119 \\
\end{array}$ \\
\hline GPM2 & \multicolumn{2}{|c|}{ Tierra del Fuego } & $\min$ & $\operatorname{Max}$ & mean & $\sigma$ \\
\hline $\mathrm{N}^{\mathrm{GPM} 2}-\mathrm{N}^{\mathrm{GPS}}$ & $\begin{array}{r}\text { Original (56 pts) } \\
\text { After } 3 \text { rms (56 pts) } \\
\text { After fit }\end{array}$ & $\begin{array}{l}\text { Before fit } \\
\text { Before fit } \\
4 \text {-param } \\
3^{\text {rd }} \text { pol } \\
\text { 7-param } \\
\end{array}$ & $\begin{array}{l}-1.089 \\
-0.482 \\
-0.251 \\
-0.346 \\
\end{array}$ & $\begin{array}{l}0.347 \\
0.514 \\
0.342 \\
0.365 \\
\end{array}$ & $\begin{array}{l}-0.510 \\
0.000 \\
0.000 \\
0.000 \\
\end{array}$ & $\begin{array}{l}0.305 \\
0.190 \\
0.118 \\
0.159 \\
\end{array}$ \\
\hline OSU81 & \multicolumn{2}{|c|}{ Tierra del Fuego } & $\min$ & $\max$ & mean & $\sigma$ \\
\hline $\mathrm{N}^{\mathrm{OSU} 81}-\mathrm{N}^{\mathrm{GPS}}$ & $\begin{array}{r}\text { Original (56 pts) } \\
\text { After } 3 \text { rms (56 pts) } \\
\text { After fit }\end{array}$ & $\begin{array}{l}\text { Before fit } \\
\text { Before fit } \\
4 \text {-param } \\
3^{\text {rd }} \text { pol } \\
\text { 7-param } \\
\end{array}$ & $\begin{array}{l}-0.744 \\
-0.581 \\
-0.247 \\
-0.350 \\
\end{array}$ & $\begin{array}{l}1.478 \\
0.714 \\
0.350 \\
0.251 \\
\end{array}$ & $\begin{array}{l}0.219 \\
0.000 \\
0.000 \\
0.000 \\
\end{array}$ & $\begin{array}{l}0.502 \\
0.207 \\
0.120 \\
0.144 \\
\end{array}$ \\
\hline JGM3 & \multicolumn{2}{|c|}{ Tierra del Fuego } & $\min$ & $\max$ & mean & $\sigma$ \\
\hline $\mathrm{N}^{\mathrm{JGM} 3}-\mathrm{N}^{\mathrm{GPS}}$ & $\begin{array}{r}\text { Original (56 pts) } \\
\text { After } 3 \text { rms (56 pts) } \\
\text { After fit }\end{array}$ & \begin{tabular}{|l} 
Before fit \\
Before fit \\
4 -param \\
$3^{\text {rd }}$ pol \\
7-param \\
\end{tabular} & $\begin{array}{r}-1.196 \\
-0.518 \\
-0.307 \\
-0.427 \\
\end{array}$ & $\begin{array}{l}0.838 \\
0.540 \\
0.353 \\
0.271 \\
\end{array}$ & $\begin{array}{l}0.054 \\
0.000 \\
0.000 \\
0.000 \\
\end{array}$ & $\begin{array}{l}0.544 \\
0.288 \\
0.140 \\
0.170 \\
\end{array}$ \\
\hline
\end{tabular}


Appendix 9: Statistics of the differences between geoids derived from global geopotential models with GPS/leveling-derived geoid in Points of the POSGAR94 network. Unit: [m]

\begin{tabular}{|c|c|c|c|c|c|c|}
\hline GPM98A & \multicolumn{2}{|c|}{ Red Posgar } & $\min$ & $\max$ & mean & $\sigma$ \\
\hline $\mathrm{N}^{\mathrm{GPM} 98 \mathrm{~A}}-\mathrm{N}^{\mathrm{GPS}}$ & $\begin{array}{l}\text { Original (24 pts) } \\
\text { After } 3 \text { rms ( } 24 \text { pts) } \\
\text { After fit }\end{array}$ & $\begin{array}{l}\text { Before fit } \\
\text { Before fit } \\
4 \text {-param } \\
3^{\text {rd }} \text { pol } \\
7 \text {-param }\end{array}$ & $\begin{array}{l}-4.528 \\
-2.190 \\
-1.729 \\
-1.846 \\
\end{array}$ & $\begin{array}{l}2.566 \\
2.051 \\
1.028 \\
1.029 \\
\end{array}$ & $\begin{array}{l}0.000 \\
0.000 \\
0.000\end{array}$ & $\begin{array}{l}1.144 \\
0.754 \\
0.801 \\
\end{array}$ \\
\hline GPM98B & \multicolumn{2}{|c|}{ Red Posgar } & $\min$ & $\max$ & mean & $\sigma$ \\
\hline $\mathrm{N}^{\mathrm{GPM} 98 \mathrm{~B}}-\mathrm{N}^{\mathrm{GPS}}$ & $\begin{array}{r}\text { Original (24 pts) } \\
\text { After } 3 \text { rms ( } 24 \text { pts) } \\
\text { After fit }\end{array}$ & $\begin{array}{l}\text { Before fit } \\
\text { Before fit } \\
4 \text {-param } \\
3^{\text {rd }} \text { pol } \\
7 \text {-param } \\
\end{array}$ & $\begin{array}{l}-4.640 \\
-1.752 \\
-1.845 \\
-2.211 \\
\end{array}$ & $\begin{array}{l}1.034 \\
1.020 \\
2.060 \\
\end{array}$ & $\begin{array}{l}0.000 \\
0.000 \\
0.000 \\
\end{array}$ & $\begin{array}{l}0.755 \\
0.802 \\
1.153 \\
\end{array}$ \\
\hline GPM98CR & \multicolumn{2}{|c|}{ Red Posgar } & & $\max$ & mean & $\sigma$ \\
\hline $\mathrm{N}^{\mathrm{GPM} 98 \mathrm{CR}}-\mathrm{N}^{\mathrm{GPS}}$ & $\begin{array}{r}\text { Original (24 pts) } \\
\text { After } 3 \text { rms ( } 24 \text { pts) } \\
\text { After fit }\end{array}$ & $\begin{array}{l}\text { Before fit } \\
\text { Before fit } \\
4 \text {-param } \\
3^{\text {rd }} \text { pol } \\
\text { 7-param }\end{array}$ & $\begin{array}{l}-2.799 \\
-2.570 \\
-1.868 \\
-2.029 \\
\end{array}$ & $\begin{array}{l}1.366 \\
1.525 \\
1.449 \\
\end{array}$ & $\begin{array}{l}-0.294 \\
0.000 \\
0.000 \\
0.000 \\
\end{array}$ & $\begin{array}{l}0.893 \\
0.755 \\
0.806 \\
\end{array}$ \\
\hline EGM96 & \multicolumn{2}{|c|}{ Red Posgar } & $\min$ & $\max$ & mean & $\sigma$ \\
\hline $\mathrm{N}^{\mathrm{EGM} 96}-\mathrm{N}^{\mathrm{GPS}}$ & $\begin{array}{r}\text { Original (24 pts) } \\
\text { After } 3 \text { rms ( } 24 \text { pts) } \\
\text { After fit }\end{array}$ & $\begin{array}{l}\text { Before fit } \\
\text { Before fit } \\
4 \text {-param } \\
3^{\text {rd }} \text { pol } \\
\text { 7-param } \\
\end{array}$ & $\begin{array}{l}-2.598 \\
-2.496 \\
-1.807 \\
-1.910 \\
\end{array}$ & $\begin{array}{l}1.608 \\
1.435 \\
1.361 \\
1.321 \\
\end{array}$ & $\begin{array}{l}-0.275 \\
0.000 \\
0.000 \\
0.000 \\
\end{array}$ & $\begin{array}{l}1.022 \\
0.819 \\
0.701 \\
0.726 \\
\end{array}$ \\
\hline EIGEN-CG01C & \multicolumn{2}{|c|}{ Red Posgar } & $\min$ & $\max$ & mean & $\sigma$ \\
\hline $\mathrm{N}^{\mathrm{EIGEN}-\mathrm{CG} 01 \mathrm{C}}-\mathrm{N}^{\mathrm{GPS}}$ & $\begin{array}{l}\text { Original (24 pts) } \\
\text { After } 3 \text { rms ( } 24 \text { pts) } \\
\text { After fit }\end{array}$ & $\begin{array}{l}\text { Before fit } \\
\text { Before fit } \\
4 \text {-param } \\
3^{\text {rd }} \text { pol } \\
7 \text {-param }\end{array}$ & $\begin{array}{l}-2.191 \\
-2.188 \\
-1.679 \\
-1.674 \\
\end{array}$ & $\begin{array}{l}1.604 \\
1.512 \\
1.435 \\
0.998 \\
\end{array}$ & $\begin{array}{l}-0.144 \\
0.000 \\
0.000 \\
0.000 \\
\end{array}$ & $\begin{array}{l}0.941 \\
0.809 \\
0.726 \\
0.729 \\
\end{array}$ \\
\hline OSU91A & \multicolumn{2}{|c|}{ Red Posgar } & $\min$ & $\max$ & mean & $\sigma$ \\
\hline $\mathrm{N}^{\mathrm{OSU} 91 \mathrm{~A}}-\mathrm{N}^{\mathrm{GPS}}$ & $\begin{array}{r}\text { Original (24 pts) } \\
\text { After } 3 \text { rms (23 pts) } \\
\text { After fit }\end{array}$ & $\begin{array}{l}\text { Before fit } \\
\text { Before fit } \\
4 \text {-param } \\
3^{\text {rd }} \text { pol } \\
7 \text {-param } \\
\end{array}$ & $\begin{array}{l}-7.817 \\
-5.961 \\
-2.868 \\
-1.564 \\
-1.967 \\
\end{array}$ & $\begin{array}{l}1.497 \\
1.497 \\
1.700 \\
1.515 \\
1.442 \\
\end{array}$ & $\begin{array}{c}-0.647 \\
-0.335 \\
0.000 \\
0.000 \\
0.000 \\
\end{array}$ & $\begin{array}{l}2.310 \\
1.773 \\
1.223 \\
0.719 \\
0.904 \\
\end{array}$ \\
\hline GPM2 & \multicolumn{2}{|c|}{ Red Posgar } & $\min$ & $\max$ & mean & $\sigma$ \\
\hline $\mathrm{N}^{\mathrm{GPM} 2}-\mathrm{N}^{\mathrm{GPS}}$ & $\begin{array}{l}\text { Original (24 pts) } \\
\text { After } 3 \text { rms (24 pts) } \\
\text { After fit }\end{array}$ & $\begin{array}{l}\text { Before fit } \\
\text { Before fit } \\
4 \text {-param } \\
3^{\text {rd }} \text { pol } \\
\text { 7-param }\end{array}$ & $\begin{array}{l}-7.582 \\
-2.565 \\
-2.860 \\
-2.700 \\
\end{array}$ & $\begin{array}{l}0.767 \\
2.783 \\
2.894 \\
3.023 \\
\end{array}$ & $\begin{array}{c}-1.564 \\
0.000 \\
0.000 \\
0.000 \\
\end{array}$ & $\begin{array}{l}2.149 \\
1.348 \\
1.194 \\
1.212 \\
\end{array}$ \\
\hline OSU81 & \multicolumn{2}{|c|}{ Red Posgar } & $\min$ & $\max$ & mean & $\sigma$ \\
\hline $\mathrm{N}^{\mathrm{OSU} 81}-\mathrm{N}^{\mathrm{GPS}}$ & $\begin{array}{r}\text { Original (24 pts) } \\
\text { After } 3 \text { rms ( } 24 \text { pts) } \\
\text { After fit }\end{array}$ & $\begin{array}{l}\text { Before fit } \\
\text { Before fit } \\
4 \text {-param } \\
3^{\text {rd }} \text { pol } \\
\text { 7-param }\end{array}$ & $\begin{array}{l}-3.483 \\
-2.353 \\
-2.094 \\
-2.480 \\
\end{array}$ & $\begin{array}{l}3.154 \\
1.836 \\
1.868 \\
2.013 \\
\end{array}$ & $\begin{array}{l}0.599 \\
0.000 \\
0.000 \\
0.000 \\
\end{array}$ & $\begin{array}{l}1.937 \\
1.186 \\
1.023 \\
1.112 \\
\end{array}$ \\
\hline$J G M 3$ & \multicolumn{2}{|c|}{ Red Posgar } & $\min$ & $\max$ & mean & $\sigma$ \\
\hline $\mathrm{N}^{\mathrm{JGM} 3}-\mathrm{N}^{\mathrm{GPS}}$ & $\begin{array}{r}\text { Original (24 pts) } \\
\text { After } 3 \text { rms ( } 23 \text { pts }) \\
\text { After fit }\end{array}$ & $\begin{array}{l}\text { Before fit } \\
\text { Before fit } \\
\text { 4-param } \\
3^{\text {rd }} \text { pol } \\
\text { 7-param }\end{array}$ & $\begin{array}{l}-9.583 \\
-4.301 \\
-4.359 \\
-3.242 \\
-4.327\end{array}$ & $\begin{array}{l}2.757 \\
2.757 \\
2.972 \\
3.125 \\
1.961\end{array}$ & $\begin{array}{l}-0.302 \\
0.101 \\
0.000 \\
0.000 \\
0.000\end{array}$ & $\begin{array}{l}2.696 \\
1.874 \\
1.755 \\
1.319 \\
1.504\end{array}$ \\
\hline
\end{tabular}


Appendix 10: Differences between EGM96 and EIGEN_CG01C geoid undulations with GPS/levelling-derived geoid. (after fit).

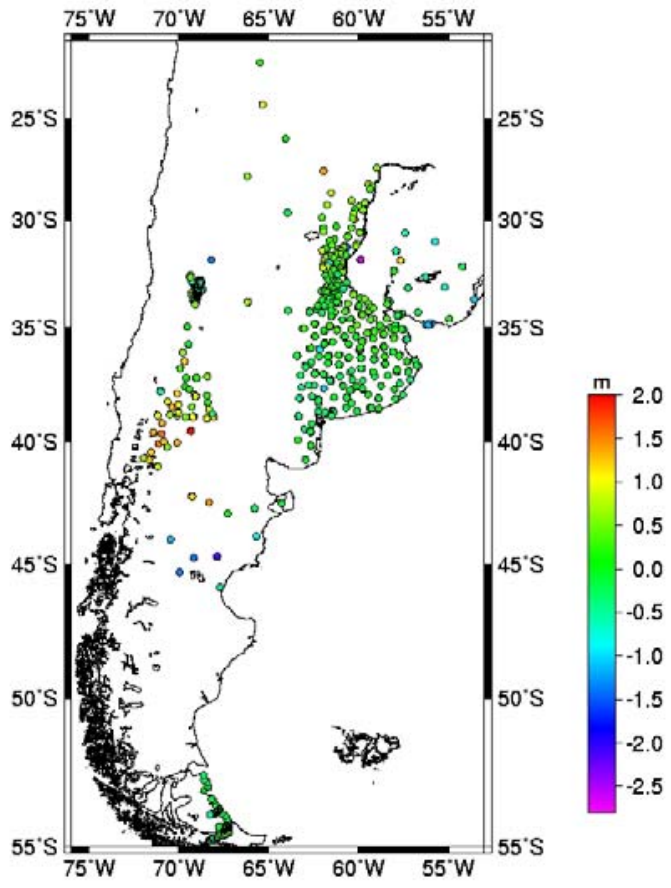

Figure 1: Differences between EGM96 and geometrical geoid heights in GPS-leveling points over Argentina

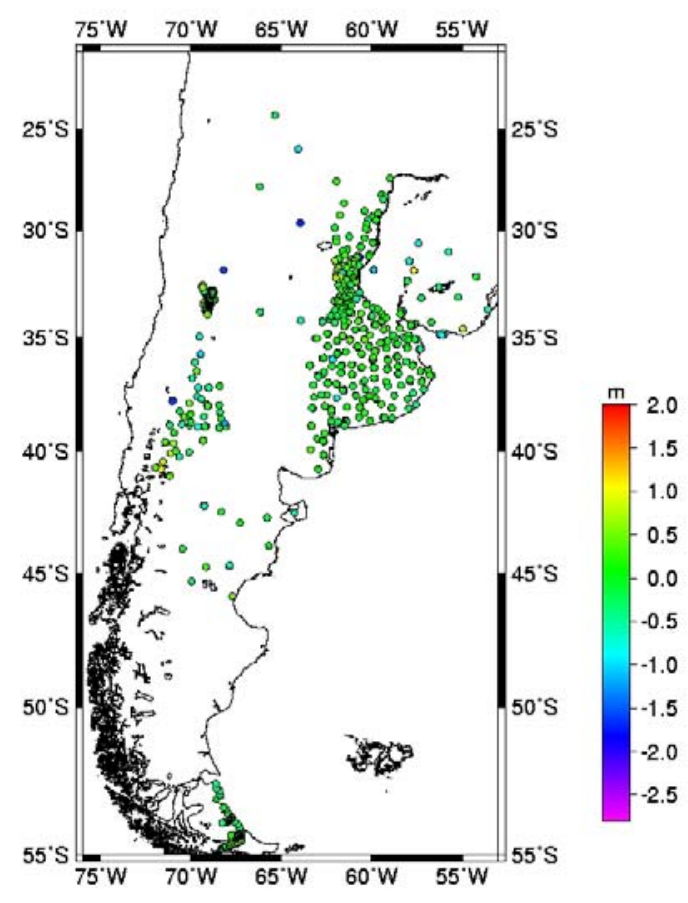

Figure 2: Differences between EIGENCG01C and geometrical geoid heights in GPS-leveling points over Argentina

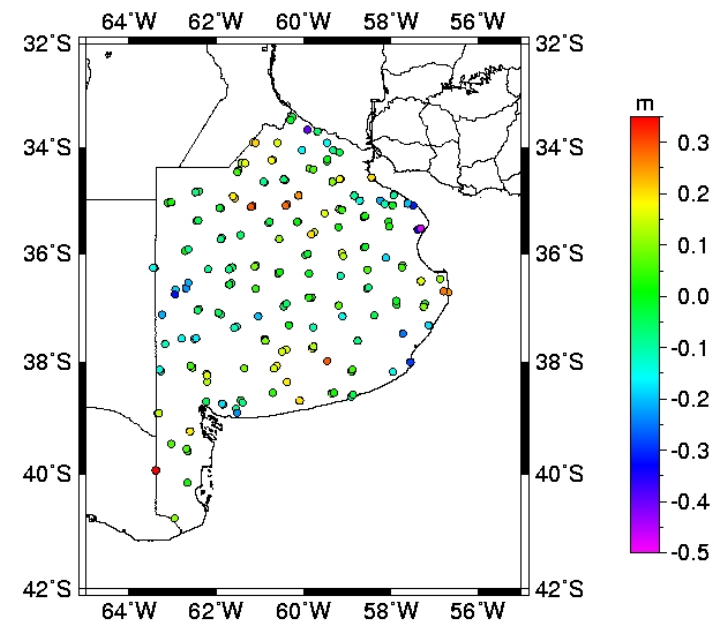

Figure 4: Differences between EIGENCG01C and geometrical geoid heights in GPS-leveling points over Buenos Aires province
Figure 3: Differences between EGM96 and geometrical geoid heights in GPS-leveling points over Buenos Aires province

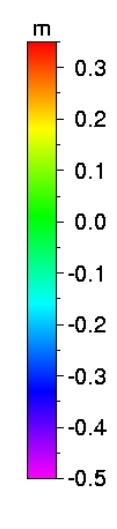




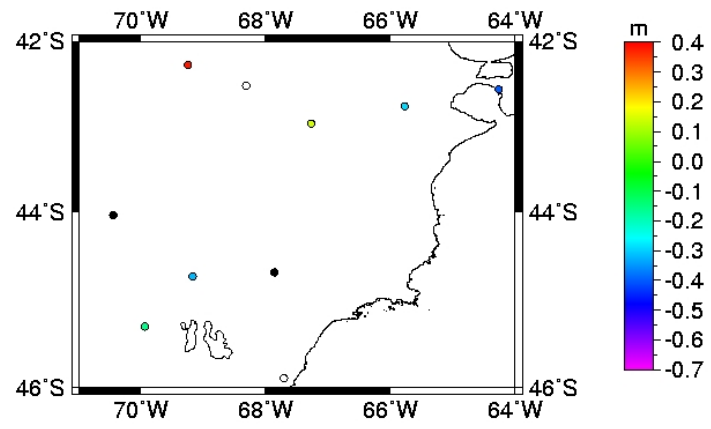

Figure 5: Differences between EGM96 and geometrical geoid heights in GPS-leveling points over Chubut province

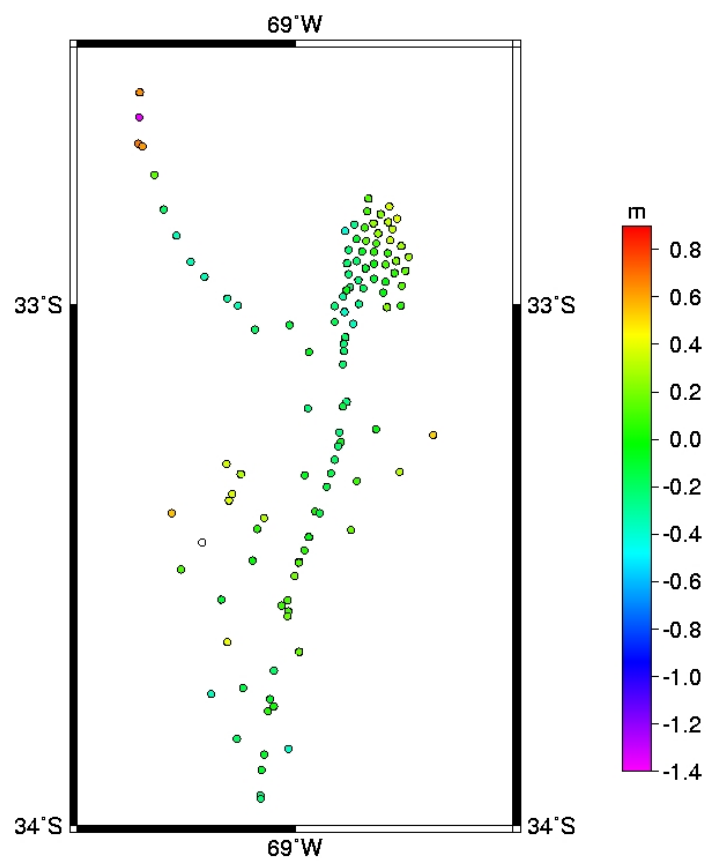

Figure 7: Differences between EGM96 and geometrical geoid heights in GPS-leveling points over Mendoza province

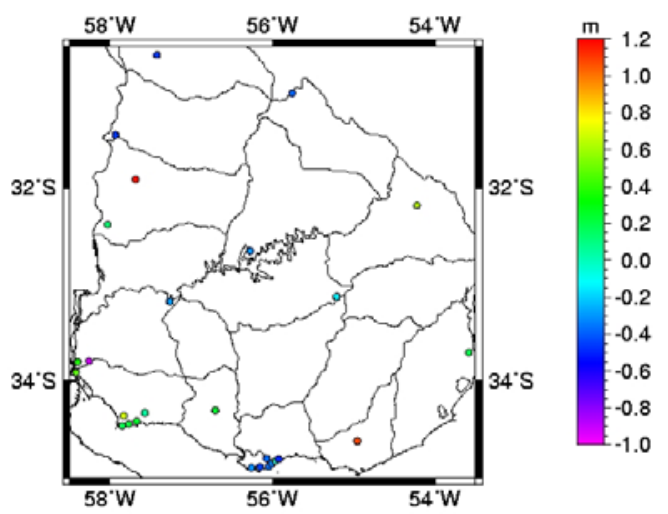

Figure 9: Differences between EGM96 and geometrical geoid heights in GPS-leveling points over Uruguay

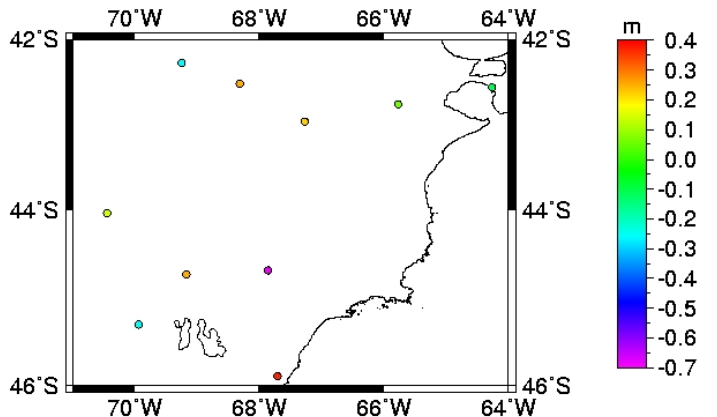

Figure 6: Differences between EIGEN-CG and geometrical geoid heights in GPSleveling points over Chubut province

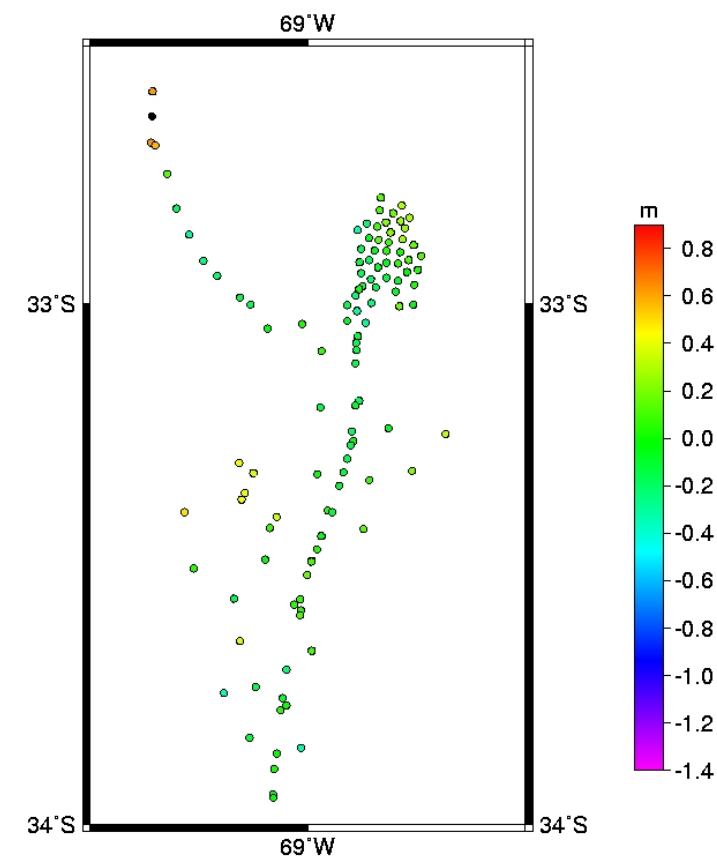

Figure 8: Differences between EIGENCG01C and geometrical geoid heights in GPS-leveling points over Mendoza province

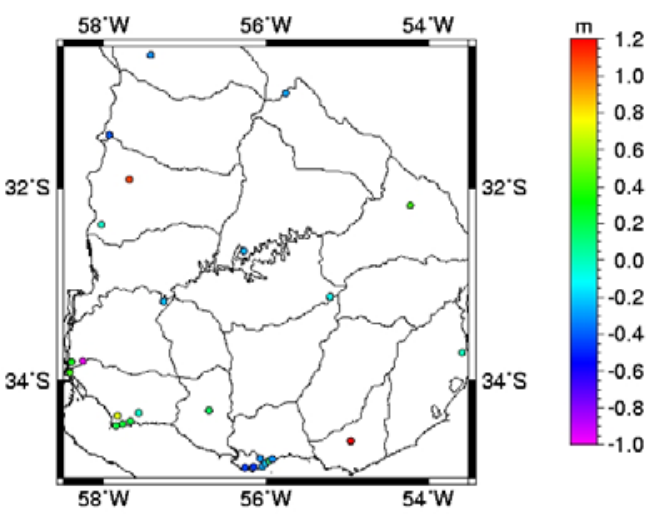

Figure 10: Differences between EIGENCG01C and geometrical geoid heights in GPS-leveling points over Uruguay 


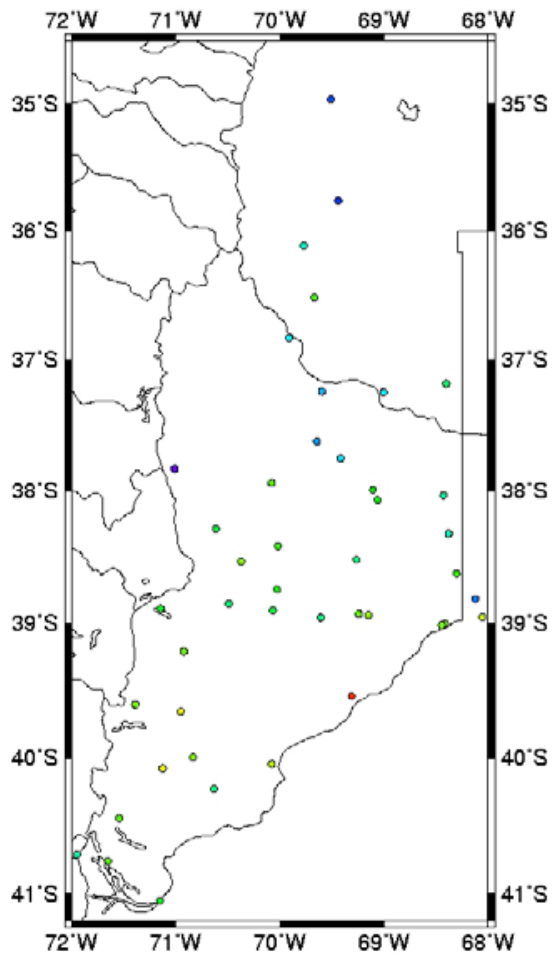

Figure 11: Differences between EGM96 and geometrical geoid heights in GPS-leveling points over Neuquen province

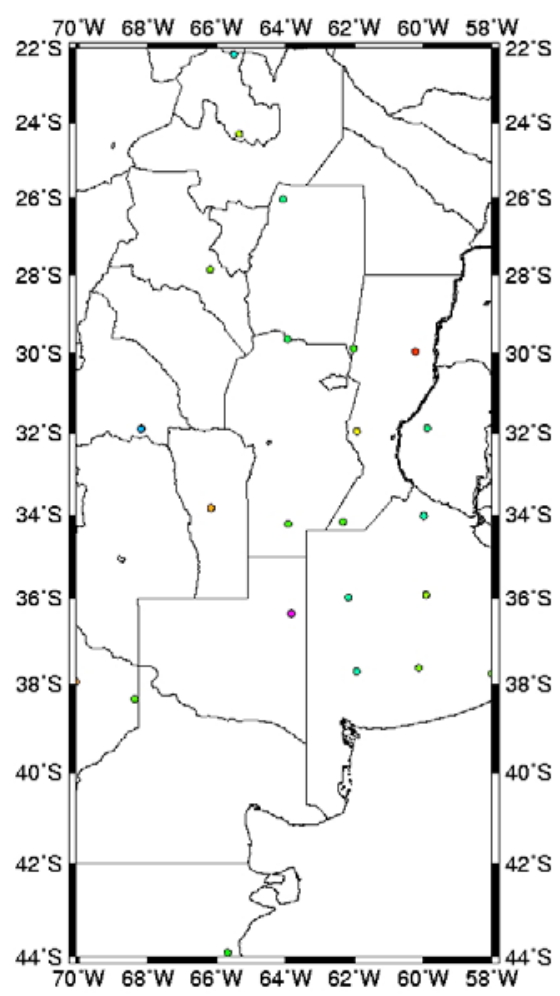

Figure 13: Differences between EGM96 and geometrical geoid heights in GPS-leveling points over POSGAR network

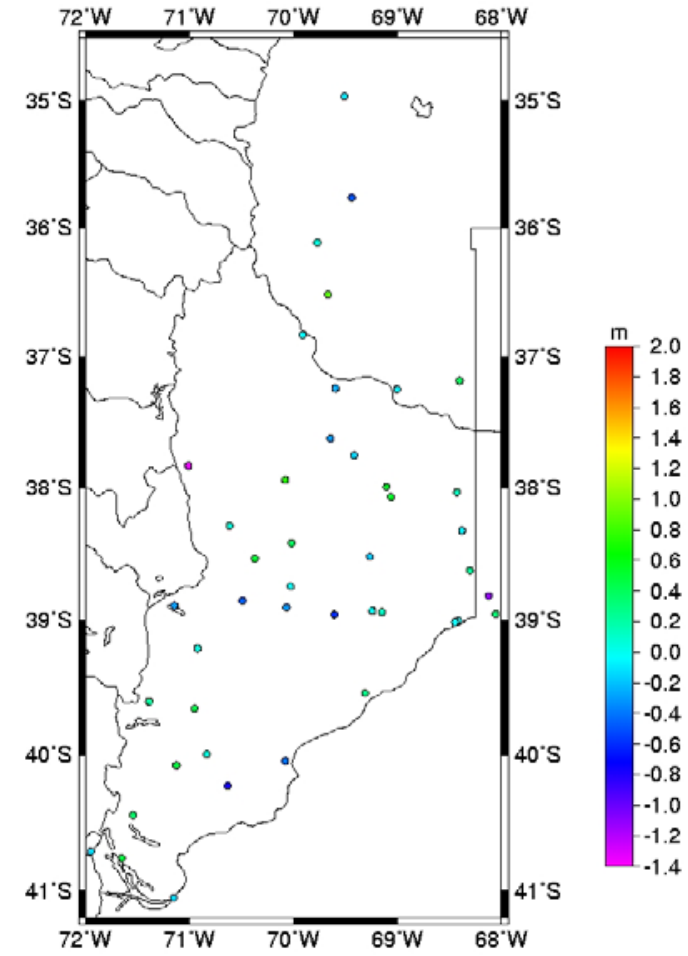

Figure 12: Differences between EIGENCG01C and geometrical geoid heights in GPS-leveling points over Neuquen province

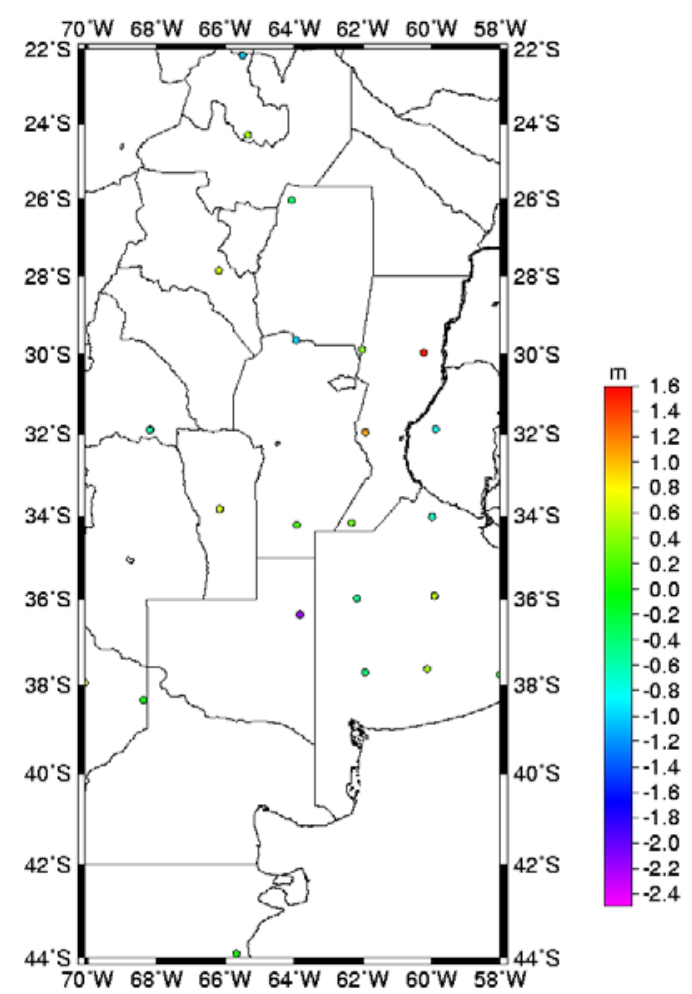

Figure 14: Differences between and EIGENCG01C geometrical geoid heights in GPSleveling points over POSGAR network 


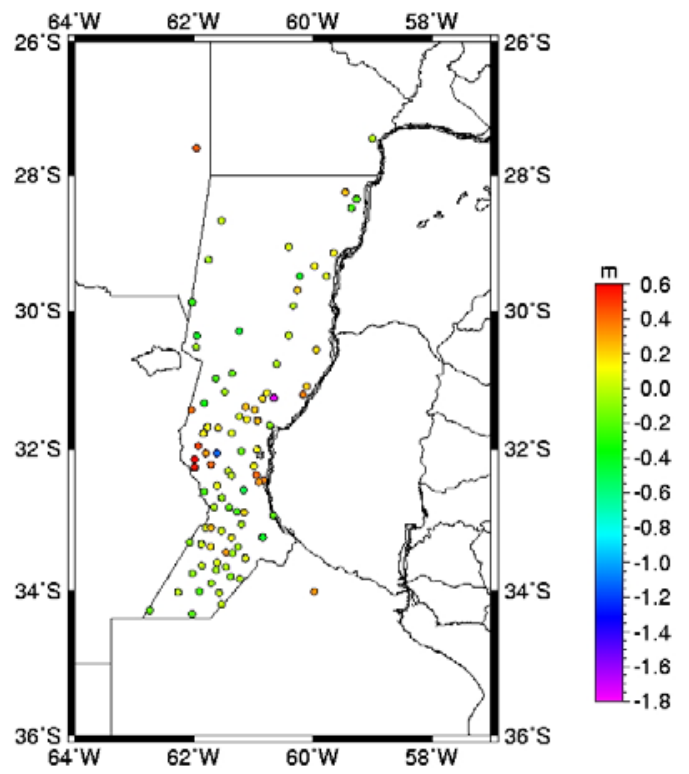

Figure 15: Differences between EGM96 and geometrical geoid heights in GPS-leveling points over Santa Fe province

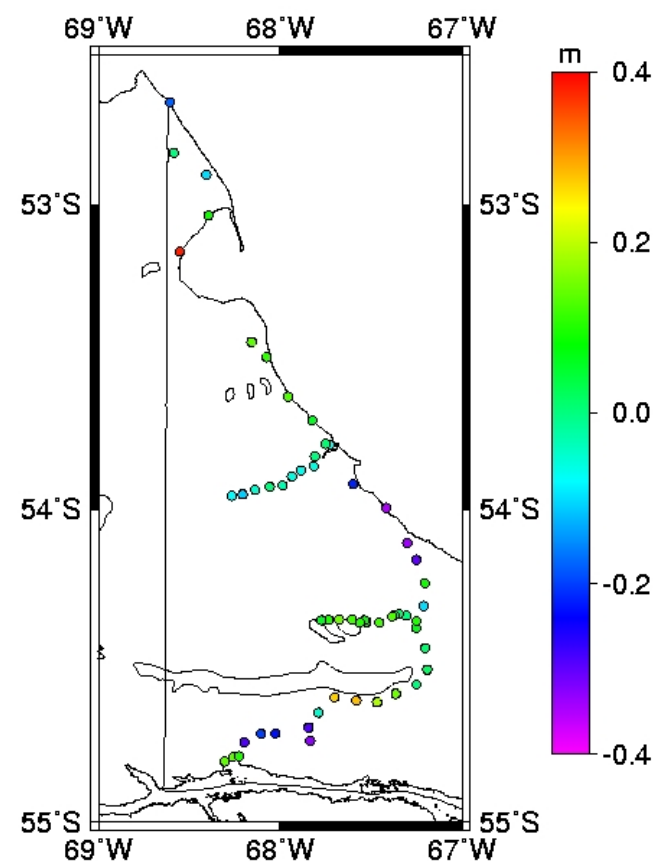

Figure 17: Differences between EGM96 and geometrical geoid heights in GPS-leveling points over Tierra del Fuego province

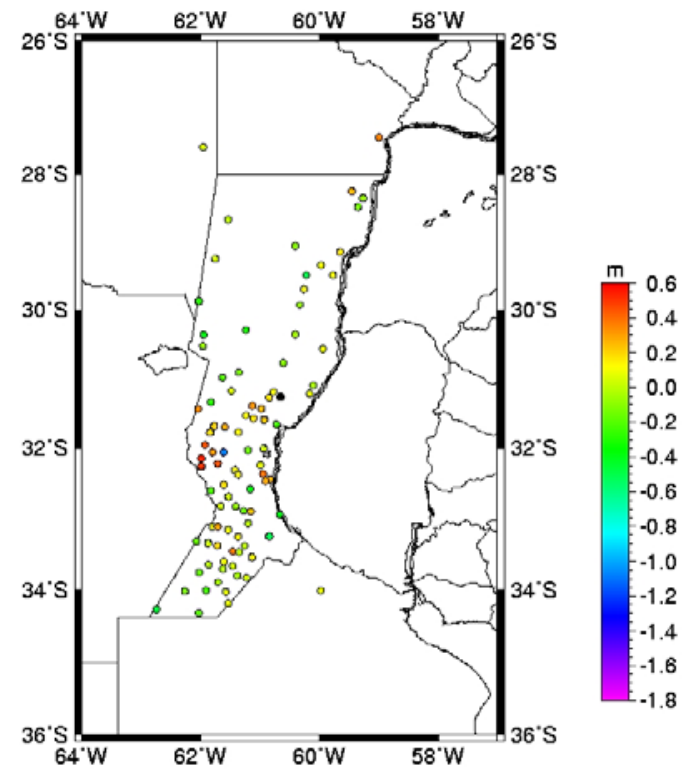

Figure 16: Differences between and EIGENCG01C geometrical geoid heights in GPSleveling points over Santa Fe province

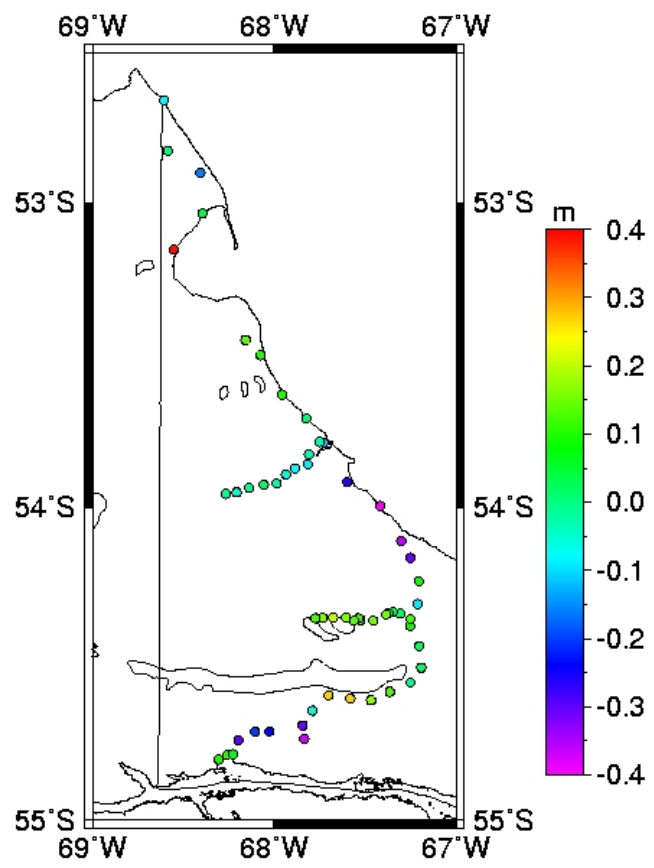

Figure 18: Differences between and EIGENCG01C geometrical geoid heights in GPSleveling points over Tierra del Fuego province 